Florida International University FIU Digital Commons

$10-10-2016$

\title{
Extending Use of Simple for Dead Load and Continuous for Live Load (SDCL) Steel Bridge System to Seismic Areas
}

Ramin Taghinezhadbilondy

rtagh001@fiu.edu

DOI: $10.25148 /$ etd.FIDC001238

Follow this and additional works at: https://digitalcommons.fiu.edu/etd

Part of the Structural Engineering Commons

\section{Recommended Citation}

Taghinezhadbilondy, Ramin, "Extending Use of Simple for Dead Load and Continuous for Live Load (SDCL) Steel Bridge System to Seismic Areas" (2016). FIU Electronic Theses and Dissertations. 2986.

https://digitalcommons.fiu.edu/etd/2986 


\section{FLORIDA INTERNATIONAL UNIVERSITY}

Miami, Florida

\section{EXTENDING USE OF SIMPLE FOR DEAD LOAD AND CONTINUOUS FOR LIVE LOAD (SDCL) STEEL BRIDGE SYSTEM TO SEISMIC AREAS}

A dissertation submitted in partial fulfillment of the

requirements for the degree of

DOCTOR OF PHILOSOPHY

in

\section{CIVIL ENGINEERING}

by

Ramin Taghinezhadbilondy 
To: Interim Dean Ranu Jung

College of Engineering and Computing

This dissertation, written by Ramin Taghinezhadbilondy, and entitled Extending Use of Simple for Dead Load and Continuous for Live Load (SDCL) Steel Bridge System to High Seismic Areas, having been approved in respect to style and intellectual content, is referred to you for judgment.

We have read this dissertation and recommend that it be approved.

$\begin{array}{r}\text { Ali Mostafavi } \\ \hline \text { Arindam Gan Chowdhury } \\ \hline \text { Teza Farimani } \\ \hline \text { Atorod Azizinamini, Major Professor }\end{array}$

Date of Defense: Oct 10, 2016

The dissertation of Ramin Taghinezhadbilondy is approved

Interim Dean Ranu Jung

College of Engineering and Computing

Andrés G. Gil

Vice President for Research and Economic Development and Dean of the University Graduate School

Florida International University, 2016 
(C) Copyright 2016 by Ramin Taghinezhadbilondy

All rights reserved. 


\section{DEDICATION}

I dedicate this thesis to my parents and my brother. Without their patience, understanding, support, and most of all love, the completion of this work would not have been possible. 


\section{ACKNOWLEDGMENT}

I would like to express my special appreciation and thanks to my advisor, Dr. Atorod Azizinamini, for his guidance and suggestions throughout the course of this research. I appreciate him for his technical advice, and letting me to be involved in many research projects during my $\mathrm{Ph} . \mathrm{D}$. program which taught me many lessons on the workings of academic studies.

My best thanks to Dr. Reza Farimani and Dr. Aaron Yakel. They are both have been a tremendous mentor for me during this research. In each stage of this research they guided me step by step, especially for building analytical models and interpreting finite element results.

Thanks to the Accelerated Bridge Construction ABC-UTC for sponsoring this research. I would like to thank my committee members Dr. Ton-Lo Wang, Dr. Reza Farimani, Dr. Arindam Gan Chowdhury and Dr. Ali Mostafavi for serving as my committee members and for their help during my studies.

I would also like to thank all of my colleagues, Dr. Jawad Gull, Alireza Mohammadi, Huy Pham, Mohamadreza Shafieifar, Mahsa Farzad, Alireza Valikhani, Azadeh Jaberi Jahromi, Amir Sadeghnejad and Sheharyar e Rehmat who supported me during my Ph.D. program.

I especially thank my mom, father, and brother. They receive my deepest gratitude and love for their encouragement, and throughout the many years of support during my academic life. My parents have sacrificed their lives for my brother and myself and provided love and care. My brother has been my best friend all my life and I love and appreciate him for all his advice and support. 


\title{
ABSTRACT OF THE DISSERTATION
}

\section{EXTENDING USE OF SIMPLE FOR DEAD LOAD AND CONTINUOUS FOR LIVE LOAD (SDCL) STEEL BRIDGE SYSTEM TO HIGH SEISMIC AREAS}

by

\author{
Ramin Taghinezhadbilondy
}

Florida International University, 2016

\author{
Miami, Florida
}

\section{Professor Atorod Azizinamini, Major Professor}

The steel bridge system referred to as Simple for Dead load and Continuous for Live load (SDCL) has gained popularity in non-seismic areas of the country. Accordingly, it results in many advantages including enhanced service life and lower inspection and maintenance costs as compared to conventional steel systems. To-date, no research studies have been carried out to evaluate the behavior of the SDCL steel bridge system in seismic areas. The main objective of this research was to extend the application of SDCL to seismic areas.

The concept of the SDCL system was developed at the University of Nebraska-Lincoln and a complete summary of the research is provided in five AISC Engineering Journal papers. The SDCL system is providing steel bridges with new horizons and opportunities for developing economical bridge systems, especially in cases for which accelerating the construction process is a priority. The SDCL steel bridge system also provides an attractive alternative for use in seismic areas.

The SDCL concept for seismic areas needed a suitable connection between the girder and pier. In this research, an integral SDCL bridge system was considered for further investigation. The 
structural behavior and force resistance mechanism of the proposed seismic detail considered through analytical study. The proposed connection evaluated under push-up, push-down, inverse and axial loading to find the sequence of failure modes. The global and local behavior of the system under push-down forces was mainly similar to non-seismic detail. The nonlinear time history analysis indicated that there is a high probability that bottom flange sustains tension forces under seismic events. The finite element model subjected to push-up forces to simulate the response of the system under the vertical component of seismic loads. However, the demand-capacity ratio was low for vertical excitation of seismic loads. Besides finite element results showed that continuity of bottom flange increased ductility and capacity of the system. While the bottom flange was not continuous, tie bars helped the system to increase the ultimate moment capacity. To model the longitudinal effect of earthquake loads, the model subjected under inverse forces as well as axial forces at one end. In this case scenario, dowel bars were most critical elements of the system. Several finite element analyses performed to investigate the role of each component of preliminary and revised detail. All the results demonstrated that continuity of the bottom flange, bolts area (in the preliminary detail), tie bars over the bottom flange (in the revised detail) were not able to provide more moment capacity for the system. The only component increased the moment capacity was dowel bars. In fact, increasing the volume ratio of dowel bars could be able to increase the moment capacity and prevent premature failure of the system.

This project was Phase I of an envisioned effort that culminated in the development of a set of details and associated design provisions to develop a version of the SDCL steel bridge system, suitable for the seismic application. Phase II of this project is an ongoing project and currently the component specimen design and test setup are under consideration. The test specimen is going to be constructed and tested in the structures lab of Florida International University. A cyclic loading will be applied to the specimen to investigate the possible damages and load resistance mechanism. These results will be compared with the analysis results. In the next step, as phase III, a complete 
bridge with all the components will be constructed in the structures lab at the University of NevadaReno. The connection between steel girders will be an SDCL connection and the bridge will be subjected to a shake table test to study the real performance of the connection due to earthquake excitation. 


\section{TABLE OF CONTENTS}

CHAPTER

PAGE

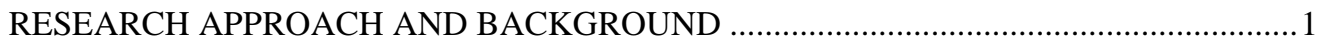

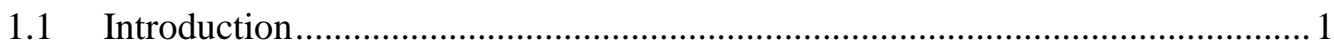

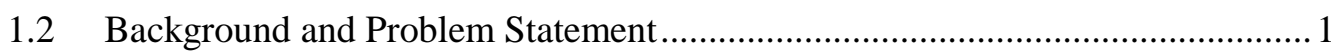

1.2.1 Simple for Dead Load Continuous for Live Load (SDCL) ......................... 1

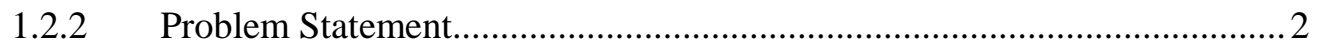

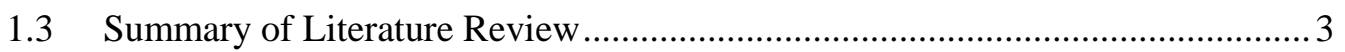

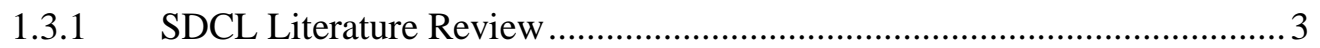

1.3.2 Seismic Performance of Integral Bridges Literature Review ...................... 7

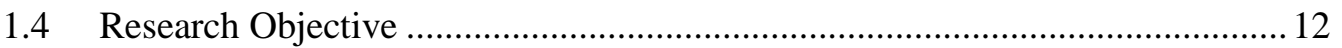

1.5 Contribution to Expanding Use of $\mathrm{ABC}$ in Practice ............................................ 13

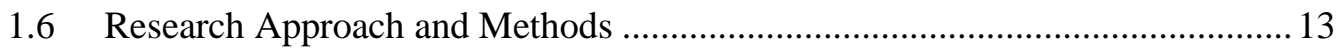

1.7 Description of Tasks Completed in This Research Project................................ 14

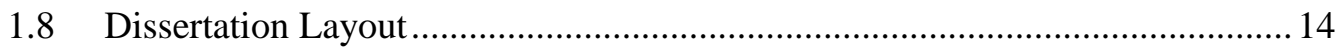

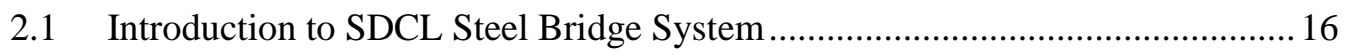

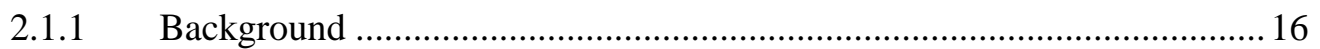

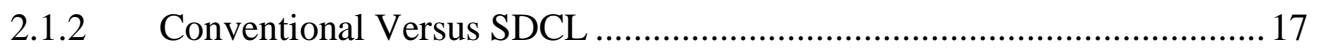

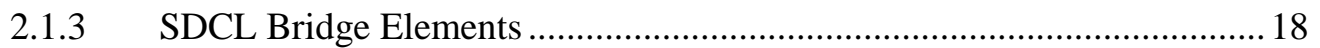

2.1.4 Benefit of SDCL to Conventional Bridge System................................... 19

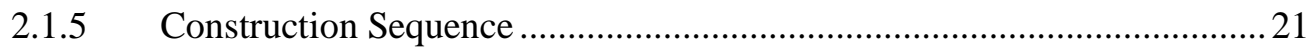

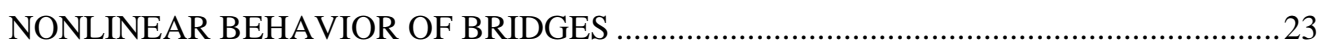

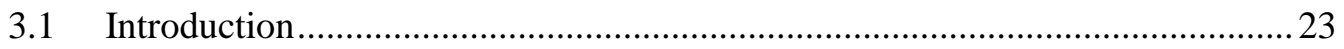

3.2 Steel vs. Concrete Bridges in the United States ...............................................2 23

3.3 Seismic Performance of Steel Bridges ...............................................................2 24

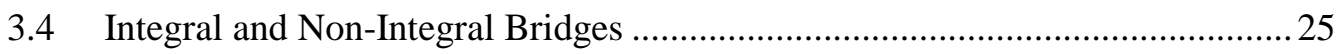

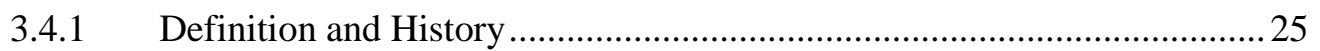

3.4.2 Seismic Behavior of Integral and Non-Integral Bridges ........................... 26

3.4.3 Integral versus Non-Integral Systems - Comparison..................................2 27

3.5 Effects of Seismic behavior on the Abutment...................................................2. 28

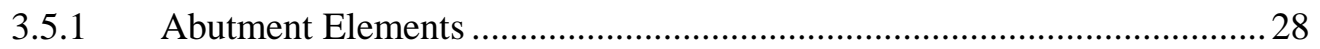




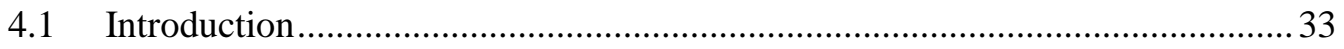

4.2 Probability of Earthquakes on the East and West Coast .....................................33

4.3 Designing Bridges According to a Different Seismic Design Category ............. 33

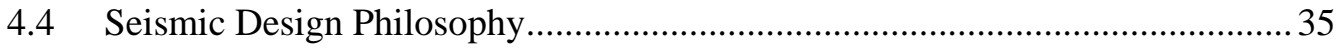

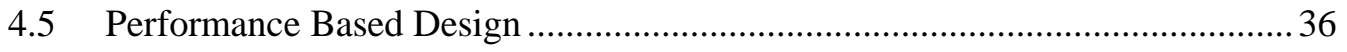

4.6 Earthquake Resisting Systems (ERS) …..................................................... 37

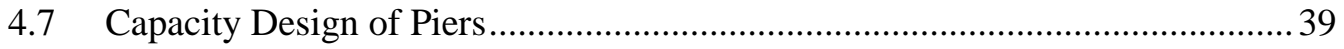

4.8 Calculating Over-Strength Moment Capacity …................................................40

4.9 Caltrans Design Requirements for Capacity Protected Members ....................... 41

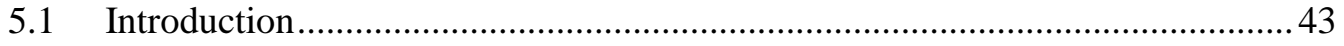

5.2 Description of the Example Bridge ................................................................... 43

5.2.1 Geometry and Element Properties ........................................................ 43

5.2.2 Material Property .............................................................................. 45

5.3 Earthquake Resistance System (ERS) ...........................................................46

5.4 Simplified Hand Calculation Method ............................................................ 48

5.5 Nonlinear Pushover and Time History Analysis............................................... 74

5.5.1 Description of the Prototype Bridge .................................................... 74

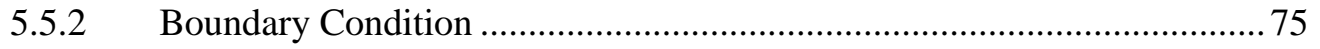

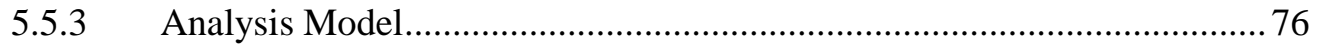

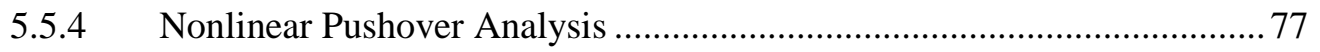

5.5.5 Nonlinear Time History Analysis......................................................... 79

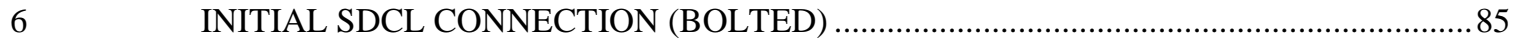

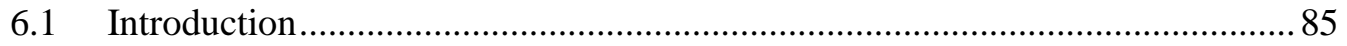

6.2 Proposed Connection for Seismic areas ........................................................... 85

6.3 Possible Failure Modes for the Proposed Connection ........................................ 86

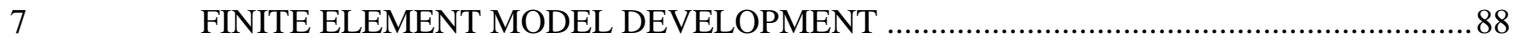

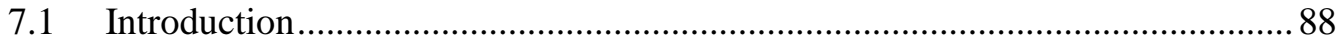

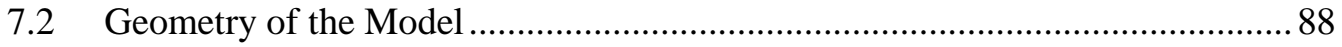




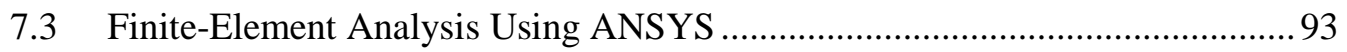

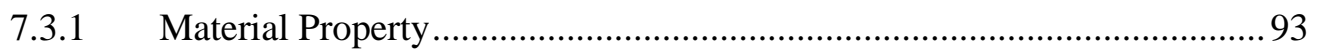

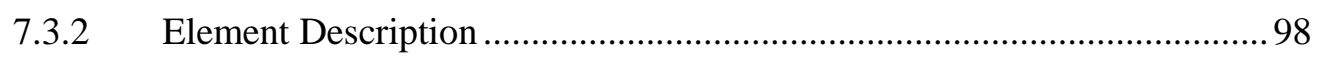

7.3.3 Smeared and Discrete Reinforcement Models ...................................... 102

7.3.4 Verifying the Finite-Element Model .................................................... 103

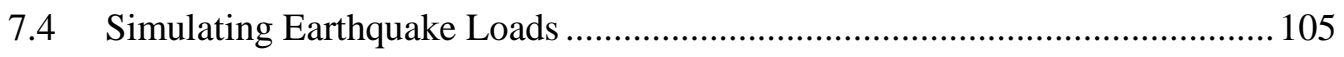

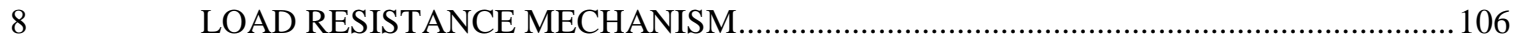

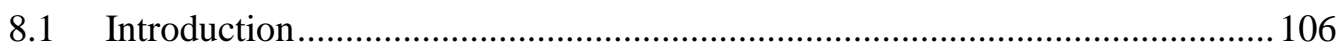

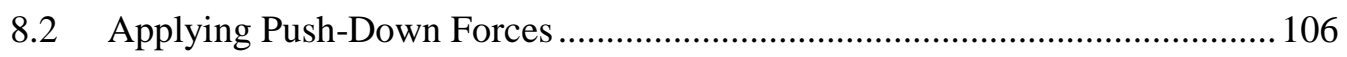

8.2.1 Global Behavior under Push-Down Forces .............................................. 106

8.2.2 Distribution of Cracks under Push-Down Forces.................................... 107

8.2.3 Load Resistance Mechanism under Push-Down Forces.......................... 108

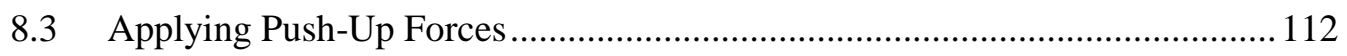

8.3.1 Global Behavior under Push-Up Forces ............................................... 113

8.3.2 Distribution of Cracks under Push-Up Forces....................................... 115

8.3.3 Load Resistance Mechanism under Push-Up Forces ............................. 116

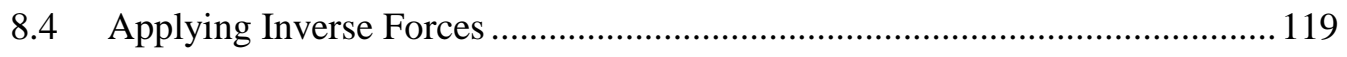

8.4.1 Global Behavior of the System under Inverse Forces ............................ 121

8.4.2 Distribution of Cracks under Inverse Forces .......................................... 127

8.4.3 Load Resistance Mechanism under Inverse Forces................................. 130

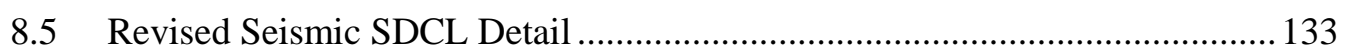

8.5.1 Configuration of the Revised Seismic Detail .......................................... 134

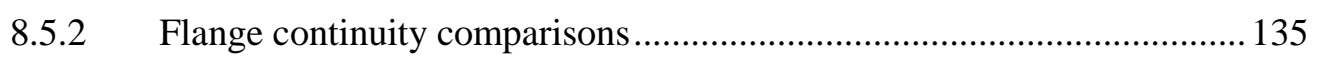

8.5.3 Evaluation of Revised Detail Under Different Load Conditions.............. 136

8.5.4 The Rate of Stress Increase In Different Elements.................................. 141

8.5.5 Monolithic Versus Cold Joint Assumption In The Moment Capacity .... 142

8.5.6 Effect Of Dowel Bars Location ............................................................ 143

8.6 Evaluating Local Behavior of Resisting Elements....................................... 144

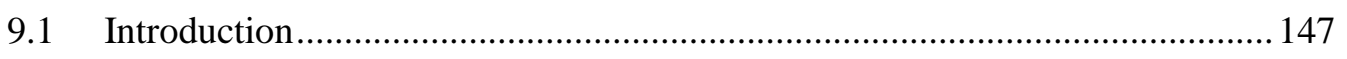

9.2 Parametric Finite Element Models ............................................................ 147

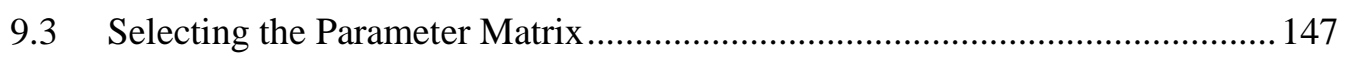

9.4 Parametric Model under Push Up Loading................................................. 148 
9.5 Parametric Model under Reverse Loading................................................. 150

9.5.1 Stress Distribution in Dowel Bars ..................................................... 153

9.5.2 Effect of Diaphragm Face Reinforcement ........................................... 154

9.6 Moment-Drift of Monolithic System ……............................................... 155

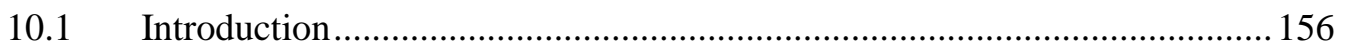

10.2 Design Formula under Different Load Condition ....................................... 156

10.2.1 Connection under Push-Down Forces .................................................... 156

10.2.2 Connection under Push-Up Forces ....................................................... 157

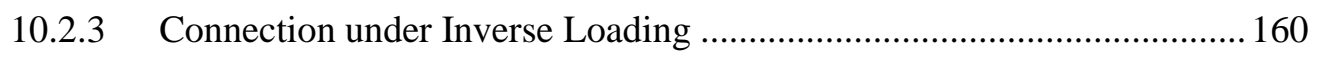

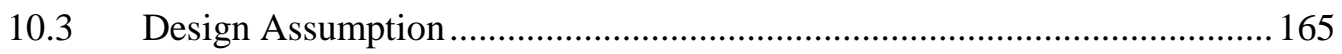

11 PHASE II, EXPERIMENTAL TEST SPECIMEN AND TEST SETUP …………….........178

11.1 A Review of Previous Test Setup for Integral Bridges ............................... 178

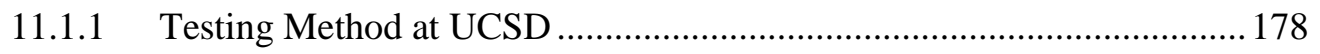

11.1.2 Testing Method at Iowa State University .............................................. 181

11.1.3 Testing Method at Iowa State University ............................................. 184

11.2 Selected System for the Phase II Component Test ...................................... 186

11.2.1 Column Property of Component Test................................................... 187

11.2.2 Calculating the steel reinforcement in the cap beam .............................. 189

11.2.3 Column and Bent Cap Flexural Capacity .............................................. 193

11.2.4 Maximum Possible Displacement of Test Specimen .............................. 198

12 CONCLUSIONS AND RECOMMENDATIONS .................................................201

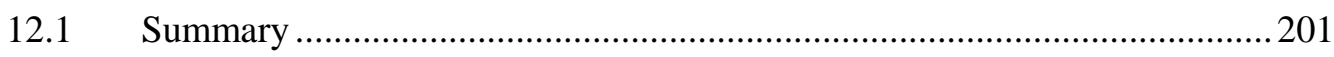

12.2 Integral and Non-Integral Bridge Systems........................................... 201

12.3 Demand Side of the SDCL Bridges ....................................................... 202

12.4 Capacity of the SDCL Bridges................................................................203

12.4.1 Load Resistance Mechanism of the Connection.....................................203

12.4.2 The Sequence of Failures in the SDCL Connection............................... 204

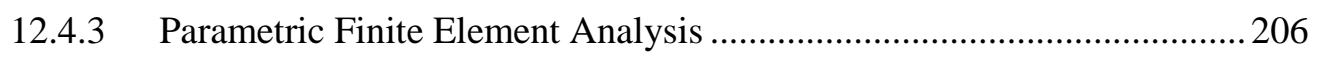

12.4.4 Developed Formula to Design Seismic Detail of SDCL ......................... 207

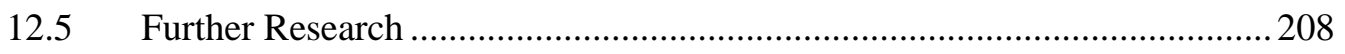




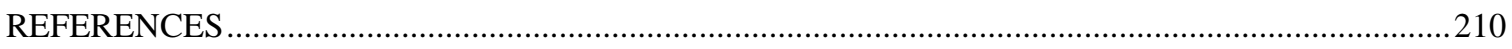

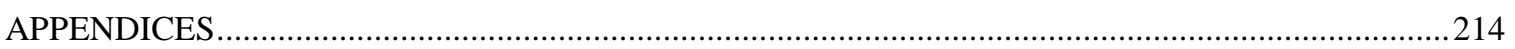

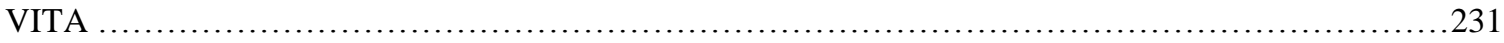




\section{LIST OF TABLES}

TABLE

PAGE

Table 4-1 Steps for seismic design based upon LRFD Bridge Design Specifications. .35

Table 4-2 Permissible earthquake resisting systems. .39

Table 5-1 A summary of bridge property. .45

Table 5-2 Minimum analysis requirements for seismic effects. .49

Table 5-3 Regular bridge requirements.

Table 5-4 Property of the structural component. .50

Table 5-5 Comparison between hand calculation and CSiBridge. .50

Table 5-6 Values of Site Factor, Fv, for Long-Period Range of Acceleration Spectrum .56

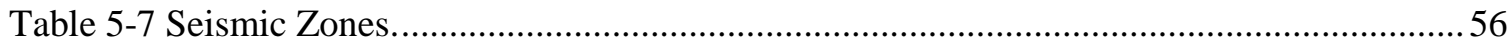

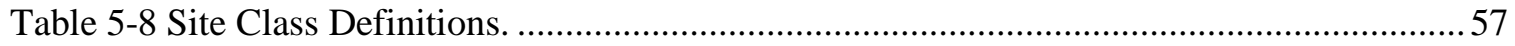

Table 5-9 Values of Site Factor, Fpga, at Zero Period on Acceleration Spectrum.......................58

Table 5-10 Values of Site Factor, Fa, for Short-Period Range of Acceleration Spectrum............58

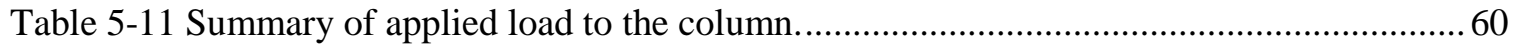

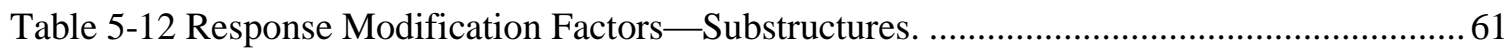

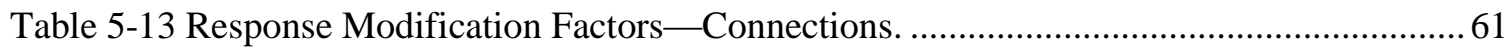

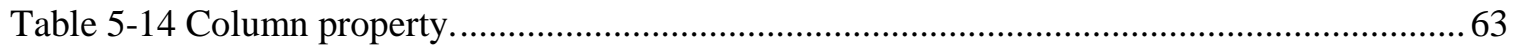

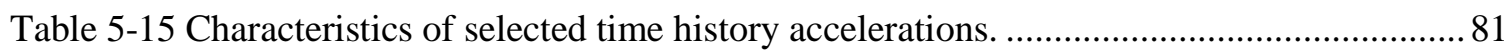

Table 5-16 Longitudinal, transverse and vertical components of selected earthquakes. ............... 81

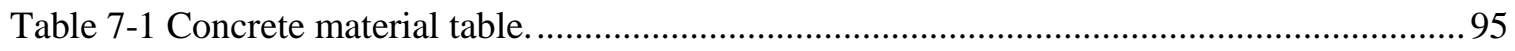

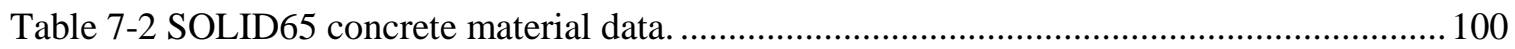

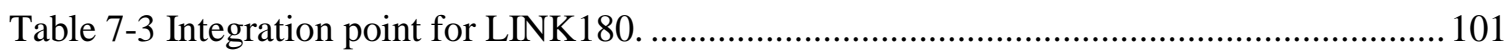

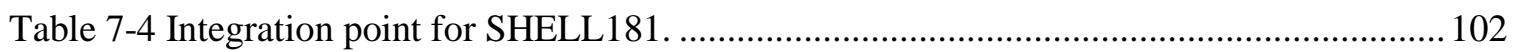

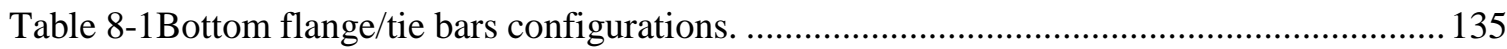


Table 9-1 Parametric Finite Element Models (FEM)

Table 10-1 Results of finite element analysis and developed formula.

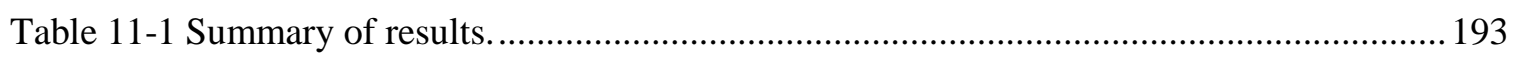




\section{LIST OF FIGURES}

FIGURE

PAGE

Figure 1-1 Conventional two spans continuous bridge girder and typical splice detail. 1

Figure 1-2 Construction sequence for SDCL bridge systems..............................................

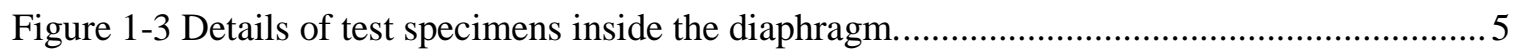

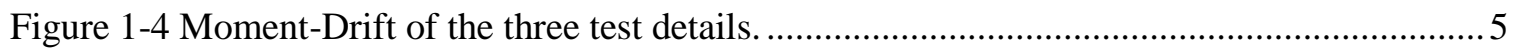

Figure 1-5 SDCL detail used in Non-Seismic areas to connect girders...................................... 6

Figure 1-6 Recommended detail for an I girder (left) and a box girder (right)............................ 6

Figure 1-7 left: Three Spring Drive, right: Washington Avenue................................................ 7

Figure 1-8 Connection detail for Spring Drive bridge......................................................... 7

Figure 1-9 details for connection between steel girder and concrete bent cap. ........................... 8

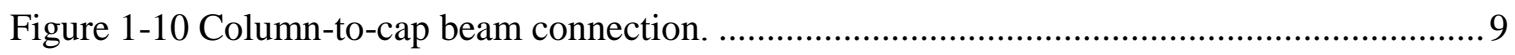

Figure 1-11 Connection detail for an I-girder to inverted-tee bent cap. ..................................... 11

Figure 1-12 Selected details for more investigation (Details A and B)................................... 11

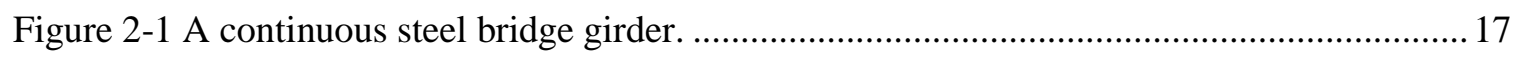

Figure 2-2 Simple for Dead and Continuous for Live detail. ................................................... 17

Figure 2-3 Different components of SDCL bridge system. …................................................ 18

Figure 2-4 Bridge cross-section for steel box girder........................................................... 19

Figure 2-5 Bridge cross-section for steel plate girder........................................................... 19

Figure 2-6 Substructure with various numbers of columns. ................................................... 19

Figure 2-7 The behavior of SDCL bridge system during construction process...........................20

Figure 2-8 Comparison between maximum positive moment for continuous and simple span. ...21

Figure 2-9 Comparison between maximum positive moment for continues and simple span. .....21

Figure 2-10 Conventional steel bridge construction sequence. ............................................. 22

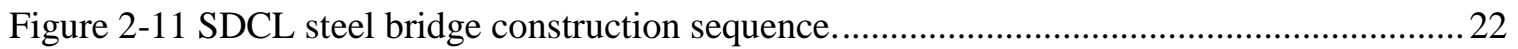


Figure 3-1 Left: non-integral steel bridge, right: integral steel bridge.

Figure 3-2 Deflected shape of a three span integral bridge system in longitudinal direction........26

Figure 3-3 left: deflected shape in the longitudinal direction for integral pier cap, ....................27

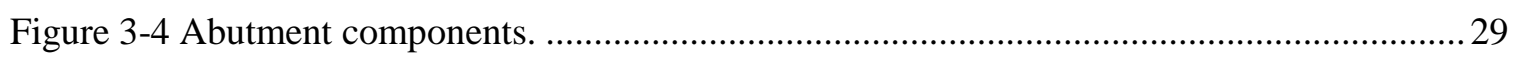

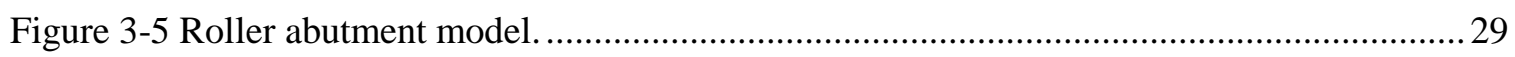

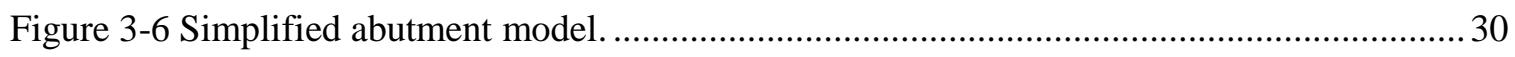

Figure 3-7 Series system for the longitudinal abutment response. ........................................... 31

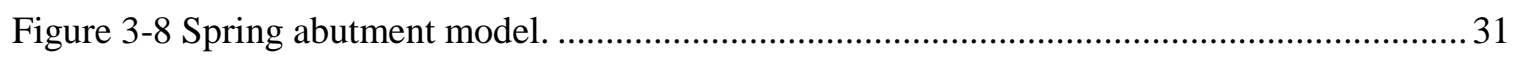

Figure 4-1 USGS National Seismic Hazard Map for Conterminous U.S. for Seismic Design Coefficient at One Second Period for 7\% Probability of Exceedance in 75 years (1,000 year Return Period) and Competent Soil (the B/C boundary)........................... 33

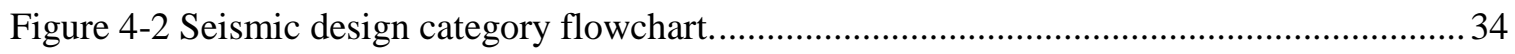

Figure 4-3 Two different path for structure behavior under seismic loads................................ 36

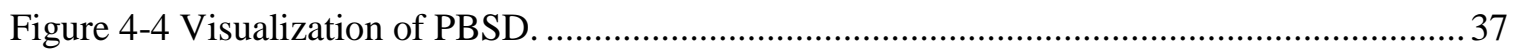

Figure 4-5 Inelastic substructure with elastic superstructure .................................................. 38

Figure 4-6 Elastic substructure with inelastic superstructure. ….............................................. 38

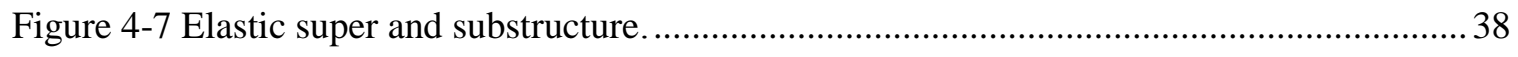

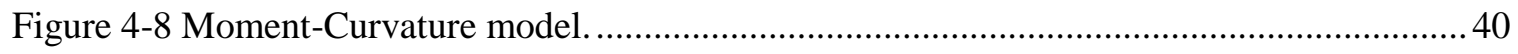

Figure 4-9 Transverse response for dual column pier......................................................... 40

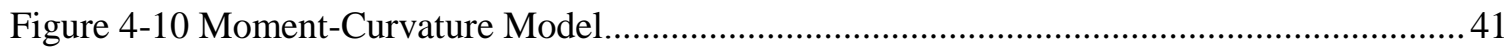

Figure 4-11 Stress-strain curve for the concrete and 0.003 strain limit for the capacity protected

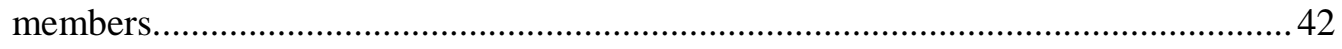

Figure 4-12 Stress-strain curve for the reinforcing steel and 0.06 and 0.09 strain limits for the capacity protected members. ............................................................................. 42

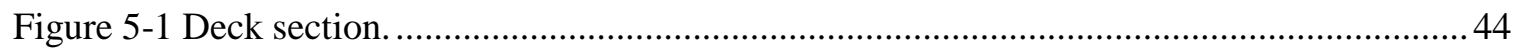

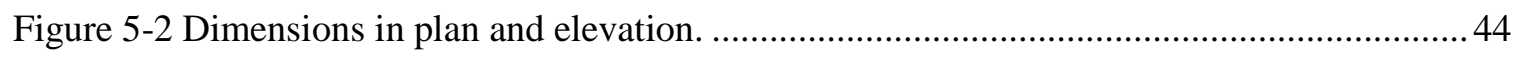

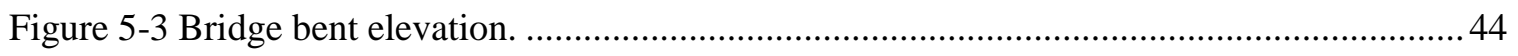

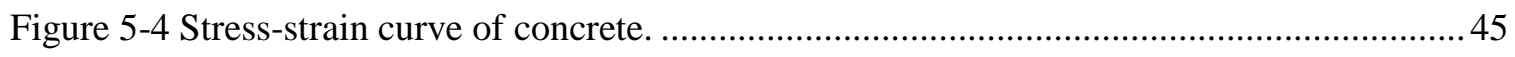


Figure 5-5 Stress-strain curve of the steel girder.

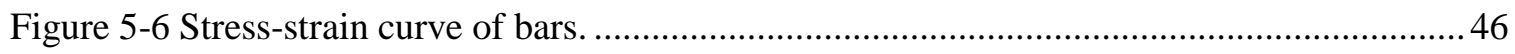

Figure 5-7 Permissible earthquake-resisting systems (ERSs) .............................................. 47

Figure 5-8 Bent frame and abutment contribution in ERS. ..................................................... 48

Figure 5-9 Mode shapes and periods of the bridge based upon CSiBridge analysis results..........52

Figure 5-10 Design response spectrum according to AASHTO...............................................52

Figure 5-11 Horizontal Peak Ground Acceleration Coefficient for the Conterminous United States (PGA) with Seven Percent Probability of Exceedance in 75 yr (Approx. 1000-yr Return Period).

Figure 5-12 Horizontal Response Spectral Acceleration Coefficient for the Conterminous United States at Period of $0.2 \mathrm{~s}$ (SS) with Seven Percent Probability of Exceedance in 75 yr (Approx. 1000-yr Return Period) and Five Percent Critical Damping. ......... 54

Figure 5-13 Horizontal Response Spectral Acceleration Coefficient for the Conterminous United States at Period of $1.0 \mathrm{~s}$ (S1) with Seven Percent Probability of Exceedance in 75 yr (Approx. 1000-yr Return Period) and Five Percent Critical Damping ...........56

Figure 5-14 Response spectrum curve according to AASHTO...............................................58

Figure 5-15 Interaction curve - design point for Strength I...................................................63

Figure 5-16 Interaction curve - design point for Extreme Event I. ..........................................64

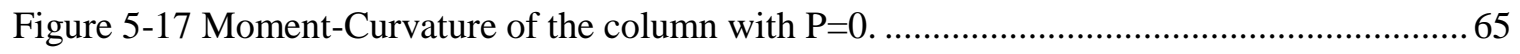

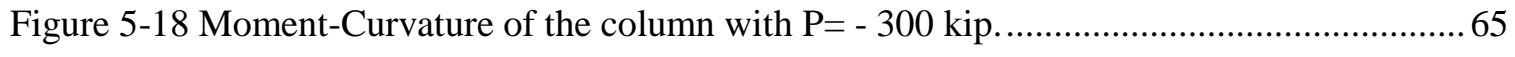

Figure 5-19 Left: effective superstructure width, right: effective bent cap width. .......................67

Figure 5-20 Effective cross section in the transverse direction of the earthquake........................68

Figure 5-21 Moment-Curvature of the current section under positive moment with \#5 side bars.

Figure 5-22 Moment-Curvature for the existing section under negative moment with \#5 side bars. .68

Figure 5-23 Moment-Curvature of the section under positive moment with \#18 side bars...........69

Figure 5-24 Moment-Curvature of the section under negative moment with \#18 side bars.......... 70

Figure 5-25 Effective cross-section in the longitudinal direction of the seismic event. .71

Figure 5-26 Moment-Curvature of the section under positive moment with one bottom flange (longitudinal dir.). 
Figure 5-27 Moment-Curvature for the existing section under negative moment with one bottom flange (longitudinal dir.)

Figure 5-28 Moment-Curvature of the section under positive moment with one bottom flange (longitudinal dir.).

Figure 5-29 Moment-Curvature for the existing section under negative moment with one bottom flange (longitudinal dir.).

Figure 5-30 Adjusting girders inside the effective width of the bent cap, left: the bent frame with two columns, right: the bent frame with one column.

Figure 5-31 Moment-Curvature of the section under positive moment with two bottom flange (longitudinal dir.).

Figure 5-32 Moment-Curvature for the existing section under negative moment with two bottom flange (longitudinal dir.)......

Figure 5-33 Analytical model of the bridge with two $95 \mathrm{ft}$. span length...................................... 74

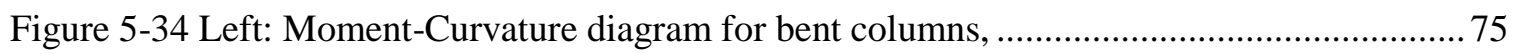

Figure 5-35 Connection between superstructure and substructure for an integral bridge system in CSiBridge.

Figure 5-36 Distribution of moment under dead load (top), super dead load (middle) and moving load (bottom) after nonlinear staged construction analysis.

Figure 5-37 Pushover curve for the longitudinal direction of earthquake excitation......................78

Figure 5-38 Pushover curve for the transverse direction of earthquake excitation....................... 78

Figure 5-39 Deformation of bridge and acceptance criteria for hinges under longitudinal load pattern......

Figure 5-40 Deformation of bridge and acceptance criteria for hinges under transverse load pattern.

Figure 5-41 Moment plot for the entire bridge section (including 4 girders) under longitudinal load pattern without gravity loads, units (Kip,ft), (Model No. 17pushover).

Figure 5-42 Moment plot for the entire bridge section (including 4 girders) under longitudinal load pattern including gravity loads, units (Kip,ft), (Model No. 17pushover). .79

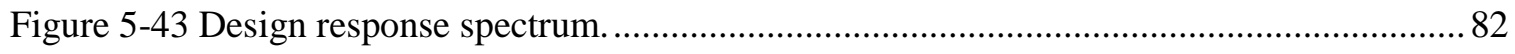

Figure 5-44 Amount of the tension stresses in bottom flange. ................................................ 84

Figure 5-45 Stress-Strain curve for the A992Fy50 steel material.............................................. 84

Figure 6-1 Proposed detail connection for the seismic region. .................................................. 86 
Figure 7-1 Different parts of the test specimen.

Figure 7-2 Left: specimen's longitudinal view, right: specimen's side view (dimensions in inches)

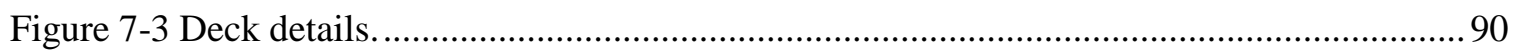

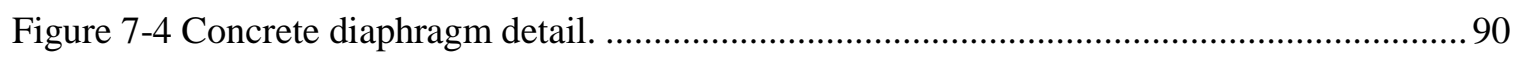

Figure 7-5 Isometric 3-D view and side views of concrete deck model.................................... 91

Figure 7-6 Finite-element model of bars in the deck and concrete diaphragm...........................91

Figure 7-7 Isometric 3-D view and side views of rebar model................................................ 91

Figure 7-8 Finite-element model of I steel girder and bearing plates...................................... 92

Figure 7-9 Isometric 3-D view and side views of steel girder model......................................92

Figure 7-10 Isometric 3-D view and side views of column model........................................... 92

Figure 7-11 Isometric 3-D view and side views of the full model.........................................92

Figure 7-12 left: stress-strain curve for reinforcement steel, right: stress-strain curve for plates

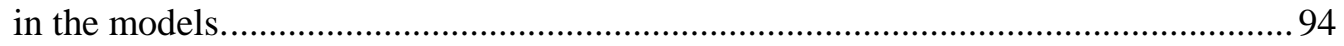

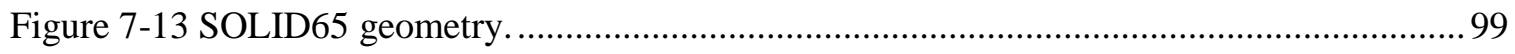

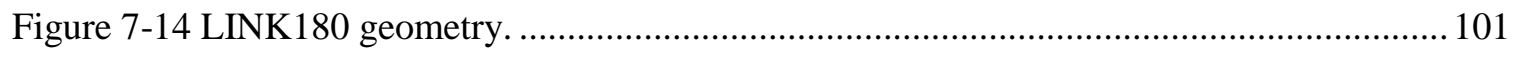

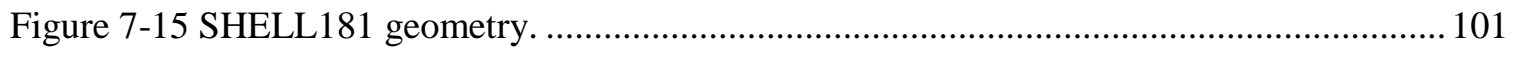

Figure $7-16$ Three connection types tested by UNL. ........................................................... 103

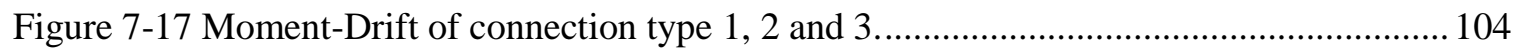

Figure 7-18 A comparison between Moment-Drift from the experimental test and finite-

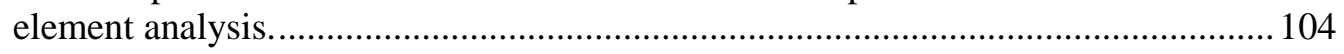

Figure 8-1 Moment-Drift for the existing and preliminary (bolted) detail. ............................... 107

Figure 8-2 Distribution of cracks in the deck and concrete diaphragm under push-down forces.

Figure 8-3 Sequence of failure events under push-down forces............................................. 109

Figure 8-4 Initial cracks in concrete deck under push-down forces at sub step 200 out of 727

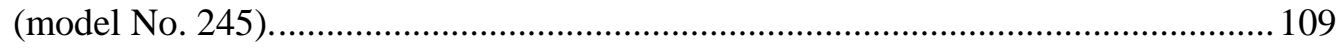

Figure 8-5 von-Mises stress in bars and girders at sub step 200 out of 727 (model No. 245)..... 110 
Figure 8-6 Initial cracks in concrete deck under push-down forces at sub step 300 out of 727 (model No. 245).

Figure 8-7 von-Mises stress in bars and girders at sub step 300 out of 727 (model No. 245).... 110

Figure 8-8 Cracks in concrete deck under push-down forces at sub step 400 out of 727 (model No. 245).

Figure 8-9 von-Mises stress in bars and girders at sub step 400 out of 727 (model No. 245). Top bars over the diaphragm start to yield.

Figure 8-10 von-Mises stress in bars and girders at sub step 470 out of 727 (model No. 245). Bottom flange started to yield.

Figure 8-11 von-Mises stress in bars, girders and bolts at sub step 420 out of 727 (model No. 245). Top bolts start to yield.

Figure 8-12 Cracks in concrete deck under push-down forces at sub step 726 out of 727 (model No. 245).

Figure 8-13 von-Mises stress in bars and girders at sub step 726 out of 727 (model No. 245)... 112

Figure 8-14 Deformation of a two span bridge under the vertical component of the earthquake.

Figure 8-15 Moment-Drift capacity of the brand-new detail for discontinuous and continuous flanges.

Figure 8-16 Moment-Drift capacity of the brand-new detail for continuous flanges with and without bolts.

Figure 8-17 Effect of bolt sizes in the capacity of the connection in integral and non-integral bridge model.

Figure 8-18 Crack pattern under push-up forces.

Figure 8-19 Sequence of failure modes under push-up forces

Figure 8-20 Crushes and cracks in concrete under push-up forces at sub step 280 out of 598 (model No. 223).

Figure 8-21 von-Mises stress in girders and bars at sub step 200 out of 598 (model No. 223).

Bottom bolts start to yield.

Figure 8-22 von-Mises stress in bars and bolts at sub step 275 out of 598 (model No. 223).

Bottom bolts start to yield.

Figure 8-23 von-Mises stress in bars at sub step 597 out of 598 (model No. 223). Top bars remained elastic.

Figure 8-24 von-Mises stress under push-up forces, cross-section area of each bolt= 0.5 in^2 $\ldots 118$ 
Figure 8-25 von-Mises stress under push-up forces, cross-section area of each bolt=0.75 in^2.

Figure 8-26 von-Mises stress under push-up forces, cross-section area of each bolt=1.0 in^2 $\ldots 119$

Figure 8-27 Deflected shape of a three-span bridge in the longitudinal (parallel to traffic) direction due to seismic loads

Figure 8-28 Finite-element model and boundary condition for two inverse loads, the stiffness of column increased artificially.

Figure 8-29 Finite-element model and boundary condition for the axial load.

Figure 8-30 Moment-Drift plot under inverse forces for the existing and new SDCL connection before adding dowel bars (stiffness of column increased). 121

Figure 8-31 Finite-element model before and after increasing the area of stirrups.

Figure 8-32 Moment-Drift plot under inverse forces for the existing SDCL connection after increasing bolts area and the number of stirrups.

Figure 8-33 Adding dowel bars at the interface of bent cap and concrete diaphragm.

Figure 8-34 Comparison between Moment-Drift before and after adding dowel bars.

Figure 8-35 Moment-Drift plot for integral bridges with different dowel bars volume ratio...... 123

Figure 8-36 Load transfer mechanism under internal forces.

Figure 8-37 Exaggerated deflection of the model under inverse loading. 124

Figure 8-38 Exaggerated deflection of the model under horizontal axial force...... 124

Figure 8-39 Different configurations for connection between bottom flanges and baseplate. .... 126

Figure 8-40 Moment-drift curve for the 4 different bottom flange/baseplate configurations...... 126

Figure 8-41 von-Mises stresses for different configuration of connection between bottom flanges and baseplate, unit=ksi.

Figure 8-42 Distribution of cracks in the concrete diaphragm and deck under inverse loading in a non-integral bridge. 128

Figure 8-43 Pattern of cracks in the system under inverse loading in non-integral bridge 128

Figure 8-44 Distribution of cracks in concrete diaphragm and deck under inverse loading in integral bridge.

Figure 8-45 Distribution of cracks in the left and right wing of model under inverse loading in integral bridge.

Figure 8-46 Concentration of nonlinearity in the system under inverse loading. 130 
Figure 8-47 Sequence of failure modes under inverse forces.

Figure 8-48 Cracks in concrete deck over the concrete diaphragm and below the girder bottom flange (push-up side) at sub step 320 out of 723 (model No. 234).....

Figure 8-49 von-Mises stress in bars and girders at sub step 320 out of 723 (model No. 234)... 131

Figure 8-50 von-Mises stress in bars at sub step 415 out of 723 (model No. 234).

Figure 8-51 Cracks in concrete deck over the concrete diaphragm and below the girder bottom flange (push-up side) at sub step 415 out of 723 (model No. 234)

Figure 8-52 Starting of crushing in concrete deck over the concrete diaphragm and below the girder bottom flange (push-up side) at sub step 450 out of 723 (model No. 234)..... 132

Figure 8-53 Sequence of failure modes under axial forces..................................................... 133

Figure 8-54 Amount of moment at connection of deck and substructure due to axial force....... 133

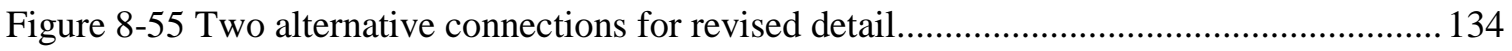

Figure 8-56 Revised seismic detail of SDCL bridge connection over the pier........................... 135

Figure 8-57 Different finite element models to check the performance of revised detail. .......... 136

Figure 8-58 Moment-Drift plot of revised seismic detail under inverse loading ........................ 137

Figure 8-59 von-Mises stresses for different finite element models under inverse loading. ........ 138

Figure 8-60 Moment-Drift plot of revised seismic detail under push-down forces..................... 139

Figure 8-61 von-Mises stresses for different finite element models under push-down forces. ... 139

Figure 8-62 Moment-Drift plot of revised seismic detail under push-up forces......................... 140

Figure 8-63 von-Mises stresses for different finite element models under push-up forces. ........ 141

Figure 8-64 Value of maximum stress in different elements.................................................. 142

Figure 8-65 Difference between models with merged joint and separated joint at the interface

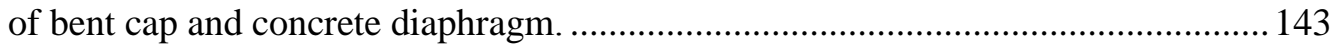

Figure 8-66 Moment capacity of the system with two different layouts for dowel bars. ............ 144

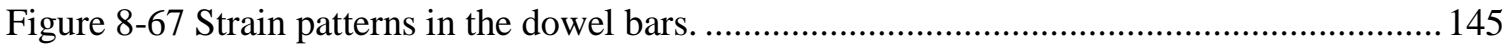

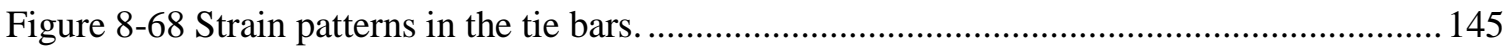

Figure 8-69 Strain patterns in the longitudinal bars in the slab. ............................................ 146

Figure 8-70 Stress patterns in the concrete below the bottom flange. ....................................... 146 
Figure 8-71 Stress patterns in the dowel bars (left) and tie bars (right). 146

Figure 9-1 Reported dowel bars and tie bars. 148

Figure 9-2 Effect of dowel bars and tie bars in the moment capacity under push-up loading..... 149

Figure 9-3 Observed capacity at $0.2 \%$ drift offset according to area of tie bar steel under pushup forces.

Figure 9-4 Observed capacity at $0.2 \%$ drift offset according to area of dowel bar steel under push-up forces.

Figure 9-5 von-Mises stresses in dowel bars and tie bars under push-up forces (dowel bars $=24.75$ in 2 , tie bars $=2.4$ in2).

Figure 9-6 Effect of dowel bars in the moment capacity under inverse loading (Cold joint)...... 151

Figure 9-7 Effect of tie bars in the moment capacity under inverse loading.

Figure 9-8 Maximum observed capacity according to area of dowel bar steel under inverse forces.

Figure 9-9 Maximum observed capacity according to area of tie bar steel under inverse forces.

Figure 9-10 Movement of bottom flange into concrete diaphragm. 153

Figure 9-11 stress distribution in dowel bars along the cap beam. 153

Figure 9-12 von-Mises stresses in two different models, left: 15.7 in2, right: 2.8 in2. 154

Figure 9-13 Moment capacity of the system with two different amounts of shear bar steel. ...... 154

Figure 9-14 Effect of dowel bars in the Monolithic model under inverse loading. 155

Figure 10-1 Equivalent static vertical loads and moments (CALTRANS, 2013)....................... 157

Figure 10-2 The value of load and moment under $0.25 \mathrm{DL}$ in one girder.

Figure 10-3 Comparison between demand and capacity for different models (steel varies for the tie bars and dowel bars).

Figure 10-4 Completing the placement of the pre-topped units for the bridge over I-80 at 262nd Street in Nebraska (AZIZINAMINI, 2014) .......................................................... 160

Figure 10-5 Exaggerate deformation of the bent cap and concrete diaphragm.

Figure 10-6 The location of applied forces in the finite-element analysis (left) and in MomentCurvature analysis (right).

Figure 10-7 The approximate distribution of stresses in finite-element model (left) and in Moment-Curvature analysis (right) when materials are in the elastic range. 162 
Figure 10-8 Ultimate moment capacity of the system based on Moment-Curvature analysis..... 163

Figure 10-9 Ultimate moment capacity of the system based on finite element analysis in cold joint model.

Figure 10-10 Ultimate moment capacity of the system based on finite element analysis in

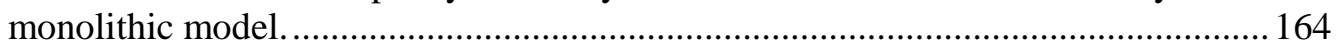

Figure 10-11 Stress distribution at the interface of bent cap and concrete diaphragm. ….......... 165

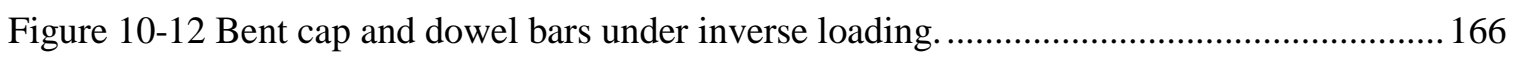

Figure 10-13 Strain diagrams at the interface of bent cap and concrete diaphragm................... 166

Figure 10-14 Stress and force diagrams at the interface of bent cap and concrete diaphragm.... 167

Figure 10-15 Beam-spring model for a slice of the concrete diaphragm and the dowel bars...... 167

Figure 10-16 A strip of the concrete diaphragm with the dowel bars and the applied force. ...... 168

Figure 10-17 Side view of concrete diaphragm and parallel cracks ........................................ 168

Figure 10-18 Value of strain in dowel bars across the length of cap beam. ............................. 171

Figure 10-19 Distribution of stress and strain across the length of bent cap............................ 173

Figure 10-20 Bar chart comparison between finite element results and developed formula....... 177

Figure 11-1 Deflected shape and column moment diagram under longitudinal component of

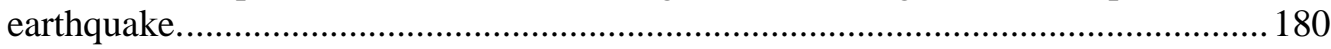

Figure 11-2 Amount of moment at boundary condition of specimen...................................... 180

Figure 11-3 Location and amount of forces in specimen model............................................ 180

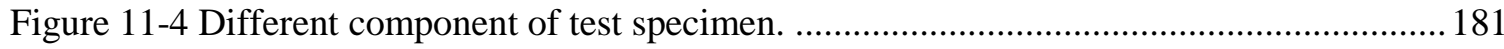

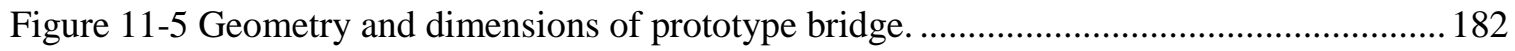

Figure 11-6 Selected portion for construction and testing.................................................... 183

Figure 11-7 Different components of test specimen........................................................... 183

Figure 11-8 Prototype bridge for testing the connection between I-girder and inverted cap

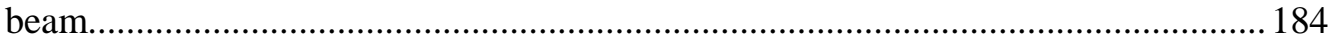

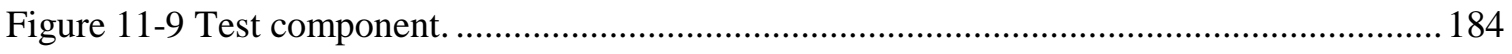

Figure 11-10 Details of looped unstressed strand connection and load transfer mechanism....... 185

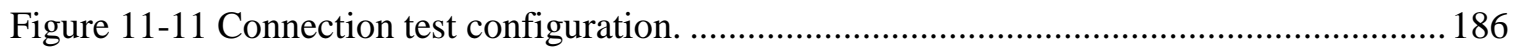


Figure 11-12 Component test including one column with two girders.

Figure 11-13 Material property for steel (left) and concrete (right). 188

Figure 11-14 Mander-Confined model right, left (full-scale ), right (one-third scale). 188

Figure 11-15 Column property definition- left (full-scale), right (one-third scale) 188

Figure 11-16 Effective Bent Cap Width 190

Figure 11-17 Location of Vertical Joint Reinforcement (Plan View of Bridge) 191

Figure 11-18 Joint Shear Reinforcement Detail 193

Figure 11-19 Bent cap geometry 194

Figure 11-20Concrete diaphragm and bent cap reinforcements (left: full-scale model, right: one-third scale model) . 195

Figure 11-21 Column Moment-Curvature for the full-scale model. 195

Figure 11-22 Cap beam Moment-Curvature in transverse direction for the full-scale model..... 195

Figure 11-23 Cap beam Moment-Drift in longitudinal direction for the full-scale model. ......... 196

Figure 11-24 Column Moment-Curvature for the one-third scale model. 196

Figure 11-25 Cap beam Moment-Curvature in transverse direction for the one-third scale model.

Figure 11-26 Cap beam Moment-Drift in longitudinal direction for one-third scale model. 197

Figure 11-27 Amount of strain in dowel bars in full-scale model (left) and one-third scale model (right).

Figure 11-28 Column deformation and curvature along the column length. 198

Figure 11-29 Yield, plastic and ultimate curvature. 198

Figure 11-30 The value of force and displacement at the end of the column. 200 


\section{RESEARCH APPROACH AND BACKGROUND}

\subsection{Introduction}

In this chapter, a brief background and description of the Simple for Dead Continuous for Live Load (SDCL) bridge system are presented. The problem statement is given and the research approach and tasks are explained.

\subsection{Background and Problem Statement}

\subsubsection{Simple for Dead Load Continuous for Live Load (SDCL)}

In continuous steel bridges, the system provides continuity for non-composite dead loads in addition to the superimposed dead load and live loads. For a large number of bridges, the construction sequence consists of first placing a middle segment over the interior support and then connecting the two end pieces using a bolted or welded field splice. Figure 1-1 shows a conventional two-span continuous steel bridge girder and its field splice.
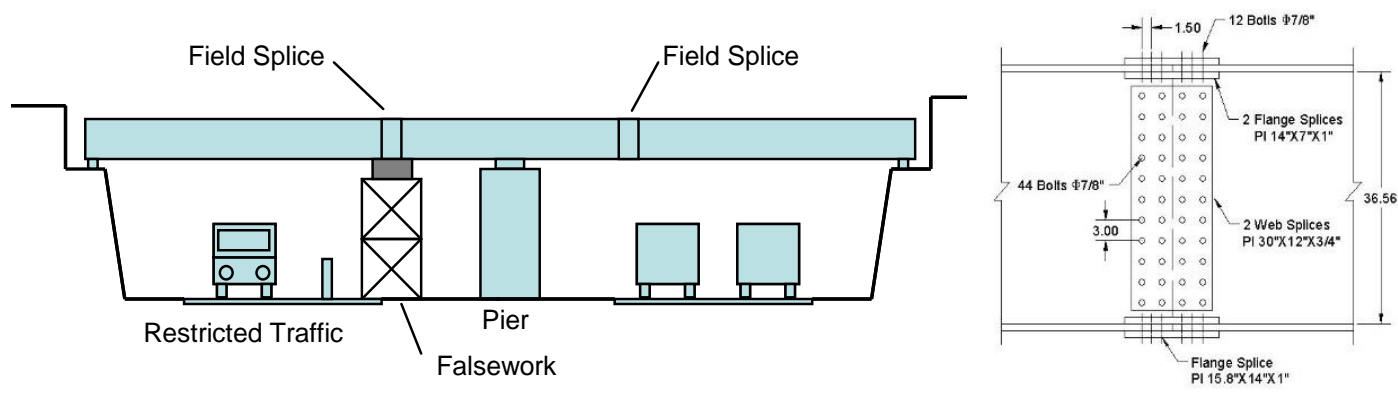

Figure 1-1 Conventional two spans continuous bridge girder and typical splice detail.

In the Simple for Dead Load and Continuous for Live Load (SDCL) system, the girders are spliced at each the pier. The girders span directly from pier to pier (or abutment to pier) within each span. The individual spans are simply supported when the deck is cast. Once the deck is in place, reinforcing steel cast into the deck provides continuity for the tensile forces imposed by live load and superimposed dead loads (weight of barrier and future wearing surfaces) only. Figure 1-2 
shows the construction process in SDCL bridges. The tensile and compressive components are transferred by longitudinal bars in the slab and steel blocks at the bottom flange, respectively.

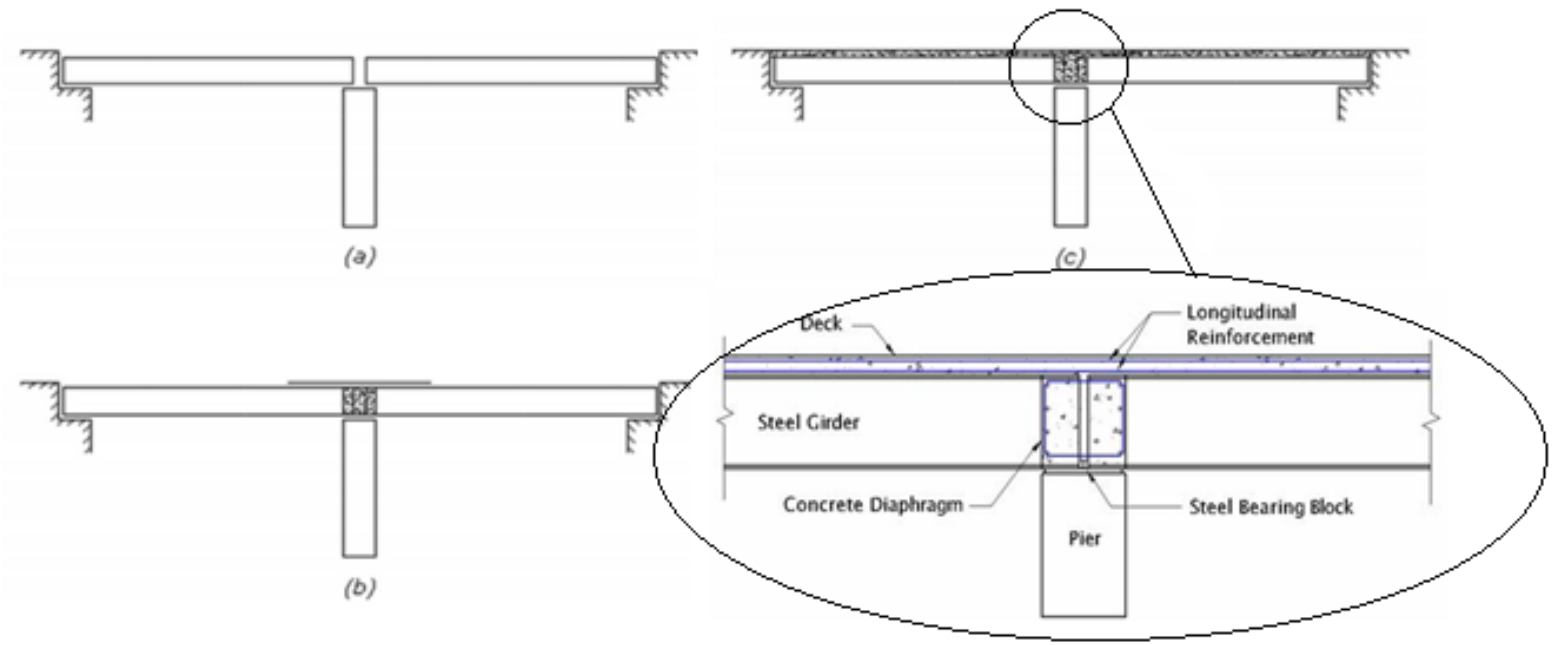

Figure 1-2 Construction sequence for SDCL bridge systems.

Reduced maintenance, life-cycle costs, and easier inspection are some advantages of the SDCL bridge system compared to conventional methods. The SDCL system is also well suited for Accelerated Bridge Construction (ABC). An ABC implementation of the SDCL method includes building individual spans off site, transporting them to the final location and then joining the spans over the middle piers to create continuity for live load.

\subsubsection{Problem Statement}

The SDCL steel bridge system has gained popularity in non-seismic areas of the country. The system provides many advantages including a longer service life and lower inspection and maintenance costs compared to conventional bridge construction methods. Additional details and benefits of the SDCL system in comparison with conventional bridge systems are more fully discussed in Chapter 2. To-date, no research studies have been conducted to extend the applicability of the SDCL system to seismic areas, either for conventional or Accelerate Bridge Construction $(\mathrm{ABC})$. The main objective of this research is to extend the application of SDCL to seismic areas. 
The project is in Phase I of an effort that is expected to culminate with the development of a set of details and associated design provisions that will allow for the use of SDCL in seismic areas. In this research, a new detail is proposed in Chapter 6 and the load resistance mechanism is described in Chapter 8.

\subsection{Summary of Literature Review}

In this section most of the research materials relevant to SDCL steel bridges and seismic performance of the connection between super structure and substructure in integral bridges are explained.

\subsubsection{SDCL Literature Review}

A comprehensive experimental, numerical and analytical research study was conducted by Dr. Azizinamini and his research group ( (Lampe N. J., December, 2001), (Mossahebi, 2004), (Otte, 2006), (Farimani M. M., 2006), (Kowalski, 2007), (Javidi S. , 2009) ) at the University of NebraskaLincoln to develop an economical detail for the SDCL steel bridge system. A summary of works that have been completed for SDCL bridge systems are as follows (Azizinamini, 2014):

Experimental Investigation. A Full-scale experimental test was carried out in the structures lab at UNL to develop an economical and suitable connection for girders in the concrete diaphragm (Lampe N. M., 2014).

Force Transfer Mechanism. To study the force, transfer mechanism for the developed detail, a comprehensive numerical and analytical study was carried out. A design approach was developed and the results compared with the experimental results. The resulting connection based on the simplified approach was conservative and practical for use in design (Farimani M. J., 2014). 
Monitoring of In-Service SDCL Bridges. Several SDCL bridges that were designed according to the recommended detail and simplified approach were constructed. The performance of these bridges was monitored during and after the construction process (Javidi S. Y., 2014).

SDCL System for Accelerated Bridge Construction (ABC). More research was conducted to adjust the SDCL construction process for accelerated bridge construction. This part was included of choosing a suitable detail for connection, conducting experimental and numerical study, and monitoring the behavior of constructed SDCL bridges according to ABC methods (Javidi S. Y., 2014).

During the experimental investigation, the main challenge was to use the right detail over the pier to connect the girder ends. The two ends of the girders are embedded in the concrete diaphragm to transmit the large stresses to the concrete. If not detailed correctly, the force can crush the concrete. Selecting an appropriate connection detail for joining girders inside of the concrete diaphragm was the main key to making this system economical and practical for use. In Figure 1-3, all three test specimens used identical details at the ends of the girders. Note that all three connection details were embedded in the concrete diaphragm. As illustrated in Figure 1-3, the only difference between tests was the detail used to join the end girders to each other. In Test one the end plates are welded to the end of the girders and the bottom flanges are connected to each other. In Test 2 there are no end plates and the bottom flanges are not continuous. Test 3 was similar to test one but the bottom flanges were not continuous. Figure 1-4 shows the details used in each test with resulting Moment-Drift for each test specimen. In Figure 1-4, results from the experimental tests showed the detail of test 1 resulted in a larger capacity and the detail of test 2 resulted in the lowest capacity. 

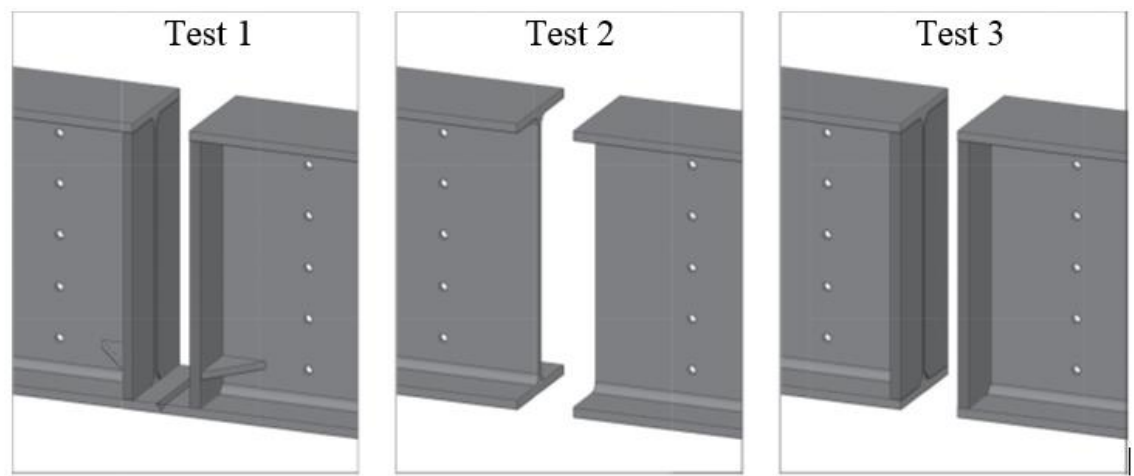

Figure 1-3 Details of test specimens inside the diaphragm.

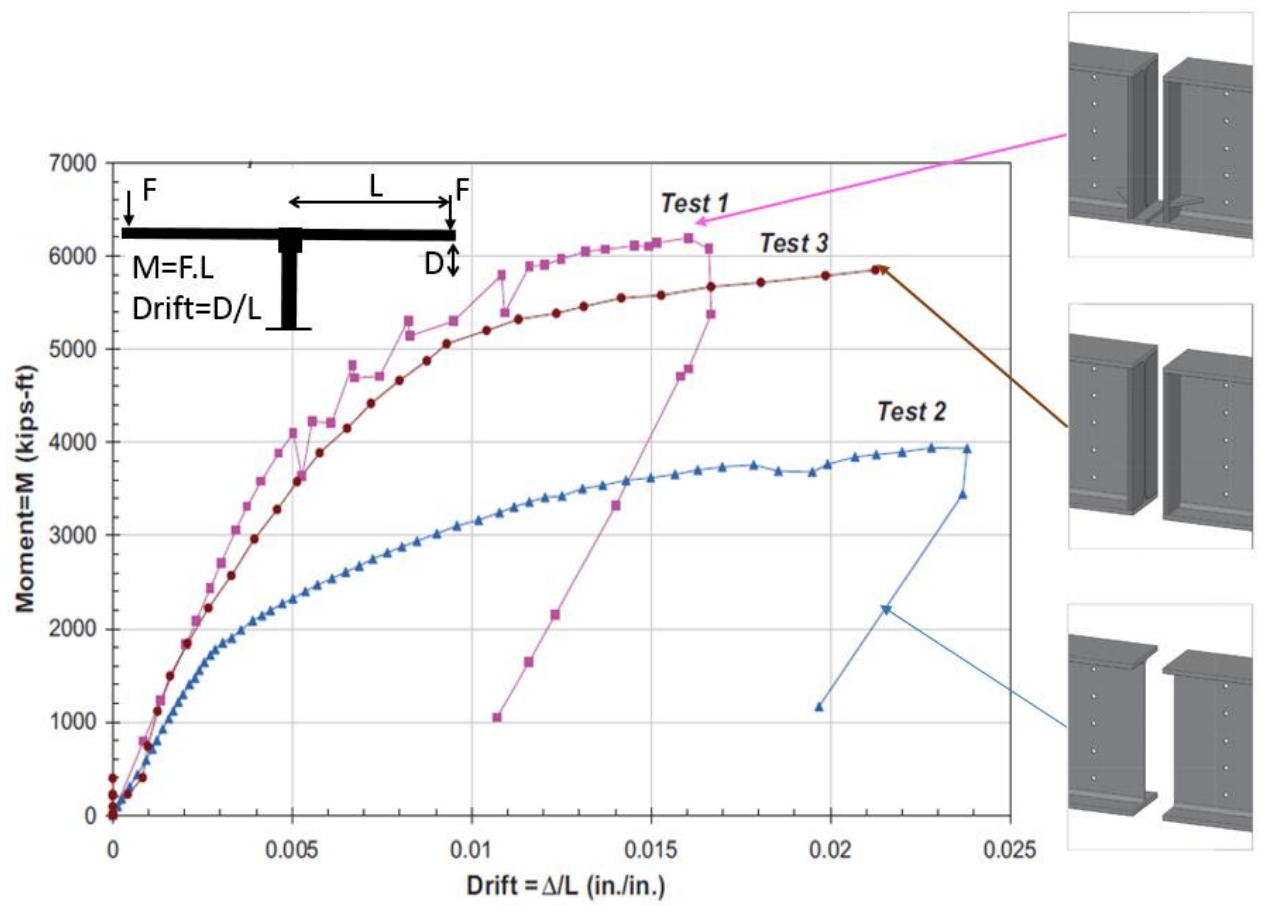

Figure 1-4 Moment-Drift of the three test details.

The main lesson learned was that the bottom flanges of the steel girders embedded in the concrete diaphragm should somehow be connected. This allows for the transfer of compressive force (generated by live loads) from girder to girder without passing through the concrete diaphragm. Figure 1-5 and Figure 1-6 show the final recommended detail to be used to embed the I girder and box girder ends in the concrete in non-seismic areas. 

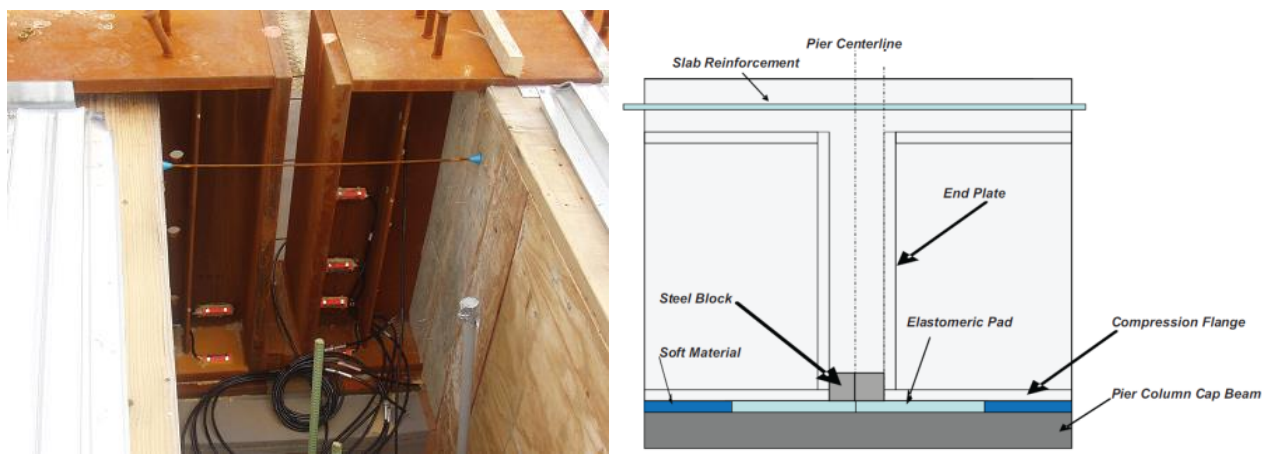

Figure 1-5 SDCL detail used in Non-Seismic areas to connect girders.

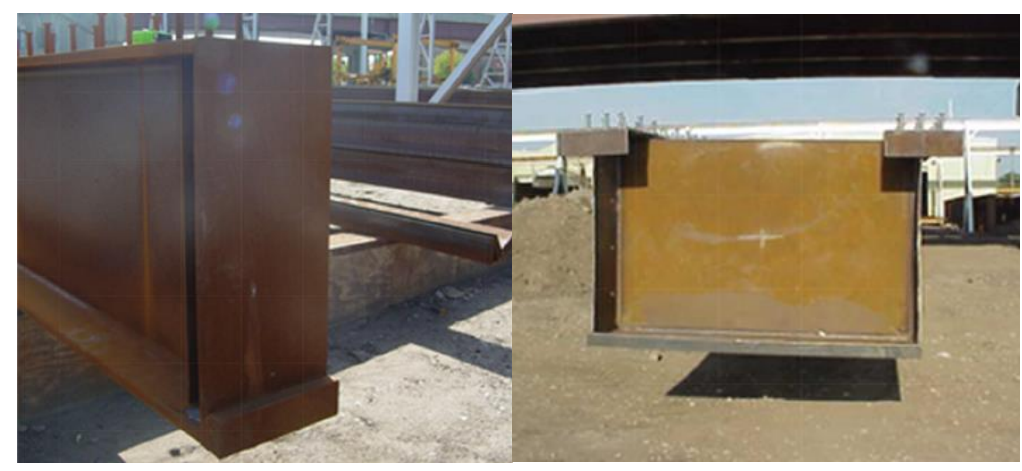

Figure 1-6 Recommended detail for an I girder (left) and a box girder (right).

The West Virginia Department of Transportation constructed two bridges using SDCL, The Three Springs Drive Bridge and the Washington Avenue Bridge (Figure 1-7 and Figure 1-8) in the northern panhandle of West Virginia and studied the advantages of the system. At the end of construction overall costs and maintenance was reduced, performance improved and construction was accelerated (BEINING, 2014). Construction of these two bridges showed that the SDCL system can be beneficial to traffic and the ability to stage construction over more conventional bridge building methods. 

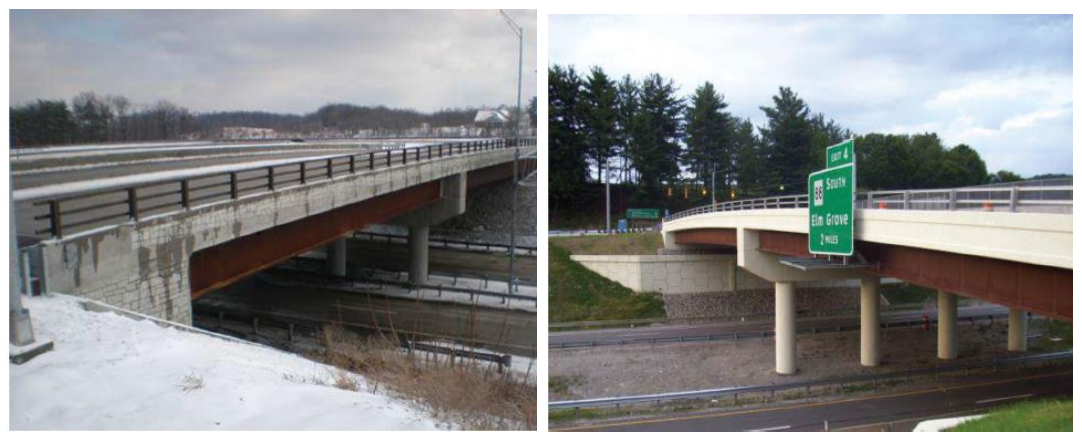

Figure 1-7 left: Three Spring Drive, right: Washington Avenue.

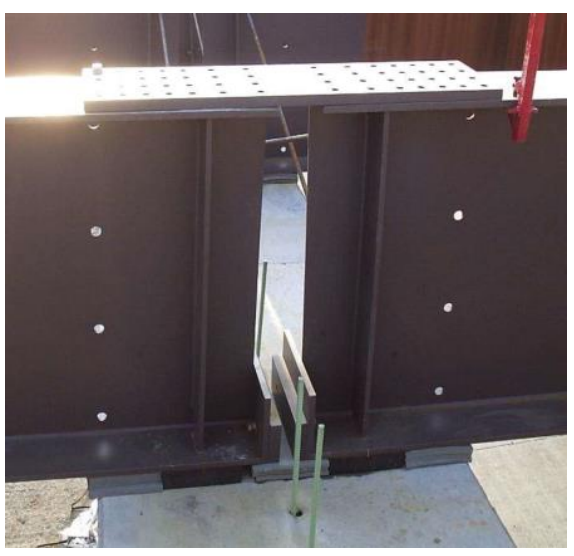

Figure 1-8 Connection detail for Spring Drive bridge.

\subsubsection{Seismic Performance of Integral Bridges Literature Review}

Comprehensive research was conducted at the University of California at San Diego (UCSD) to investigate the seismic behavior of steel girders with an integral concrete bent cap subjected to longitudinal and transverse components of seismic loads. For the connection between the steel girder and concrete bent cap, four different details were considered as illustrated in Figure 1-9. In this research, the first detail (CR-NS) represents a conventional reinforced bent cap without any stiffening element. The second test (CR-S) was similar to the first but inside of the concrete diaphragm full height bearing stiffeners are welded to the girder. The third test (PT-NS) specimen was also similar to the first but the bent cap was post tensioned. Finally, the forth test (PT-S) was a combination of the second and third specimen and contained full height bearing stiffeners and the concrete bent cap was post tensioned. It was evident that the stiffeners increased the maximum torsional moment capacity around $20 \%$. Furthermore, post tensioning of the bent cap increased the 
performance of the system by limiting the cracks in the compression zone of the bent cap. The experimental tests showed that the superstructure remained in the elastic range while a full failure mechanism developed in the column.

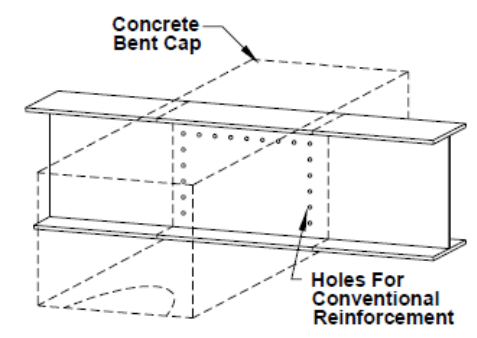

a) CR-NS

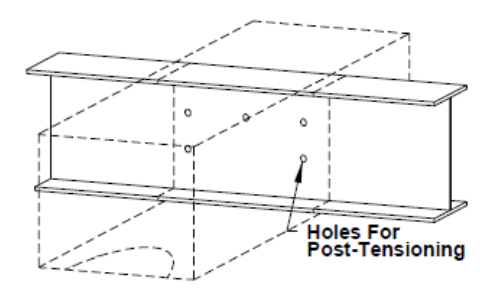

c) PT-NS

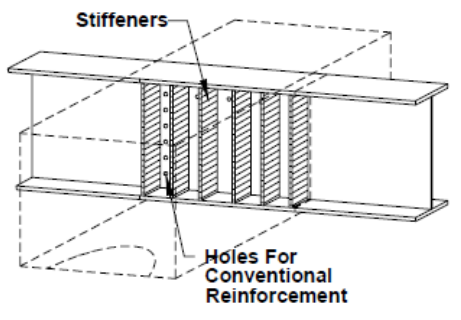

b) CR-S

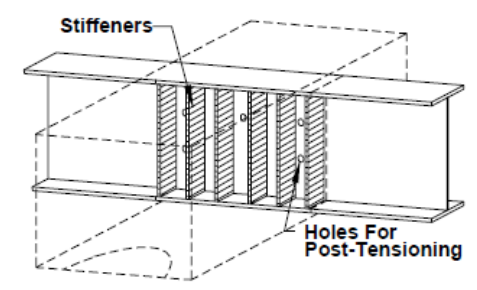

d) PT-S

Figure 1-9 details for connection between steel girder and concrete bent cap.

NCHRP report 527 investigated integral bridge systems where girders are connected to the steel box-beam cap. Fourteen different connections for integral bridge systems were examined based on the expected economy, constructability, and performance of each system. The final selected system contains a steel box cap beam that connected to a steel I girder and reinforced concrete column. The single column connected to the cap beam by extending longitudinal reinforcement into steel box-beam cap through holes in the bottom flange of the pier cap as illustrated in Figure 1-10. The compartment that was created by the bent cap and two steel plates at the two sides was filled with concrete to transfer the forces to the longitudinal reinforcement. To validate the performance of the connection, analytical and experimental investigations were conducted. It was evident that the suggested connection between the column and the bent cap is 
sufficient to develop plastic hinges at the columns. The test specimen with the deeper pier cap and longer anchorage length resulted in greater ductility than that obtained from the specimen with a shallower pier cap. The reason for reduced ductility in the second specimen is due to the loss of bond between the column longitudinal reinforcement and concrete in the integral connection region. The results also revealed that nonlinearity occurred and damage formed at the end of column in the vicinity of the bent cap, as was expected. The superstructure behaved elastically throughout the entire test specimen.
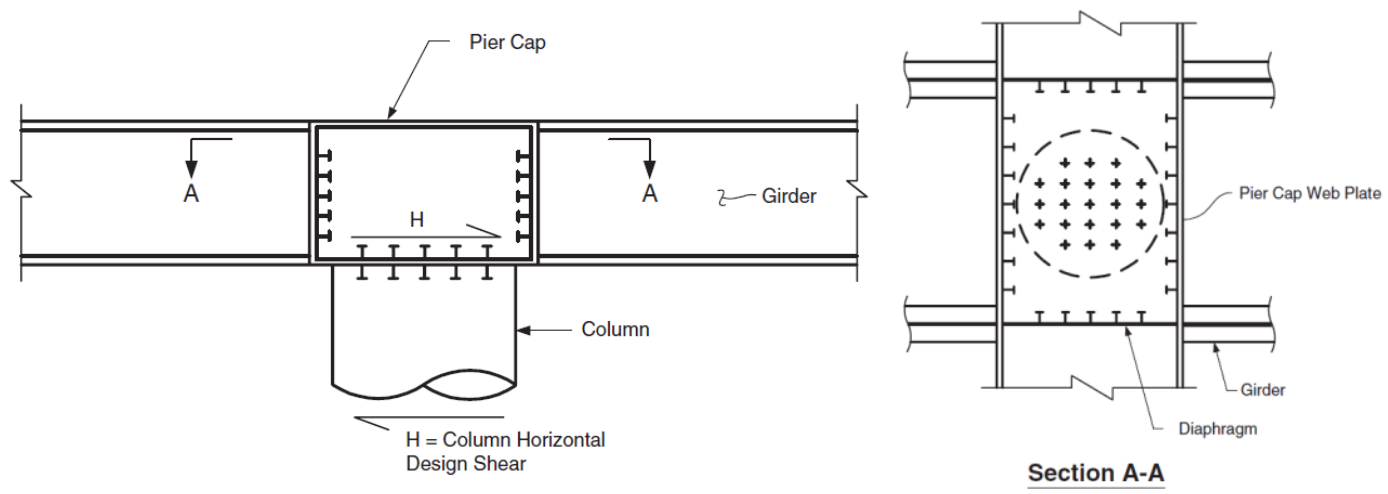

Figure 1-10 Column-to-cap beam connection.

An investigation was completed at Iowa State University looking at the seismic performance of a reinforced concrete column that was integrally connected to an inverted cap beam and I shaped precast concrete girder (R. Snyder, SEPTEMBER 2011). A finite-element analysis and half scale experimental test was conducted to investigate the performance of the connection between the concrete girders and an inverted tee cap beam, overall seismic behavior of the system, the behavior of the connection between the pier and the bent cap. Finally, a design procedure was recommended. Four different connections with six different details were considered. The following describes the different details: 
In GUSC (Grouted Unstressed Strand Connection), continuous unstressed strands are placed through the duct in the girder and cap. The strand is then grouted in place. Three dowel bars are placed transversely through the web of the girder. This detail is shown in

Figure 1-11(A). In LUSC (Looped Unstressed Strand Connection), looped, unstressed strands are placed in the girder. The looped, unstressed strands are placed in the cap beam and diaphragm around the large headed dowel bars. Three dowel bars are placed transversely through the web of the girder. This detail has been shown in

Figure 1-11(B). In ESBF (Extended Strand Bent with Free End), some of the strands are extended from the girder with a 90-degree bend, at the end. Three dowel bars are placed transversely through the web of the girder. This detail is shown in

Figure 1-11(C). In ESSP (End Plate), some of the girder pre-stressing strands are extended a short distance with a bearing plate, a barrel anchor and wedges. Transverse dowel bars are similar to ESBF Connection. This detail has been shown in

Figure 1-11(D). In ESLS (Extended Strand Lapped Splice), some of the girder pre-stressing strands are extended a short distance with a bearing plate, a barrel anchor and wedges and lapped with strands extended from the opposite girder. Transverse dowel bars are extended through web of the girder with U-shaped confinement steel. This detail is shown in Figure 11-1(E). In ESMS (Extended Strand Mechanical Splice), some of girder pre-stressing strands are extended and connected to extended strands from the opposite girder with a mechanical splice chuck. Transverse dowel bars are similar to ESLS Connection. This detail is shown in Figure 11-1(F).

Details A and B were selected for more testing (Figure 1-12). Results of this research indicates that contrary to current design assumptions, these types of connections (inverted-tee concept) behaved as a fully continuous connection under both positive and negative moments and 
the connection transferred shear force form the superstructure to the bent cap. The inverted tee pier cap in integral bridges could be developed plastic hinge at the top of the column.
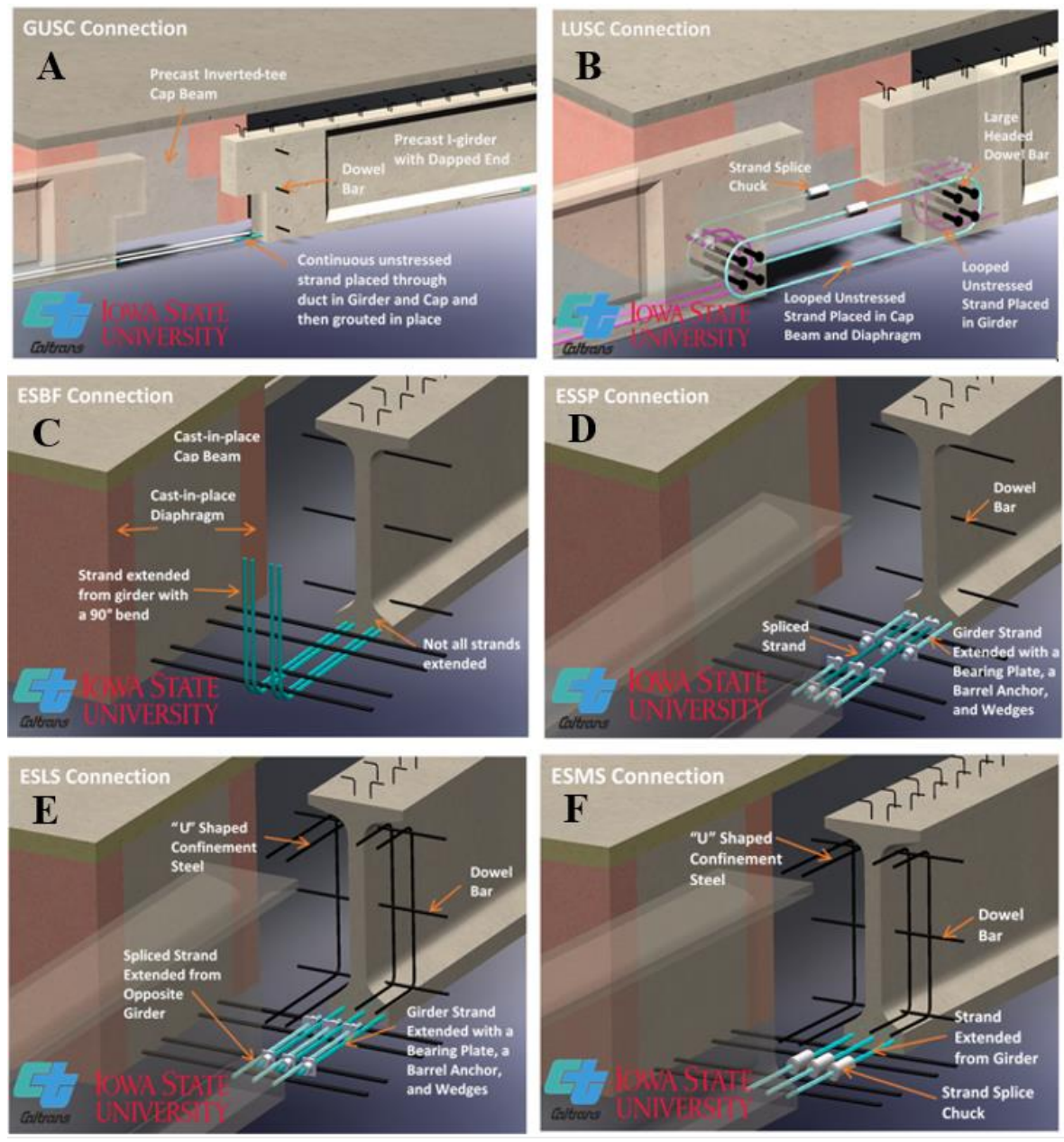

Figure 1-11 Connection detail for an I-girder to inverted-tee bent cap.
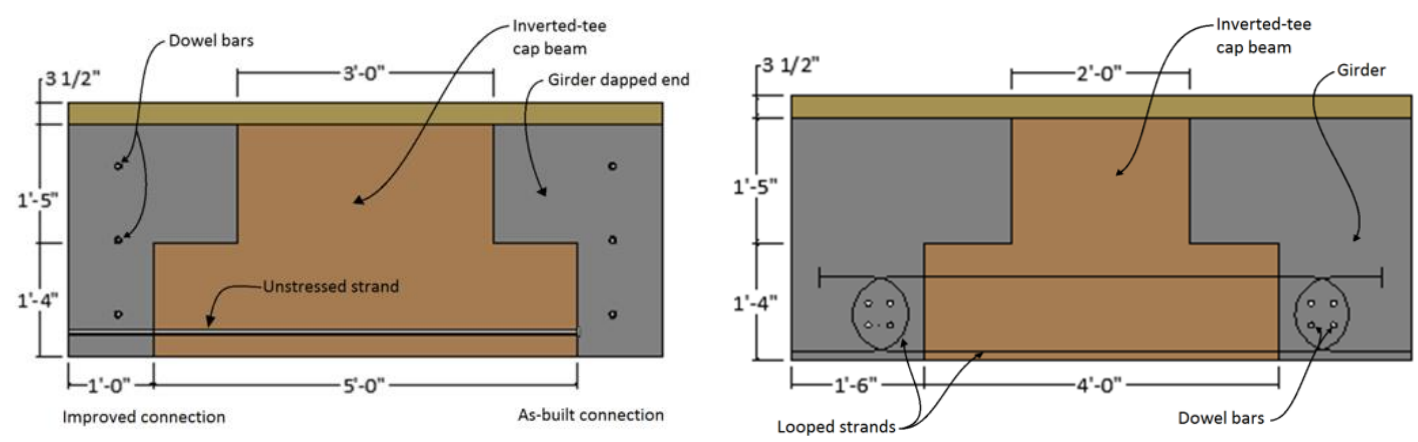

Figure 1-12 Selected details for more investigation (Details A and B). 
The seismic response of typical multi-span simply supported (MSSS) and multi-span continuous steel girder bridges was evaluated for the central and southeastern region of the United States under a nonlinear time history analysis by the Georgia Institute of Technology (Reginald DesRoches, 2004). The results of this research indicates that typical bridges show a linear response for a 475-year return period earthquake while seismic response under a 2,475-year return period quake resulted in significant vulnerabilities in the bridge response. Furthermore, the results confirm the impact between the deck in the multi span simple supported bridge and between the deck and abutment led to damage in the steel bearing. For the multi-span simple supported bridge, the demand drift was greater than the capacity in the column designed for non-seismic areas in the central and southeastern of United States. Larger mass in the multi span continuous bridges resulted in a larger demand capacity ratio.

\subsection{Research Objective}

Due to the lack of existing research for seismic performance of SDCL system, designers are reluctant to embrace this system in seismic areas. To-date, no research studies have been conducted to extend the applicability of the SDCL system to seismic areas. The specific concern is the behavior and performance of the connection in the concrete diaphragm due to the longitudinal force of earthquakes.

The object of this research is to extend the application of SDCL to seismic areas and develop a recommended detail and design methodology for SDCL bridge systems. The recommended detail should be in a form suitable for $\mathrm{ABC}$ (Accelerated Bridge Construction). The research was narrowed to exclude non-integral bridges and only include the integral connection between I steel girders, concrete diaphragm and beam cap. This project is in Phase I of an ongoing effort expected to culminate in the development of a set of details and associated design provisions that will allow the use of SDCL in seismic areas, (using ABC). 
Phase I, concentrated on developing suitable details through numerical analysis. During Phase II of the project, experimental tests will be carried out to verify the validity of the design recommendations.

\subsection{Contribution to Expanding Use of $\mathrm{ABC}$ in Practice}

Development of the necessary details and design provisions for extending the application of the SDCL steel bridge system to seismic areas will provide an excellent steel bridge alternative that does not have expansion joints and potentially produces long service life, while meeting seismic design requirements.

\subsection{Research Approach and Methods}

An extensive amount of research data exists for the non-seismic detail of SDCL bridge system. However, there are specific requirements for seismic applications that need to be addressed. For seismic applications, the detail over the pier should have the following characteristics:

1. It should be adequate to resist reversal and cyclic loads (be designed for tension and compression)

2. The plastic hinge locations should be at some distance away from the superstructure.

3. Design should follow capacity design philosophy and the detail used to connect the girders over the pier should remain elastic during the entire seismic event.

4. The detail connecting the girders over the pier should be monolithic with the pier and develop frame action. 


\subsection{Description of Tasks Completed in This Research Project}

The description of research tasks is provided below.

Task 1: Modify the existing detail for seismic areas to determine the force transfer mechanisms of the details. A comprehensive non-linear finite-element model should be developed to:

- Study the force transfer mechanism for the proposed connection.

- Numerically identify the modes of failure.

- Modify the proposed connection, so that concrete diaphragm remains elastic during the entire seismic event.

Task 2: Conducting a non-linear FE model for a parametric study to understand the behavior of the proposed connection detail(s) during the seismic event at the macro and micro levels.

Task 4: The proposed detail should be discussed with state bridge engineers in seismic areas and ensured that we are moving in the right direction for developing the detail suitable for seismic areas.

Task 5: Developing an experimental testing program, capable of verifying the project recommendation in Phase II of the study.

\subsection{Dissertation Layout}

This dissertation discusses a revised connection detail for SDCL bridge systems that will make construction of SDCL bridges feasible in seismic areas. The goal of this dissertation is to propose a new detail that is usable in seismic areas, calculate the demand and capacity side of the connection, and find the load resistance mechanism under seismic loads to provide a simple design formula that is suitable for use in designing new bridges in seismic areas. 
In Chapter 1 a literature review of SDCL and integral bridge systems is summarized. Furthermore, problem statement, research approach and tasks of this project discussed. Chapter 2 introduced the SDCL bridge system and made a comparison between conventional and SDCL systems. The effect of different elements of the bridge system, like abutments and the type of connection between the deck and bent cap and its nonlinear behavior of the system are pointed out in Chapter 3. In Chapter 4, a review of seismic design provisions according to AASHTO LRFD specification are summarized. In Chapter 5, a prototype bridge was modeled using CSiBridge and the design results were controlled by hand calculations. Afterward, a nonlinear pushover and a time history analysis were conducted to evaluate the demand side of the SDCL bridge system due to strong ground motions. The demand side of the connection was investigated based on results obtained from the previous chapter and then a new connection was proposed in Chapter 6 . The failure mode and expected performance of this connection was studied before starting a detailed nonlinear finite element analysis. In Chapter 7, a finite element model for the proposed connection was developed. At the end of this chapter, the finite element model of existing SDCL connection was verified by comparing it with available experimental test results from UNL. In Chapter 8, the load resistance mechanism of the new connection was found for different load conditions. To simulate seismic loads, the model was subjected to discrete loadings and the failure mode of connection was considered in each load condition. The finite element analysis was repeated for different models to investigate the role of different parts of connection. Based upon results obtained from previous chapters, a simple design approach for the new connection is proposed in Chapter 10. In Chapter 11 the experimental test specimen was designed and the load setup for the component test was selected. A summary of research observation was provided in Chapter 12. 


\section{LITERATURE REVIEW AND INTRODUCTION TO SDCL BRIDGE SYSTEM}

\subsection{Introduction to SDCL Steel Bridge System}

In this section, background information and concepts behind "Simple for Dead Load Continuous for Live load" (SDCL for short) or also called "Simple Made continuous" will be explained. Moreover, it will describe how this type of bridge system will increase the cost effectiveness.

\subsubsection{BACKGROUND}

The increase in the use of concrete coincided with a decrease in the use of steel in short- to medium-span bridges. In steel bridges, costly details such as bolted splices contributed to this trend. One factor that could reverse this trend is eliminating unnecessary details to decrease cost and increase service life. In the late 1990s and early 2000s, a series of discussions with designers, steel fabricators and contractors was conducted to develop an innovative multi-span steel bridge system with a maximum span length of about $150 \mathrm{ft}$ (Azizinamini, 2014). According to National Bridge Inventory (NBI) data, the maximum span length in about $90 \%$ of the bridges, in service, is less than $150 \mathrm{ft}$ (Lampe N. M., 2014). According to discussions with steel fabricators and constructors, eliminating bolted splices and simplifying the construction needs to improve the cost of steel bridges. A conclusion of all the gathered information resulted to a system in which the girders are simple supported during deck casting and are continuous during service life. The background of this idea originally came from precast, pre-stressed concrete girders which are simple-span girder for dead load and continuous for live load. 


\subsubsection{Conventional Versus SDCL}

In the conventional construction method, the continuous girder consists of three parts. After erecting the middle section over the pier, two end sections are connected to middle using either bolted or welded field splices. Figure 2-1 shows two steel girders that are continuous over the pier in the conventional method.

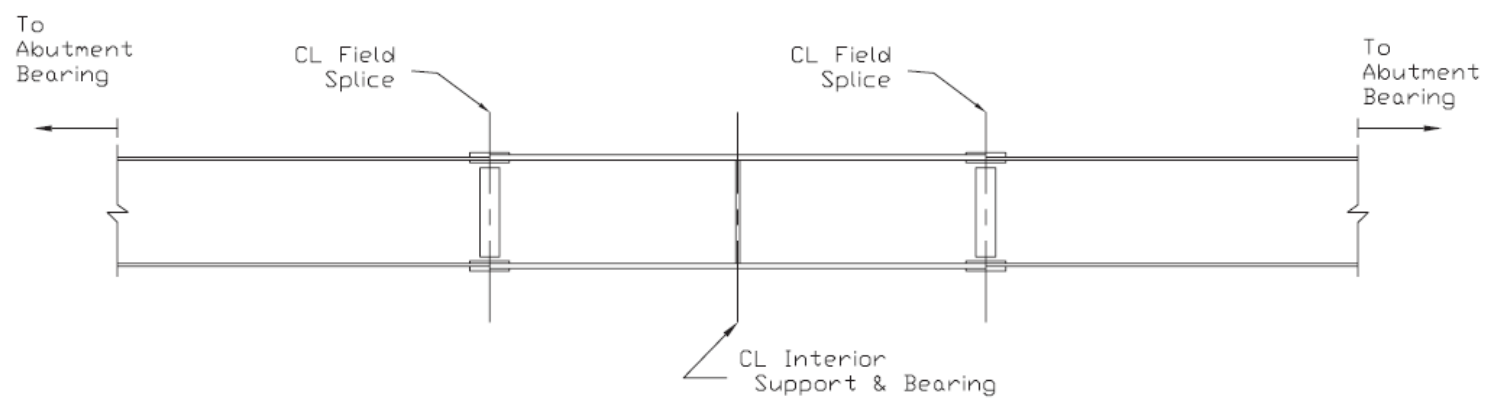

Figure 2-1 A continuous steel bridge girder.

Another way to make the girders continuous is by placing the girders directly from the abutment to the pier within each span. The individual spans are simply supported when the deck is cast. Once the deck is in place, reinforcing steel cast into the deck provides continuity for tensile forces due to live load and superimposed dead loads. The compressive stresses over the pier are transferred through the welded block to the bottom flange providing continuity of the bottom flanges. An example of this detail is shown in Figure 2-2.

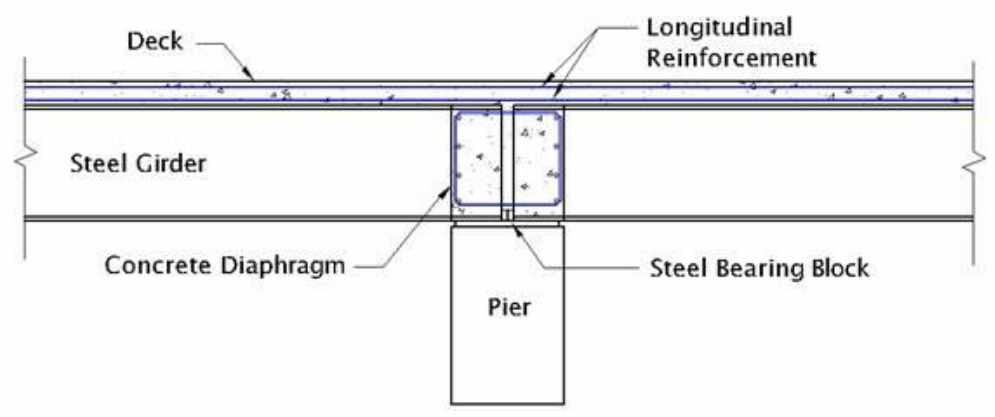

Figure 2-2 Simple for Dead and Continuous for Live detail. 
In this construction process, the two girders are embedded in the concrete diaphragm. Note that negative moments produced by traffic loads and superimposed dead loads transfer compressive forces to the concrete diaphragm in the vicinity of the bottom flanges. In the precast and prestressed concrete girders, the bottom flanges have large areas that can distribute the compressive force from the bottom flange to the concrete diaphragm and prevent crushing of the concrete that is between two bottom flanges.

\subsubsection{SDCL Bridge Elements}

The SDCL system is suitable for short to medium span bridges. Figure 2-3 shows different components of a SDCL bridge system. The bridge bent is composed of the columns, bent cap and concrete diaphragm. The width of bent cap is typically equal to the width of the bridge superstructure.

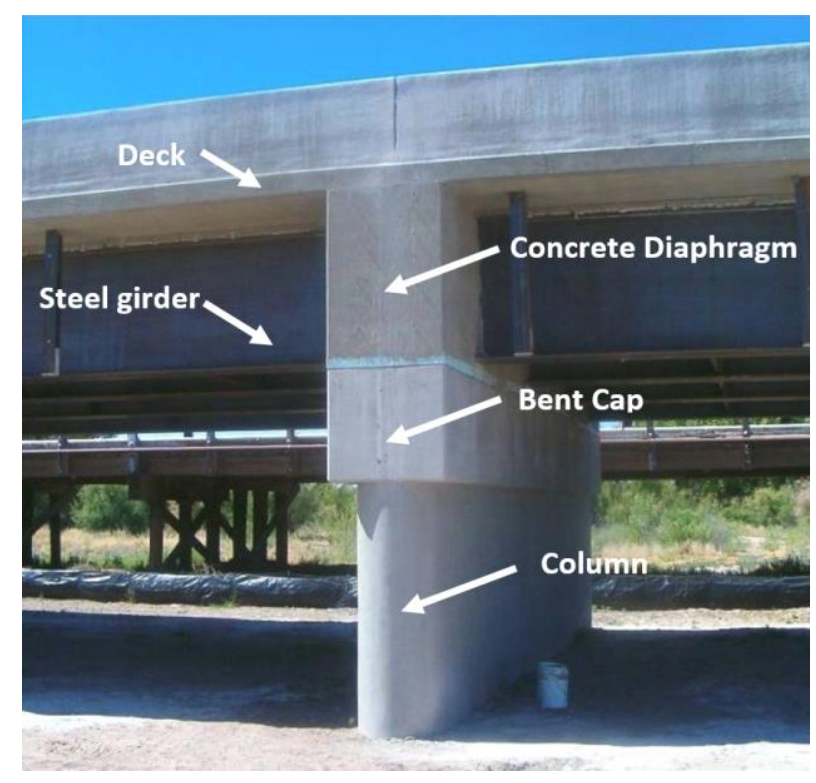

Figure 2-3 Different components of SDCL bridge system.

In SDCL bridge system, steel box girders (Figure 2-4) or steel plate girders (Figure 2-5) can be used as longitudinal girder and make a composite section with the concrete of the deck. The bent frame typically consists of two or three columns (Figure 2-6). 


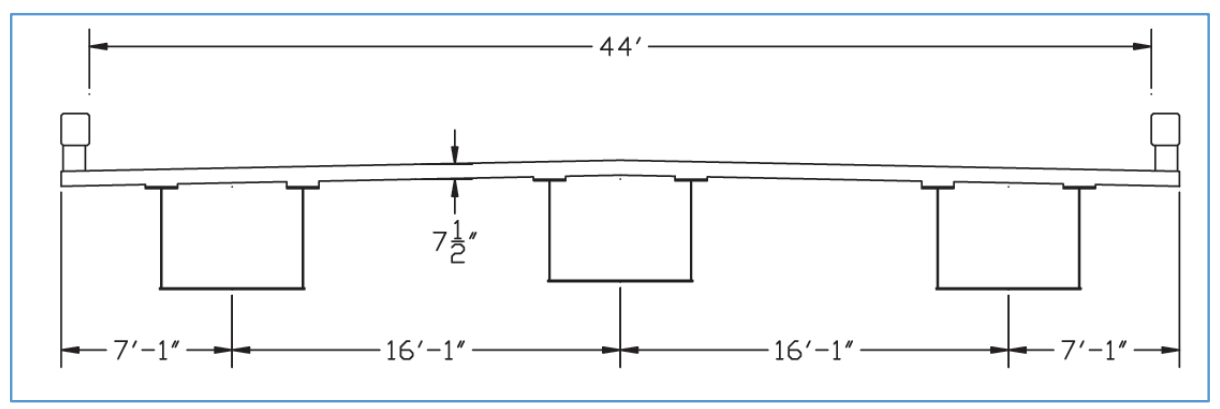

Figure 2-4 Bridge cross-section for steel box girder.

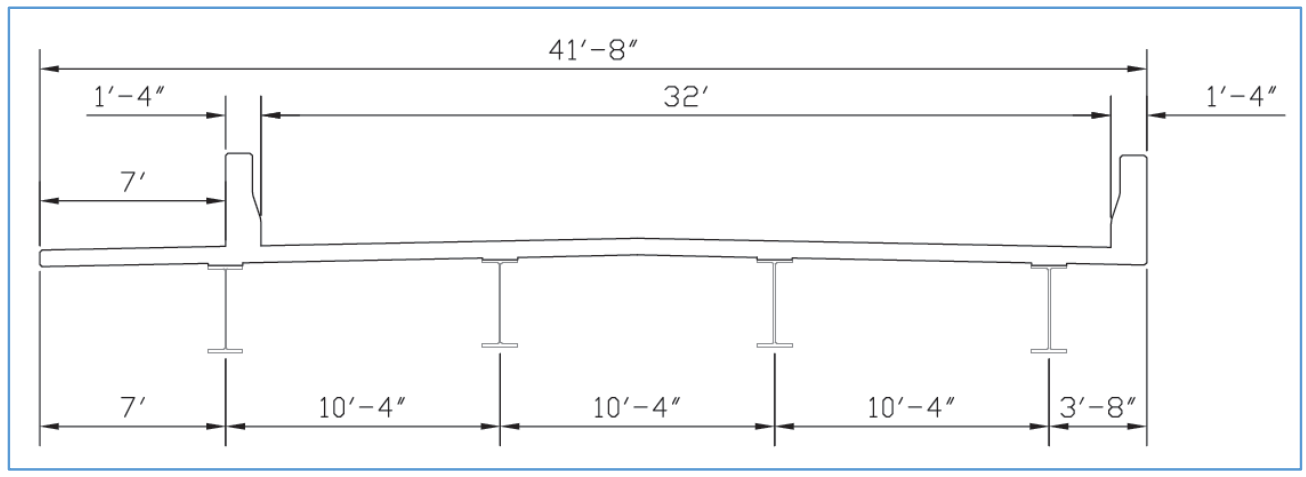

Figure 2-5 Bridge cross-section for steel plate girder.
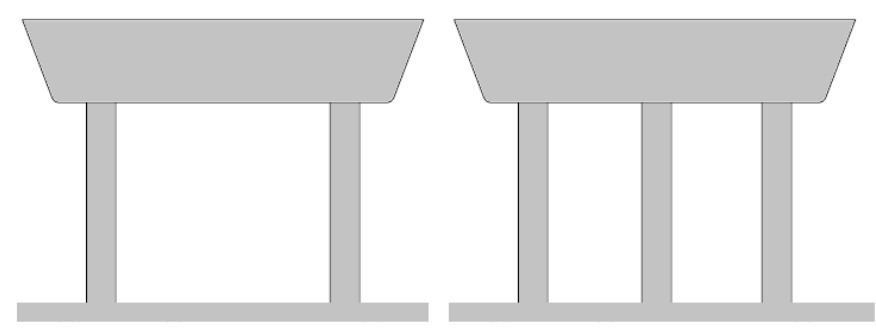

Figure 2-6 Substructure with various numbers of columns.

\subsubsection{Benefit of SDCL to Conventional Bridge System}

\subsubsection{Faster for Construction and More Convenient for ABC}

In conventional steel bridge construction, the process of using bolted splice for connecting together multi-span bridges makes this type of connection expensive due to cost of material, installation and inspection. In addition, conventional steel construction method requires extra cranes or temporary shoring that increases the duration of the project. In the existing SDCL bridge system there are no bolts or expansion joints in the system resulting in higher service life, in 
addition to many other advantages. This system is also best suited for accelerating the construction process. It is ideal for building individual spans off site, transporting them to the final location and then joining the spans over the middle piers to create continuity for live load.

\subsubsection{Reducing Amount of Negative Moment Over Bent Cap}

Another benefit of SDCL over conventional construction method is the amount of negative moment that exists over the pier centerline. In the conventional method, the steel girders are continuous over the pier before casting the concrete deck, thereby creating negative moment over the pier due to self-weight of steel girders and concrete in the slab. In the SDCL system, the girders are separate during construction process and there is no negative moment over the pier for weight of steel girders and concrete of slab as shown in Figure 2-7. To compare conventional and SDCL systems, a two span bridge with equal span length analyzed and maximum positive and negative moments determined. Figure 2-8 and Figure 2-9 shows a comparison between the maximum positive and negative moments respectively (Azizinamini, 2014).

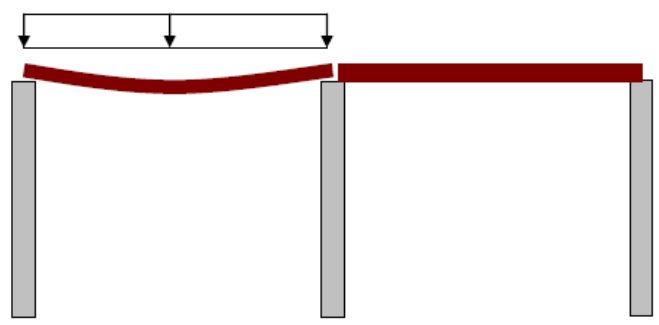

Figure 2-7 The behavior of SDCL bridge system during construction process. 


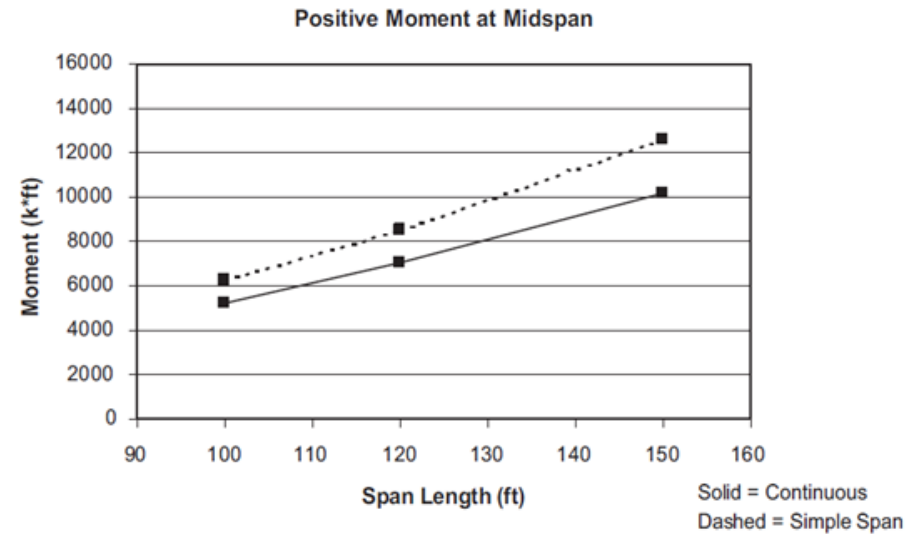

Figure 2-8 Comparison between maximum positive moment for continuous and simple span.

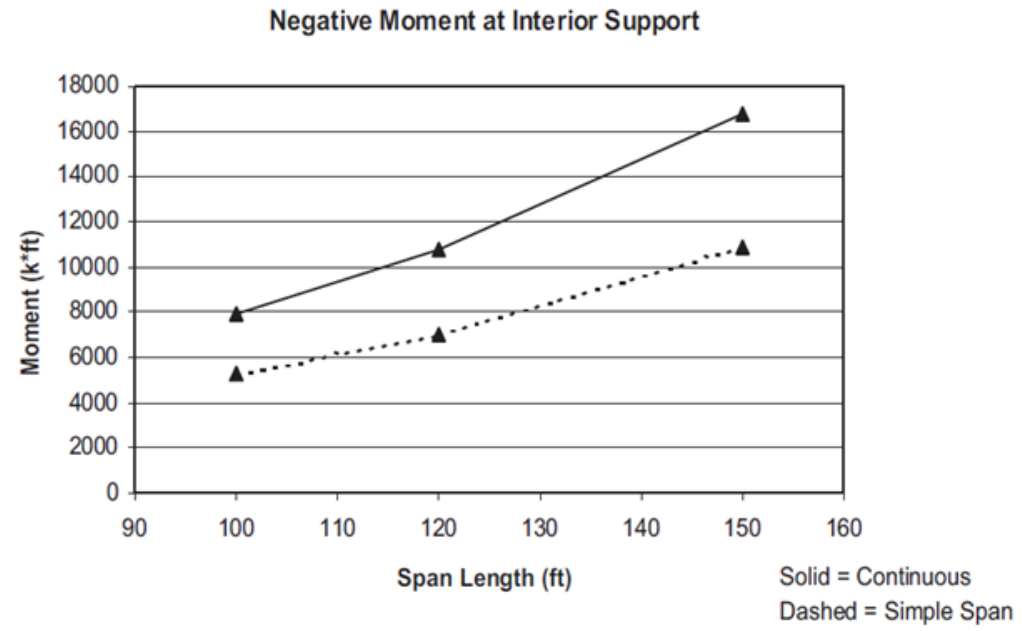

Figure 2-9 Comparison between maximum positive moment for continues and simple span.

\subsubsection{Construction Sequence}

\subsubsection{Conventional Method}

In the conventional method, the construction sequence consists of first placing a middle segment over the interior support and then connecting the two end pieces using a bolted or welded field splice. This type of construction needs extra crane or shoring during the construction process with a possible interruption to traffic. In Figure 2-10 the construction process for conventional method is shown schematically. 


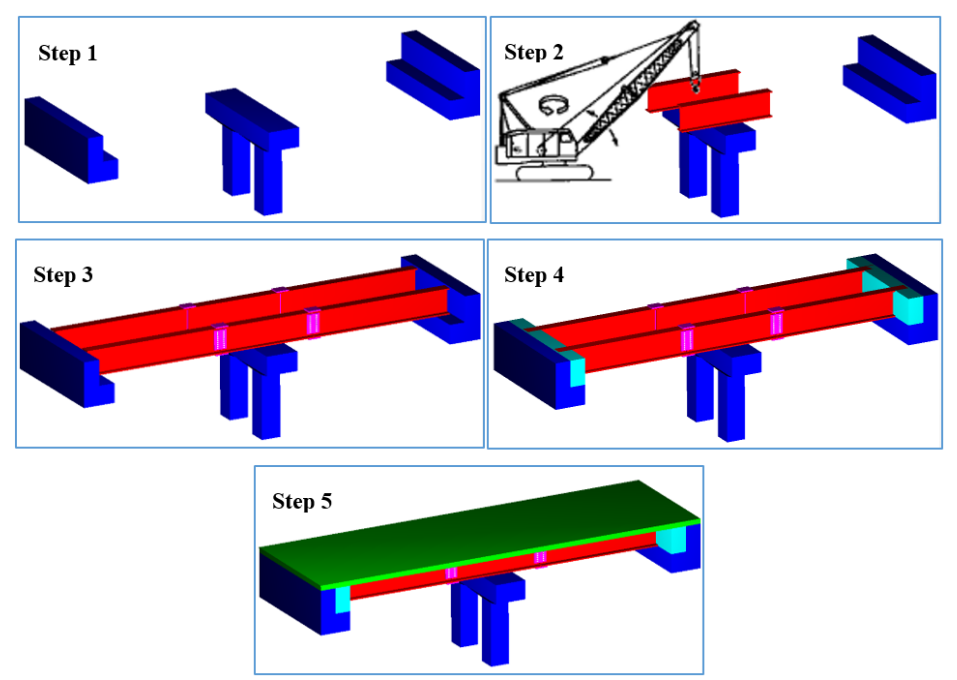

Figure 2-10 Conventional steel bridge construction sequence.

\subsubsection{SDCL Method}

In the SDCL construction process, each span is simply supported for the construction loads such as the weight of the concrete slab and girders. The steel girders are then connected through the concrete diaphragm. After this stage of construction, the deck becomes continuous for the applied live loads. Therefore, the connection between deck and bent cap is simple during the slab pour and continues during the service life of the bridge. In Figure 2-11 the construction process for the SDCL method is shown schematically.

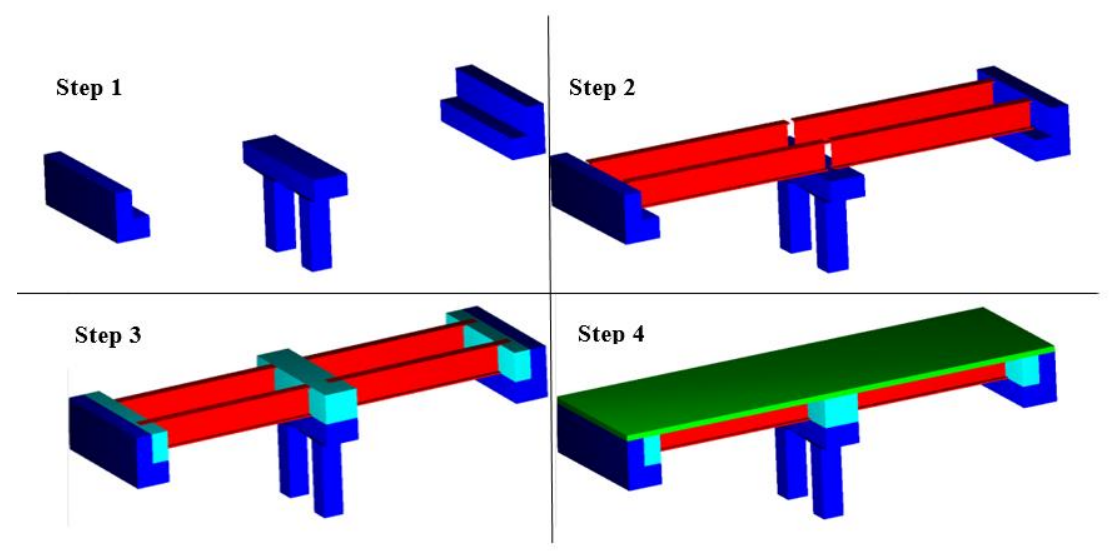

Figure 2-11 SDCL steel bridge construction sequence. 


\section{NONLINEAR BEHAVIOR OF BRIDGES}

\subsection{Introduction}

In this chapter, the nonlinear behavior of bridges and its components will be described. To understand the real performance of a bridge underground motions, the nonlinear behavior of three specific components should be considered. The seismic forces transfer from the deck to the foundation through the bents and abutments. There are two kinds of bridges, integral and nonintegral based on the connection between the deck and the bent frame. In this section, first the differences between integral and non-integral bridges and advantages and disadvantages of each one are discussed. Finally, the nonlinear behavior of the abutment and modeling techniques for nonlinear analysis are discussed.

\subsection{Steel vs. Concrete Bridges in the United States}

According to the Federal Highway Administration (FHWA, 2003), 99 percent of bridges in the United States are pre-stressed concrete, reinforced concrete, steel, or timber ridges. National Bridge Inventory Program (NBIP) data indicates that in the central and southeastern United States, one-third of simple and continuous bridges (single and multi-span) were built of steel girders with reinforced concrete slabs and the remaining bridges were built of reinforced or pre stressed concrete girders (National Bridge Inventory (NBI), 2015). The initial and maintenance cost are the most important factors that are to be considered to select a bridge system (Smith et. al. (1995)). Prestressed concrete bridges have become more popular for economical and durability reasons. For example, the majority of California's bridges are concrete multi-cell box girders that are constructed monolithically with the concrete column. This system provides a clean system with low maintenance over its lifetime. In this system, the multi-cell box girder is connected to the concrete column without a bent cap (Jill Patty, 2001). Increasing the use of concrete in bridge 
structures decreased the steel bridge construction. The main reason for concrete bridges becoming more popular than steel bridges in the market is material price, labor and equipment.

\subsection{Seismic Performance of Steel Bridges}

Steel bridges are better for short span bridges and generally easier to repair and easier to add travel lanes or sidewalks than their concrete counterparts. Steel bridges are lighter than concrete alternatives and performed better in past major earthquakes. According to the American Iron and Steel Institute report in 1994, the Northridge earthquake in California destroyed the surrounding transportation infrastructure, "96 percent of all the existing steel bridges were completely undamaged, even though they were designed using 1940's technology." Use of incorrect details or systems in steel bridges have resulted in severe damage in areas struck by strong earthquakes and even some recent moderate earthquakes (Astaneh-Asl, 1994).

Past earthquakes show that even minor damage can be difficult to investigate and repair. Consequently, critical elements such as diaphragms should be protected from any level of damage under extreme seismic loads and remain elastic during the entire earthquake excitation. The plastic regions also need to be detailed to provide the desired capacities while deforming beyond the elastic limit during a seismic event. In seismic areas, the use of a SDCL steel bridge system will demand the incorporation of a detail that can resist cyclic loading. Further, in seismic applications, the entire concrete diaphragm region, including the girder ends and connections, needs to remain completely elastic (protected elements) during the entire seismic event. An additional requirement is that the predefined damage areas (plastic hinge locations) must be forced to be at some distance away from the concrete diaphragm region allowing repair and inspections after a major seismic event. 
In non-integral bridge systems, the bent frame is the only earthquake resistance system (ERS) in the bridge. An integral bridge system relies on the rigid connection between the deck and the bent frame making both of these elements part of the ERS.

\subsection{Integral and Non-Integral Bridges}

\subsubsection{Definition and History}

In non-integral bridges, the girders are simply supported or they are continuous over the pier cap with a separation detail such as an elastomeric pad or isolation bearing between the bent cap and the superstructure. In this case, the bearings support the vertical reaction of the superstructures. The superstructure and substructure behave as two separate systems resisting lateral loads.

Unlike non-integral bridges, in integral bridge systems the connection between the superstructure and substructure respond monolithically. The first integral steel bridge was constructed by the Tennessee Department of Transportation in 1978. After that, another three integral bridges were constructed in Knoxville, Tennessee between 1978 and 1982. All of these bridges provided a high level of serviceability. The first integral steel girder in a seismic region was built by the Ohio Department of Transportation in 2001. In this bridge, a drop hammer bent cap was omitted to accommodate the required overhead clearance. Figure 3-1 shows an example of a typical integral and non-integral steel bridge. 

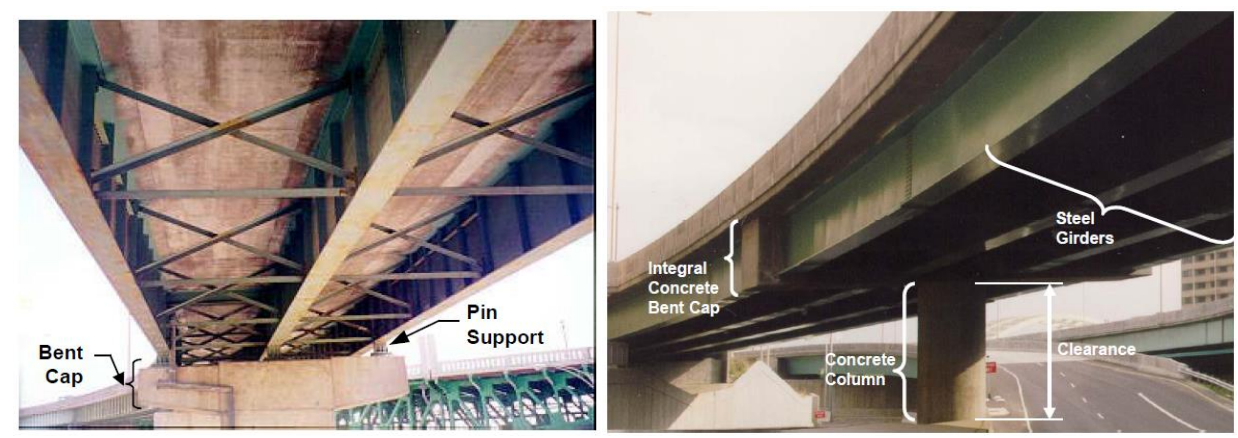

Figure 3-1 Left: non-integral steel bridge, right: integral steel bridge.

\subsubsection{Seismic Behavior of Integral and Non-Integral Bridges}

In the first step of this research, the type of connection between the superstructure and substructure needs to be determined. In the direction of traffic, due to rigid or semi-rigid connection between superstructure and substructure in the integral pier caps, the deformation of the columns is in double curvature under earthquake excitation. Under transverse excitation, the plastic hinge is located near the bottom of the pier column.

In non-integral pier caps, the connection between the superstructure and bent columns are simply supported and in both longitudinal and transverse directions the deformation of columns is single curvature. Figure 3-2 and Figure 3-3 shows the deflected shape of the integral and nonintegral system in the longitudinal and transverse directions. Under seismic forces, bent columns will act as either a cantilever or a frame.

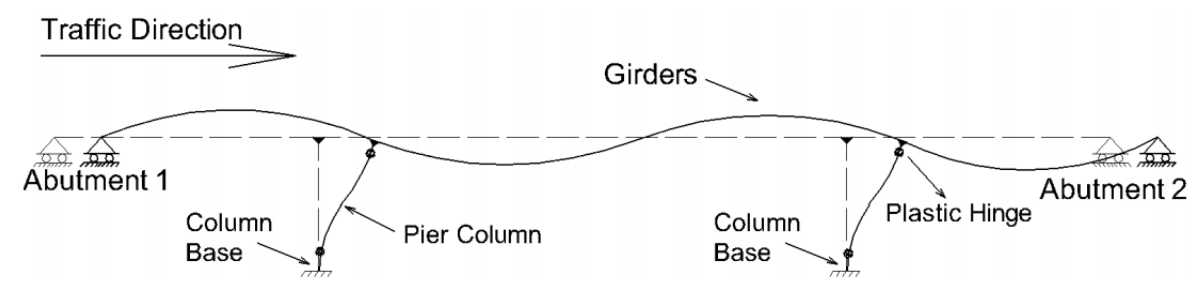

Figure 3-2 Deflected shape of a three span integral bridge system in longitudinal direction. 

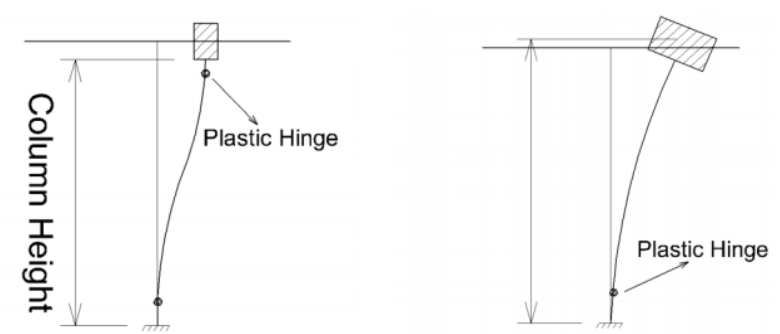

Figure 3-3 left: deflected shape in the longitudinal direction for integral pier cap, right: deflected shape in the transverse direction for integral pier cap.

\subsubsection{Integral versus Non-Integral Systems - Comparison}

There are two major research studies about integral versus non-integral bridges (NCHRP, 2004), (Jill Patty, 2001). Major differences between two systems are described below.

- According to an inquiry, Alaska and Washington states prefer non-integral connections between the deck and the pier. Due to fewer details, it takes less time for construction.

- The total number of bridges with integral pier caps reported in the responses is 59 . According to an inquiry from the California department of transportation, there is only one integral I steel girder bridge in California.

- In general, past performance of integral pier cap bridges appears to be satisfactory. Deck cracking transverse to the girders is the most cited problem.

- The main reason for using integral pier caps in the past has been to increase vertical clearance and to avoid placing the pier caps at a sharp skew. Enhancing seismic performance was cited in 33 percent of the cases.

- No accurate cost data was available. The respondents estimated that the weight of the steel was decreased by 5 to 10 percent and the cost of fabrication and the cost of erection both increased 5 to 10 percent. 
- The difficulties faced during the construction of integral pier cap bridges included the congestion of reinforcement at the column to the pier cap joint and the need for a substantial temporary shoring system.

- A post-tensioned bent gave the most desirable performance in the elastic range due to its minimal cracking in comparison with the conventionally reinforced bent cap.

- Using a pin or a rocker bearing connection between the superstructure and substructure requires regular maintenance to prevent the pin connection from rusting.

- In non-integral bridge systems, there is a relative rotation between the superstructure and substructure.

\subsection{Effects of Seismic behavior on the Abutment}

\subsubsection{Abutment Elements}

The different elements of a typical abutment are shown in Figure 3-4. ATC 32 classified the abutment as pile cap, stub, stub "L", cantilever, cantilever "L", spill-trough, and rigid frame abutments (Nutt, 1996). Caltrans alternatively categorized them as seat and diaphragm abutment types (CALTRANS, 2013). An accurate mass, and hysteretic behavior should be assigned to abutment to capture the real nonlinear behavior of bridges. Abutment system has a critical effect on period of bridge system in dynamic analysis. Soil-structure interaction behind the abutment and the abutment foundation are two other important parameters that affect the seismic behavior of bridges and requires further investigations. 


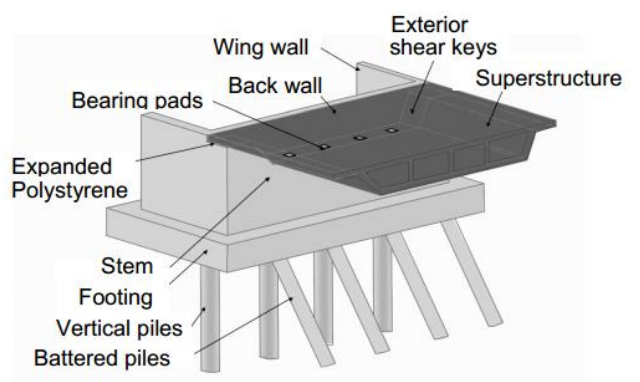

Figure 3-4 Abutment components.

\subsubsection{Abutment Modeling}

The choice of abutment models affects the response of the bridges under nonlinear static and dynamic analysis. The Abutment could be modeled as a roller abutment, simplified abutment or a spring abutment (Ady Aviram, 2008).

\subsubsection{Roller Abutment Model}

The roller abutment is a simple boundary condition at the end of girders, free for displacement in the longitudinal direction (or both longitudinal and transverse direction) and restraint in the vertical direction as illustrated in Figure 3-5. The nonlinear response of bridges modeled by the roller at two ends is dominated by the ductility capacity and formation of nonlinear hinges in columns. This kind of bridge model shows the lower bound estimate of seismic resistance under longitudinal and transverse earthquake loads. The roller abutment is the minimum requirement for the modeling nonlinear behavior of bridges under seismic loads.

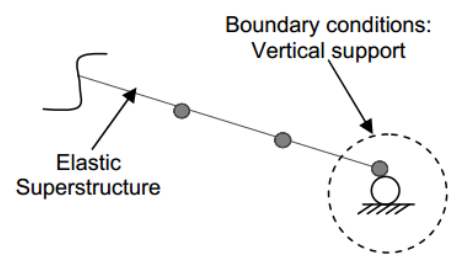

Figure 3-5 Roller abutment model. 


\subsubsection{Simplified Abutment Model}

A Simplified abutment model is a simplified model of a spring abutment that shows the real behavior of abutment more accurately than the roller abutment model. The general scheme of the simplified model is presented in Figure 3-6.

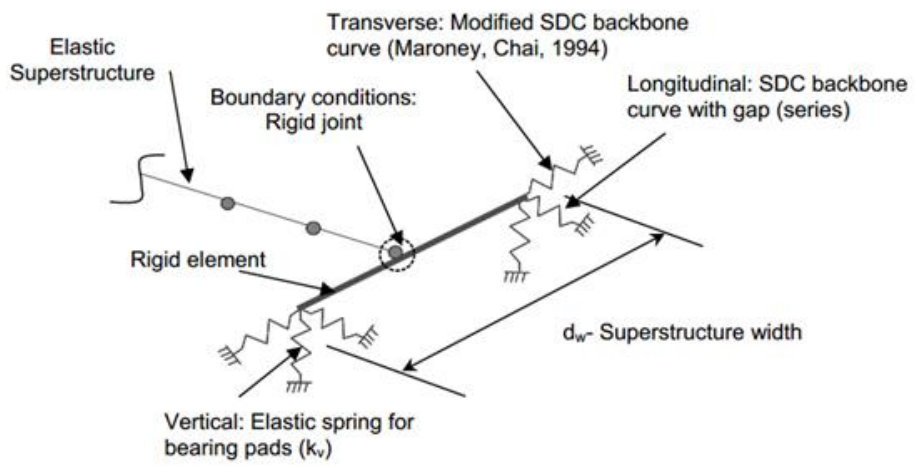

Figure 3-6 Simplified abutment model.

The simplified abutment model includes a rigid frame element perpendicular to the superstructure. The length of this rigid frame element is equal to the width of the deck. The boundary condition of the abutment is modeled at two ends. A simplified abutment system includes three springs in each direction of the rigid frame element as shown in Figure 3-7. In the longitudinal direction, the abutments and superstructure behave as series system. In the longitudinal direction, a rigid element with shear and moment release is connected to a gap element that translate only longitudinal displacement. The end of gap element is connected to a zero length element with a Caltrans Seismic Design Criteria (SDC) backbone curve for the longitudinal response. An Elastic Perfectly Plastic (EPP) backbone curve with abutment stiffness and ultimate strength assigned to this curve (Roy A. Imbsen, May 2007). In the transverse direction, a zero length element is assigned to each end of the rigid element. The zero length element has an elastic-perfectly plastic behavior which represents the property of backfill, wing wall and pile system response. Vertical springs at the two ends of the rigid element represents the elastic behavior of bearing pads. 


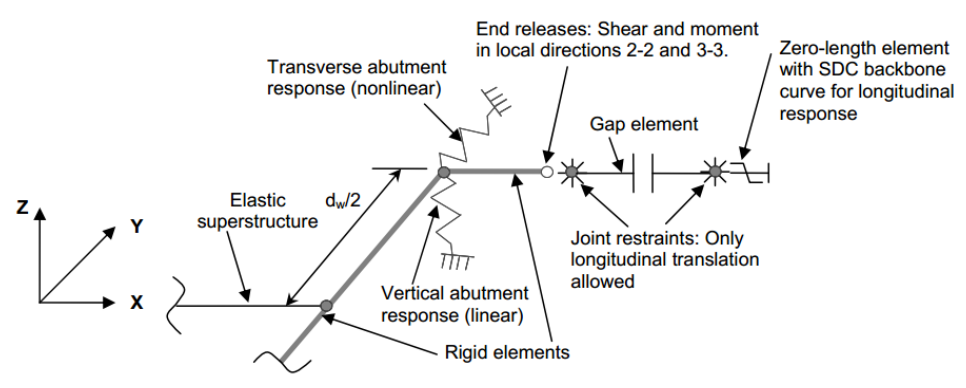

Figure 3-7 Series system for the longitudinal abutment response.

\subsubsection{Spring Abutment Model}

The spring abutment model is the most complex model for representing the nonlinear behavior of abutments in the nonlinear analysis of bridges. The spring abutment model suggested by Mackie and Stojadinović (Mackie, 2006) takes into account the longitudinal, transverse, vertical nonlinear abutment response, and mass of concrete abutment and mobilized embankment soil. Figure 3-8 shows different elements of spring abutment model.

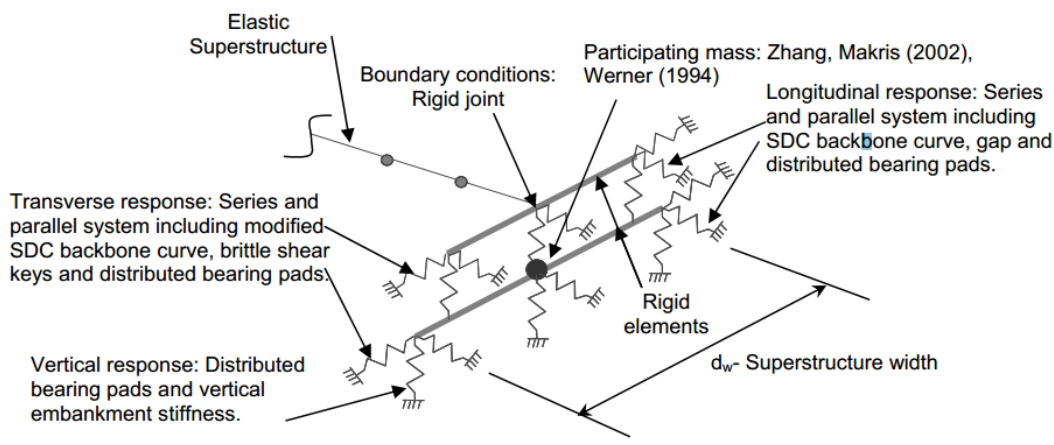

Figure 3-8 Spring abutment model.

The longitudinal response of the spring abutment model includes responses of the elastomeric bearing pads, gap, abutment back wall, abutment piles, and soil backfill material. In this system, the force path is from the elastomeric bearing pads to the stem wall, subsequently from to the piles and backfill while they act the same as a series system. More information of this system can be found in the references (Zhang, 2002), (Roy A. Imbsen, May 2007), (Bozorgzadeh, 2006), (Maroney, 1994). 
The nonlinear modeling of the abutment, with restraining, in the two principal directions of the earthquake, reduces the displacement demand in both directions. The response of the bridge is significantly different when using the simplified abutment model and spring abutment model in both the longitudinal and transverse direction of the seismic forces. Initial stiffness, ultimate capacity, and degradation of strength behavior are different in the pushover analysis as well as in the nonlinear time history analysis.

In pushover analysis, a comparison between the simplified abutment model and roller abutment model shows the capacity for the bridges with roller abutment models is less than that of the simplified abutment model for both the longitudinal and transverse directions of the bridge. In one example bridge (Ady Aviram, 2008) the simplified abutment model produced a higher initial stiffness and an increase in the ultimate base shear approximately $100 \%$ on average. Using the spring abutment model in a pushover analysis produces different results in comparison with the two other abutment models. In the spring abutment model, the ultimate base shear and initial stiffness of the bridge increased $30 \%$ compared to the pushover analysis. In the transverse direction, the initial responses increased similar to the simple abutment model.

In the nonlinear time history analysis of sample bridges using the simplified abutment model, the abutment significantly contributes in the overall nonlinear behavior of the short span bridges since in long span bridges the contribution of the abutment is smaller and they have no significant effect on the overall nonlinear behavior of bridges. 


\section{SEISMIC DESIGN PHILOSOPHY}

\subsection{Introduction}

A summary of the AASHTO LRFD seismic design specifications are gathered in this chapter. Additionally, a brief description of the capacity design methodology is described.

\subsection{Probability of Earthquakes on the East and West Coast}

According to the U.S. Geological Survey, at least $40 \%$ of the highway bridges located in the United States can expect to experience some kind of damage during their lifetime due to earthquakes ground motions. Figure 4-1 shows the USGS National Seismic Hazard Map for seismic design coefficients at one-second period and 1000 year return period and competent soil B/C (M. Lee Marsh I. G., October 2014). This figure shows some major earthquakes have occurred on the west coast and California in particular as well as central and eastern U.S.

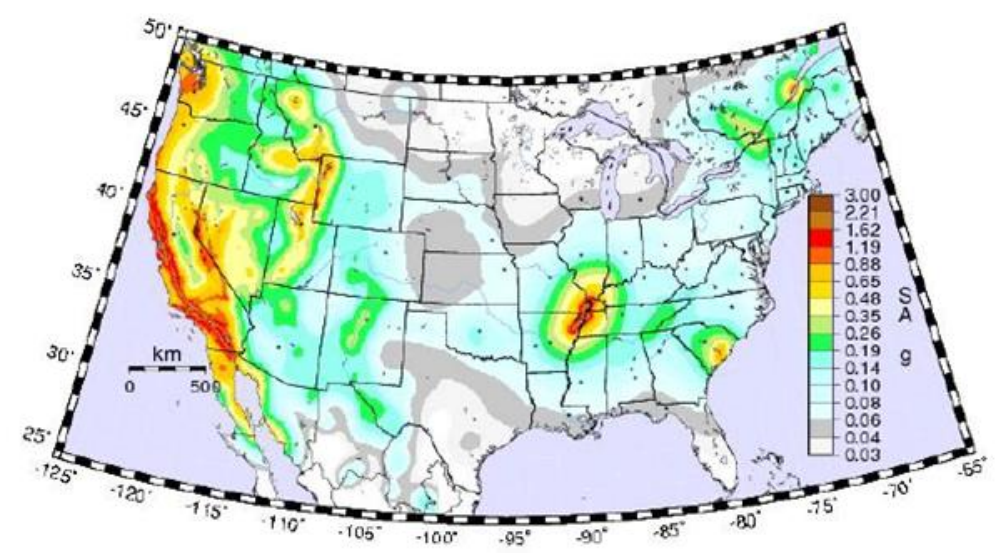

Figure 4-1 USGS National Seismic Hazard Map for Conterminous U.S. for Seismic Design Coefficient at One Second Period for $7 \%$ Probability of Exceedance in 75 years $(1,000$ year Return Period) and Competent Soil (the B/C boundary).

\subsection{Designing Bridges According to a Different Seismic Design Category}

There are four Seismic Design Categories (SDCs) in the United States for bridge structures. The design requirements for each category are shown in the Figure 4-2 flowchart. According to this flowchart, for seismic design category C and D, an Earthquake Resisting System (ERS) should 
be selected. In seismic design category $\mathrm{D}$, conducting a pushover analysis is needed to find the capacity side of the system. In this research, it was assumed the SDCL bridges are to be constructed in seismic design category D. To find the capacity of the system, a nonlinear time history analysis was conducted as well as a pushover analysis.

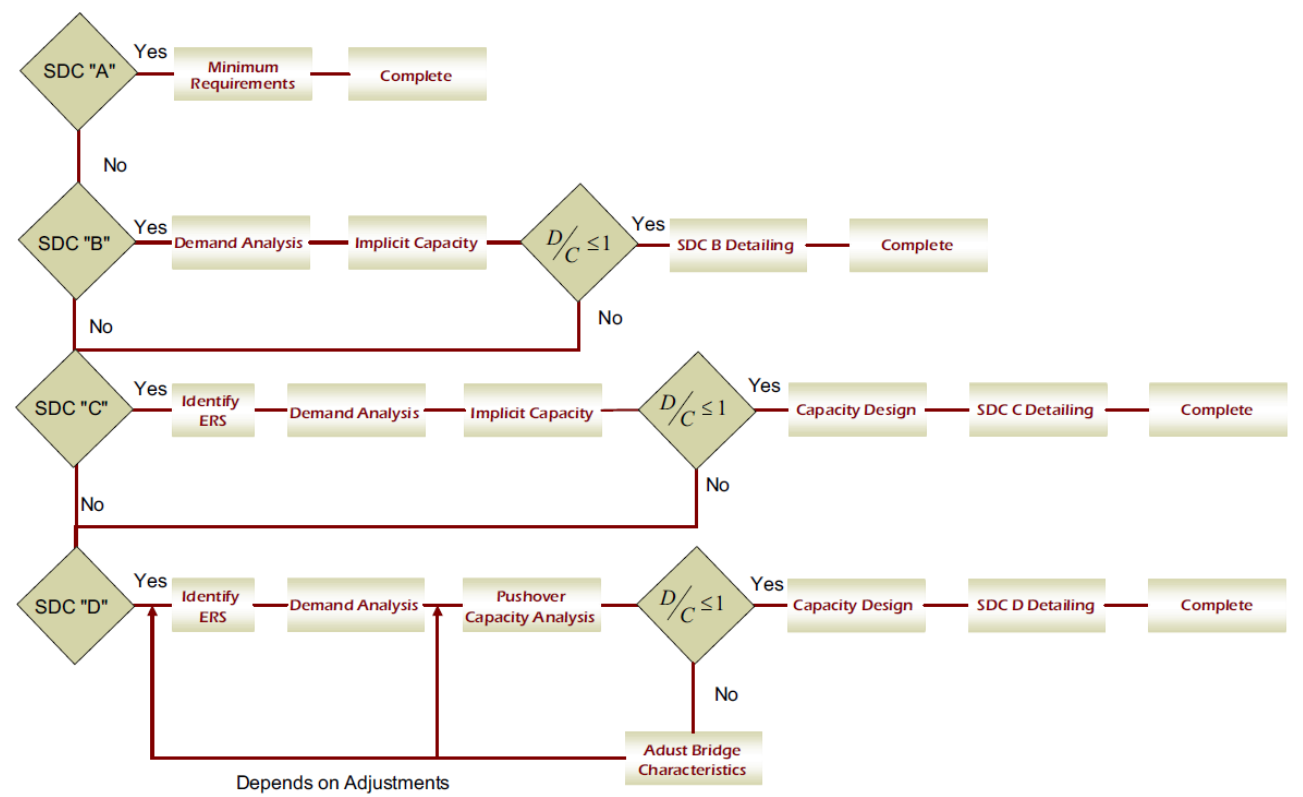

Figure 4-2 Seismic design category flowchart.

A seismic design step for a bridge has been shown in Table 4-1 based upon LRFD Bridge Design Specification (M. Lee Marsh I. G., October 2014). 
Table 4-1 Steps for seismic design based upon LRFD Bridge Design Specifications.

\begin{tabular}{|c|c|}
\hline Step & Design Activity \\
\hline 1. & $\begin{array}{l}\text { Determine Seismic Input } \\
\text { a) Seismic hazard } \\
\text { b) Site classification } \\
\text { c) Response spectra or other input }\end{array}$ \\
\hline 2. & $\begin{array}{l}\text { Establish Design Procedures } \\
\text { a) Seismic Zone or Design Category } \\
\text { b) Importance } \\
\text { c) Analysis procedures } \\
\text { d) Foundation modeling }\end{array}$ \\
\hline 3. & $\begin{array}{l}\text { Identify the Earthquake Resisting System and Global Design Strategy } \\
\text { a) Where damage or yielding will be accepted } \\
\text { b) What system of deformation tolerance/articulation will be used } \\
\text { c) Participation of abutments } \\
\text { d) Use of non-preferred EREs }\end{array}$ \\
\hline 4. & $\begin{array}{l}\text { Perform Demand Analysis } \\
\text { a) Linear elastic, pseudo static loading } \\
\text { b) Multimode elastic method } \\
\text { c) Time history method } \\
\text { d) Directional combination }\end{array}$ \\
\hline 5. & $\begin{array}{l}\text { Design and Check Earthquake Resisting Elements (Ductile or Other) } \\
\text { a) Force-based - Use of R, Extreme Event load factors } \\
\text { b) Displacement-based - Non-seismic loads or minimum strengths, displacement } \\
\text { c) Detailing of ductile EREs }\end{array}$ \\
\hline 6. & $\begin{array}{l}\text { Capacity Protect the Remaining Elements } \\
\text { a) Shear in ductile EREs } \\
\text { b) Cap beams } \\
\text { c) Foundations and abutments } \\
\text { d) Superstructure, connections, bearings, support lengths }\end{array}$ \\
\hline
\end{tabular}

\subsection{Seismic Design Philosophy}

The modern building and bridge seismic design codes are based on expected damage levels in a predefined location, energy dissipation, and ductility for a selected performance level. Figure 4-3 shows a linear (dashed line) and a nonlinear behavior of a structure system (solid line) (Taghinezhad, 2011). There are two possibilities for energy dissipation, one following the linear path behavior with load level Ceu and deformation $\Delta \mathrm{e}$ and the other one following the nonlinear path with load level $\mathrm{Cy}$ and deformation $\Delta \mathrm{m}$. Current seismic codes, including AASHTO and Caltrans, accept bridge damage and nonlinear behavior during the design earthquake up to a deformation Delta $\mathrm{m}$ by providing ductility at certain locations (for example at two ends of a column) and let the bridge be designed for a lower load level, Cy. To achieve this, AASHTO seismic design specifications force damages of the bridge to predefined locations that are more accessible for inspection and repair. In fact, it is not necessary that entire bridges be designed to 
remain fully elastic during strong ground motions since the design to this level of force is not economical.

To achieve large deformation, critical members should be designed and detailed for the associated plastic deformation while the rest of the structure should be capacity protected and stay elastic. For instance, in most bridges, ductile elements in the bridges are columns with nonlinearity at two ends of columns. The superstructure deck and their connections are capacity protected.

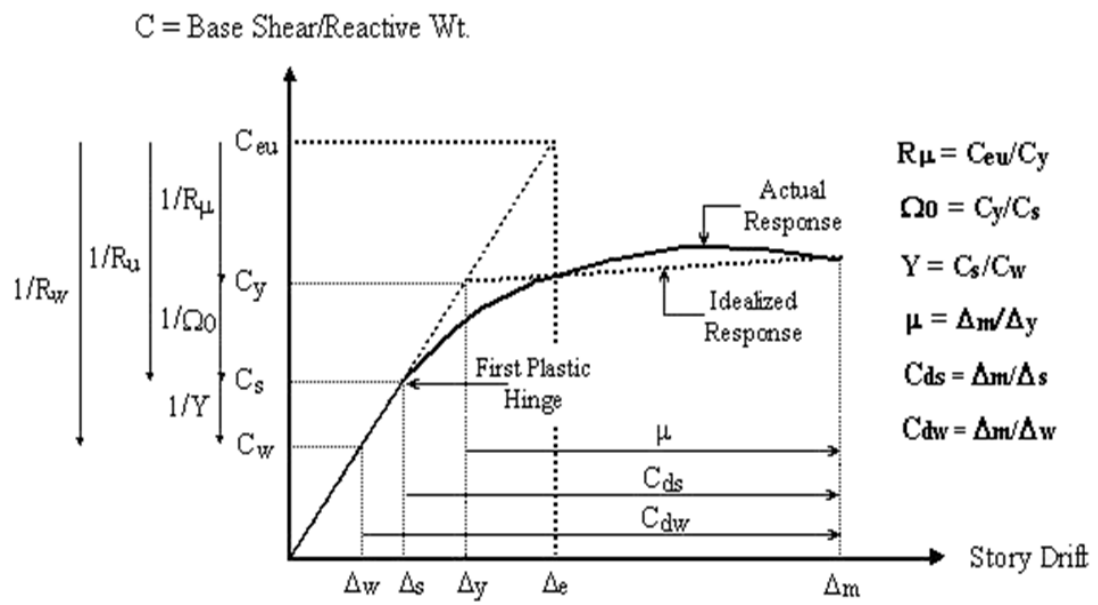

Figure 4-3 Two different path for structure behavior under seismic loads.

\subsection{Performance Based Design}

Performance Based Seismic Design (PBSD) is a design process which is going to connect seismic input to facility input and facility damage (M. Lee Marsh S. J., 2013). Bridges should be designed based on their expected performance level that is determined by the designer of the bridge. Consequently, the desired seismic performance level does not directly control the different earthquake inputs, seismic hazard levels and operational classifications. In PBSD, the owner is advised by a knowledgeable engineer to establish a desired performance outcome. In PBSD, there are four steps consisting of seismic hazard, structural, damage, and loss analysis. Figure 4-4 demonstrates a visualization of the PBSD process. The force displacement curve is an outcome of 
a nonlinear static analysis (pushover analysis). The damage level at the column base represents the performance level of the bridge schematically.

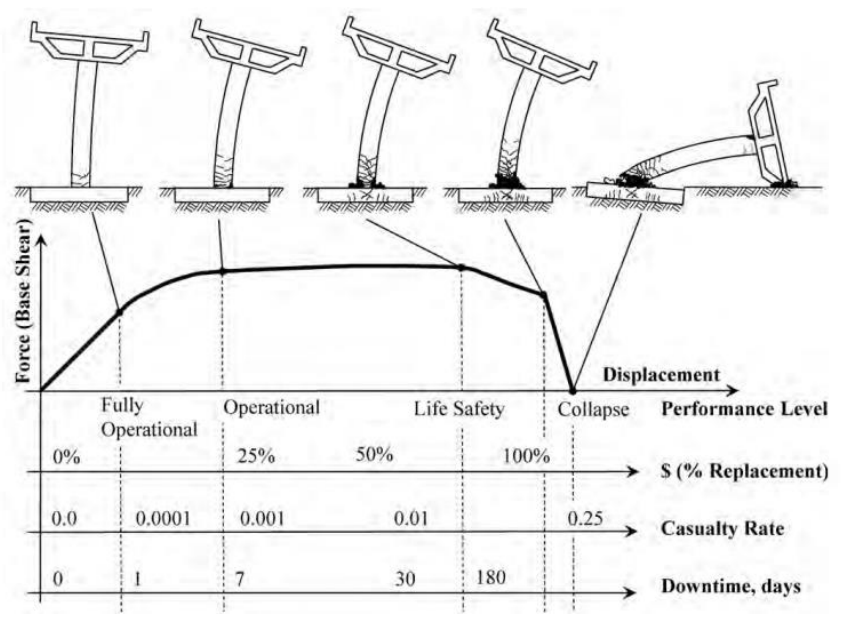

Figure 4-4 Visualization of PBSD.

\subsection{Earthquake Resisting Systems (ERS)}

There are three global design strategies for designing bridges, including ductile substructure with elastic superstructure (focus is on the capacity design method), elastic substructure with ductile superstructure (effective in I-girder superstructures in the transverse direction), and elastic superstructure and substructure with a fusing interface (suitable for low seismic areas). Error! Reference source not found., Error! Reference source not found. and Error! Reference source not found. presents a schematic view of these three different systems (M. Lee Marsh I. G., October 2014). Permissible bridge systems are described for both the longitudinal and transverse directions in Table 4-2. As illustrated in this table, plastic hinges at intermediate supports, isolation bearings, and a combination of both permitted for seismic areas.

In this research, according to Table 4-2, the Case 1 ERS was selected for the SDCL bridge system in seismic areas and assumed plastic hinges formed at two ends of the column. 


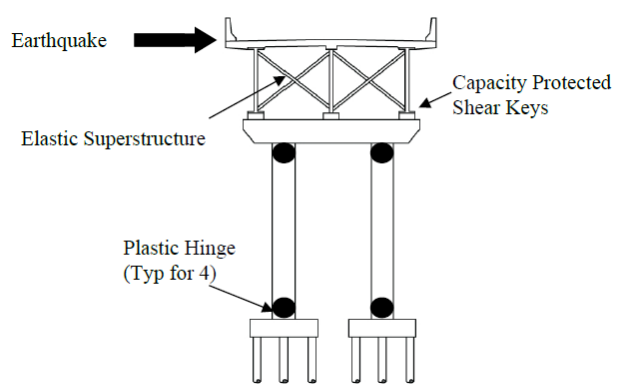

Figure 4-5 Inelastic substructure with elastic superstructure.

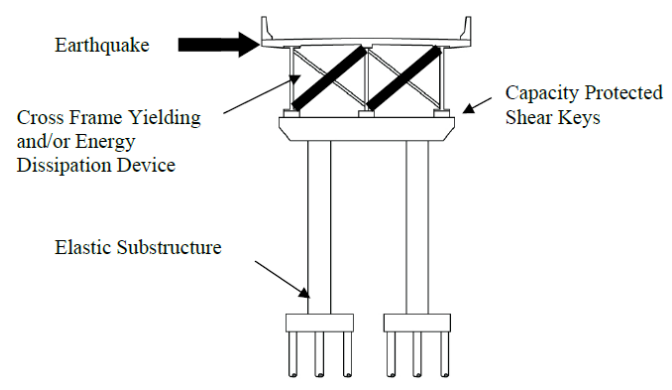

Figure 4-6 Elastic substructure with inelastic superstructure.

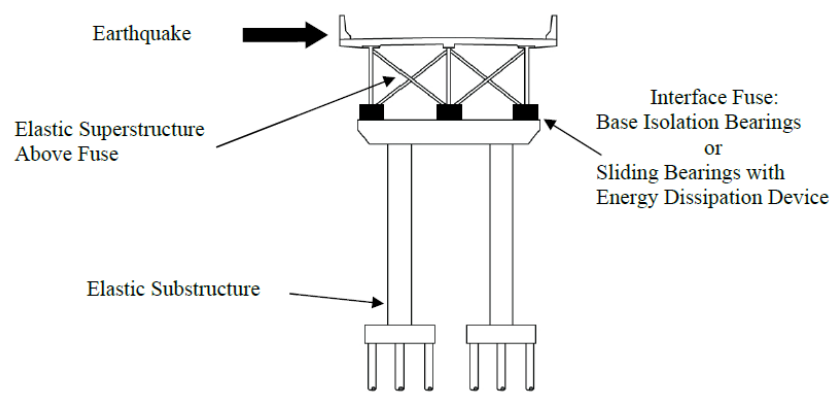

Figure 4-7 Elastic super and substructure. 
Table 4-2 Permissible earthquake resisting systems.

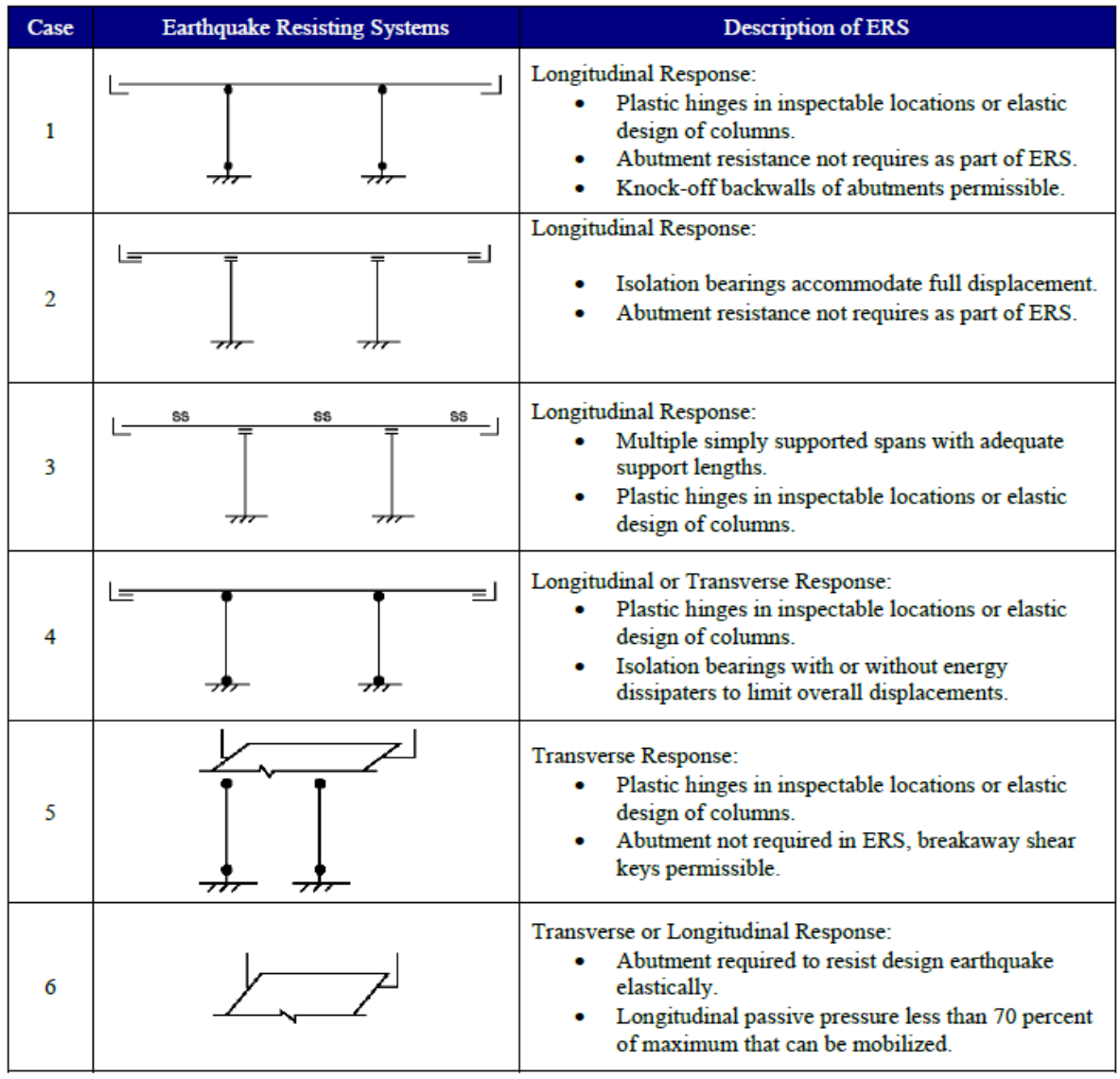

\subsection{Capacity Design of Piers}

The strength of capacity-protected elements should be greater than the strength of the energy dissipation elements taking into consideration the possibility of over-strength. To achieve this goal, a pushover analysis should be performed to determine the full over-strength capacity of the elements developed in the bridge system. Then, shear forces and moments can be calculated in the bent column and bent cap for a single column or two columns as shown in Figure 4-8 and Figure 4-9. An example with detailed calculation is presented in section 4.9. 


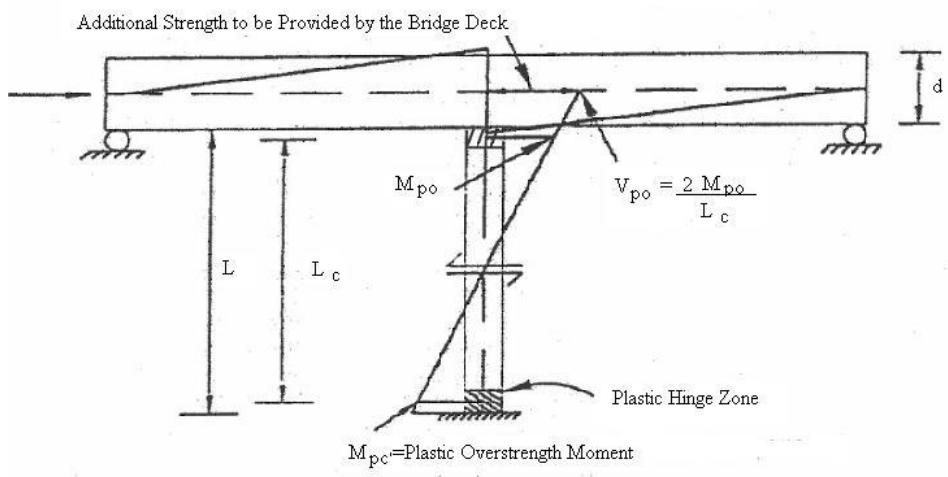

Figure 4-8 Moment-Curvature model.

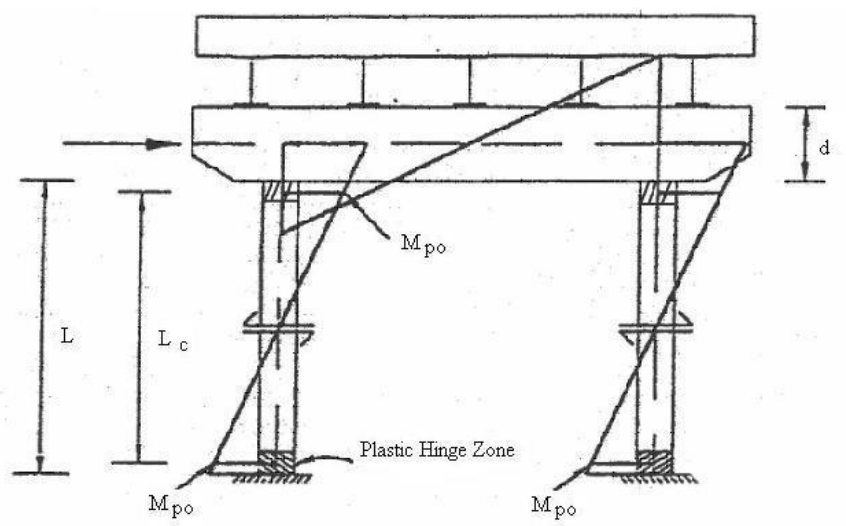

Figure 4-9 Transverse response for dual column pier.

\subsection{Calculating Over-Strength Moment Capacity}

According to CALTRANS, capacity protected members such as footings, bent cap, and superstructure should be designed to remain essentially elastic during seismic events when the column reaches its over-strength moment capacity (CALTRANS, 2013). The plastic moment capacity of ductile columns should be calculated based on expected material properties using a Moment-Curvature analysis as shown in Figure 4-10. This Moment-Curvature could be simplified to a bilinear elastic perfectly plastic curve. The line represents the elastic part that must connect the origin to the point where the first reinforcement bar yields. The area below the actual and idealized Moment-Curvature should be equal beyond the first reinforcing bar yield point. The over- strength factor for reinforced concrete members should be determined using the formulas below:

$\mathrm{M}_{\mathrm{po}}=\lambda_{\mathrm{mo}} \mathrm{M}_{\mathrm{p}}$ 
$\mathrm{M}_{\mathrm{p}}=$ plastic moment capacity of column (kip-in.)

$\lambda_{\text {mo }}=$ over-strength factor taken as 1.2 or 1.4

The plastic moment capacity of the column is calculated using a Moment-Curvature section analysis. The effect of expected yield strength and strain hardening of material, effects of the longitudinal reinforcement, and confined concrete should be considered in the Moment-Curvature analysis. In Figure 4-10 $\mathrm{M}_{\mathrm{ne}}$ is the nominal moment capacity once the strain in the concrete reaches 0.003. $\mathrm{M}_{\mathrm{p}}$ is determined using an elastic perfect plastic curve.

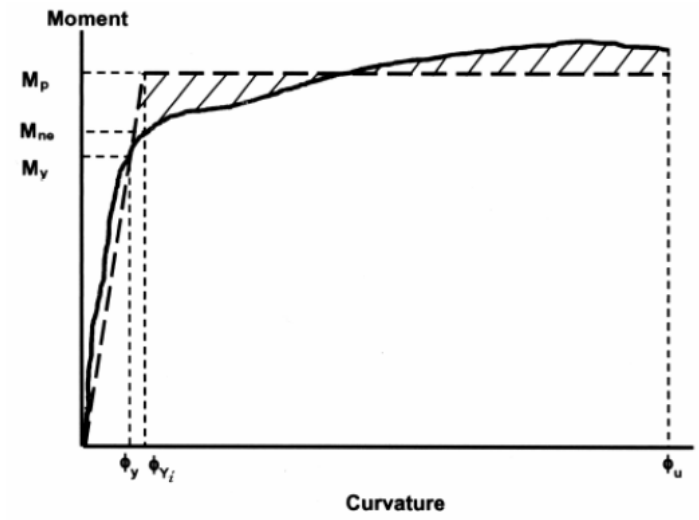

Figure 4-10 Moment-Curvature Model.

\subsection{Caltrans Design Requirements for Capacity Protected Members}

To calculate the $\mathrm{M}_{\mathrm{ne}}$ of capacity protected members, the expected material property should be used in the calculation of moment capacity under earthquake loads and resistance factor $\Phi$ should be taken equal to one for flexure. Expected nominal moment capacity for capacity protected concrete components should be calculated based on expected concrete and steel strength when concrete strain reaches 0.003 or steel bars strain reaches 0.09 for \#10 bars and smaller and 0.06 for \#11 bars and larger. According to AASHTO design of superstructure and substructure components and their connections to the column should be based on the expected concrete and reinforcing steel strengths when the concrete strain reaches a magnitude of 0.003 . These strain limits are illustrated 
in Figure 4-11 and Figure 4-12 for concrete and steel reinforcement, respectively. In the meantime, for the capacity protected members a factor of safety is not required and resistance factor assumed to be one for flexure $(\varnothing=1)$. Expected material property should only be used for assessing the flexural component of capacity-protected members under earthquake loads.

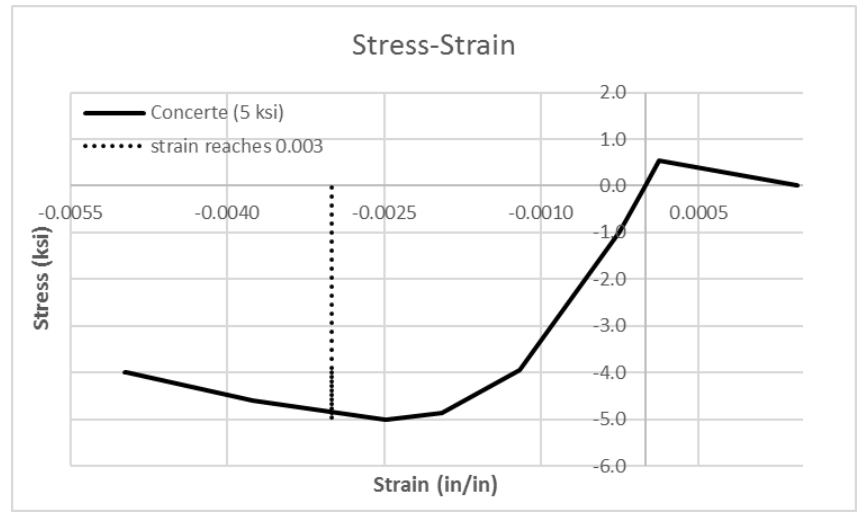

Figure 4-11 Stress-strain curve for the concrete and 0.003 strain limit for the capacity protected members.

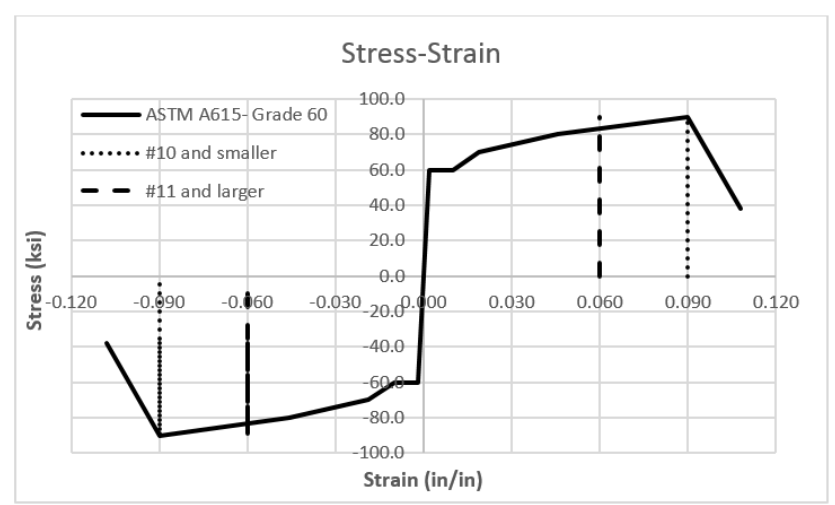

Figure 4-12 Stress-strain curve for the reinforcing steel and 0.06 and 0.09 strain limits for the capacity protected members. 


\section{DEMAND SIDE OF A SDCL PROTOTYPE BRIDGES}

\subsection{Introduction}

To control a detail under seismic loads, the demand side should be considered as well as the capacity side under different earthquake ground motions. The main purpose of this chapter is finding the demand over the pier due to seismic forces. In order to consider the distribution of forces over the pier and along the bridge, a prototype bridge designed with hand calculations and controlled using CSiBridge. The effect of the bottom flange in the moment capacity of the diaphragm was determined by moment- curvature analysis according to CALTRANS seismic provisions. Then, a nonlinear time history analysis was conducted to consider the nonlinear behavior of the bridge subjected to different ground motions. The results indicated there is demand for the positive moment over the pier.

\subsection{Description of the Example Bridge}

\subsubsection{Geometry and Element Properties}

The prototype example bridge is a two-span steel I-girder bridge with the following features. The deck system is reinforced concrete with steel I girders (Figure 5-1). The deck consists of four W40X215 steel I-girders that support a 71/2-inch-thick deck and a wearing surface weighing 56 psf. The deck width is 32 '-4" from the edge-of-deck to edge-of-deck and the bridge has two spans of approximately 95'-0" each (Figure 5-2). There is one interior bent with two 36-inchdiameter columns (Figure 5-3). The bent columns are 35-inch-diameter circular reinforced concrete sections. The concrete is reinforced with $18 \# 14$ verticals and \#4 hoop bars. The bent cap is connected monolithically to the columns. The dimension of the bent cap is 41 ' -0 ' x 39 '-0" x 30 '0". The abutments are assumed to be free in both longitudinal and transverse directions, consequently a roller abutment model was used in the analysis. A summary of bridge properties is shown in Table 5-1. 


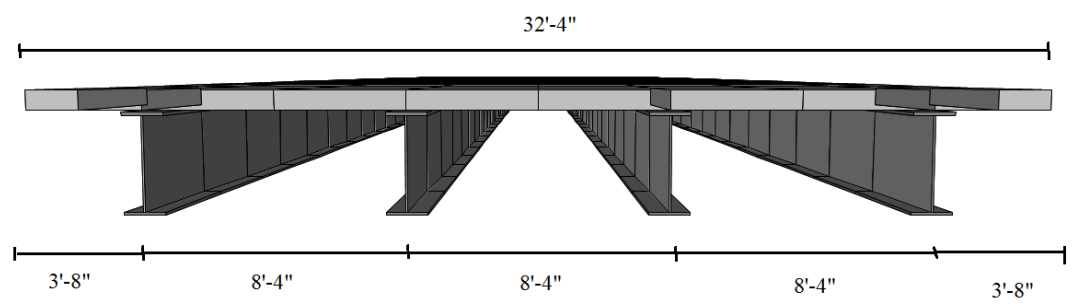

Figure 5-1 Deck section.

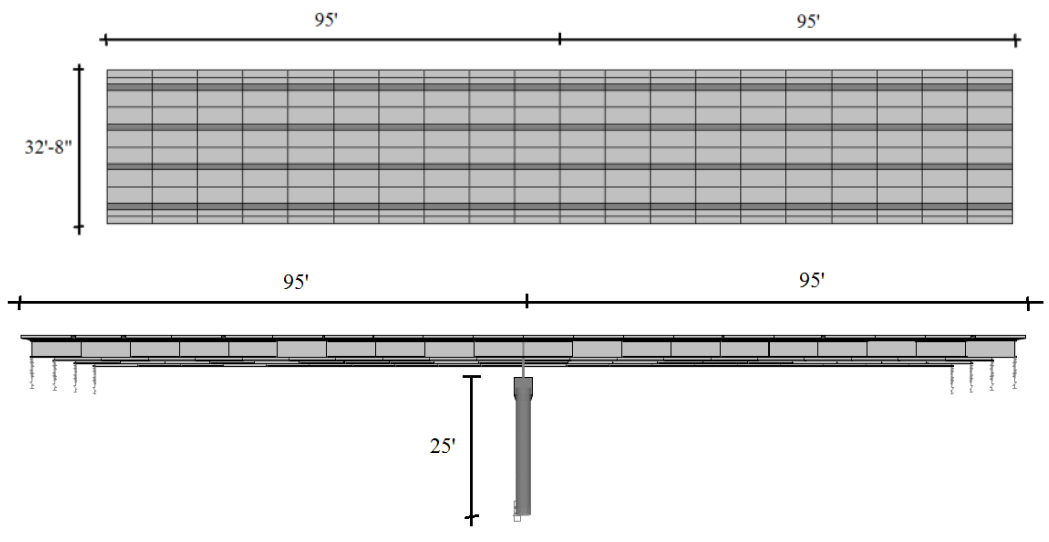

Figure 5-2 Dimensions in plan and elevation.

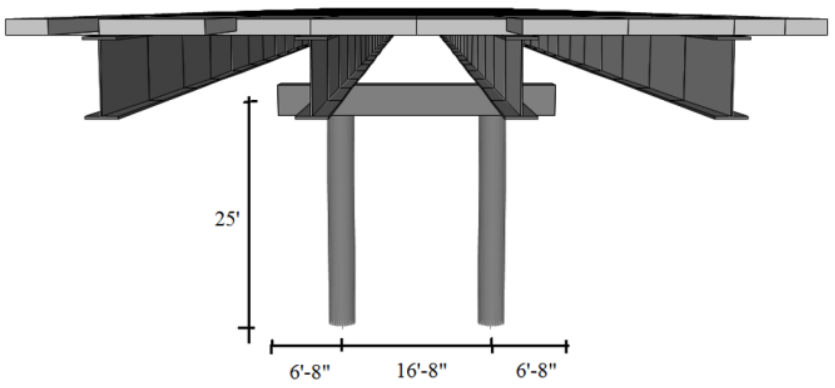

Figure 5-3 Bridge bent elevation. 
Table 5-1 A summary of bridge property.

\begin{tabular}{|c|}
\hline Total width of the deck: 388 in \\
\hline Top slab thickness: 7.5 in \\
\hline Girder section: W40X215 \\
\hline Right and left overhang length to center of steel girder=44 in \\
\hline Location of the bridge: Berkeley, California \\
\hline Maximum response spectrum acceleration: $0.954 \mathrm{~g}$ \\
\hline Soil type and profile: B \\
\hline Operational classification: other bridges regular (not essential or critical) \\
\hline Seismic performance zone: 4
\end{tabular}

\subsubsection{Material Property}

The material properties used are similar to those encountered in typical bridge construction and are close to the properties of the SDCL test specimen used at the UNL structures lab (Nick Lampe, 2014). The stress-strain curve of the materials are shown below (Figure 5-4, Figure 5-5 and Figure 5-6).

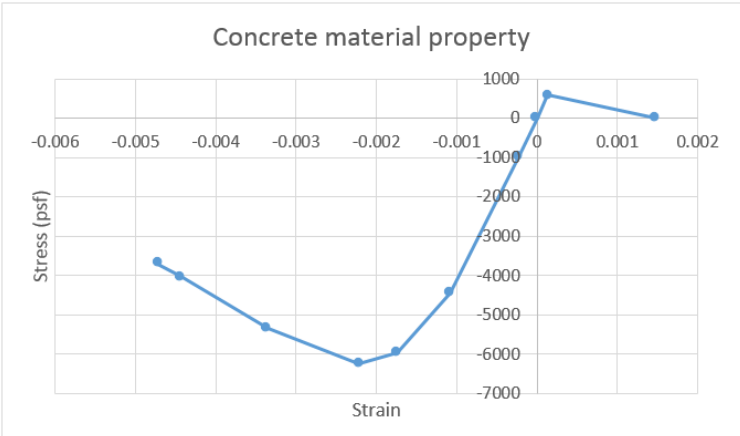

Figure 5-4 Stress-strain curve of concrete.

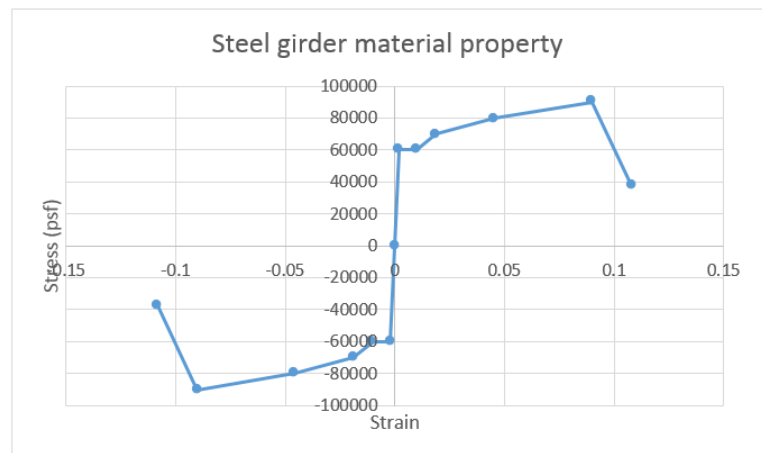

Figure 5-5 Stress-strain curve of the steel girder. 


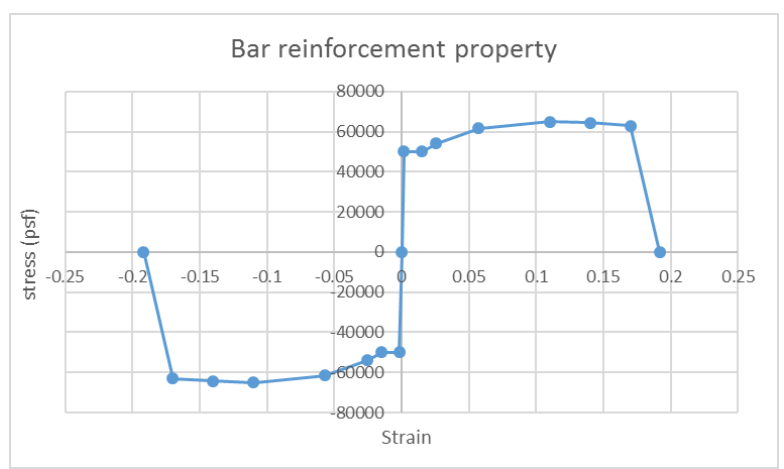

Figure 5-6 Stress-strain curve of bars.

\subsection{Earthquake Resistance System (ERS)}

The connection between the superstructure and the bent cap is integral and the abutments are assumed to be free in both the longitudinal and transverse directions. The earthquake resistance system is permissible according to AASHTO (Roy A. Imbsen, May 2007). Figure 5-7 shows permissible earthquake-resisting systems (ERSs) according to AASHTO specifications. With the abutment modeled as a roller in the longitudinal direction, the bent frame is the earthquake resistance frame. In the transverse direction, the seismic behavior of the bridge depends on the abutment boundary conditions. Theoretically, with the abutment modeled as a roller in transverse direction, the bent frame resists all the transverse seismic forces and with the abutment modeled as pinned in transverse direction, the bent frame with the contribution of abutment resist transverse seismic forces. 


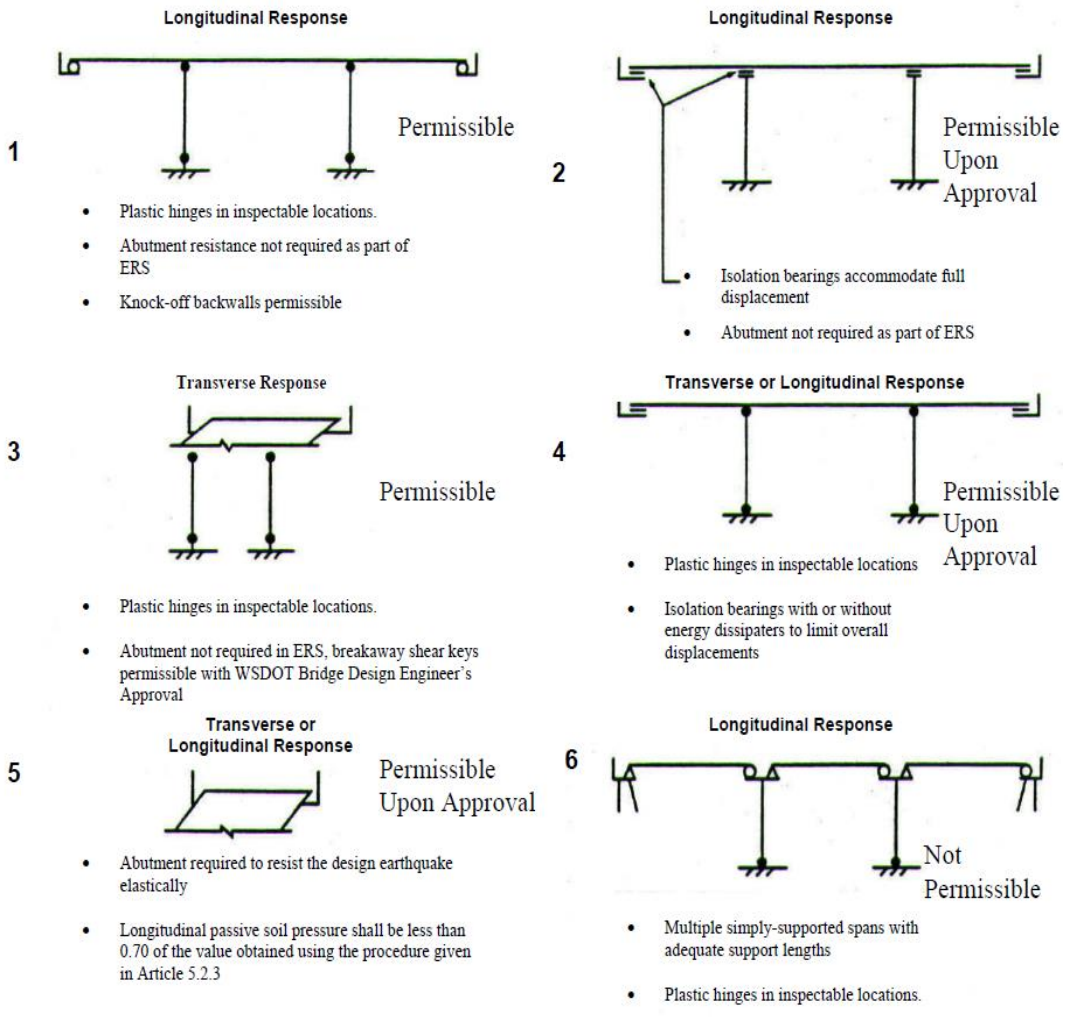

Figure 5-7 Permissible earthquake-resisting systems (ERSs).

Thus, two alternatives might be considered for the earthquake resistance system of the bridge in seismic design category D (Roy A. Imbsen, May 2007) as illustrated in Figure 5-8. In case one, the abutment provides no contribution to the seismic earthquake resistance system. In this case, the pier was designed to resist all seismic loads and zero stiffness at the abutment should be assumed. In case two, the abutment is part of the resisting system and was designed and analyzed to sustain the design earthquake displacement. Transversely, the superstructure behaves like a simply supported beam, and the abutment and bent cap resists transverse seismic forces. 


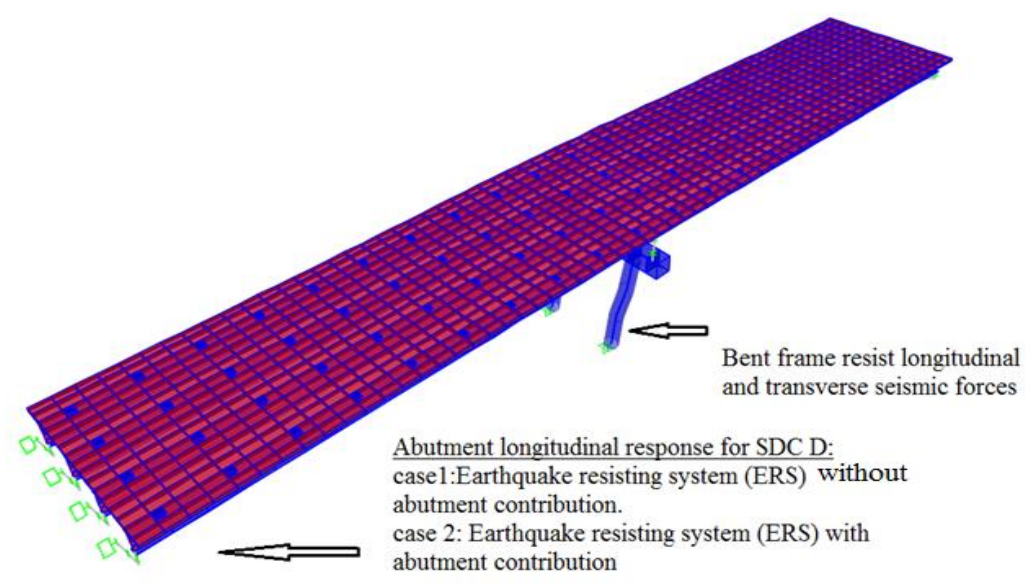

Figure 5-8 Bent frame and abutment contribution in ERS.

\subsection{Simplified Hand Calculation Method}

\subsubsection{Analysis for Earthquake Loads}

Minimum analysis requirements for seismic effects should be as specified according to Table 5-2. In this table *, UL, SM, MM and TH denotes as below. Table 5-3 shows the conditions of regular and irregular bridge systems. This example bridge is a regular bridge and the uniform load elastic method was used to analyze this prototype bridge.

$*=$ no seismic analysis required

$\mathrm{UL}=$ uniform load elastic method

$\mathrm{SM}=$ single-mode elastic method

MM = multimode elastic method

$\mathrm{TH}=$ time history method 
Table 5-2 Minimum analysis requirements for seismic effects.

\begin{tabular}{|c|c|c|c|c|c|c|c|}
\hline \multirow{3}{*}{$\begin{array}{c}\text { Seismic } \\
\text { Zone }\end{array}$} & \multirow{3}{*}{$\begin{array}{c}\text { Single-Span } \\
\text { Bridges }\end{array}$} & \multicolumn{6}{|c|}{ Multispan Bridges } \\
\hline & & \multicolumn{2}{|c|}{ Other Bridges } & \multicolumn{2}{|c|}{ Essential Bridges } & \multicolumn{2}{|c|}{ Critical Bridges } \\
\hline & & regular & irregular & regular & irregular & regular & irregular \\
\hline 1 & \multirow{4}{*}{$\begin{array}{l}\text { No seismic } \\
\text { analysis } \\
\text { required }\end{array}$} & * & * & * & * & * & * \\
\hline 2 & & $\mathrm{SM} / \mathrm{UL}$ & SM & $\mathrm{SM} / \mathrm{UL}$ & MM & MM & MM \\
\hline 3 & & $\mathrm{SM} / \mathrm{UL}$ & MM & MM & MM & MM & TH \\
\hline 4 & & $\mathrm{SM} / \mathrm{UL}$ & MM & MM & MM & TH & TH \\
\hline
\end{tabular}

Table 5-3 Regular bridge requirements.

\begin{tabular}{|l|c|c|c|c|c||}
\hline \hline Parameter & \multicolumn{5}{|c|}{ Value } \\
\hline \hline Number of Spans & 2 & 3 & 4 & 5 & 6 \\
\hline Maximum subtended angle for a curved bridge & $90^{\circ}$ & $90^{\circ}$ & $90^{\circ}$ & $90^{\circ}$ & $90^{\circ}$ \\
\hline Maximum span length ratio from span to span & 3 & 2 & 2 & 1.5 & 1.5 \\
\hline $\begin{array}{l}\text { Maximum bent/pier stiffness ratio from span to span, } \\
\text { excluding abutments }\end{array}$ & - & 4 & 4 & 3 & 2 \\
\hline \hline
\end{tabular}

In Table 5-2 operational classification is one of the parameters that defines the minimum analysis requirements. In this example, the bridge was assumed to be "other bridges". All the bridges should be classified into three categories including critical bridges, essential bridges or other bridges. Bridges in the essential category should be open to emergency vehicles immediately after the design earthquake, i.e., a 1,000-yr return period event. Bridges in the critical category should remain open to all traffic after the design earthquake and be usable by emergency vehicles immediately after a large earthquake, e.g., a 2,500-yr return period event. Operation importance affects the strength and extreme event limit states. For the strength limit state, operation importance values are: $\eta I \geq 1.05$ for critical or essential bridges $=1.00$ for typical bridges and $\geq 0.95$ for relatively less important bridges. For all other limit states: $\eta I=1.00$

\subsubsection{Calculating the Weight of the Structure}

The following calculation shows the magnitude of the dead load and superimposed dead loads that were applied to the bridge. Table 5-4 shows the property of the structural components and Table 5-5 shows a comparison between the hand calculations and CSiBridge results. 
Table 5-4 Property of the structural component.

\begin{tabular}{|c|c|c|c|}
\hline & Superstructure & Column & Cap beam \\
\hline A (ft2) & 31.9 & 6.64 & 11.1 \\
\hline I33 (ft4) & 50.7 & 3.5 & 9.7 \\
\hline I22 (ft4) & 2778.3 & 3.5 & 10.8 \\
\hline \multicolumn{3}{|c|}{ Base material is concrete $(E=635788.9 \mathrm{kip} / \mathrm{ft} 2)$} \\
\hline
\end{tabular}

Dead load=weight of deck+ weigh of cap beam+ half weight of two columns

Weight of deck $=(32 \times .625 \times 2 \times 95) \times 0.15+0.4403 \times 4 \times 2 \times 95 \times 0.49=570+164=734 \mathrm{kip}$

Weigh of cap beam $=3.25 \times 4.17 \times 30 \times 0.15=61 \mathrm{kip}$

Half weight of two columns $=3.14 \times 4.16 \times 4.16 / 4 \times 25 / 2 \times .15 \times 2=51$

Total dead load $=734+61+51=846 \mathrm{kip}$

Super imposed dead load $=0.0547 \times 2 \times 95 \times 32=332.5$

$\mathrm{W}=734+61+51+332.5=1179$ kip

Table 5-5 Comparison between hand calculation and CSiBridge.

\begin{tabular}{|c|c|c|c|}
\hline & Dead load & $\begin{array}{c}\text { Super imposed } \\
\text { dead load }\end{array}$ & $\begin{array}{c}\text { Total } \\
\text { weight of } \\
\text { structure }\end{array}$ \\
\hline CSiBridge results & $837 \mathrm{kip}$ & $344 \mathrm{kip}$ & $1156 \mathrm{kip}$ \\
\hline Hand calculation & $846 \mathrm{kip}$ & $344 \mathrm{kip}$ & $1190 \mathrm{kip}$ \\
\hline
\end{tabular}

\subsubsection{The Uniform Load Method}

The uniform load method may be used for both transverse and longitudinal earthquake motions. In this method, a uniform lateral load was applied to the bridge in the longitudinal and transverse directions to approximate the effects of seismic loads. When the fundamental modes of vibration are in the principal directions, the calculated responses of the bridge display good 
accuracy relative to exact methods. In this method, an arbitrary uniform load equal to P0 is applied to the bridge and the displacement $\mathrm{Vs}(\mathrm{x})$ calculated. Then the bridge stiffness is determined by $\mathrm{K}=\mathrm{P} 0 \mathrm{~L} / \mathrm{Vs}$, max. The third step is calculating the weight of the structure under dead load and superimposed dead loads. By calculating the mass and stiffness of the bridge, the period of the bridge will be known. The step-by-step period calculations of the bridge are shown below for the transverse and longitudinal directions. Mode shape and period of bridge based upon CSiBridge analysis results are shown in Figure 5-9:

$\mathrm{P} 0=100 \mathrm{kip} / \mathrm{ft}$ (Arbitrary)

Longitudinal direction

Delta $\max =9.8 \mathrm{ft}$

$\mathrm{K}=\mathrm{P} 0 \mathrm{~L} /$ Deltamax=100x190/9.8= $1939 \mathrm{kip} / \mathrm{ft}$

$\mathrm{T}=2 \mathrm{pi}(\mathrm{W} / \mathrm{gK})^{\wedge} .5=2 \times 3.1415(1190 /(32.2 \times 1939))^{\wedge} .5=0.86 \mathrm{sec}$

Transverse direction

Delta $\max =7 \mathrm{ft}$

$\mathrm{K}=\mathrm{P} 0 \mathrm{~T} /$ Deltamax $=100 \times 190 / 7=2714 \mathrm{kip} / \mathrm{ft}$

$\mathrm{T}=2 \mathrm{pi}(\mathrm{W} / \mathrm{gK})^{\wedge} .5=2 \times 3.1415(1190 /(32.2 \times 2714))^{\wedge} .5=0.73 \mathrm{sec}$ 


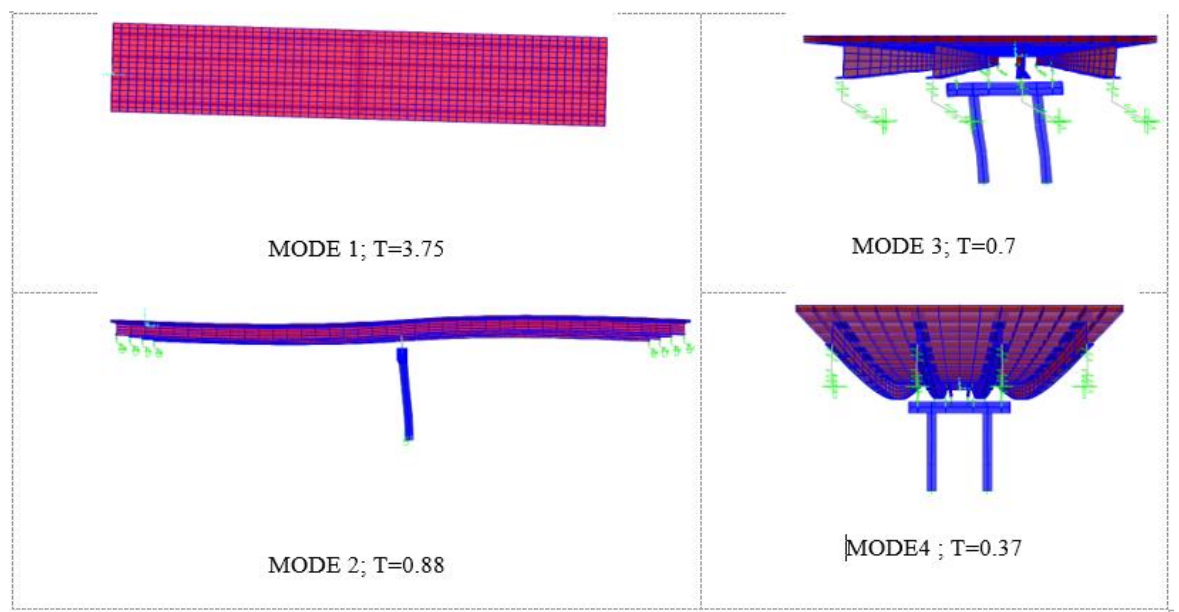

Figure 5-9 Mode shapes and periods of the bridge based upon CSiBridge analysis results.

\subsubsection{Calculating Design Response Spectrum}

According to AASHTO, a 5\% damped design response spectrum should be used for the seismic design of the structure (Figure 5-10). In this example, it was assumed that the bridge was located in Berkeley California (zip code 947014).

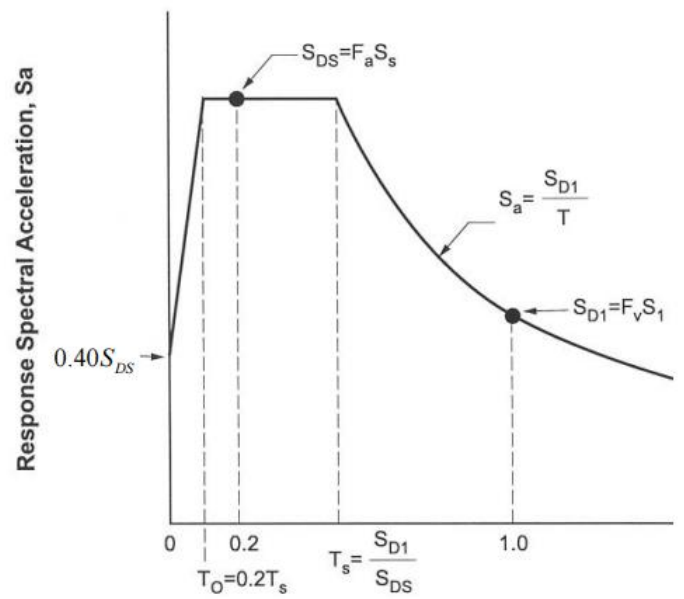

Figure 5-10 Design response spectrum according to AASHTO.

The definition of different parameters in this figure are:

$\mathrm{C}_{\mathrm{sm}}=\mathrm{A}_{\mathrm{S}}+\left(\mathrm{S}_{\mathrm{DS}}-\mathrm{A}_{\mathrm{S}}\right)\left(\mathrm{T}_{\mathrm{m}} / \mathrm{T}_{0}\right)$

In which: 
$\mathrm{A}_{\mathrm{S}}=\mathrm{F}_{\mathrm{pga}} \mathrm{PGA}$

$\mathrm{S}_{\mathrm{DS}}=\mathrm{F}_{\mathrm{a}} \mathrm{S}_{\mathrm{S}}$

Where:

PGA = peak ground acceleration coefficient on rock (Site Class B)

$\mathrm{S}_{\mathrm{S}}=$ horizontal response spectral acceleration coefficient at 0.2-sec period on rock (Site Class B)

$\mathrm{T}_{\mathrm{m}}=$ period of vibration of $\mathrm{m}$ th mode $(\mathrm{s})$

$\mathrm{T}_{0}=$ reference period used to define spectral shape $=0.2 \mathrm{~T}_{\mathrm{S}}(\mathrm{s})$

$\mathrm{T}_{\mathrm{S}}=$ corner period at which spectrum changes from being independent of period to being inversely proportional to period $=\mathrm{S}_{\mathrm{D} 1} / \mathrm{S}_{\mathrm{DS}}(\mathrm{s})$

For periods greater than or equal to $\mathrm{T}_{0}$ and less than or equal to $\mathrm{T}_{\mathrm{S}}$, the elastic seismic response coefficient should be:

$\mathrm{C}_{\mathrm{sm}}=\mathrm{S}_{\mathrm{DS}}$

For periods greater than $\mathrm{T}_{\mathrm{S}}$, the elastic seismic response coefficient should be:

$\mathrm{C}_{\mathrm{sm}}=\mathrm{S}_{\mathrm{D} 1} / \mathrm{T}_{\mathrm{m}}$

In which: $S_{D 1}=F_{v} S_{1}$

The horizontal peak ground acceleration coefficient and horizontal response spectral acceleration coefficient at 0.2 -sec period on rock (Site Class B) were obtained from contour maps (Figure 5-11 and Figure 5-12) for the location of the bridge that equal to PGA=0.954 and Ss=2.29. 


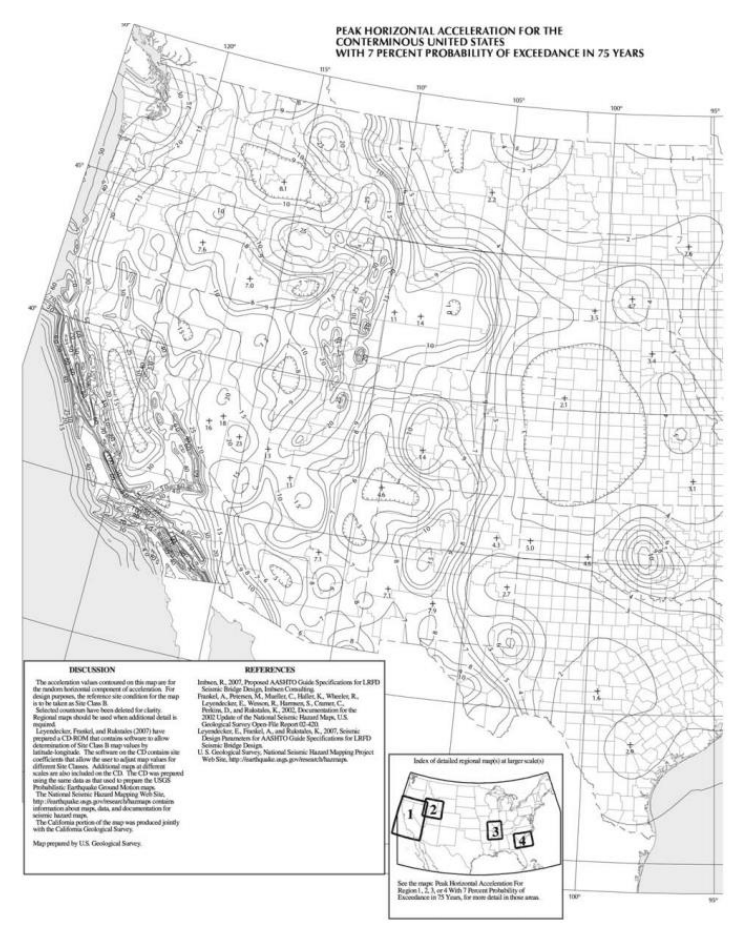

Figure 5-11 Horizontal Peak Ground Acceleration Coefficient for the Conterminous United States (PGA) with Seven Percent Probability of Exceedance in 75 yr (Approx. 1000-yr Return Period).

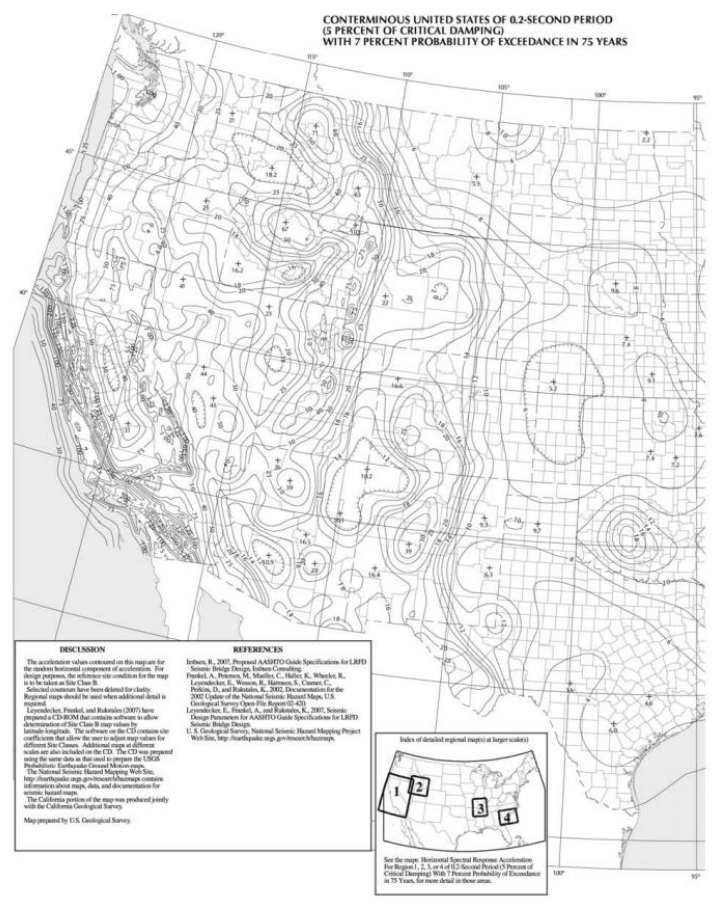

Figure 5-12 Horizontal Response Spectral Acceleration Coefficient for the Conterminous United States at Period of $0.2 \mathrm{~s}$ (SS) with Seven Percent Probability of Exceedance in $75 \mathrm{yr}$ (Approx. 1000-yr Return Period) and Five Percent Critical Damping. 
Table 5-6 Values of Site Factor, Fv, for Long-Period Range of Acceleration Spectrum

\begin{tabular}{|c|c|c|c|c|c||}
\hline \multirow{2}{*}{ Site } & \multicolumn{5}{|c||}{$\begin{array}{c}\text { Spectral Acceleration Coefficient } \\
\text { at Period } 1.0 \sec \left(S_{1}\right)^{1}\end{array}$} \\
\cline { 2 - 6 } Class & $S_{1}<$ & $\begin{array}{c}S_{1}= \\
S_{1}=\end{array}$ & $\begin{array}{c}S_{1}= \\
0.1\end{array}$ & $\begin{array}{c}S_{1}> \\
0\end{array}$ \\
\hline \hline A & 0.8 & 0.8 & 0.8 & 0.8 & 0.8 \\
\hline B & 1.0 & 1.0 & 1.0 & 1.0 & 1.0 \\
\hline C & 1.7 & 1.6 & 1.5 & 1.4 & 1.3 \\
\hline D & 2.4 & 2.0 & 1.8 & 1.6 & 1.5 \\
\hline E & 3.5 & 3.2 & 2.8 & 2.4 & 2.4 \\
\hline $\mathrm{F}^{2}$ & $*$ & $*$ & $*$ & $*$ & $*$ \\
\hline \multicolumn{7}{|c|}{} \\
\hline
\end{tabular}

$\mathrm{S}_{1}$ is the horizontal response spectral acceleration coefficient for a $1.0 \mathrm{sec}$ period on the rock (Site Class B) and should be taken from the contour map (Figure 5-13). This parameter for the location of the bridge is equal to 0.869 .

$\mathrm{S}_{\mathrm{D} 1}=\mathrm{F}_{\mathrm{v}} \mathrm{S}_{1}=1 \mathrm{x} .869=0.859$ 
Table 5-6 Values of Site Factor, Fv, for Long-Period Range of Acceleration Spectrum

\begin{tabular}{||c|c|c|c|c|c||}
\hline \hline \multirow{4}{*}{ Site } & \multicolumn{5}{|c||}{$\begin{array}{c}\text { Spectral Acceleration Coefficient } \\
\text { at Period } 1.0 \mathrm{sec}\left(S_{1}\right)^{1}\end{array}$} \\
\cline { 2 - 6 } Class & $S_{1}<$ & $S_{1}=$ & $S_{1}=$ & $S_{1}=$ & $S_{1}>$ \\
\hline A & 0.1 & 0.2 & 0.3 & 0.4 & 0.5 \\
\hline B & 0.8 & 0.8 & 0.8 & 0.8 & 0.8 \\
\hline C & 1.0 & 1.0 & 1.0 & 1.0 & 1.0 \\
\hline D & 2.4 & 1.6 & 1.5 & 1.4 & 1.3 \\
\hline E & 3.5 & 3.2 & 1.8 & 1.6 & 1.5 \\
\hline $\mathrm{F}^{2}$ & $*$ & $*$ & $*$ & $*$ & $*$ \\
\hline
\end{tabular}

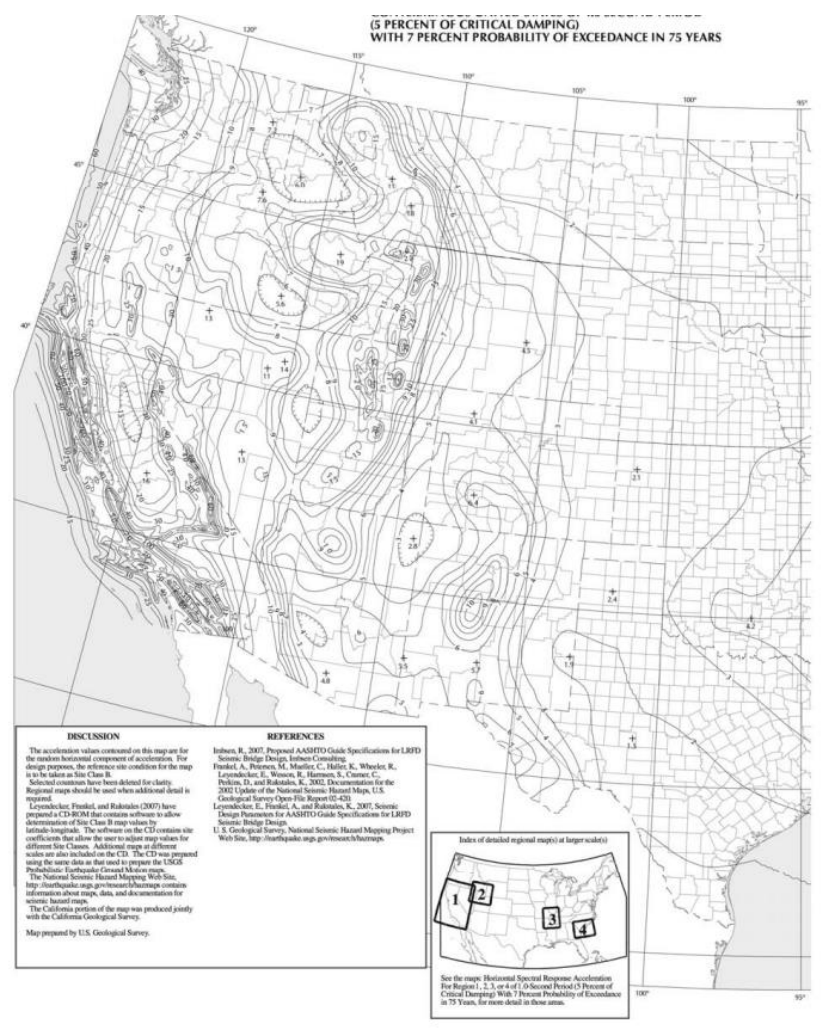

Figure 5-13 Horizontal Response Spectral Acceleration Coefficient for the Conterminous United States at Period of $1.0 \mathrm{~s}$ (S1) with Seven Percent Probability of Exceedance in $75 \mathrm{yr}$ (Approx. 1000-yr Return Period) and Five Percent Critical Damping

Table 5-7 Seismic Zones.

\begin{tabular}{||l|c||}
\hline \multicolumn{1}{|c|}{ Acceleration Coefficient, $S_{D 1}$} & Seismic Zone \\
\hline$S_{D 1} \leq 0.15$ & 1 \\
\hline $0.15<S_{D 1} \leq 0.30$ & 2 \\
\hline $0.30<S_{D 1} \leq 0.50$ & 3 \\
\hline $0.50<S_{D 1}$ & 4 \\
\hline
\end{tabular}

According to Table 5-7, $0.5<\mathrm{SD} 1=0.859$ and the seismic zone for this bridge is zone4. In this example, it was assumed the bridge is located at site class category B according to the Table 
5-8. Fpga and Fa should be taken from Table 5-9 and Table 5-10 and for this example, they are equal to 1 in both conditions for site class B. After calculating all required parameters, the response spectrum could be defined as the figure below.

Table 5-8 Site Class Definitions.

\begin{tabular}{|c|l|}
\hline $\begin{array}{c}\text { Site } \\
\text { Class }\end{array}$ & \multicolumn{1}{c|}{ Soil Type and Profile } \\
\hline \hline A & Hard rock with measured shear wave velocity, $\bar{v}_{s}>5,000 \mathrm{ft} / \mathrm{s}$ \\
\hline B & Rock with $2,500 \mathrm{ft} / \mathrm{sec}<\bar{v}_{s}<5,000 \mathrm{ft} / \mathrm{s}$ \\
\hline C & $\begin{array}{l}\text { Very dense soil and soil rock with } 1,200 \mathrm{ft} / \mathrm{sec}<\bar{v}_{s}<2,500 \mathrm{ft} / \mathrm{s}, \\
\text { or with either } \bar{N}>50 \text { blows/ft, or } \bar{s}_{u}>2.0 \mathrm{ksf}\end{array}$ \\
\hline D & $\begin{array}{l}\text { Stiff soil with } 600 \mathrm{ft} / \mathrm{s}<\bar{v}_{s}<1,200 \mathrm{ft} / \mathrm{s}, \text { or with either } 15<\bar{N}<50 \mathrm{blows} / \mathrm{ft}, \\
\text { or } 1.0<\bar{s}_{u}<2.0 \mathrm{ksf}\end{array}$ \\
\hline E & $\begin{array}{l}\text { Soil profile with } \bar{v}_{s}<600 \mathrm{ft} / \mathrm{s} \text { or with either } \bar{N}<15 \text { blows/ft or } \bar{s}_{u}<1.0 \text { ksf, or any profile with more } \\
\text { than } 10 \mathrm{ft} \text { of soft clay defined as soil with } P I>20, w>40 \text { percent and } \bar{s}_{u}<0.5 \text { ksf }\end{array}$ \\
\hline F & \begin{tabular}{l} 
Soils requiring site-specific evaluations, such as: \\
$\bullet \quad \begin{array}{l}\text { Peats or highly organic clays }(H>10 \mathrm{ft} \text { of peat or highly organic clay where } H=\text { thickness of soil) } \\
\text { Very high plasticity clays }(H>25 \mathrm{ft} \text { with } P I>75) \\
\text { Very thick soft/medium stiff clays }(H>120 \mathrm{ft})\end{array}$ \\
\hline
\end{tabular} \\
\hline
\end{tabular}

Where:

vs $=$ average shear wave velocity for the upper $100 \mathrm{ft}$ of the soil profile

$\mathrm{N}=$ average Standard Penetration Test (SPT) blow count (blows/ft) (ASTM D1586) for the upper $100 \mathrm{ft}$ of the soil profile

$\mathrm{su}=$ average undrained shear strength in ksf (ASTM D2166 or ASTM D2850) for the upper $100 \mathrm{ft}$ of the soil profile

PI = plasticity index (ASTM D4318)

$\mathrm{w}=$ moisture content $(\mathrm{ASTM}$ D2216) 
Table 5-9 Values of Site Factor, Fpga, at Zero Period on Acceleration Spectrum.

\begin{tabular}{||c|c|c|c|c|c||}
\hline \multirow{2}{*}{$\begin{array}{c}\text { Site } \\
\text { Class }\end{array}$} & \multicolumn{5}{|c|}{ Peak Ground Acceleration Coefficient $(P G A)^{1}$} \\
\cline { 2 - 6 } & $\begin{array}{c}1 \\
0 A\end{array}$ & $P G A=$ & $P G A=$ & $P G A=$ & $P G A>$ \\
\hline \hline A & 0.8 & 0.8 & 0.30 & 0.40 & 0.50 \\
\hline B & 1.0 & 1.0 & 1.0 & 0.8 & 0.8 \\
\hline C & 1.2 & 1.2 & 1.1 & 1.0 & 1.0 \\
\hline D & 1.6 & 1.4 & 1.2 & 1.1 & 1.0 \\
\hline E & 2.5 & 1.7 & 1.2 & 0.9 & 0.9 \\
\hline $\mathrm{F}^{2}$ & $*$ & $*$ & $*$ & $*$ & $*$ \\
\hline
\end{tabular}

Table 5-10 Values of Site Factor, Fa, for Short-Period Range of Acceleration Spectrum.

\begin{tabular}{||c|c|c|c|c|c||}
\hline \multirow{2}{*}{$\begin{array}{c}\text { Site } \\
\text { Class }\end{array}$} & \multicolumn{5}{|c||}{$\begin{array}{c}\text { Spectral Acceleration Coefficient } \\
\text { at Period } 0.2 \sec \left(S_{S}\right)^{1}\end{array}$} \\
\cline { 2 - 6 } & $S_{S}<$ & $S_{S}=$ & $S_{S}=$ & $S_{S}=$ & $S_{S}>$ \\
\hline A & 0.25 & 0.50 & 0.75 & 1.00 & 1.25 \\
\hline B & 1.0 & 0.8 & 0.8 & 0.8 & 0.8 \\
\hline C & 1.2 & 1.2 & 1.0 & 1.0 & 1.0 \\
\hline D & 1.6 & 1.4 & 1.1 & 1.0 & 1.0 \\
\hline E & 2.5 & 1.7 & 1.2 & 1.1 & 1.0 \\
\hline $\mathrm{F}^{2}$ & $*$ & $*$ & $*$ & $*$ & 0.9 \\
\hline \hline
\end{tabular}

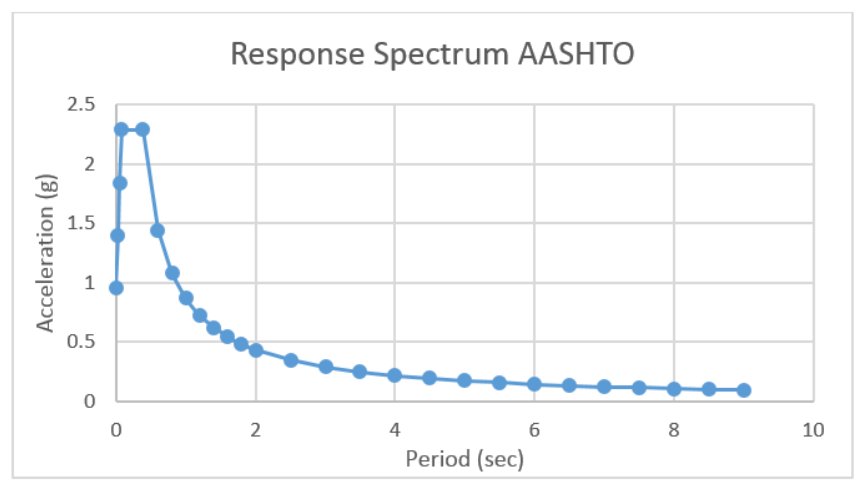

Figure 5-14 Response spectrum curve according to AASHTO.

After finding the response spectrum and calculating the period of structure in the principal directions, the equivalent static earthquake loading Pe could be calculated from the expression below.

Longitudinal direction $\mathrm{T}=0.86 \mathrm{sec} \mathrm{Csm}=1$

$\operatorname{Pe}(\mathrm{L})=\mathrm{CsmW} / \mathrm{L}=1 \times 1190 / 190=6.26 \mathrm{kip} / \mathrm{ft}$

Transverse direction $\mathrm{T}=0.73 \mathrm{sec} \mathrm{Csm}=1.2$ 
$\operatorname{Pe}(\mathrm{T})=\mathrm{CsmW} / \mathrm{L}=1.2 \times 1190 / 190=\mathrm{kip} / \mathrm{ft}=7.51 \mathrm{kip} / \mathrm{ft}$

\subsubsection{Calculating the Distribution of Forces in the Bent Frame}

Distribution of forces in each bent column and bent cap should be calculated in both the longitudinal and transverse directions under seismic loads and the most critical forces used for the design. The columns behave as a single column in the perpendicular plane of the bent while there is frame action between the bent columns and bent cap when loaded in plane. The following steps describe the design process in each case.

- For single columns and piers, shear forces and moments in the superstructure and bent caps should be determined for the two principal axes of a column as follows:

In Step 1, the column over-strength moment capacity is determined by multiplying the over-strength factor times the plastic moment capacity. The nominal moment capacity or plastic moment capacity is calculated using the expected yield strength of the material and apply the dead load on the section of consideration. In Step 2, the corresponding column shear force is determined using the column over-strength moment (Figure 4-8). These steps are repeated to calculate the forces in the superstructure for the longitudinal direction of loading.

- In bents with two or more columns, forces should be calculated in the plane of the bent and perpendicular to the plane of the bent. In the direction perpendicular to the plane of the bent, forces are calculated us a similar method as the single column in the previous section.

In Step 1 the column over-strength moment capacity is determined by multiplying the over-strength factor times the plastic moment capacity. The nominal moment capacity or plastic moment capacity is calculated using the expected yield strength of the material and apply the dead load on the section of consideration. In Step 2 the corresponding column shear force is determined using the column over-strength moment. Shear forces in the bent 
are equal to the sum of the column shears of the bent (Figure 4-9). In Step 3, the axial forces in the columns are calculated due to applied shear forces applied to the top of the bent when the column reaches to the over-strength moment. In Step 4, the column axial forces are combined with the dead load axial forces and the revised column over-strength moments calculated.

In the following, axial force, shear force and moment of column were calculated.

Axial force under dead load $=846 / 4=211 \mathrm{kip}$

Axial force under super imposed dead load=344/4=86 kip

Shear force in each column in longitudinal direction $=\mathrm{V}=\mathrm{Pe}(\mathrm{L}) \times \mathrm{L} / 2=6.26 \times 95 \times 2 / 2=595 \mathrm{kip}$

Moment force in each column in longitudinal direction $=\mathrm{Vx}(\mathrm{Lcol}) / 2=595 * 25 / 2=7440 \mathrm{kip}-\mathrm{ft}$

Shear force in each column in transverse direction $=\mathrm{V}=\mathrm{Pe}(\mathrm{T}) \times \mathrm{L} / 2=7.51 \times 95 \times 2 / 2=713 \mathrm{kip}$

Moment force in each column in transverse direction $=\mathrm{Vx}(\mathrm{Lcol}) / 2=713 * 25 / 2=8912 \mathrm{kip}-\mathrm{ft}$

Table 5-11 Summary of applied load to the column.

\begin{tabular}{|c|c|c|c|c|c|}
\hline & $\begin{array}{c}\text { Moving } \\
\text { load(from } \\
\text { CSiBridge) }\end{array}$ & $\begin{array}{c}\text { Dead } \\
\text { load }\end{array}$ & Super imposed dead load & $\operatorname{Pe}(\mathrm{L})$ & $\mathrm{Pe}(\mathrm{T})$ \\
\hline $\mathrm{P}$ (axial force) kip & -225 & -211 & -86 & 0 & 0 \\
\hline $\mathrm{M}$ (longitudinal dir.) kip-ft & 209 & 0 & 0 & 7440 & \\
\hline $\mathrm{M}$ (transverse dir.) kip-ft & & 0 & 0 & 0 & 8912 \\
\hline $\mathrm{V}$ (longitudinal dir.) kip & 5.2 & 0 & 0 & 595 & \\
\hline V (transverse dir.) kip & & 0 & 0 & 0 & 713 \\
\hline
\end{tabular}

In an elastic analysis, calculated forces for designing the substructure and the connections between different parts should be divided by the appropriate response modification factor according to Table 5-12 and Table 5-13. In an inelastic time history analysis, the $\mathrm{R}$ factor should be taken 
equal to one. Some elements of the bridge develop an inelastic behavior during earthquakes, such as the column-to-footing connection or column to multi column bent. An alternative method to use an $\mathrm{R}$ for connections of structural members that were designed to transfer the maximum applied loads is to design according to the maximum load transmitted by inelastic hinging at the two ends of columns.

In this example, forces are calculated based on the Strength I and Extreme Event I limit states load combinations and earthquake forces divided by the $\mathrm{R}$ factor $(\mathrm{R}=5)$ for operational category "Other" and multi column bents. In the final step, the interaction curve was derived and the capacity of columns was calculated. The cross section of the column and reinforcement are shown in Table 5-14.

Table 5-12 Response Modification Factors-Substructures.

\begin{tabular}{|c|c|c|c|}
\hline \multirow[b]{2}{*}{ Substructure } & \multicolumn{3}{|c|}{ Operational Category } \\
\hline & Critical & Essential & Other \\
\hline Wall-type piers-larger dimension & 1.5 & 1.5 & 2.0 \\
\hline $\begin{array}{l}\text { Reinforced concrete pile bents } \\
\text { - Vertical piles only } \\
\text { - } \quad \text { With batter piles }\end{array}$ & $\begin{array}{l}1.5 \\
1.5\end{array}$ & $\begin{array}{l}2.0 \\
1.5\end{array}$ & $\begin{array}{l}3.0 \\
2.0\end{array}$ \\
\hline Single columns & 1.5 & 2.0 & 3.0 \\
\hline $\begin{array}{l}\text { Steel or composite steel and concrete pile bents } \\
\text { - } \quad \text { Vertical pile only } \\
\text { - } \quad \text { With batter piles }\end{array}$ & $\begin{array}{l}1.5 \\
1.5\end{array}$ & $\begin{array}{l}3.5 \\
2.0\end{array}$ & $\begin{array}{l}5.0 \\
3.0\end{array}$ \\
\hline Multiple column bents & 1.5 & 3.5 & 5.0 \\
\hline
\end{tabular}

Table 5-13 Response Modification Factors-Connections.

\begin{tabular}{||l|c||}
\hline \multicolumn{1}{|c|}{ Connection } & All Operational Categories \\
\hline Superstructure to abutment & 0.8 \\
\hline Expansion joints within a span of the superstructure & 0.8 \\
\hline Columns, piers, or pile bents to cap beam or superstructure & 1.0 \\
\hline Columns or piers to foundations & 1.0 \\
\hline
\end{tabular}

Two load combinations were considered in this research to evaluate the performance of the SDCL bridge system, including Strength I as the critical load for gravity load and Extreme Event I as the critical load for seismic loads. In the Extreme Event I load combination, the live load factor $(\gamma \mathrm{EQ})$, should be determined on a project-specific basis. Past editions of the standard specifications used $\gamma \mathrm{EQ}=0.0$ and this issue was not yet resolved. However, the possibility of partial live load, i.e., $\gamma \mathrm{EQ}<1.0$, with earthquakes should be considered. Application of Turkstra's rule for 
combining uncorrelated loads indicates that $\gamma \mathrm{EQ}=0.50$ is reasonable for a wide range of values of average daily truck traffic (ADTT), in this research 0.5 was used as an earthquake load coefficient for the Extreme Event I load combination. In the Extreme Event I load combination, one component of the earthquake was used. A combined vertical/horizontal load analysis is not required for Ordinary Standard Bridges. Interaction curve for Strength I and Event I were shown in Figure 5-15 and Figure 5-16 respectively. The calculations for the resulting two load combinations are given below:

Strength I=1.25DC+1.5DW+1.75LL

Extreme Event I=1.25DC+1.5DW+0.5LL+ (mean) EQ

$\mathrm{DC}=$ dead load of structural components and nonstructural attachments

DW $=$ dead load of wearing surfaces and utilities

$\mathrm{LL}=$ vehicular live load

$\mathrm{EQ}=$ earthquake load

Strength $\mathbf{I}=1.25 \mathrm{DC}+1.5 \mathrm{DW}+1.75 \mathrm{LL}$ for longitudinal direction

$\mathrm{P}(\mathrm{S} 1)=1.25 \times 211+1.5 \times 86+1.75 \times 225=786.5 \mathrm{kip}$

$\mathrm{M}(\mathrm{S} 1, \mathrm{~L})=1.75 \times 209=365.75 \mathrm{kip}-\mathrm{ft}$

$\mathrm{V}(\mathrm{S} 1, \mathrm{~L})=1.75 \times 5.2=9.1 \mathrm{kip}$

$\mathrm{M}(\mathrm{S} 1, \mathrm{~T})=0$

$\mathrm{V}(\mathrm{S} 1, \mathrm{~T})=0$ 
Table 5-14 Column property.

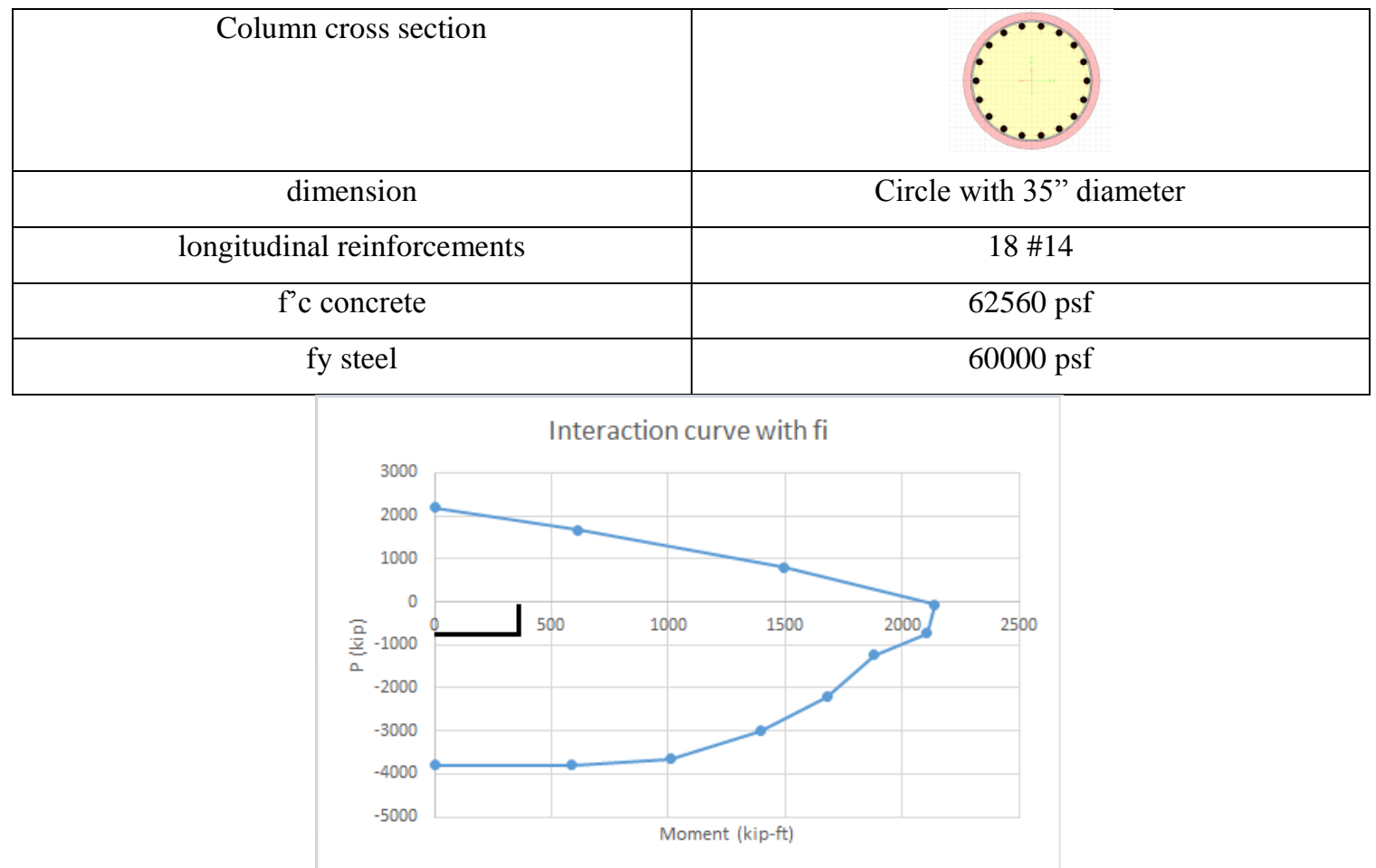

Figure 5-15 Interaction curve - design point for Strength I.

Extreme Event I=1.25DC+1.5DW+0.5LL+EQ

$P(E 1)=1.25 \times 211+1.5 \times 86+0.5 \times 225=505 \mathrm{kip}$

$\mathrm{M}(\mathrm{E} 1, \mathrm{~L})=0.5 \times 209+7440 /(\mathrm{R}=5)=1592 \mathrm{kip}-\mathrm{ft}$

$\mathrm{V}(\mathrm{E} 1, \mathrm{~L})=1.25 \times 5.2+595 /(\mathrm{R}=5)=125.5 \mathrm{kip}$

$\mathrm{M}(\mathrm{E} 1, \mathrm{~T})=8912 /(\mathrm{R}=5)=1782 \mathrm{kip}-\mathrm{ft}$

$\mathrm{V}(\mathrm{E} 1, \mathrm{~T})=713 /(\mathrm{R}=5)=142 \mathrm{kip}$ 


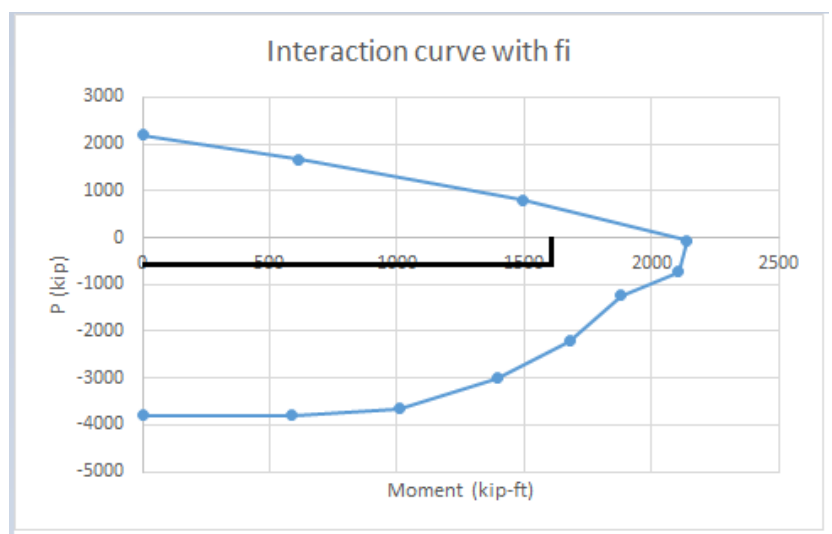

Figure 5-16 Interaction curve - design point for Extreme Event I.

\subsubsection{Requirements Capacity Protected Members}

Bent caps are considered integral if they terminate at the outside of the exterior girder and respond monolithically with the girder system during dynamic excitation (Roy A. Imbsen, May 2007). The capacity of protected members such as bent caps and integral superstructure elements that are adjacent to the plastic hinge locations should be designed to remain elastic when the plastic hinges form at the two ends of the column and the over-strength moment in columns is equal to $\mathbf{M}_{\mathrm{po}}$. The expected nominal capacity, $\mathrm{M}_{\mathrm{ne}}$, is used to find the capacity of essentially elastic members and should be found from the M- $\Phi$ diagram when the strain in concrete reaches a magnitude of 0.003 .

Moment-Curvature analysis based on the expected material properties should be used for calculating the plastic moment capacity of ductile concrete members such as bent columns (CALTRANS, 2013). Dead load with the axial forces due to overturning should be included in the Moment-Curvature analysis. Bilinear elastic perfectly plastic response should be used to find an estimation of plastic moment capacity. The first line should pass from zero to the point making the first reinforcing bar yield. The area below and above real M- $\Phi$ and idealized bilinear should be equal beyond the first reinforcing bar yield point as illustrated in Figure 4-10. 


\subsubsection{Moment-Curvature for the Effective Width}

In this example for columns, the Moment-Curvature curves were obtained with and without axial load and the idealized Moment-Curvature curves were derived according the CALTRANS specifications (Figure 5-17 and Figure 5-18). The over strength moment capacity is computed based on the AASHTO specification.

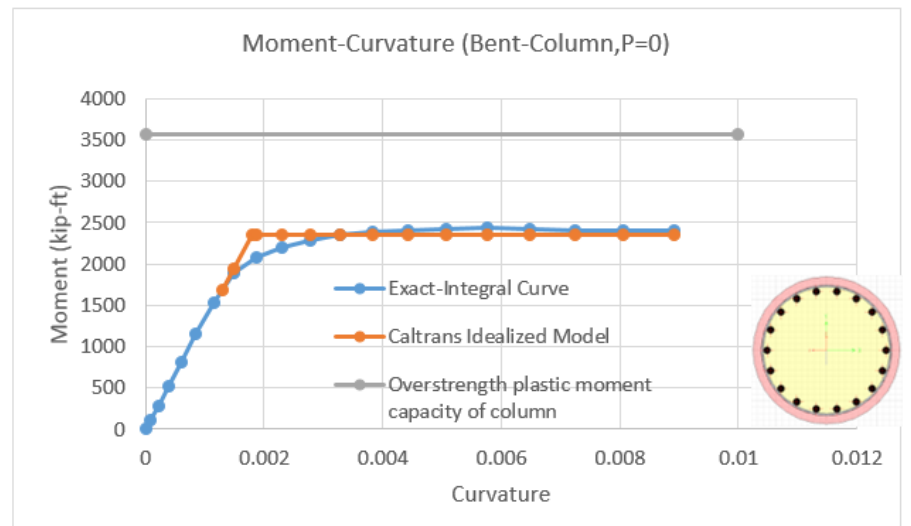

Figure 5-17 Moment-Curvature of the column with $\mathrm{P}=0$.

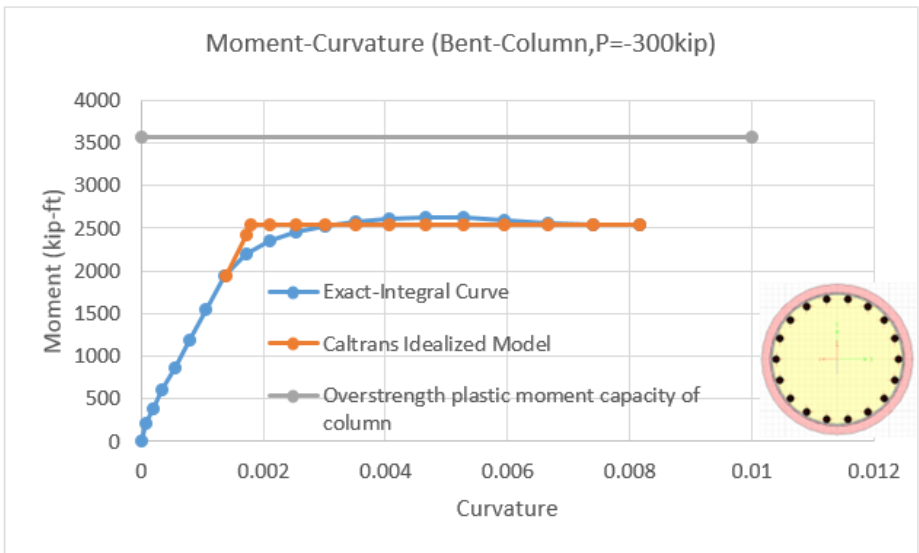

Figure 5-18 Moment-Curvature of the column with $\mathrm{P}=-300$ kip.

All loads acting on the capacity protected members should be considered when determining the factored nominal capacity of the member. For example, the axial demands on a bent cap beam due to the lateral loads should be included when calculating the cap beam's nominal capacity. In order to determine the force demands on capacity protected members connected to a hinging 
member, the plastic moment capacity should be increased by an over-strength magnifier, $\lambda_{\text {mo, }}$ as below:

$\mathrm{M}_{\mathrm{po}}=\lambda_{\mathrm{mo}} \cdot \mathrm{M}_{\mathrm{p}}$

Where:

$\mathrm{M}_{\mathrm{p}}=$ idealized plastic moment capacity of reinforced concrete member based upon expected material properties (kip-ft.)

$\mathrm{M}_{\mathrm{po}}=$ Over-strength plastic moment capacity (kip-ft.)

$\lambda_{\mathrm{mo}}=$ over-strength magnifier

$=1.2$ for ASTM A 706 reinforcement

$=1.4$ for ASTM A 615 Grade 60 reinforcement

In this example, according to Figure 5-18, the idealized moment capacity of the section is equal to 2550 kip-ft. Thus, the over-strength moment capacity is equal to $1.4 \times 2550=3570 \mathrm{kip}$-ft. The bent cap should be designed as an essentially elastic member. Any moment demand caused by the dead load or secondary pre-stress effects should be considered and distributed to the effective width of

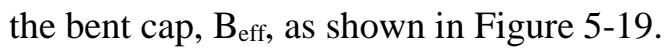



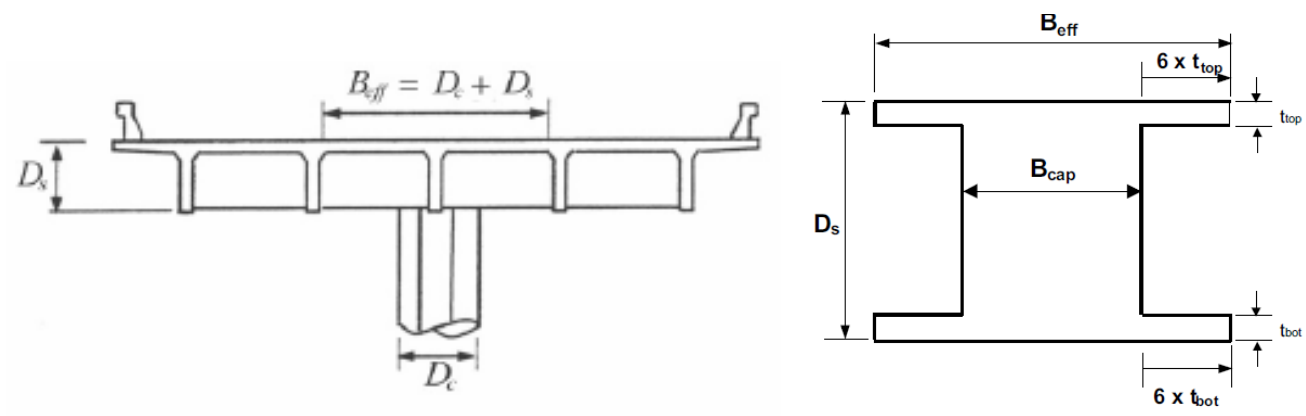

Figure 5-19 Left: effective superstructure width, right: effective bent cap width.

In the transverse direction, $\mathrm{B}_{\text {eff }}=\mathrm{B}_{\text {cap }}+12 \mathrm{t}$ and in the longitudinal direction for a box girder and solid superstructure $B_{\text {eff }}=D_{c}+2 D_{\text {s. }}$. For open soffit, girder deck superstructure, $B_{\text {eff }}=D_{c}+D_{s}$.

Where:

$\mathrm{t}=$ thickness of the top or bottom slab (in.)

$\mathrm{D}_{\mathrm{c}}=$ diameter of column (in.)

$\mathrm{D}_{\mathrm{s}}=$ depth of superstructure (in.)

$\mathrm{B}_{\text {cap }}=$ thickness of the bent cap (in.)

$\mathrm{B}_{\text {eff }}=\mathrm{B}_{\text {cap }}+12 \mathrm{t}=41+12 \times 7.5=131 \mathrm{in}$, in transverse direction

$\mathrm{B}_{\text {eff }}=\mathrm{D}_{\mathrm{c}}+\mathrm{D}_{\mathrm{s}}=35+39+7.5=81.5$ in, in longitudinal direction

The capacity protected member should be designed for forces resulting from the overstrength plastic hinge capacity at the face of the column. The expected nominal moment capacity, $\mathrm{M}_{\mathrm{ne}}$, for an essentially elastic response should be calculated using the expected material properties when the concrete strain reaches a magnitude of 0.003 . Figure 5-20 shows the effective section, in the transverse direction. The material properties and dimensions were derived from the test specimen at UNL (Nick Lampe, 2014). The effective width was calculated according to AASHTO 
seismic specification. The Moment-Curvature results, of the effective section of the concrete diaphragm, are shown in Figure 5-21 and Figure 5-22 under positive and negative moment, respectively.

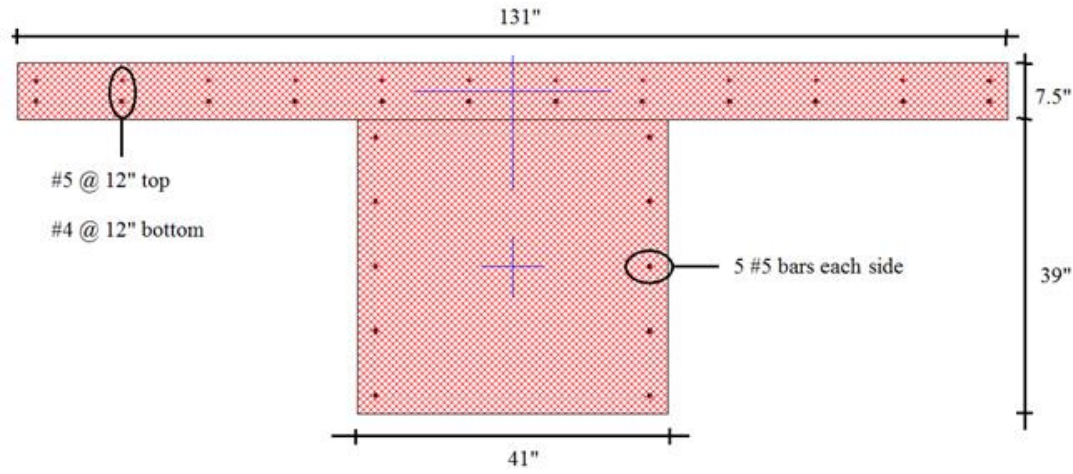

Figure 5-20 Effective cross section in the transverse direction of the earthquake.

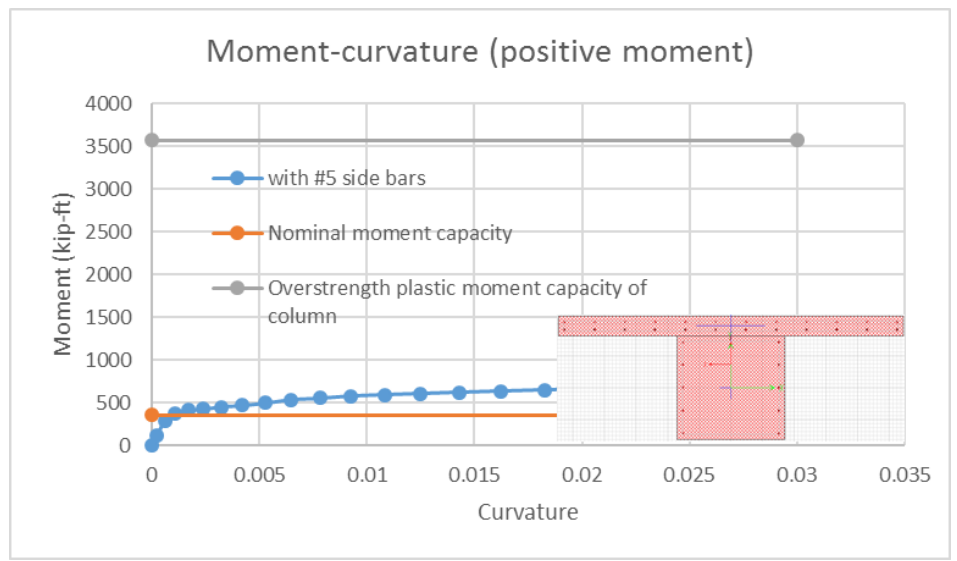

Figure 5-21 Moment-Curvature of the current section under positive moment with \#5 side bars.

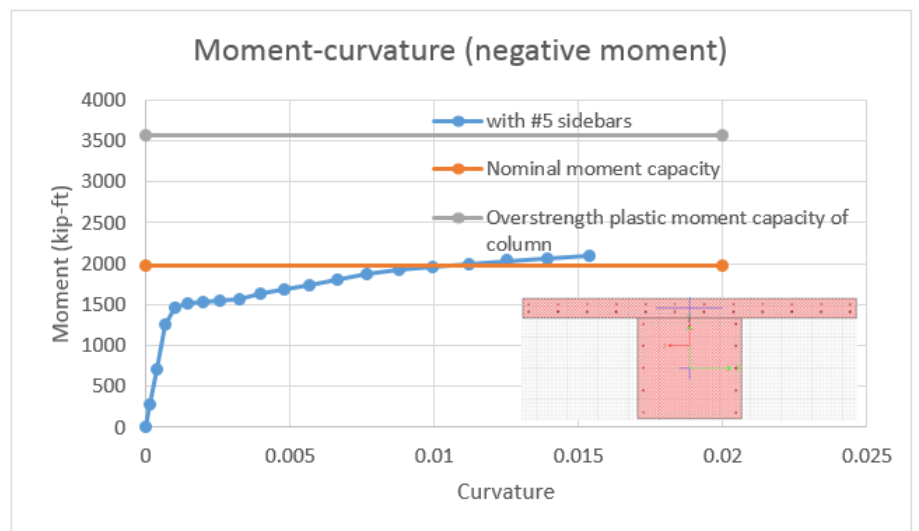

Figure 5-22 Moment-Curvature for the existing section under negative moment with \#5 side bars. 
Since the bent cap beam is a capacity protected member, the maximum nominal moment capacity should be larger than the over-strength plastic moment capacity of the column. According to Figure 5-21 and Figure 5-22 the nominal moment capacity of the section is less than the overstrength moment capacity of the column and the section is therefore not satisfactory. To enhance the nominal moment capacity, in lieu of \#5 reinforcing bars on two sides of the concrete diaphragm, \#18 bars were used. At this stage of the research, it was decided to only increase the side bars to determine how much flexural capacity should be increased in the transverse direction without changing the current detail of SDCL connection. The nominal moment capacity of the strengthened section was recalculated and the resulting Moment-Curvature is illustrated in Figure 5-23 and Figure 5-24. The nominal moment capacity of the strengthened section is equal to $5750 \mathrm{kip}-\mathrm{ft}$ and 4320 kip-ft under positive and negative moment, respectively. This capacity is greater than the over-strength moment capacity of the column $(1.4 \times 2550=3570 \mathrm{kip}-\mathrm{ft})$. Therefore, the nominal moment capacity of the concrete diaphragm in the transverse direction is satisfactory.

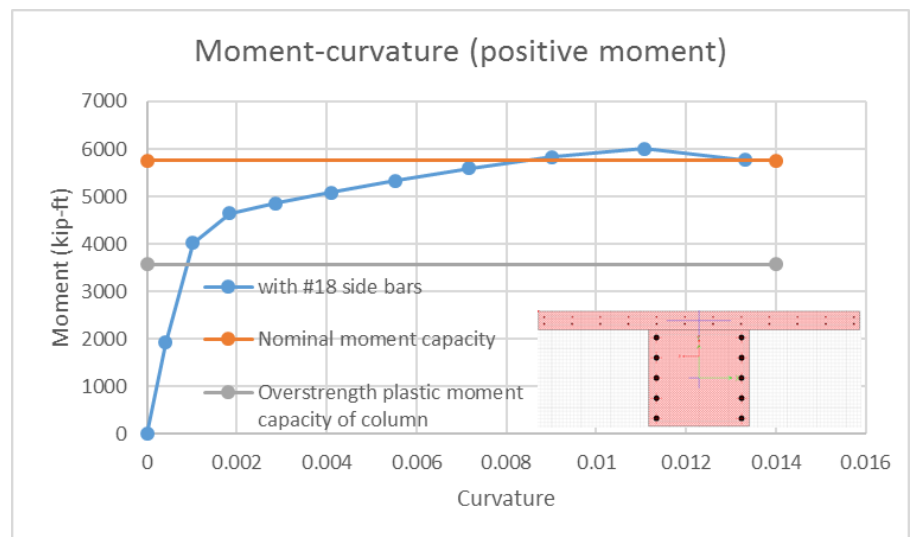

Figure 5-23 Moment-Curvature of the section under positive moment with \#18 side bars. 


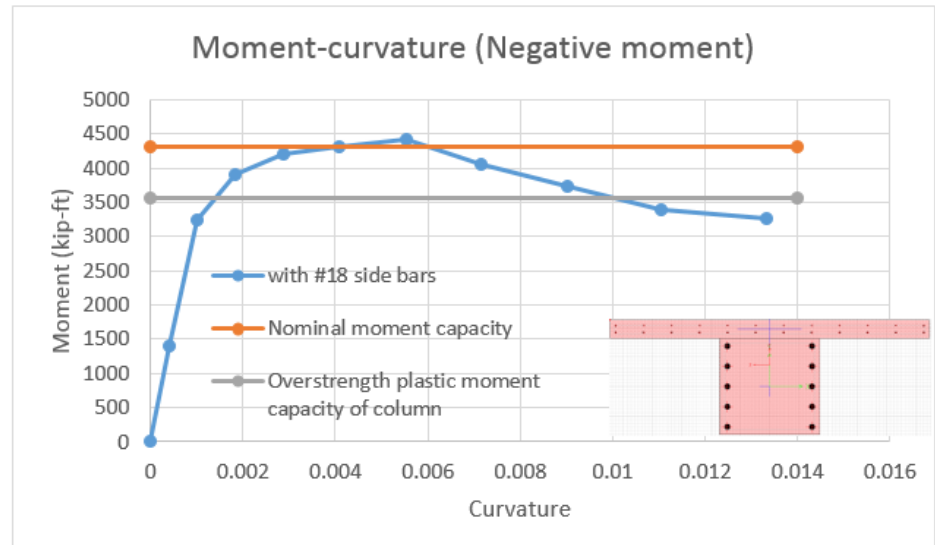

Figure 5-24 Moment-Curvature of the section under negative moment with \#18 side bars.

The same methodology was repeated for the concrete diaphragm in the longitudinal direction with and without considering the effect of the bottom flange of the girder. Figure 5-25 shows the detail of effective width in the longitudinal direction. According to Figure 5-26, without considering the effect of the bottom flange in Moment-Curvature, the nominal moment capacity of bent cap is not satisfactory. This outcome shows the two ends of bottom flange should somehow be connected to each other. According to Figure 5-27, the section is satisfactory under negative moment without considering the effect of the bottom flange in the moment capacity. Figure 5-28 and Figure 5-29 show the Moment-Curvature of the effective cross section under positive and negative moments respectively.

The magnitude of nominal moment capacity under positive moment without considering the effect of bottom flange is less than the over-strength moment capacity of the column, however, when the effect of the bottom flange is considered, the nominal moment capacity in the longitudinal direction is satisfactory. 


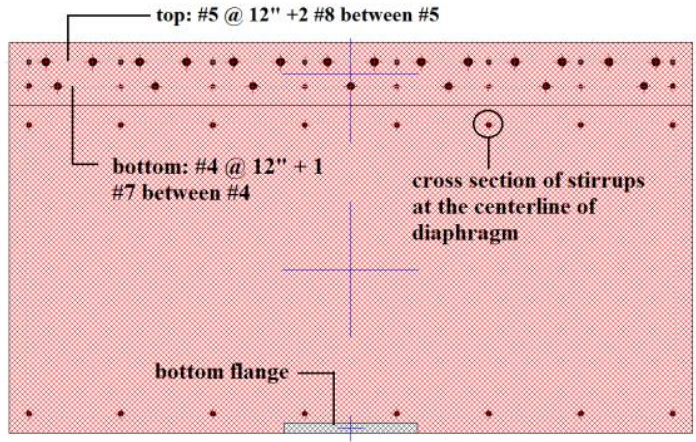

Figure 5-25 Effective cross-section in the longitudinal direction of the seismic event.

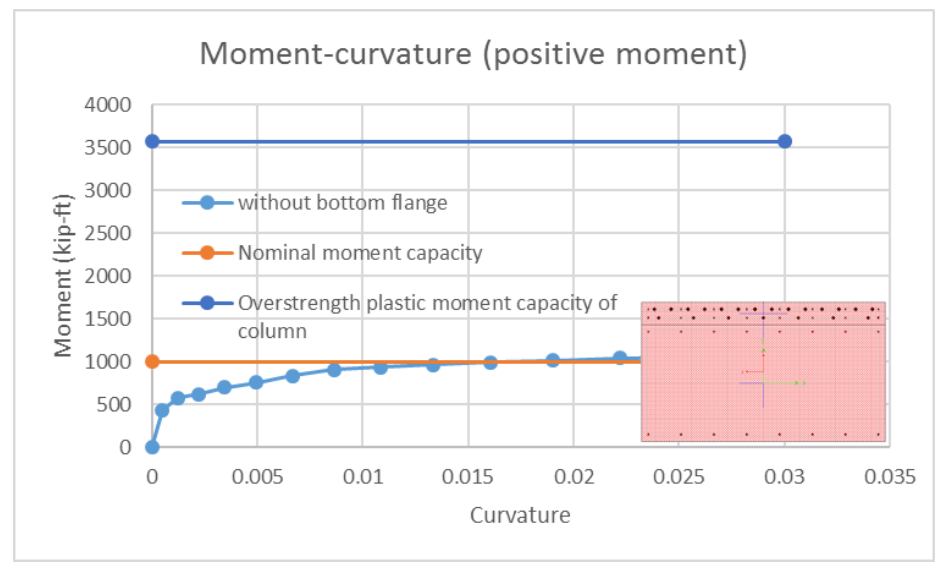

Figure 5-26 Moment-Curvature of the section under positive moment with one bottom flange (longitudinal dir.).

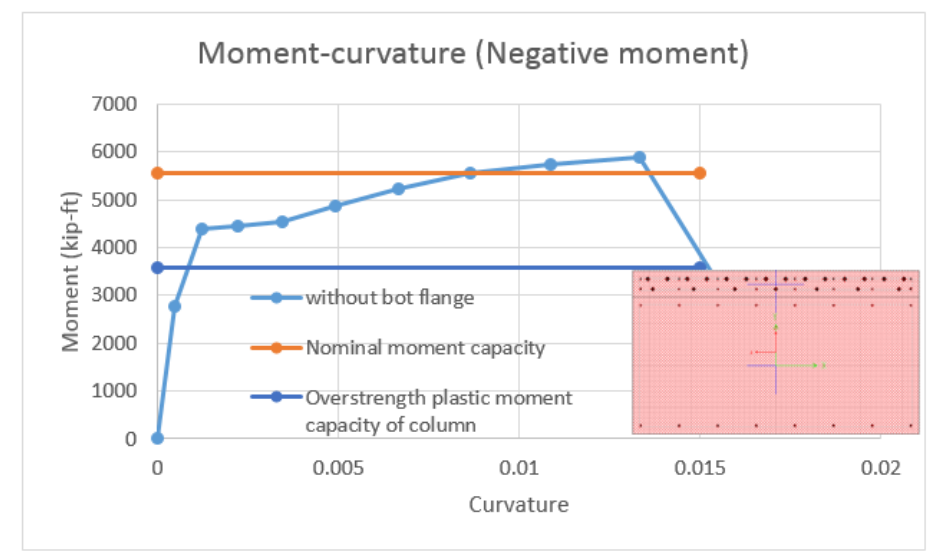

Figure 5-27 Moment-Curvature for the existing section under negative moment with one bottom flange (longitudinal dir.). 


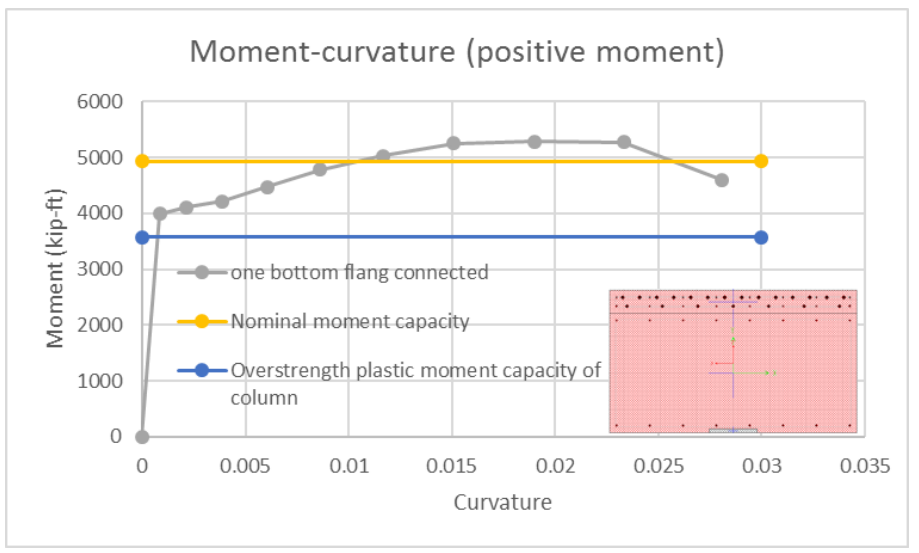

Figure 5-28 Moment-Curvature of the section under positive moment with one bottom flange (longitudinal dir.).

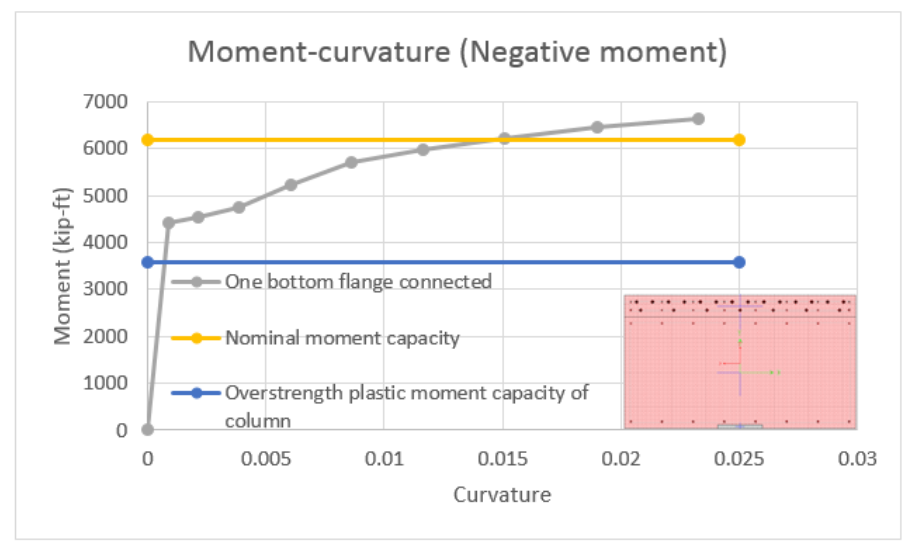

Figure 5-29 Moment-Curvature for the existing section under negative moment with one bottom flange (longitudinal dir.).

In seismic areas, to transfer the majority of demand forces to abutment it would be preferred to place two girders at the two sides of the column rather than place one girder over the column especially in the case of integral or semi-integral abutments. Figure 5-30 shows the desired location of the girders for longitudinal seismic events while the abutments are part of earthquake resistance system. 


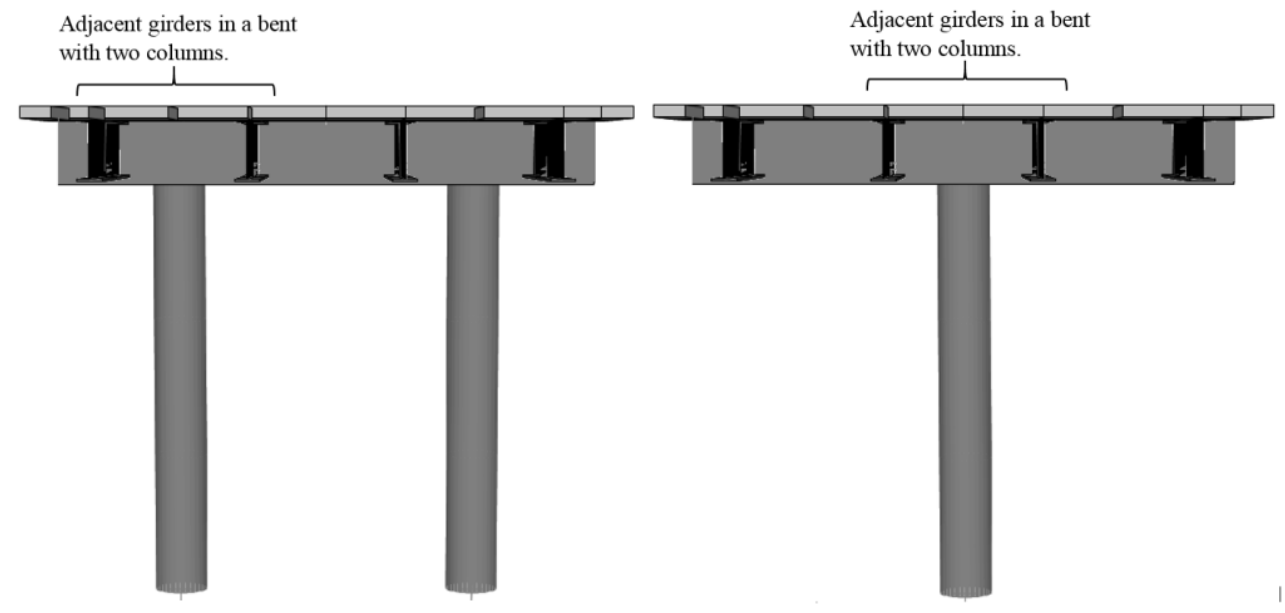

Figure 5-30 Adjusting girders inside the effective width of the bent cap, left: the bent frame with two columns, right: the bent frame with one column.

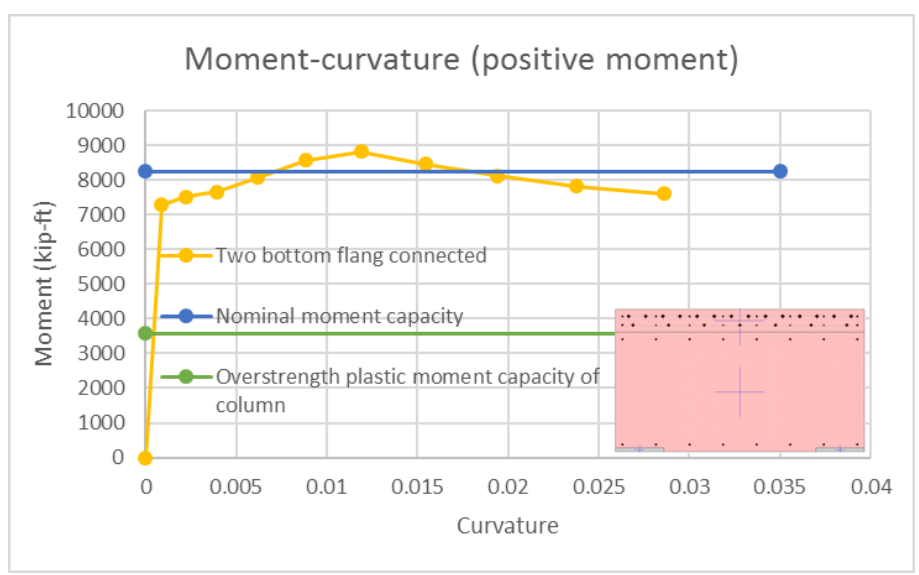

Figure 5-31 Moment-Curvature of the section under positive moment with two bottom flange (longitudinal dir.).

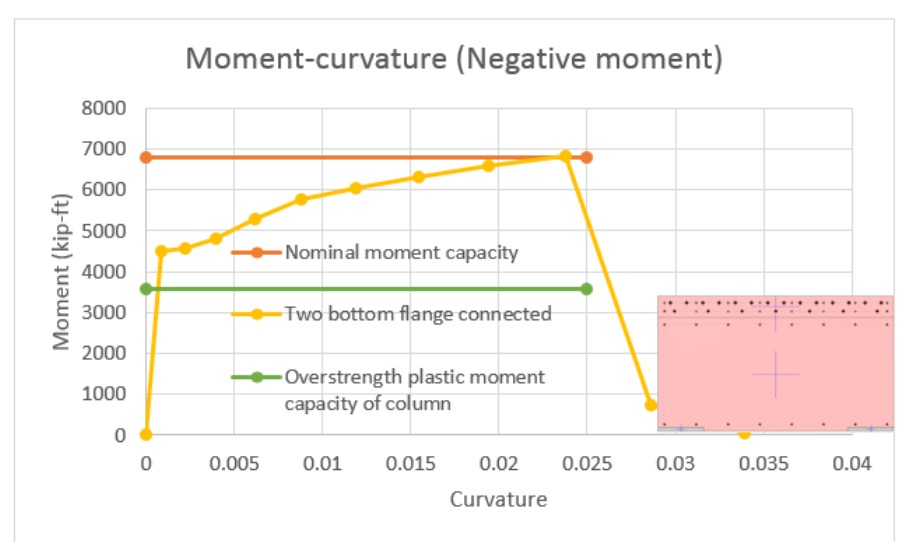

Figure 5-32 Moment-Curvature for the existing section under negative moment with two bottom flange (longitudinal dir.). 


\subsection{Nonlinear Pushover and Time History Analysis}

\subsubsection{Description of the Prototype Bridge}

In this prototype bridge model, the bent cap, girders, piers and girder's flange were modeled using frame elements. The deck and girder webs were modeled using shell elements. Link elements were used to model the connection of the deck to the bent cap and abutments. Figure 5-33 shows the analytical model of the bridge with a $95 \mathrm{ft}$ span length. As discussed in the previous sections, the piers of this bridge model are designed based on AASHTO 2012 (AASHTO, 2012).

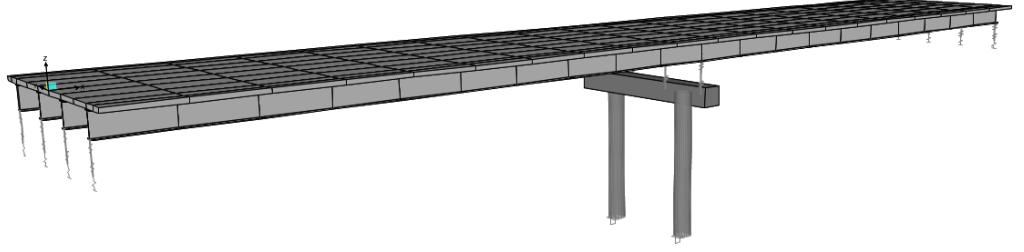

Figure 5-33 Analytical model of the bridge with two $95 \mathrm{ft}$. span length.

Under seismic loads, the bent columns participate as part of the ERS. For performing a nonlinear time history analysis, the column plastic hinges are assigned to each end of the column at distances from each end equal to 0.5 the hinge length. The plastic hinge lengths were determined according to the AASHTO Seismic Guide Specification as follows:

$\mathrm{L}_{\mathrm{P}}=0.08 \mathrm{~L}+0.15 \mathrm{f}_{\mathrm{ye}} \mathrm{d}_{\mathrm{bl}}$

Where:

$\mathrm{L}_{\mathrm{P}}=$ Plastic Hinge Length

$f_{y e}=$ the effective yield strength of the longitudinal reinforcing

$b_{\mathrm{ld}}=$ the diameter of the longitudinal reinforcing 
The controlling value of the calculated hinge length and the maximum hinge length $\left(L_{P}=0.3 f_{y e} d_{b l}\right)$ are assigned to the hinge property. Figure 5-34 shows moment rotation of the bent column with a schematic figure of the cross section.

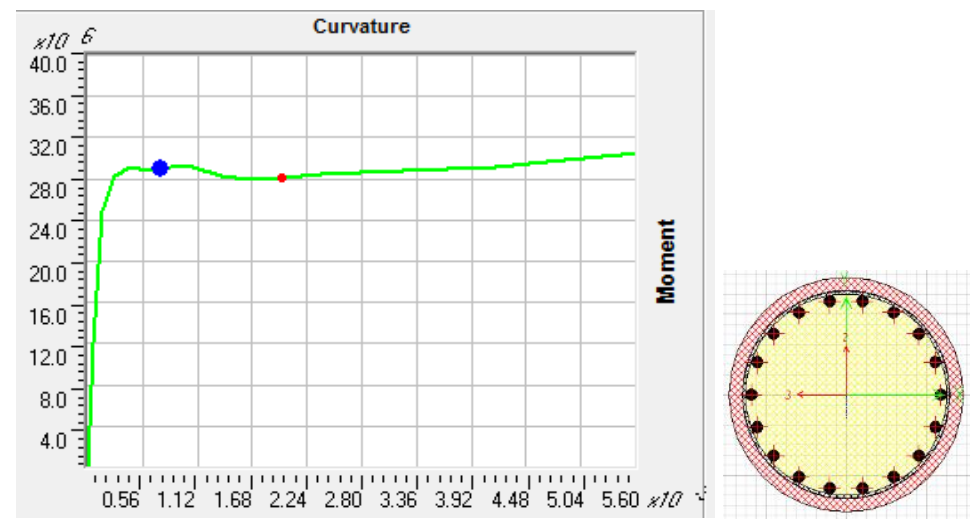

Figure 5-34 Left: Moment-Curvature diagram for bent columns, right: cross section of bent columns.

\subsubsection{Boundary Condition}

The connection between the deck and abutments were assumed to be rollers; thus, the abutments are not part of the seismic resistance system. Figure 5-35 shows the connection between the superstructure and substructure used in CSiBridge. The connection between the deck and cap beam over the pier was assumed integral. Therefore, there is continuity between the superstructure and substructure. In this example, the centroid of the bent cap was connected to the joint, which represents bearing by a link. This joint was connected to the bottom and the top of the girder by two separate links. 


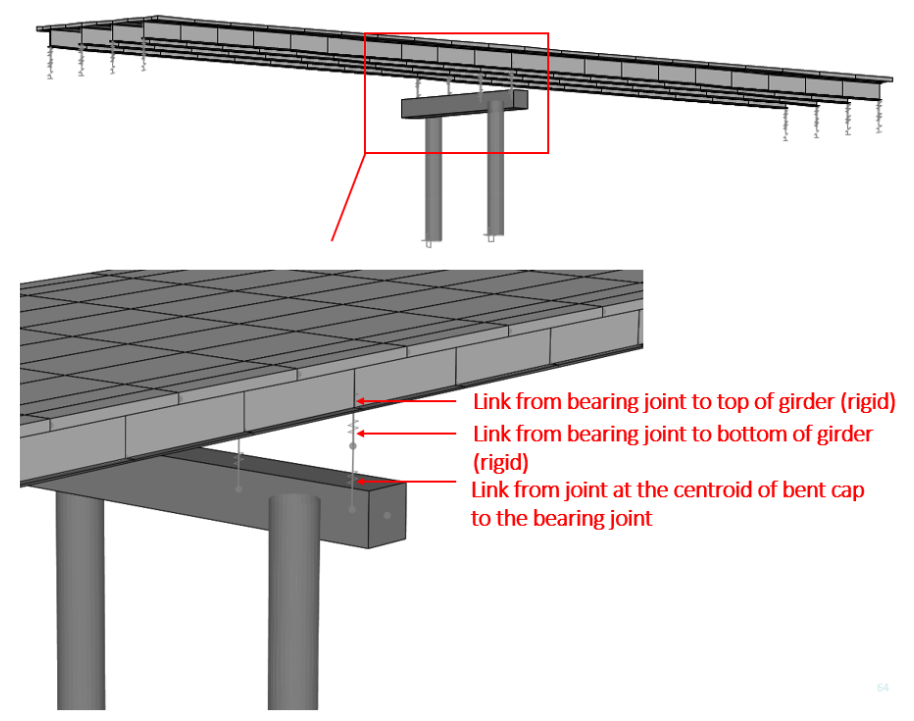

Figure 5-35 Connection between superstructure and substructure for an integral bridge system in CSiBridge.

\subsubsection{Analysis Model}

An analytical model was developed for this prototype bridge to investigate the nonlinear behavior of an integral SDCL steel bridge. CSiBridge, a user-friendly integrated 3-D bridge software was used for seismic performance evaluation. Nonlinear pushover and time history analysis was used for this purpose. To distribute the gravity loads (self-weight of the girders, superimposed dead load and moving load) before and after casting of the deck onto the girders according to the SDCL construction sequence, a nonlinear staged construction analysis was conducted before the nonlinear analysis. Figure 5-36 demonstrates the distribution of the dead load before casting the concrete and the superimposed dead and moving load after the hardening of the deck concrete. 


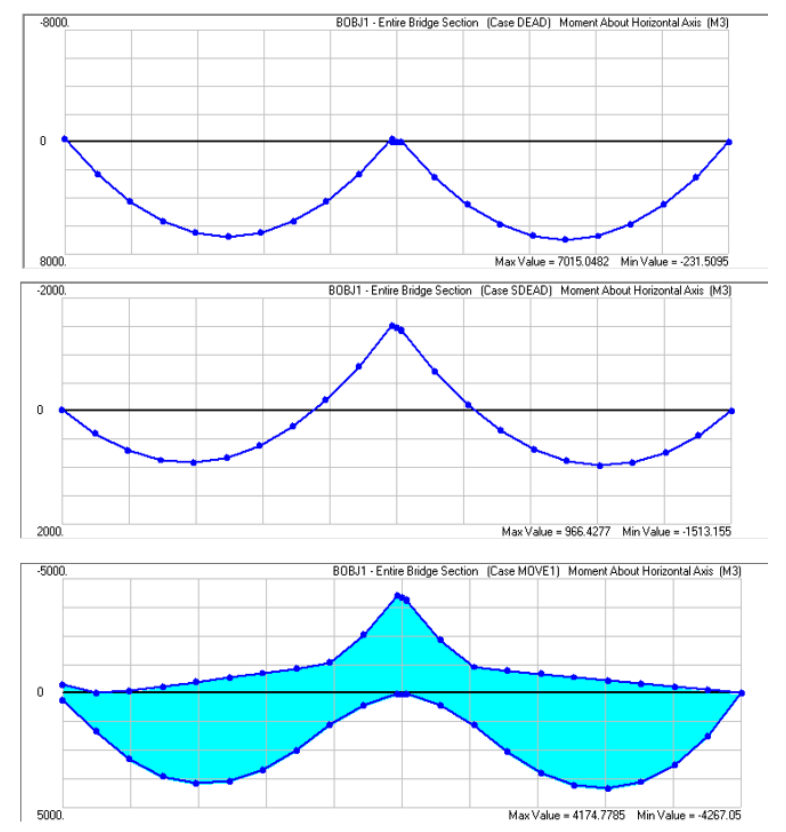

Figure 5-36 Distribution of moment under dead load (top), super dead load (middle) and moving load (bottom) after nonlinear staged construction analysis.

\subsubsection{Nonlinear Pushover Analysis}

\subsubsection{Push-Over Method}

An Inelastic Static Analysis (ISA) or push over analysis can determine the reliable displacement capacities of a structure as it reaches its limit of structural stability (CALTRANS, 2013). In a pushover analysis, a pattern of lateral forces is applied to a structural model that includes non-linear material properties to initiate the plastic action. The total force is plotted against a reference displacement to define the pushover curve. During the pushover analysis, the load patterns are incrementally increased until the potential collapse mechanism is achieved. The structure stiffness changes during the analysis due to cracking and plastic hinge formation and subsequent rotation. According to AASHTO, in (SDC) D, an inelastic static analysis, commonly referred to as pushover analysis, needs to be performed to determine the capacity displacement. In this method, the response spectrum displacements are used as the displacement demands. The capacity displacements were identified as the maximum displacement of the pushover curve just before strength loss as the capacity curves reach a negative slope. 


\subsubsection{Push-Over Analysis Results}

For the prototype bridge, a pushover analysis was performed and the capacity curve was derived for the longitudinal and transverse load patterns. Figure 5-37 and Figure 5-38 show the pushover curve in the longitudinal and transverse directions. Figure 5-39 and Figure 5-40 presents the deformation of the bridge and acceptance criteria of hinges. Figure 5-41 and Figure 5-42 shows the moment plot of the entire bridge section under the longitudinal load pattern both considering and without considering gravity loads. These outcomes indicate that while in responding to a earthquake excitation, the bottom flange might sustain tension stresses, the pushover analysis results do not show positive moment over the pier.

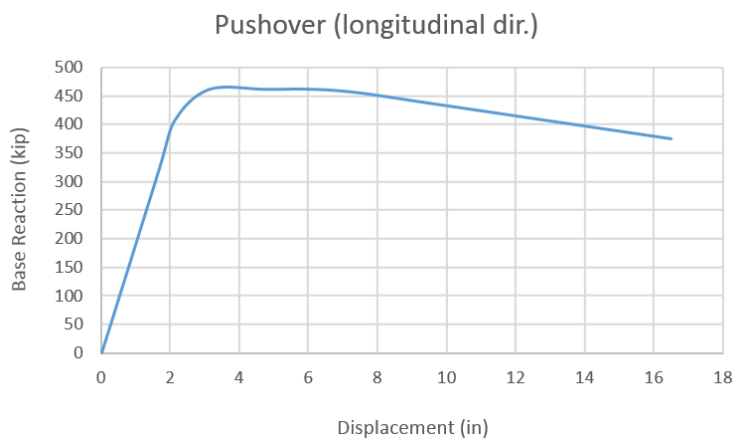

Figure 5-37 Pushover curve for the longitudinal direction of earthquake excitation.

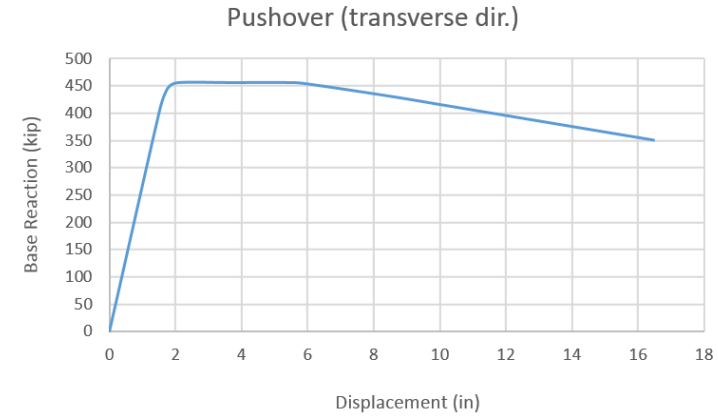

Figure 5-38 Pushover curve for the transverse direction of earthquake excitation. 


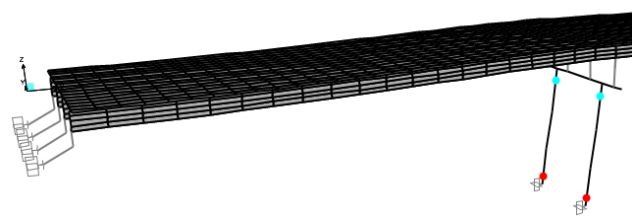

Figure 5-39 Deformation of bridge and acceptance criteria for hinges under longitudinal load pattern.

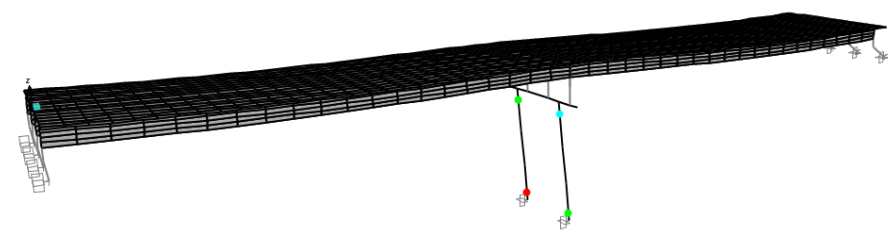

Figure 5-40 Deformation of bridge and acceptance criteria for hinges under transverse load pattern.

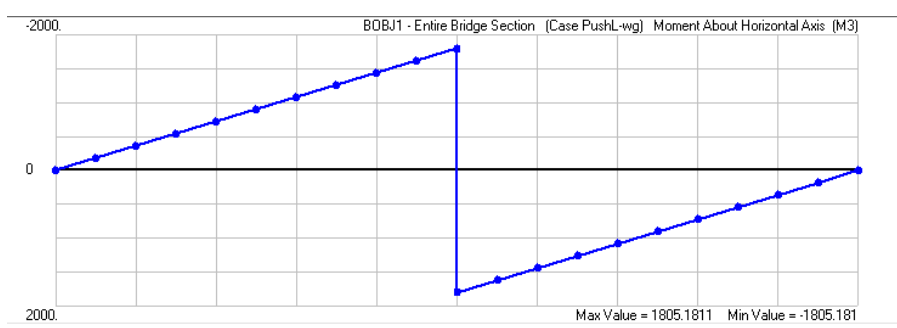

Figure 5-41 Moment plot for the entire bridge section (including 4 girders) under longitudinal load pattern without gravity loads, units (Kip,ft), (Model No. 17pushover).

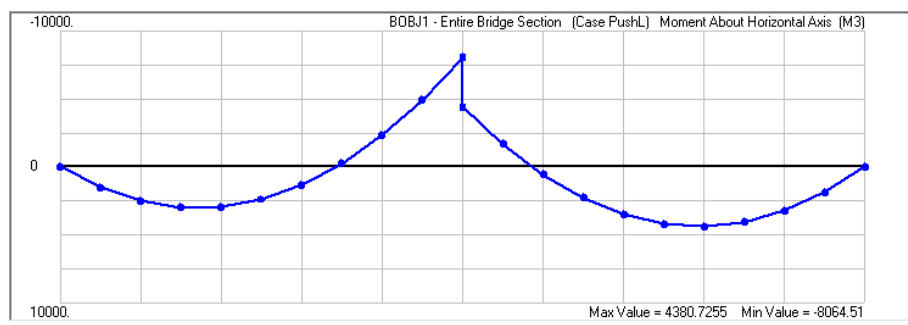

Figure 5-42 Moment plot for the entire bridge section (including 4 girders) under longitudinal load pattern including gravity loads, units (Kip,ft), (Model No. 17pushover).

\subsubsection{Nonlinear Time History Analysis}

\subsubsection{Selecting Time History Functions}

A time history analysis was performed after a nonlinear staged construction analysis. Seven time histories functions, which are representative of the seismic environment of the site and the local site conditions, were selected for this purpose. Response-spectrum-compatible time histories were used as developed from representative recorded motions. Table 5-15 and Table 5-16 show the 
selected time history acceleration from the Pacific Earthquake Engineering Research Center (PEER) (Pacific Earthquake Engineering Research Center (PEER), n.d.). Since seven responsespectrum-compatible time histories were used for each component of motion in representing the design earthquake, the design actions could be taken as the mean response calculated for each principal direction (Roy A. Imbsen, May 2007). 
Table 5-15 Characteristics of selected time history accelerations.

\begin{tabular}{|c|c|c|c|c|c|c|c|c|c|}
\hline Earthquake Name & $\begin{array}{r}\text { Scale } \\
\text { Factor }\end{array}$ & $\begin{array}{l}\text { Arias Intensity } \\
(\mathrm{m} / \mathrm{sec})\end{array}$ & Year & Station Name & Magnitude & Mechanism & $\mathrm{Rjb}(\mathrm{km})$ & Rrup (km) & $\begin{array}{c}\mathrm{V}_{\mathrm{s}} 30 \\
(\mathrm{~m} / \mathrm{sec})\end{array}$ \\
\hline "San Fernando" & 3.3358 & 0.3 & 1971 & "Palmdale Fire Station" & 6.61 & Reverse & 24.16 & 28.99 & 452.86 \\
\hline "Imperial Valley-06" & 1.9876 & 1.3 & 1979 & "Cerro Prieto" & 6.53 & strike slip & 15.19 & 15.19 & 471.53 \\
\hline "Irpinia" & 2.1188 & 0.8 & \begin{tabular}{|l|} 
Italy $-01^{\prime \prime}$ \\
\end{tabular} & 1980 & "Calitri" & 6.9 & Normal & 13.34 & 17.64 \\
\hline "Loma Prieta" & 3.6419 & 0.1 & 1989 & "Anders on Dam (L Abut)" & 6.93 & Reverse Oblique & 19.9 & 20.26 & 488.77 \\
\hline "Northridge-01" & 2.4706 & 0.5 & 1994 & "Sunland -Mt Gleason Ave" & 6.69 & Reverse & 12.38 & 13.35 & 402.16 \\
\hline "Duzce" & \begin{tabular}{|l|}
3.407 \\
\end{tabular} & 0.2 & \begin{tabular}{|l|} 
Turkey" \\
\end{tabular} & 1999 & "Lamont 1061" & 7.14 & strike slip & 11.46 & 11.46 \\
\hline "Manjil" & 0.7572 & 7.5 & Iran" & 1990 & "Abbar" & 7.37 & strike slip & 12.55 & 12.55 \\
\hline "Darfield" & 1.2595 & 4.1 & \begin{tabular}{|c|} 
New \\
Zealand" \\
\end{tabular} & 2010 & "Heathcote Valley Primary School " & 7 & strike slip & 24.36 & 24.47 \\
\hline
\end{tabular}

Table 5-16 Longitudinal, transverse and vertical components of selected earthquakes.

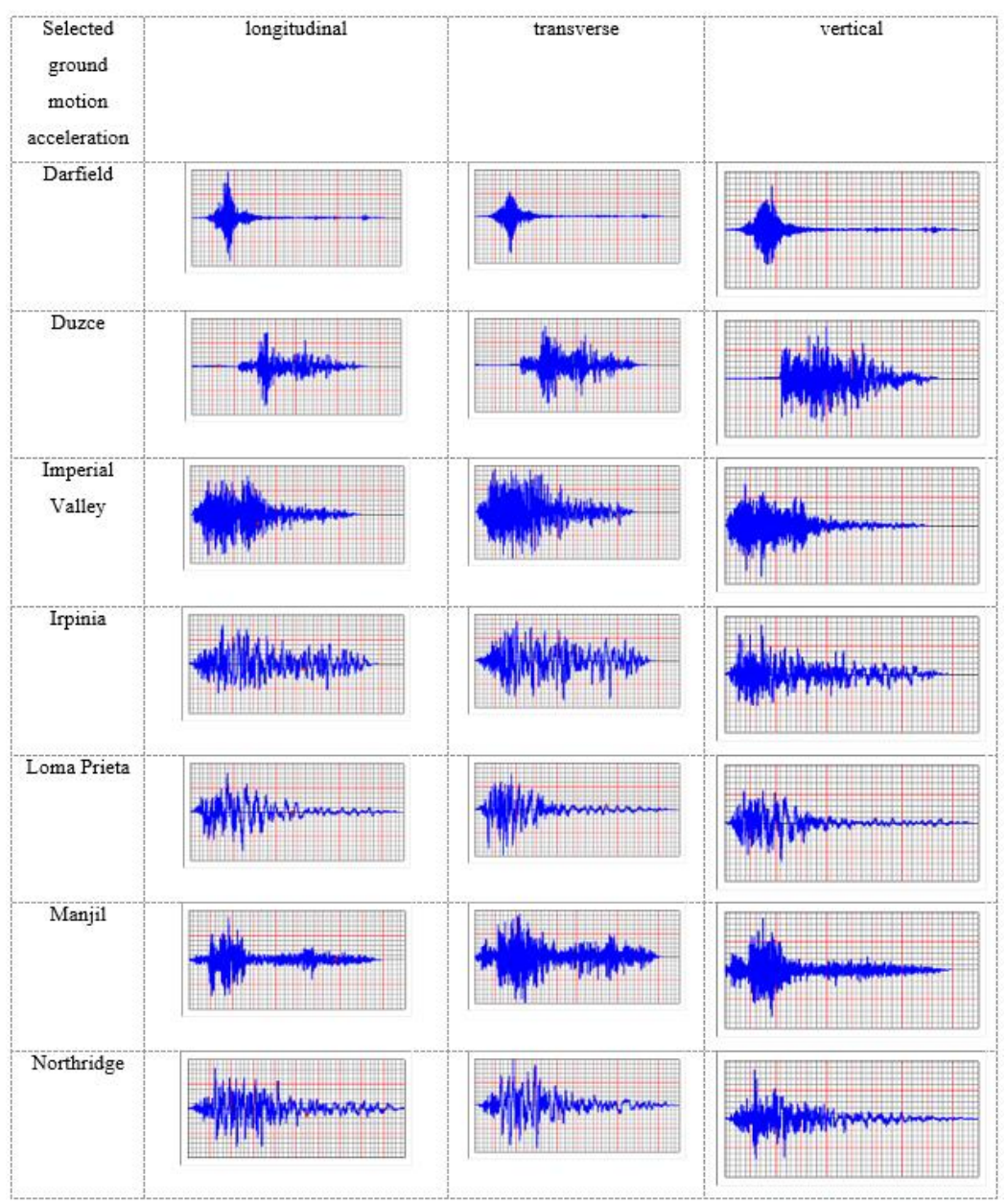

\subsubsection{Scaling Time History Functions}

The PEER Ground Motion Database (PEER Ground Motion Database, n.d.) was used as a source to select the time history accelerations. Computed weighted mean squared error of record and suite average were used for spectrum matching, which was capable of achieving seismologically realistic time series that are similar to the time series of the initial time histories 
selected for spectrum matching (Venture, 2011). The five-percent-damped-design response spectrums have been taken as specified in Figure 5-43. This spectrum was calculated using the mapped peak ground acceleration coefficients and the spectral acceleration, scaled by the zeroshort, and long-period site factors, Fpga, Fa, and Fv, respectively. This response spectrum derived from AASHTO 2012, with:

$0.2 \mathrm{sec}$ spectral acceleration, $\mathrm{Ss}=2.29$

$1 \mathrm{sec}$ spectral acceleration, $\mathrm{S} 1=0.869$

Peak ground acceleration, $\mathrm{PGA}=0.954$

Site class $=\mathrm{B}$

Therefore, calculated values for response spectrum curve are:

$\mathrm{SDS}=\mathrm{Fa} * \mathrm{Ss}=2.29$

$\mathrm{SD} 1=\mathrm{Fv} * \mathrm{~S} 1=0.869$

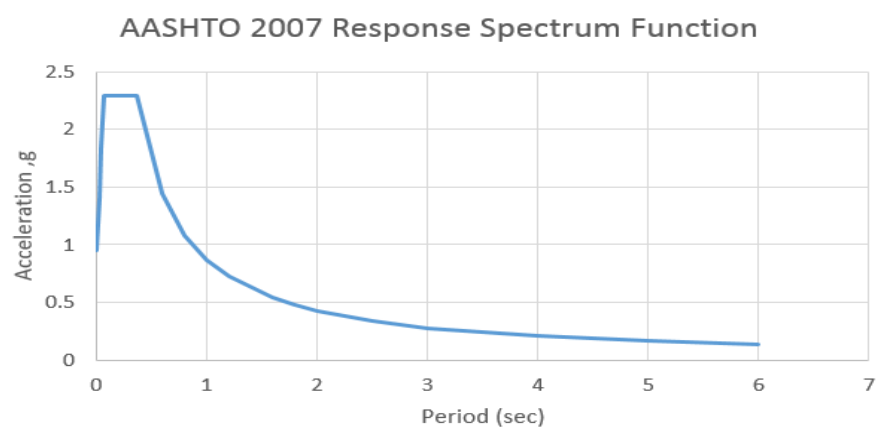

Figure 5-43 Design response spectrum. 


\subsubsection{Amount of Tensile Stresses in Bottom Flange}

The existing detail of SDCL was analyzed (Farimani M. J., 2014) and tested experimentally (Nick Lampe, 2014) for non-seismic areas. The existing detail of SDCL is used to carry gravity loads resulting in tension in the deck reinforcement and compression in the bottom flange at the centerline of pier. Maximum and minimum response values due to moving loads and seismic loads were obtained to determine the force and stress distribution along the bridge length, deck, and concrete diaphragm. An envelope of the response values due to moving and seismic loads were used in a combination with the dead and super imposed dead loads for computing the critical forces in each element. All three orthogonal components of design ground motion should be considered simultaneously when conducting a nonlinear time-history analysis (Roy A. Imbsen, May 2007) . The nonlinear time history analysis was conducted after applying the dead load and superimposed dead loads. The results indicated that there is a high probability that the bottom flange over the interior support will experience tension forces due to a seismic event. Therefore, a modified detail of SDCL should be provided for transferring tension forces from the bottom flange of one girder to the next girder under earthquake loads.

To find the demand in the bottom flange of the girders, the amount of tensile stresses was extracted from the bottom flange results, in CSiBridge. Due to the composite action between the steel section and presence of the concrete slab, the tension stresses cannot be simply calculated by dividing the moment by the height of the section. The value of stresses in bottom flange was obtained directly from the software. Figure 5-44 shows the level of tensile stress in the bottom flange of the girders. In order to evaluate the tension force independent from the section dimension, the value of the stresses was determined. Figure 5-45 shows the level of tensile stresses compared with yielding stress (A992 Gr. 50) in the bottom flange. 


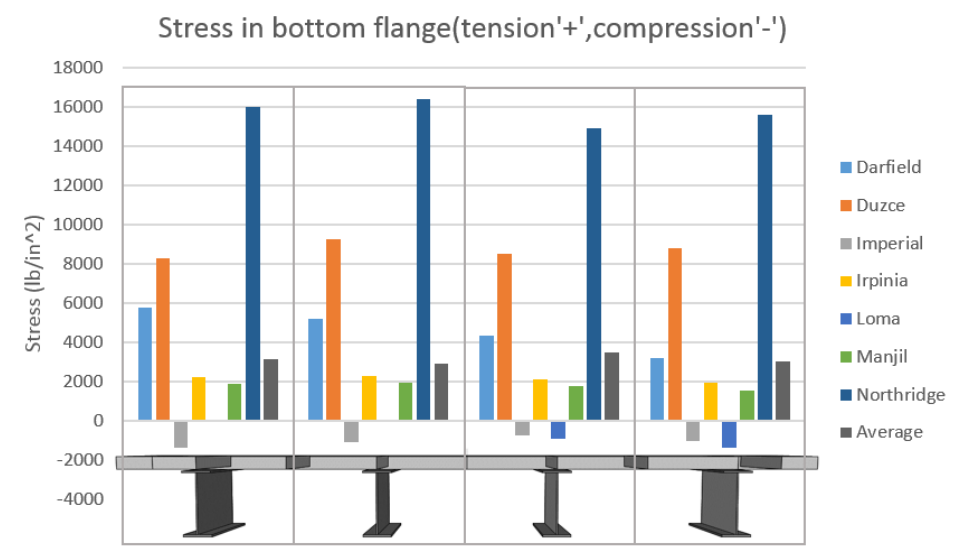

Figure 5-44 Amount of the tension stresses in bottom flange.

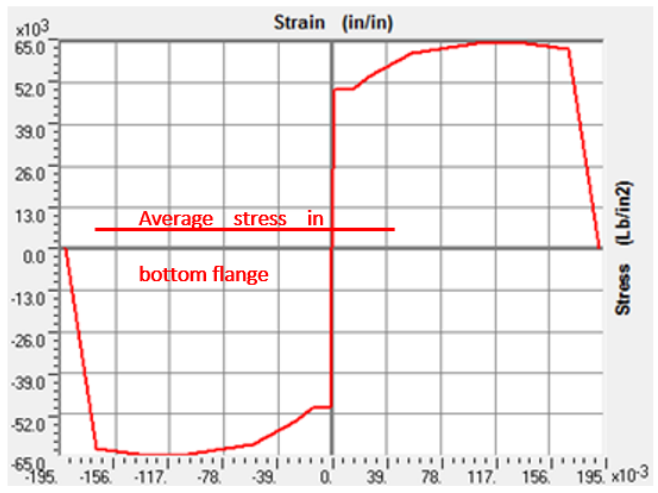

Figure 5-45 Stress-Strain curve for the A992Fy50 steel material. 


\section{INITIAL SDCL CONNECTION (BOLTED)}

\subsection{Introduction}

Based on the performance of the existing SDCL connection and preliminarily investigation of earthquake loads on the connection, a new detail is presented in this chapter. Before investigating the performance of the connection, possible failure modes of the system were predicted. In the next chapter, the proposed connection was modeled in the finite element software ANSYS, to study the behavior of the system with more details.

\subsection{Proposed Connection for Seismic areas}

A new connection was proposed for seismic areas that consists of the existing SDCL detail with the addition of four bolts at the top and four bolts at the bottom, in the vicinity of the girder flanges. This detail is able to provide live load continuity over the pier for the system. However, the newly proposed detail provides some continuity under self-weight after placing the girders over the bent cap and tightening the bolts. At the end of the construction process, the bolts and concrete diaphragm connect the two girders to each other and produce continuity. Figure 6-1 shows the connection detail for seismic areas. The components of the connection detail include the following:

- concrete diaphragm, which should be cast at least a few days prior to casting the deck,

- steel slab reinforcement to provide live load continuity (this reinforcement is placed before casting the deck),

- end plates with four holes welded to the ends of each girder and bolts and nuts to connect the top and bottom of the end plate to each other,

- $\quad$ steel blocks welded to the bottom of each end plate,

- $\quad$ elastomeric pads where the steel girders sit. 
Adequate reinforcement must also be placed to connect the cap beam to the concrete diaphragm in order to prevent movement and rotation between superstructure and substructure.
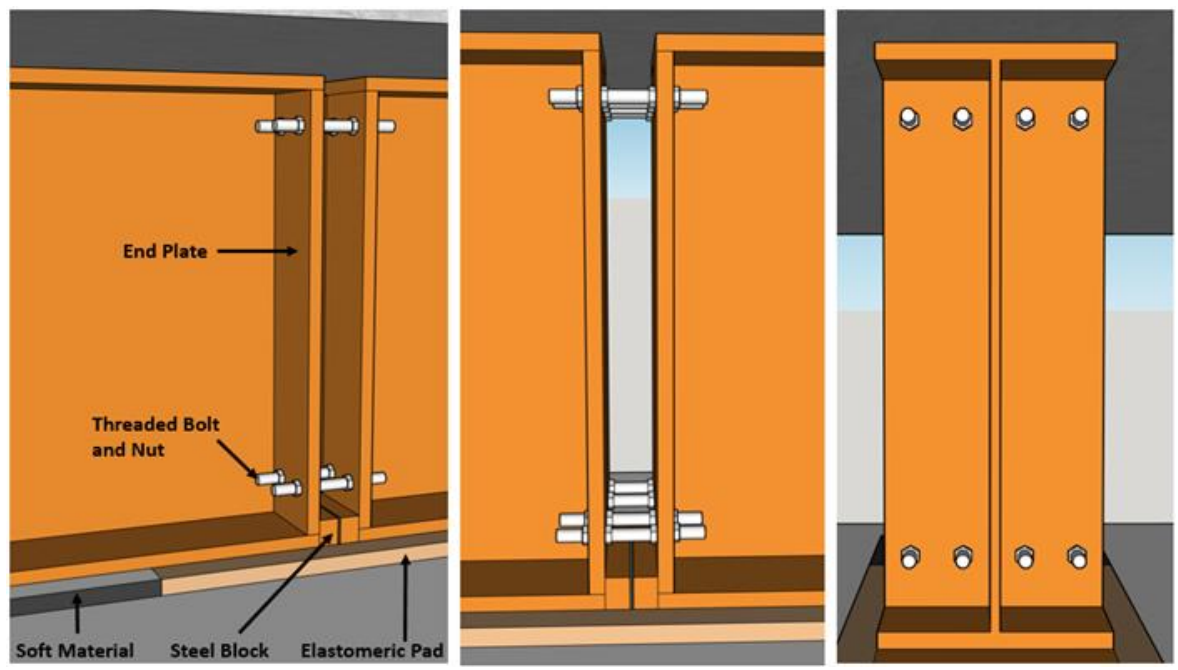

Figure 6-1 Proposed detail connection for the seismic region.

The construction process is similar to the existing detail of SDCL. The only difference is that after placing the girders over the bent cap, the bolts should be inserted into the end plates and the nuts tightened. There is no field welding in the proposed connection. The existing detail of SDCL was tested for non-integral bridge systems and the connection between the bent cap and concrete diaphragm was not rigid. Therefore, a sufficient amount of vertical reinforcement (dowel bars) should be placed between the interface of concrete diaphragm and bent cap to provide enough strength for tension stresses at the interface of concrete diaphragm and bent cap. The load transfer mechanism of the proposed connection is easy to understand. From a service life point of view, the connection is embedded in the concrete diaphragm and no rust will occur.

\subsection{Possible Failure Modes for the Proposed Connection}

Even though finite element analysis is an extremely versatile and powerful method to study the behavior of complicated structure, the output results must be carefully examined and compared 
with experimental test data. For this reason, before performing a detailed finite-element analysis, the possible failure modes of the system were considered.

Under push-down (gravity type) forces, the finite-element and experimental test results for the existing detail of SDCL in non-integral bridges are available. In the proposed detail, tension forces carry through longitudinal bars in the slab and top bolts while compression forces carry through steel blocks and bottom bolts. Since the top bolts help the slab bars and bottom bolts help the steel block, the proposed detail should be able to provide more capacity for the system.

Under push-up (vertical acceleration/uplift) forces, the bottom flange needs to be continuous to provide tension equilibrium forces against compression forces from the concrete and reinforcement of the deck. In the new proposed detail, the tension forces should be transferred through the bottom bolts and bottom flanges.

The final loading to consider results in upward forces applied on one side of the pier and downward force on the other (inverse loading). This loading can arise because of longitudinal forces. When the model is subjected to inverse loading, the direction of forces from one side to other side is parallel in the top and bottom of the connection and understanding the load transfer mechanism is complicated. Consequently, a comprehensive finite-element analysis should be conducted to investigate the nonlinear behavior and failure modes of the system. 


\section{FINITE ELEMENT MODEL DEVELOPMENT}

\subsection{Introduction}

To address the load resistance mechanism of a connection, the capacity of various modes of failure must be evaluated. In this chapter, a revised version of SDCL detail is presented. A threedimensional model was constructed to understand the nonlinear behavior of the proposed detail at the maximum load level. The finite-element model was constructed in ANSYS mechanical APDL 16 (ANSYS, 2014). The geometry and the material properties of the model were derived from the specimen that was tested at the University of Nebraska-Lincoln.

The existing SDCL connection was modeled and nonlinear finite element analyses conducted simulating the physical testing. The Moment-Drift plots from the finite-element analyses were compared with the corresponding plots from the experimental test to verify the accuracy of the model.

The proposed SDCL detail for seismic areas and was then loaded under push-up, pushdown and inverse scenarios. Finally, the force transfer mechanism for each load scenario was identified and evaluated.

\subsection{Geometry of the Model}

In order to perform a nonlinear finite-element analysis for the existing and new proposed connection, dimensions and properties of materials were obtained from Mohammadeza Mahboob Farimani Ph.D. dissertation (Farimani M. M., 2006) and Nick Lampe's Master thesis (Lampe N. J., December, 2001). The specimen tested at the UNL structures lab was designed according to the AASHTO-LRFD provision and practical considerations. The design of this test specimen was based on a two span continuous I-girder bridge (Military Road Bridge, Nebraska). This bridge has two 95-ft spans with four girder lines. The middle portion of this bridge was constructed in the lab 
as two cantilever beams to simulate the real load condition. This system allowed the behavior of the bridge over the pier to be modeled without constructing the whole bridge. Figure 7-1 shows the different parts of the experimental specimen including the slab, diaphragm, and steel girders. The dimensions of the specimen are shown in Figure 7-2, Figure 7-3 and Figure 7-4. These figures show the dimensions of different elements and the locations of reinforcing bars in the system. The concrete diaphragm detail was similar to the Nebraska Department of Road (NDoR) for the prestress concrete diaphragm.

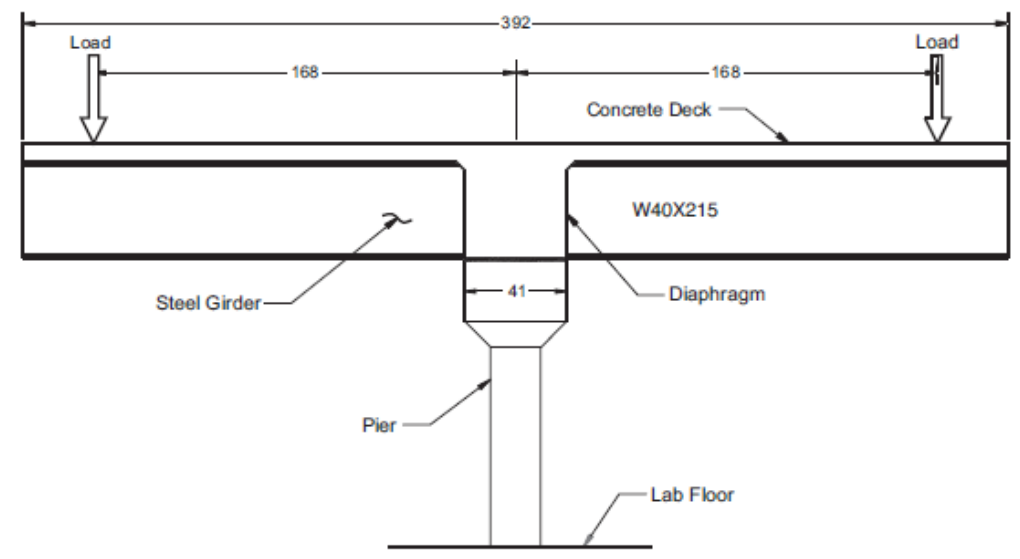

Figure 7-1 Different parts of the test specimen.

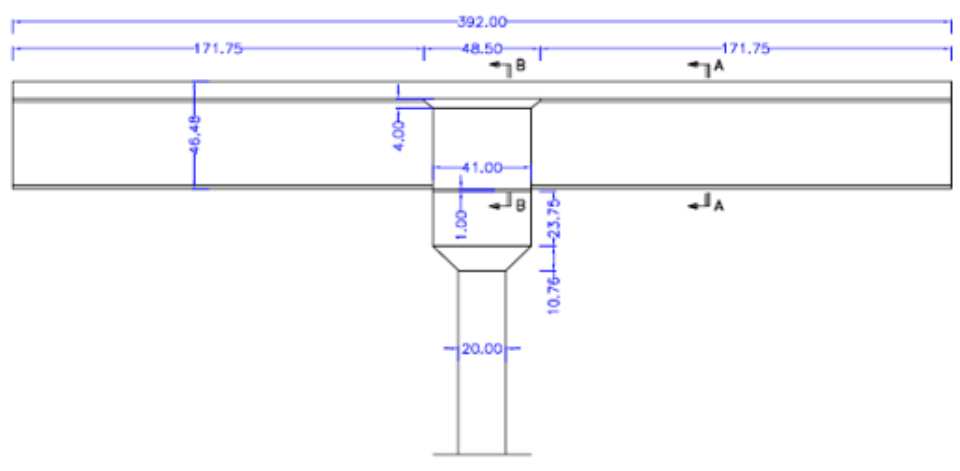

Longitudinal View

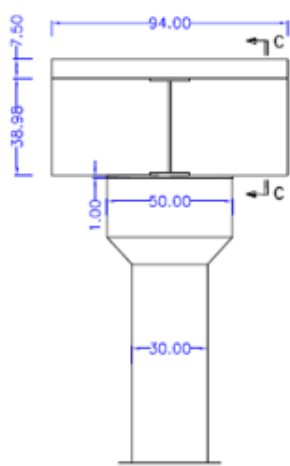

Side View

Figure 7-2 Left: specimen's longitudinal view, right: specimen's side view (dimensions in inches). 


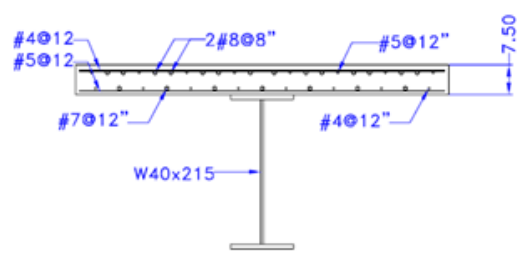

SEC. $A-A$

Figure 7-3 Deck details.

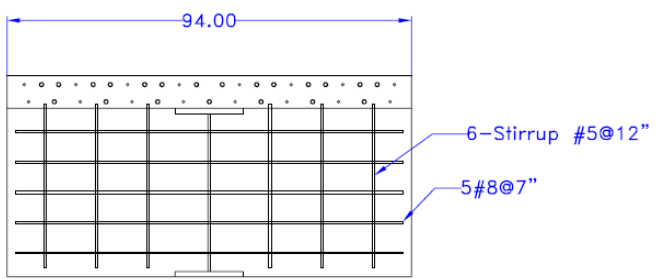

SEC. $B-B$

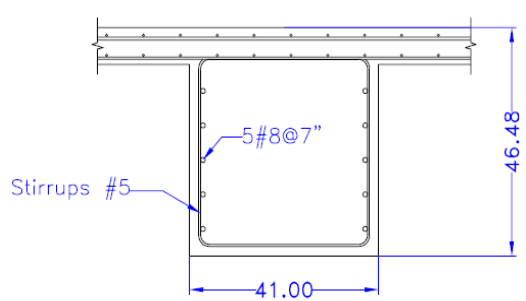

SEC. $\mathrm{C}-\mathrm{C}$

Figure 7-4 Concrete diaphragm detail.

Figure 7-5 shows different views of the deck finite-element model. Two layers of reinforcement were used in the longitudinal and transverse direction. In the numerical model, the longitudinal, transverse and added bars over the concrete diaphragm were modeled separately similar to the layout of reinforcement in the test specimen. Transverse reinforcement was modeled as well as closed hoops inside of the concrete diaphragm. Locations and areas of each bar was modeled exactly the same as in the test specimen. The width of the concrete deck was equal to 93 inches and the thickness was equal to 7.5 inches without a haunch. Bars in the concrete deck were designed based on empirical deck design and consisted of \#4 bars at 12-inches, in the top layer and \#5 bars at 12-inches, in the bottom layer. Transverse reinforcement was \#5 bars at 12-inches in the bottom layer and \#4 bars at 12-inches in the top layer. The additional upper layer longitudinal reinforcement was two \#8 bars centered between adjacent \#4 bars. Similarly, one \#7 bar is centered between the adjacent \#5 bars, in the bottom longitudinal layer. Figure 7-6 presents the finiteelement model of the longitudinal and transverse bars, added longitudinal bars and closed hooks. Figure 7-7 shows the layout of bars from different views. 


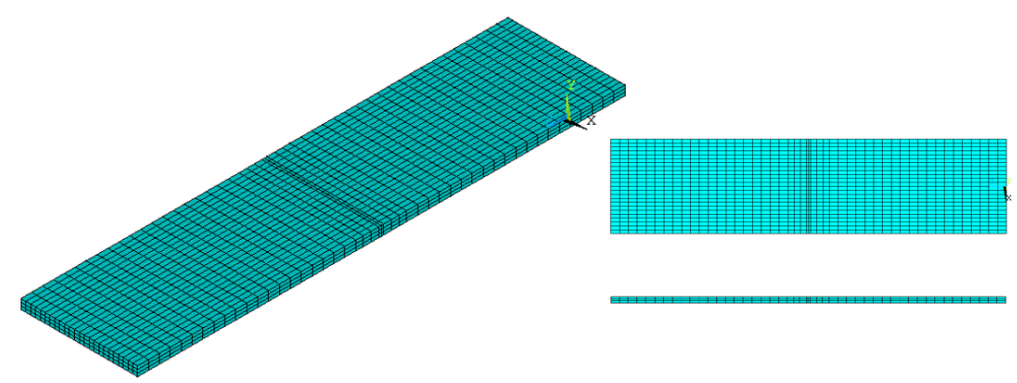

Figure 7-5 Isometric 3-D view and side views of concrete deck model.

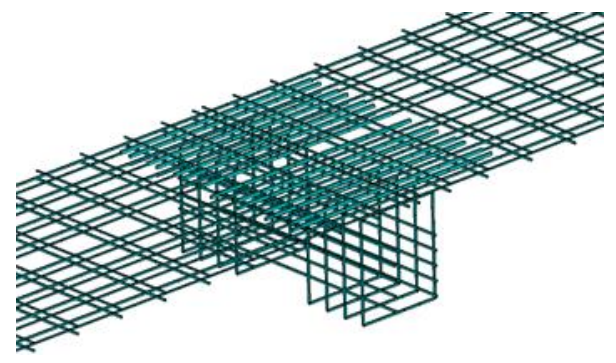

Figure 7-6 Finite-element model of bars in the deck and concrete diaphragm.

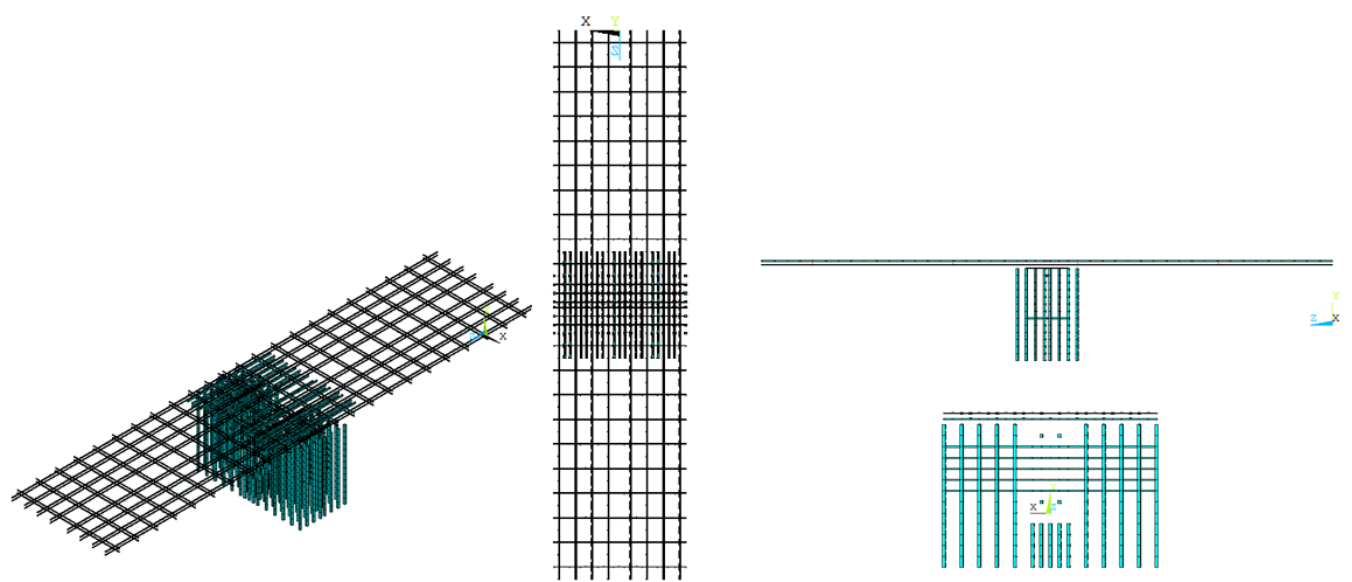

Figure 7-7 Isometric 3-D view and side views of rebar model.

The length of the cantilever deck was $12 \mathrm{ft}$ each direction. A bearing plate was welded to the end of the girders. The steel I-girder beam was a rolled W40X215. The finite-element model of the steel I girder and bearing plates is shown in Figure 7-8 and Figure 7-9 from different views. The column and bent cap were modeled in finite-element as well. Dimensions and material properties were assumed similar to the experimental specimen. A 3D view of the columns is shown in Figure 7-10. For the column and bent cap, smeared concrete was assigned to the elements and reinforcement was not modeled separately. The full finite-element model is shown in Figure 7-11. 


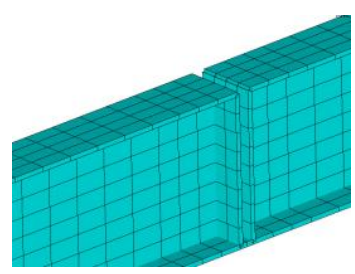

Figure 7-8 Finite-element model of I steel girder and bearing plates.

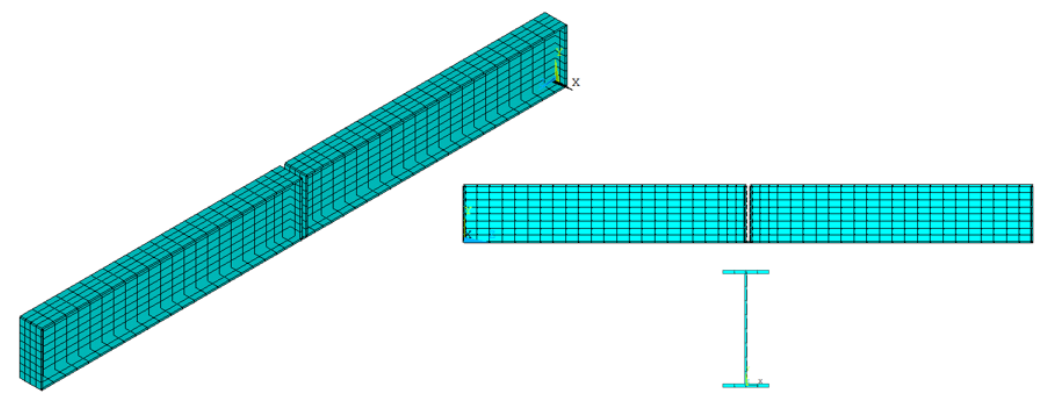

Figure 7-9 Isometric 3-D view and side views of steel girder model.

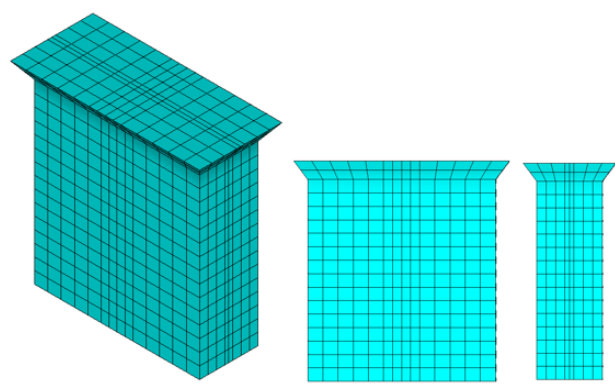

Figure 7-10 Isometric 3-D view and side views of column model.

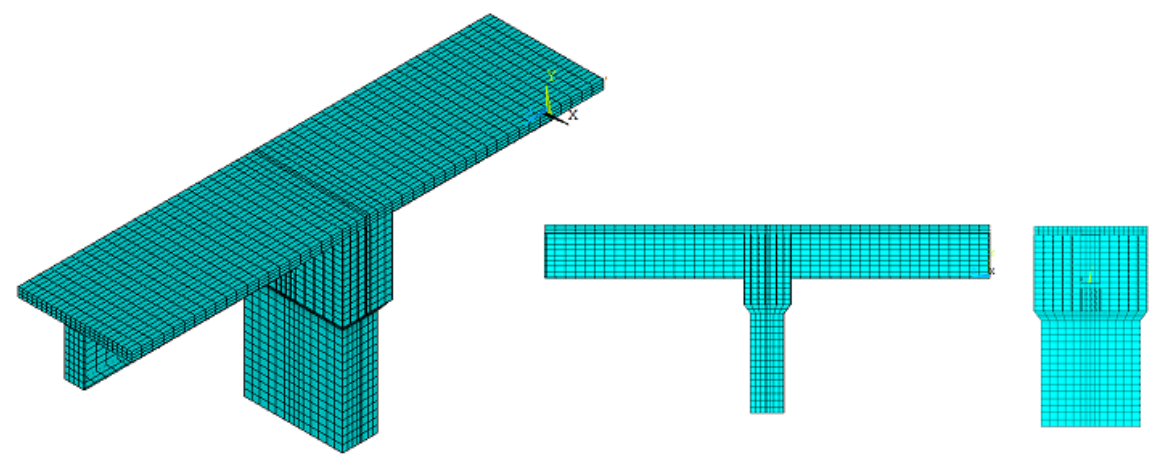

Figure 7-11 Isometric 3-D view and side views of the full model.

In the current research being presented, the Type 1 detail was considered for further study. In this detail, two end-bearing plates were welded to the end of girders. Additional stiffeners on the end bearing plates were not included. For numerical stability, a small-volume ratio (0.002) of 
smeared reinforcement was included in the concrete model. It was previously found that shear studs had an insignificant effect on the load transfer mechanism, so they were not considered in the finiteelement modeled (Farimani M. M., 2006). Although some loading patterns would allow the use of symmetry to reduce the model size, the full model was retained for all loading conditions.

\subsection{Finite-Element Analysis Using ANSYS}

\subsubsection{Material Property}

In this section, details of the material properties used in the finite-element model are presented. It should be pointed out here that the nonlinear behavior of the system comes primarily from material nonlinearity.

\subsubsection{Steel Material Property}

A multi-linear isotropic hardening material model was used for simulating the stress-strain curves of steel. This plasticity material model is often used in large strain analysis and should not be used for cyclic or highly non-proportional load histories in small-strain analyses. During plastic deformation, isotropic hardening causes a uniform increase in the size of the yield surface and results in an increase in the yield stress. Hardening models assume a von-Mises yield criterion, unless an anisotropic Hill yield criterion is defined. The von-Mises yield criterion is commonly used in plasticity models for a wide range of materials. It is a good first approximation for metals materials. The engineering stress-strain curves for the steel I-girder was obtained from the UNL experimental test (Farimani M. M., 2006) and converted to true stress-strain curve for use in the finite-element model. For the steel I-girder material property, the modules of elasticity, Possion's ratio and yield stress is assumed to be $29000 \mathrm{ksi}, 0.3$ and $54 \mathrm{ksi}$ respectively. The yield stress and tangent modulus of the bearing plate and stiffeners was assumed similar to the I-beam section. The material properties of the concrete reinforcement in the deck were obtained from tensile tests 
carried out at UNL (Farimani M. M., 2006). Average results from these tests were used for the yield stress and ultimate stress. For the reinforcement's material property, the modules of elasticity, possion's ratio and yield stress were assumed to be $29000 \mathrm{ksi}, 0.3$ and $69 \mathrm{ksi}$ respectively. Figure 7-12 shows the stress-strain curve of steel girder and reinforcement.
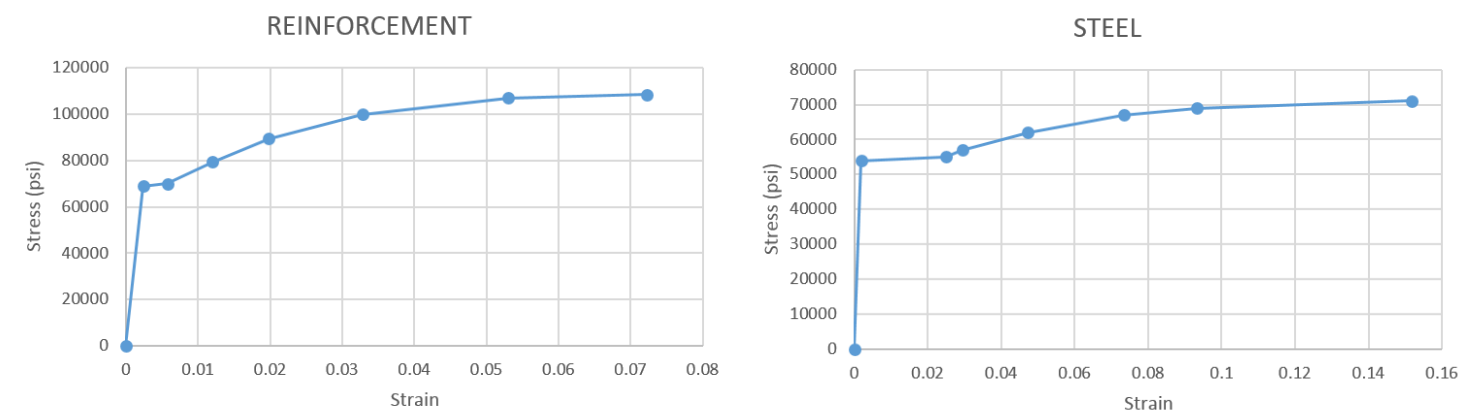

Figure 7-12 left: stress-strain curve for reinforcement steel, right: stress-strain curve for plates in the models.

\subsubsection{Concrete Material Property}

The concrete material model predicts the failure of brittle materials. Both cracking and crushing failure modes are accounted for. The criterion for failure of concrete due to a multiaxial stress state can be expressed in the form:

$\frac{F}{f_{c}}-S \geq 0$

Where:

$\mathrm{F}=\mathrm{a}$ function of the principal stress state $\left(\sigma_{\mathrm{xp}}, \sigma_{\mathrm{yp}}, \sigma_{\mathrm{zp}}\right)$

$S=$ failure surface expressed in terms of principal stresses and five input parameters $f_{t}, f_{c}, f_{c b}$, $\mathrm{f}_{1}$ and $\mathrm{f}_{2}$ 
$\mathrm{f}_{\mathrm{c}}=$ uniaxial crushing strength

$\sigma_{\mathrm{xp}}, \sigma_{\mathrm{yp}}, \sigma_{\mathrm{zp}}=$ principal stresses in principal directions

If $\frac{F}{f_{c}}-S \geq 0$ is satisfied, the material will crack or crush.

Five input parameters are needed to define the failure surface, as well as an ambient hydrostatic stress state. These parameters are defined in Table 7-1.

Table 7-1 Concrete material table.

\begin{tabular}{|c|c|c|}
\hline \multicolumn{3}{|c|}{ (Input on TBDATA Commands with TB,CONCR) } \\
\hline Label & Description & Constant \\
\hline $\mathrm{f}_{\mathrm{t}}$ & Ultimate uniaxial tensile strength & 3 \\
\hline $\mathrm{f}_{\mathrm{c}}$ & Ultimate uniaxial compressive strength & 4 \\
\hline $\mathrm{f}_{\mathrm{cb}}$ & Ultimate biaxial compressive strength & 5 \\
\hline & Ambient hydrostatic stress state & 6 \\
\hline $\mathrm{f}_{1}$ & $\begin{array}{c}\text { Ultimate compressive strength for a state of biaxial compression } \\
\text { superimposed on hydrostatic stress state }\end{array}$ & 7 \\
\hline $\mathrm{f}_{2}$ & $\begin{array}{c}\text { Ultimate compressive strength for a state of uniaxial compression } \\
\text { superimposed on hydrostatic stress state }\end{array}$ & 8 \\
\hline
\end{tabular}

However, the failure surface can be specified with a minimum of two constants, $\mathrm{ft}$ and fc. The remaining three constants can be approximated and result in the following (Willam and Warnke):

$f_{c b}=1.2 f_{c}$

$f_{1}=1.45 f_{c}$

$f_{2}=1.725 f_{c}$

However, these default values are valid only for stress states where the following condition is satisfied:

$\left|\sigma_{h}\right| \leq \sqrt{3} f_{c}$ 
$\left(\sigma_{h}=\right.$ hydrostatic stress state $\left.=\frac{1}{3}\left(\sigma_{x p}+\sigma_{y p}+\sigma_{z p}\right)\right)$

Thus, the above formula applies to stress situations with a low hydrostatic stress component. All five failure parameters should be specified when a large hydrostatic stress component is expected. If the condition above is not satisfied and the default values shown in Fcb, $f 1, f 2$ are assumed, the strength of the concrete material may be incorrectly evaluated.

When the crushing capability is suppressed with $\mathrm{f}_{\mathrm{c}}=-1.0$, the material cracks whenever a principal stress component exceeds $\mathrm{f}_{\mathrm{t}}$. Both the function $\mathrm{F}$ and the failure surface $\mathrm{S}$ are expressed in terms of principal stresses denoted as $\sigma_{1}, \sigma_{2}$, and $\sigma_{3}$ where:

$\sigma_{1}=\max \left(\sigma_{x p}, \sigma_{y p}, \sigma_{z p}\right)$

$\sigma_{3}=\min \left(\sigma_{x p}, \sigma_{y p}, \sigma_{z p}\right)$

And $\sigma 1 \geq \sigma 2 \geq \sigma 3$. The failure of concrete is categorized into four domains:

$0 \geq \sigma 1 \geq \sigma 2 \geq \sigma 3$ (compression - compression - compression)

$\sigma 1 \geq 0 \geq \sigma 2 \geq \sigma 3$ (tensile - compression - compression)

$\sigma 1 \geq \sigma 2 \geq 0 \geq \sigma 3$ (tensile - tensile - compression)

$\sigma 1 \geq \sigma 2 \geq \sigma 3 \geq 0$ (tensile - tensile - tensile)

In each domain, independent functions describe $\mathrm{F}$ and the failure surface $\mathrm{S}$. The four functions describing the general function F are denoted as F1, F2, F3, and F4 while the functions describing $\mathrm{S}$ are denoted as $\mathrm{S} 1, \mathrm{~S} 2, \mathrm{~S} 3$, and $\mathrm{S} 4$. The functions $\mathrm{Si}(\mathrm{i}=1,4)$ have the properties that 
the surface they describe is continuous while the surface gradients are not continuous when any one of the principal stresses changes sign (ANSYS, 2014).

Material properties for concrete were assumed similar to the test specimen in the Nebraska. During that testing, several 6-in diameter by 12-in long cylinder samples were taken during the casting of both the diaphragm and the deck (Nick Lampe, 2014).

\subsubsection{Cracking and Crushing Indications}

ANSYS, the finite-element analysis software used in this study, has the capability to predict and display cracking and crushing in the reinforced concrete members due to loading. The concrete element, Solid65, has eight integration nodes (three degrees of freedom at each node). Cracking and crushing can be drawn at the integration points or the average value can be drawn at the element centroid. Cracking is shown with a circle outline in the plane of the crack and crushing is shown with an octahedron outline. If the crack has opened and then closed, the circle outline will have an $\mathrm{X}$ through it. Each integration point can crack in up to three different planes perpendicular to the principal axes. The first crack at an integration point is shown with a red circle outline, the second crack with a green outline, and the third crack with a blue outline.

A circle is displayed at locations of cracking or crushing in concrete elements. Symbols shown at the element centroid are based upon the status of all the element's integration points. If any integration point in the element has been crushed, the crushed (octahedron) symbol is shown at the centroid. If any integration point has cracked or cracked and closed, the cracked symbol is shown at the element centroid. If at least five integration points have cracked and closed, the cracked and closed symbol is shown at the element centroid. Finally, if more than one integration point has cracked, the circle outline at the element centroid shows the average orientation of all cracked planes for that element. 


\subsubsection{Equivalent (Von-Mises) Stress}

Equivalent stress is related to the principal stresses by the equation:

$\sigma_{e}=\left[\frac{\left(\sigma_{1-} \sigma_{2}\right)^{2}+\left(\sigma_{2-} \sigma_{3}\right)^{2}+\left(\sigma_{3-} \sigma_{1}\right)^{2}}{2}\right]^{\frac{1}{2}}$

Equivalent stress (also called von-Mises stress) is often used in design work because it allows any arbitrary three-dimensional stress state to be represented as a single positive stress value. Equivalent stress is part of the maximum equivalent stress failure theory used to predict yielding in a ductile material. The von-Mises or equivalent strain $\varepsilon e$ is computed as:

$\varepsilon_{e}=\frac{1}{1+\vartheta^{\prime}}\left(\frac{1}{2}\left[\left(\varepsilon_{1}-\varepsilon_{2}\right)^{2}+\left(\varepsilon_{2}-\varepsilon_{3}\right)^{2}+\left(\varepsilon_{3}-\varepsilon_{1}\right)^{2}\right]\right)^{\frac{1}{2}}$

Where:

$v^{\prime}=$ effective Poisson's ratio, which is defined as follows:

Material Poisson's ratio for elastic and thermal strains computed at the reference temperature of the body.

\subsubsection{Element Description}

\subsubsection{SOLID65 Element}

SOLID65 is used for 3-D modeling of solids with or without reinforcing bars (rebar). The solid is capable of cracking in tension and crushing in compression. In concrete applications, for example, the solid capability of the element may be used to model the concrete while the rebar capability is available for modeling reinforcement behavior. The element is defined by eight nodes 
having three degrees of freedom at each node: translations in the nodal $\mathrm{x}, \mathrm{y}$, and $\mathrm{z}$-directions. Up to three different rebar specifications may be defined.

The concrete element is similar to a 3-D structural solid but with the addition of special cracking and crushing capabilities. The most important aspect of this element is the treatment of nonlinear material properties. The concrete is capable of cracking (in three orthogonal directions), crushing, plastic deformation, and creep. The rebar is capable of tension and compression, but not shear. They are also capable of plastic deformation and creep. Figure 7-13 shows the geometry, node locations, and the coordinate system for SOLID65 element.

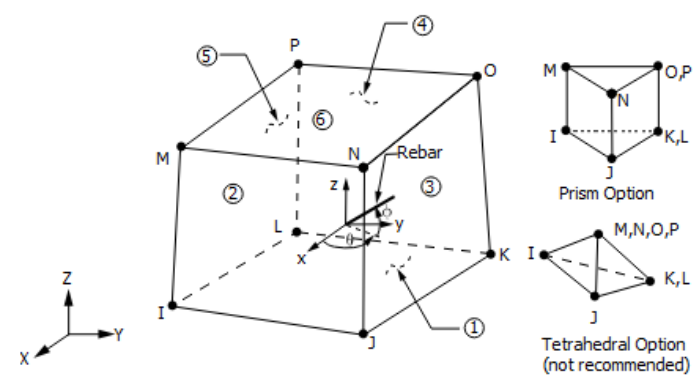

Figure 7-13 SOLID65 geometry.

SOLID65 is defined by the isotropic material properties and eight nodes. This element includes one solid material and up to three rebar materials. The volume ratio of rebar is defined as the rebar volume divided by the element volume. The orientation is defined by two angles (in degrees) with respect to the element coordinate system. Concrete material data, such as the shear transfer coefficients, tensile stresses, and compressive stresses are according to Table 7-2. 
Table 7-2 SOLID65 concrete material data.

\begin{tabular}{|c|c|}
\hline Constant & Meaning \\
\hline 1 & Shear transfer coefficients for an open crack. \\
\hline 2 & Shear transfer coefficients for a closed crack. \\
\hline 3 & Uniaxial tensile cracking stress. \\
\hline 4 & Uniaxial crushing stress (positive). \\
\hline 5 & Ambient hydrostatic stress state for use with constants 7 and 8. \\
\hline 6 & Biaxial crushing stress (positive) under the ambient hydrostatic stress state (constant 6). \\
\hline 7 & Uniaxial crushing stress (positive) under the ambient hydrostatic stress state (constant 6). \\
\hline 8 & Stiffness multiplier for cracked tensile condition, used if KEYOPT(7) = 1 (defaults to 0.6). \\
\hline 9
\end{tabular}

In Table 7-2 shear transfer coefficients should be defined between 0.0 to 1.0 , with 0.0 representing a smooth crack (complete loss of shear transfer) and 1.0 representing a rough crack (no loss of shear transfer). This specification is defined for both the closed and open crack. CSTIF is stiffness multiplier for a cracked or crushed element to aid numerical stability. The default number for this parameter is $1.0 \mathrm{E}-6$. Ambient hydrostatic stress was taken to be zero and constants 7 and 8 were not required.

\subsubsection{LINK 180 Element}

LINK 180 can be used in a variety of engineering applications such as modeling bars inside of the concrete. Figure 7-14 shows Link 180 geometry. The element can carry uniaxial tensioncompression forces. LINK180 has three degrees of freedom at each node including translations in the nodal $\mathrm{x}, \mathrm{y}$, and $\mathrm{z}$ directions. Plasticity, large deflection, and large strain capabilities are included. The element is defined by two nodes, the cross-sectional area, and the material properties. Table 7-3 shows the number of integration points for LINK 180. 

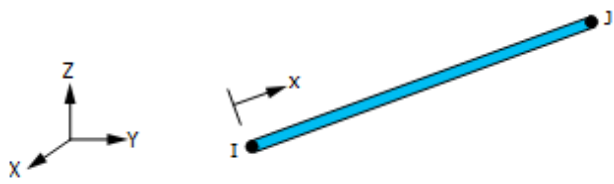

Figure 7-14 LINK180 geometry.

Table 7-3 Integration point for LINK180.

\begin{tabular}{|c|c|}
\hline Matrix or Vector & $\underline{\underline{\text { Integration }}}$ \\
\hline Points \\
\hline Stiffness Matrix; and Thermal, Newton-Raphson & 1 \\
\hline Hydrostatic and Hydrodynamic Load Vectors & 2 \\
\hline Mass and Stress Stiffening Matrices & 1 \\
\hline
\end{tabular}

\subsubsection{SHELL181 Element}

SHELL181 can be used for analyzing thin to moderately thick shell structures. Figure 7-15 shows SHELL181 geometry. It has four nodes with six degrees of freedom at each node including translations in the $\mathrm{x}, \mathrm{y}$, and $\mathrm{z}$-directions, and rotations about the $\mathrm{x}, \mathrm{y}$, and $\mathrm{z}$-axes. When the membrane option is activated, the behavior of the element restricted to translational degrees of freedom only. SHELL181 can be used for linear and large strain nonlinear applications. True stress measures were used in the element formulation. The element kinematics considers finite membrane strains. Table 7-4 shows the number of integration points for SHELL181.

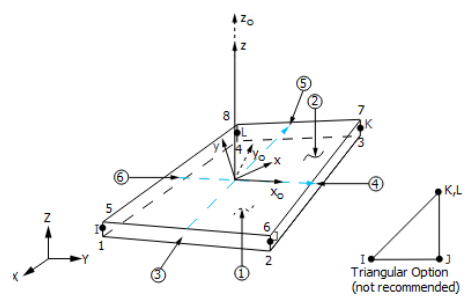

Figure 7-15 SHELL181 geometry. 
Table 7-4 Integration point for SHELL181.

\begin{tabular}{|c|c|}
\hline Matrix or Vector & Integration Points \\
\hline & In-plane: \\
& $1 \times 1(\mathrm{KEYOPT}(3)=0)$ \\
& $2 \times 2(\mathrm{KEYOPT}(3)=2)$ \\
& Thru-the-thickness: \\
& $1,3,5,7$, or 9 per layer for \\
& data input for section general \\
& shell option $(\mathrm{KEYOPT}(1)=0)$ \\
& Thru-the-thickness: \\
& 1 per layer for section data \\
& input for membrane shell \\
& option $(\mathrm{KEYOPT}(1)=1)$ \\
\hline Consistent Mass and Stress Stiffness Matrices & Closed form integration \\
\hline Lumped Mass Matrix & Closed form integration \\
\hline Transverse Pressure Load Vector & $2 \times 2$ \\
\hline Edge Pressure Load Vector & 2 \\
\hline
\end{tabular}

\subsubsection{Smeared and Discrete Reinforcement Models}

There are two options available in ANSYS to model reinforcement bars in the concrete; one is using smeared reinforcement to determine the global nonlinear response and the other is using discrete reinforcement in the form of link elements. Using smeared versus discrete reinforcement depends on the goal of the analysis. For an elastic analysis, the reinforcement could be neglected since the stiffness contribution of concrete is much greater than steel bars.

Adding a small percentage of smeared reinforcement provides a small tensile stiffness after cracking of the Solid 65 concrete elements and can help overcome non-convergence issues in models with concrete, Otherwise, Link or beam elements can be used for modeling reinforcements in the concrete explicitly.

In the presented research, a set of nonlinear finite element analysis was needed to compute the ultimate strength of the connection. Therefore, proper modeling of reinforcement bars was 
critical. In the early stages of this research, both methods were used to capture the nonlinear behavior of the system.

Two different sets of finite element models were analyzed and the results compared. In one set, only the reinforcement bars in the deck modeled as discrete reinforcement; the hooks and shear reinforcement were modeled as smeared reinforcement. This decision was based on preliminary finite element results that indicated these elements are not part of load resistance mechanism of the system and remain in the elastic range.

In the second set, all reinforcement was explicitly modeled. Subsequent results provided in this paper are based on the model will all reinforcement modeled as discrete elements.

\subsubsection{Verifying the Finite-Element Model}

As described in Chapter 1, three different connection details were constructed and tested in the structure lab at UNL. These three connection types are shown in Figure 7-16. In connection type one, there are two bearing plates at the end of the girders over the pier and the bottom flanges welded to each other. In type two, the girders are placed over the bent cap and there are no bearing plates nor connection between bottom flanges. In type three, there are end-bearing plates but the bottom flanges are not connected. Figure 7-17 shows the Moment-Drift curves obtained from the experimental results (Azizinamini, 2014).

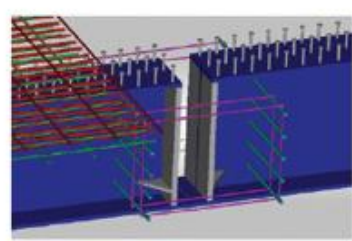

Test 1: Connection type 1

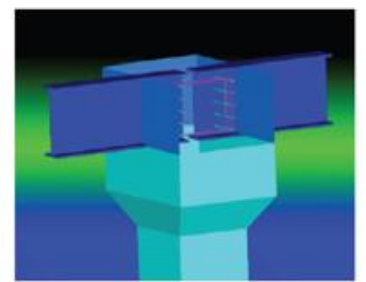

Test 2: Connection type 2

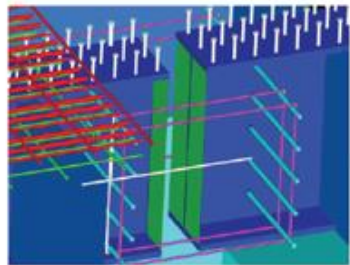

Test 3:

Connection type 3

Figure 7-16 Three connection types tested by UNL. 


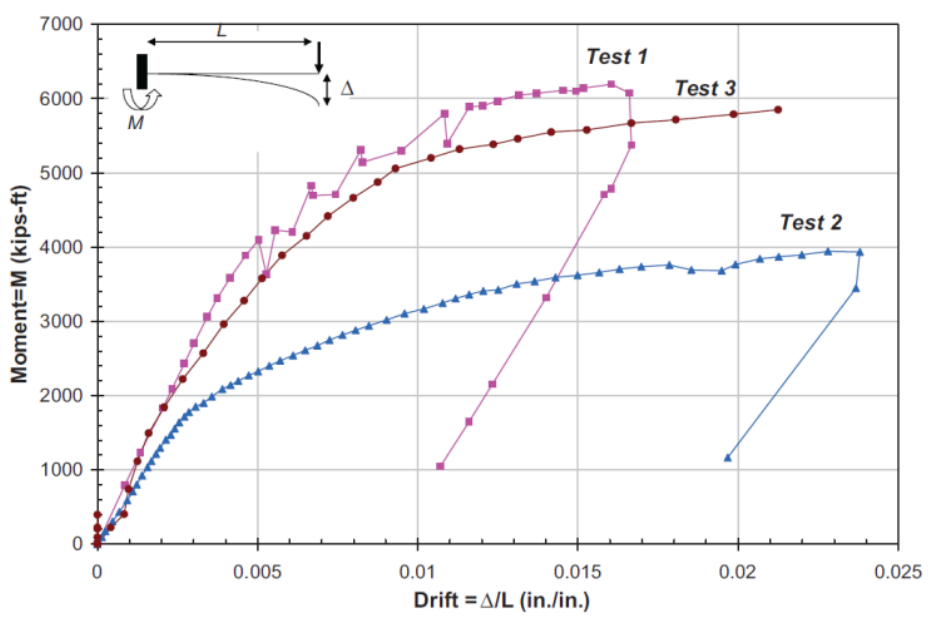

Figure 7-17 Moment-Drift of connection type 1, 2 and 3.

To verify the finite element model, the type one test specimen was modeled in the finiteelement software ANSYS with similar dimensions, material properties, and boundary conditions. The Moment-Drift curve was determined, which is presented in Figure 7-18, and compared with the experimental test results. Moment-Drift comparison indicates there is good agreement between the finite-element and experimental test results.

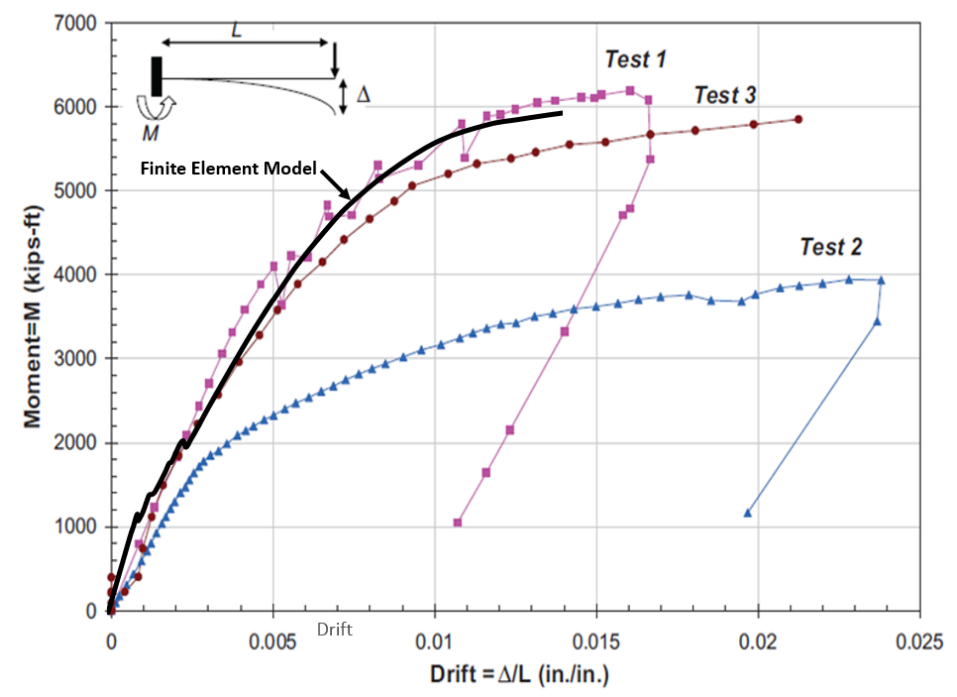

Figure 7-18 A comparison between Moment-Drift from the experimental test and finiteelement analysis. 


\subsection{Simulating Earthquake Loads}

A series of nonlinear finite-element analysis was to be carried out to understand the force transfer mechanism. One of the challenging points in identifying the modes of failure is determining the type of loading to which the model should be subjected. Ideally, a series of prototype bridges should be designed based on recommended design provisions and subjected to various ground motions. However, detailed modeling entire bridges and conducting nonlinear time-history finiteelement analyses is prohibitively time-consuming.

Accordingly, three essential modes of loading were identified that are of interest in evaluating the behavior of the connection. These are:

- downward loading caused by gravity loads such as self-weight, superimposed dead loads, and live loads,

- upward loading (uplift), caused by vertical acceleration, and

- longitudinal loading caused by accelerations along the direction of traffic.

The area of interest is near the interior support. The remainder of the bridge has no effect on the behavior of the connection. Therefore, in lieu of modeling the entire bridge, the middle part of the bridge from inflection point to inflection point was modeled. The three types of loading were modeled by apply load at the free ends of the modeled girders:

-Pushing-down at the ends of the girders

-Pushing-up at the ends of the girders

-Pulling up one end of the girder and pushing down the other end of the girder (inverse loading) 


\section{LOAD RESISTANCE MECHANISM}

\subsection{Introduction}

This chapter presents the load resistance mechanism of the preliminary (bolted) connection under different load conditions. In each section, the effect that different components of the connection have on the ultimate flexural strength of the proposed connection was investigated.

\subsection{Applying Push-Down Forces}

The main purpose of applying push-down forces is understanding the system performance due to dead loads, super imposed loads and traffic live loads. This loading pattern is the identical to loading considered in the conventional SDCL research. For non-integral bridge systems, fullscale testing had been carried out to develop practical details for joining girders over the interior supports for live load continuity using conventional construction practices (Lampe N. J., December, 2001). In addition, comprehensive numerical and analytical studies had been carried out to provide an understanding of the force transfer mechanism for the details that were developed to connect the steel girders in the SDCL system over the interior supports (Farimani M. M., 2006). The following section presents the results of additional work carried out to evaluate the behavior of the proposed detail.

\subsubsection{Global Behavior under Push-Down Forces}

The behavior under push-down forces was expect to be similar to the conventional SDCL connection. Figure 8-1 shows the Moment-Drift curves obtained for the existing and preliminary (bolted) connection. It is evident from the results that the bolts provide more capacity to the system. The early drops in both curves are due to initial cracks developing in the concrete during the first steps of loading. At drift levels lower than 0.004 the performance of both details is similar while beyond, the new proposed connection possesses more capacity. This outcome was predicted since 
the bottom bolts are expected to help the steel block in the compression zone and top bolts aid the longitudinal bars in the tension zone.

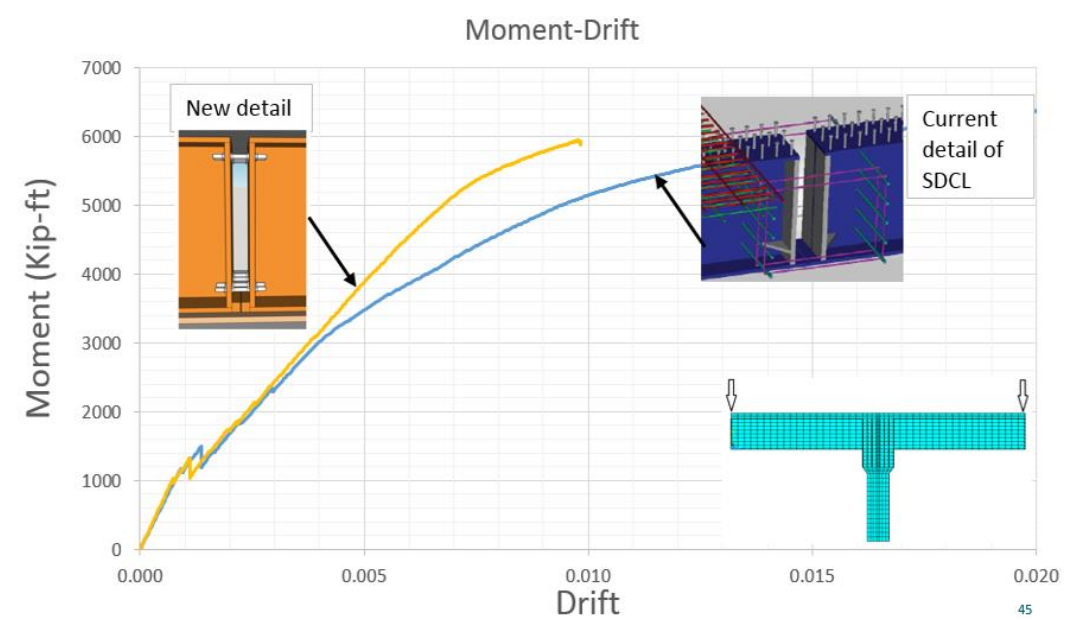

Figure 8-1 Moment-Drift for the existing and preliminary (bolted) detail.

\subsubsection{Distribution of Cracks under Push-Down Forces}

Figure 8-2 presents the distribution of cracking that developed during different steps of the analysis. The first cracks that formed in the bolted connection detail as well as the existing SDCL detail were cracks in the deck at the two sides of the concrete diaphragm. In the initial steps of loading, the longitudinal bars of the slab carry the majority of tension forces and micro-cracks form in the concrete. Note that there is no crushing below the bottom flange or at the interface of the concrete diaphragm and bent cap due to push-down forces. 


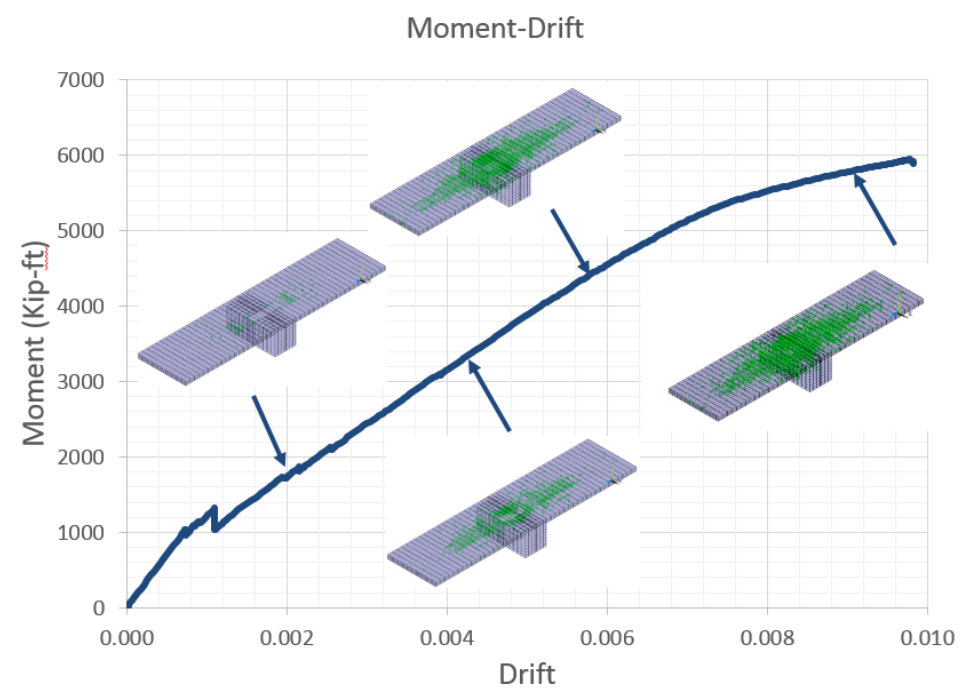

Figure 8-2 Distribution of cracks in the deck and concrete diaphragm under push-down forces.

\subsubsection{Load Resistance Mechanism under Push-Down Forces}

In the bolted seismic SDCL detail, tensile forces are carried by longitudinal bars in the slab and top bolts while compressive forces are carried by the bottom flanges and bottom bolts. Figure 8-3 shows events that occurred at various steps of the finite-element analysis. In the initial steps of analysis, cracks started to form in the deck and made the behavior of the system nonlinear. Additional cracks begin to form at a drift level of 0.00025 , corresponding to the moment of 2000 kip-ft. In Figure 8-4, the locations of these cracks are indicated by blue circles at two sides of the concrete diaphragm. At this stage of loading, there is no yielding in the bars, bolts, or girders as shown in Figure 8-5.

Around a drift level of 0.005 , concrete on the top of the deck started to crack and longitudinal bars in the slab started to yield. The bottom flanges, bottom bolts and top bolts remained in the elastic range, as shown in Figure 8-6 and Figure 8-7.

As loading continued, the top longitudinal bars in the slab yield and at a drift value of around of 0.0055 , the top bolts began to display nonlinearity. The majority of the compressive force 
is carried by the bottom flanges and they began to yield at a drift level of 0.007 , as shown in Figure 8-9, Figure 8-10, Figure 8-11, Figure 8-12, Figure 8-13. Figure 8-13 indicates that the von-Mises stresses have the highest value in the girder at the edge of concrete diaphragm. The reason is that the part of the girder that is supported by the bent cap and embedded in the concrete diaphragm missed its support at this location.

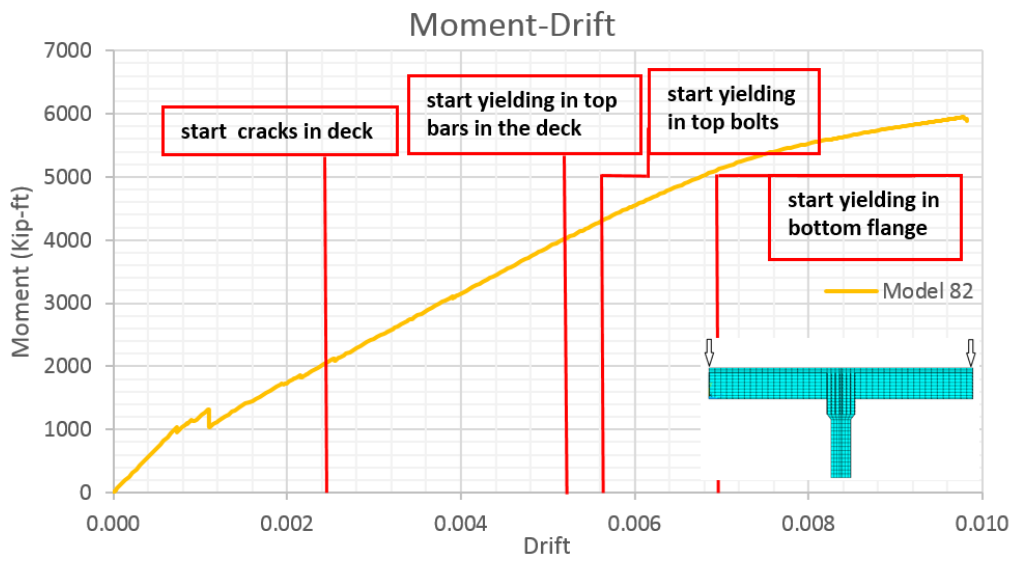

Figure 8-3 Sequence of failure events under push-down forces.

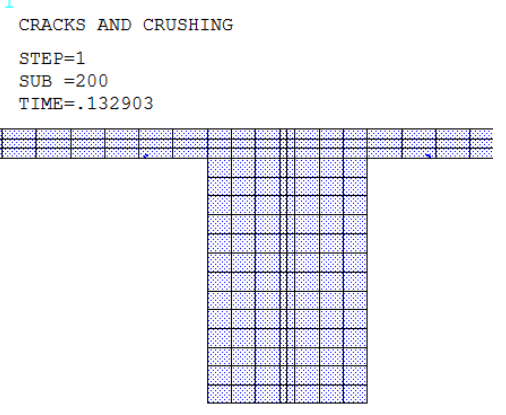

Figure 8-4 Initial cracks in concrete deck under push-down forces at sub step 200 out of 727 (model No. 245). 


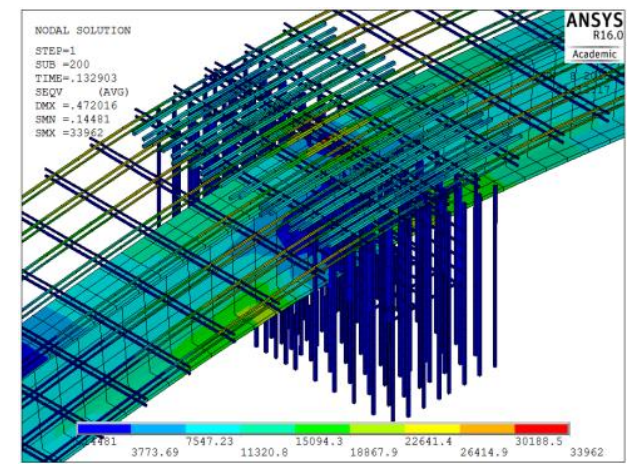

Figure 8-5 von-Mises stress in bars and girders at sub step 200 out of 727 (model No. 245).

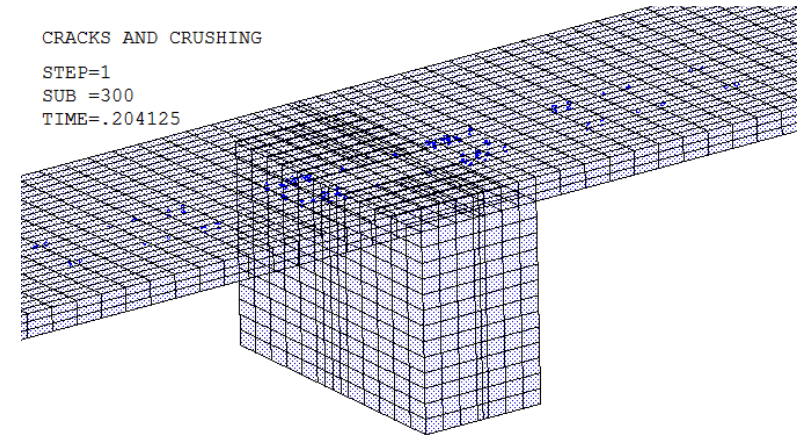

Figure 8-6 Initial cracks in concrete deck under push-down forces at sub step 300 out of 727 (model No. 245).

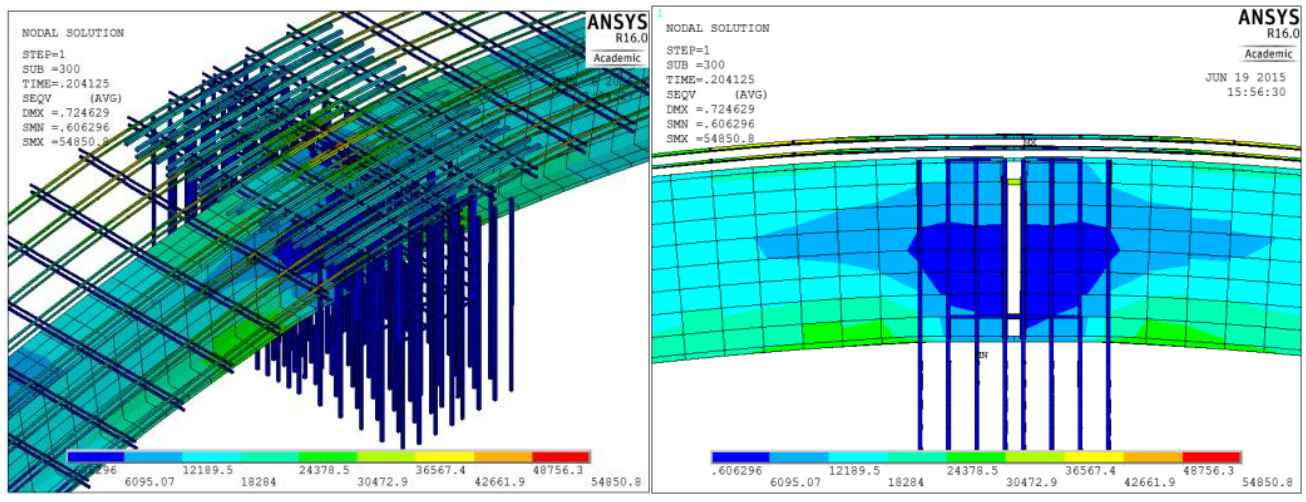

Figure 8-7 von-Mises stress in bars and girders at sub step 300 out of 727 (model No. 245). 


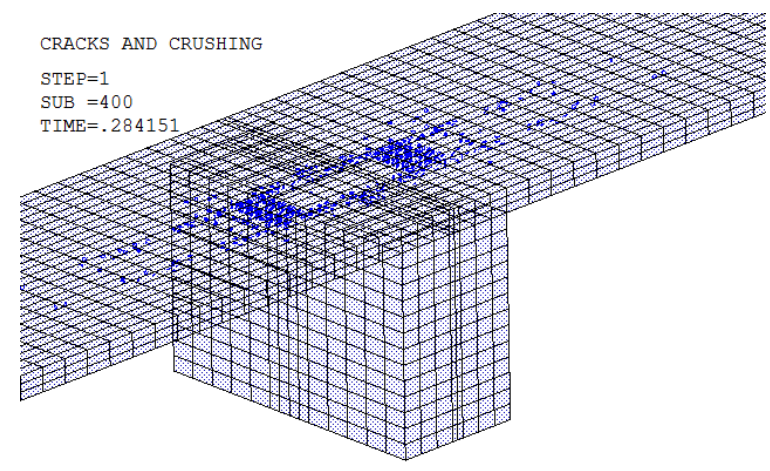

Figure 8-8 Cracks in concrete deck under push-down forces at sub step 400 out of 727 (model No. 245).

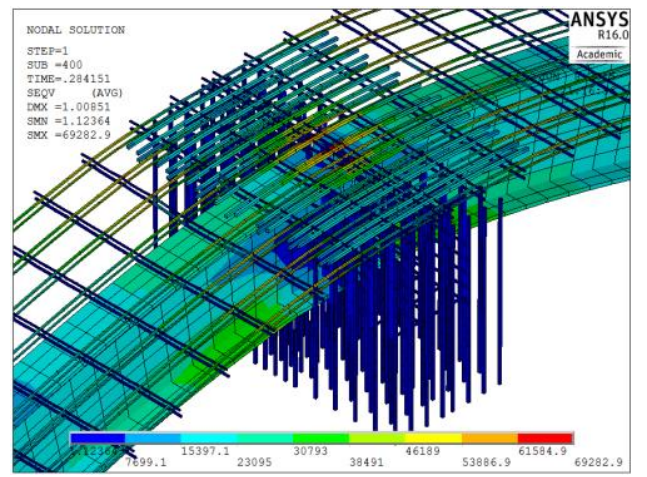

Figure 8-9 von-Mises stress in bars and girders at sub step 400 out of 727 (model No. 245). Top bars over the diaphragm start to yield.

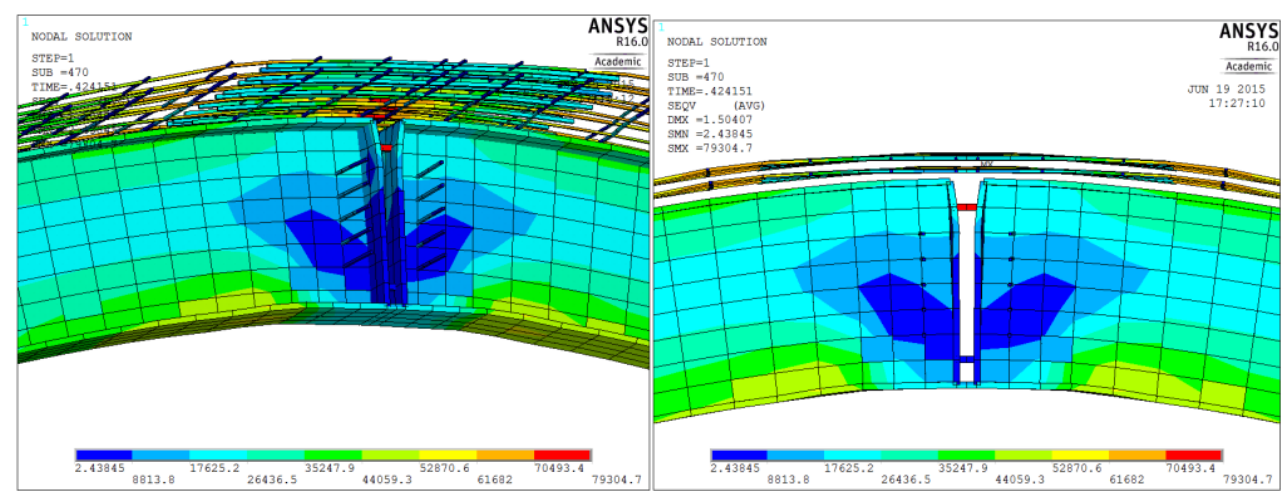

Figure 8-10 von-Mises stress in bars and girders at sub step 470 out of 727 (model No. 245). Bottom flange started to yield. 


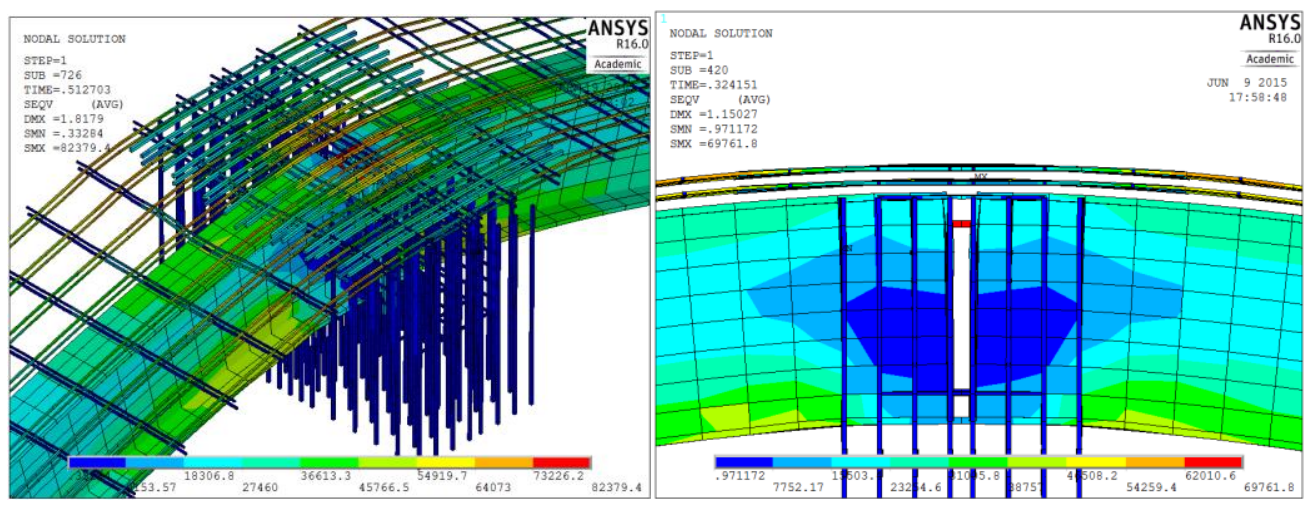

Figure 8-11 von-Mises stress in bars, girders and bolts at sub step 420 out of 727 (model No. 245). Top bolts start to yield.

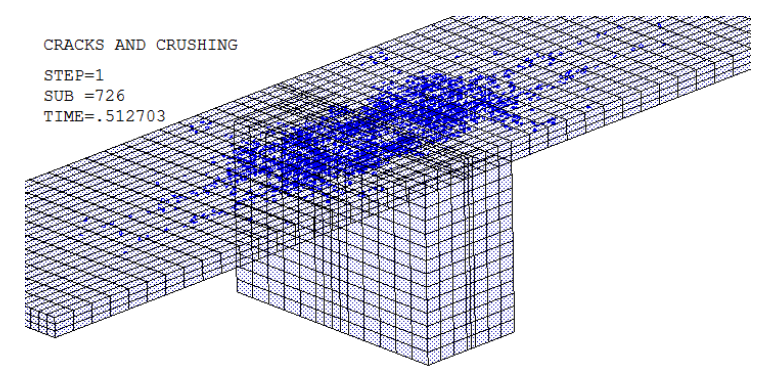

Figure 8-12 Cracks in concrete deck under push-down forces at sub step 726 out of 727 (model No. 245).

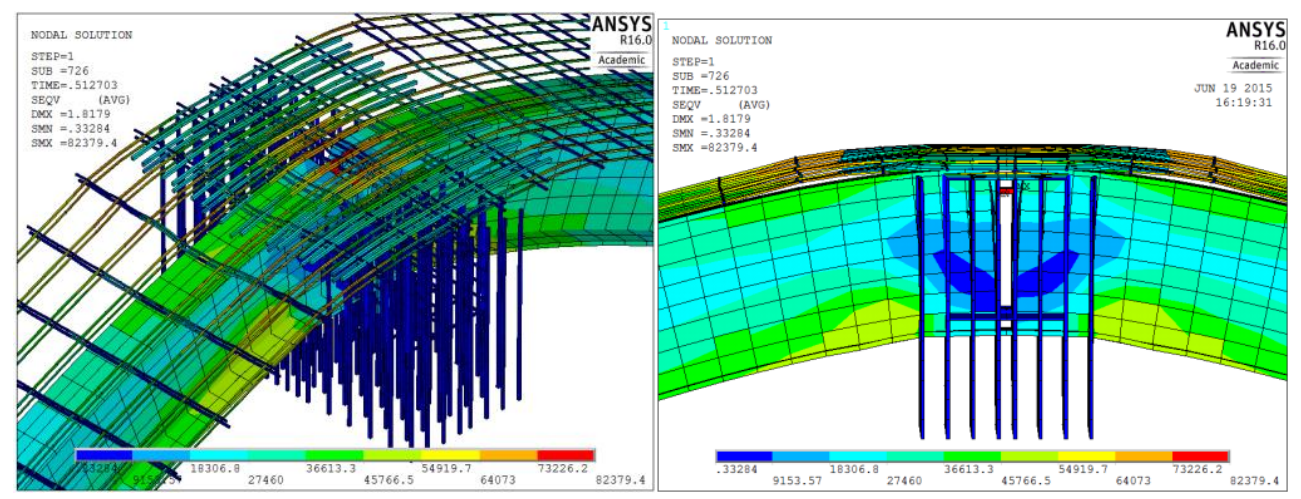

Figure 8-13 von-Mises stress in bars and girders at sub step 726 out of 727 (model No. 245).

\subsection{Applying Push-Up Forces}

Under seismic loads, the vertical component of an earthquake applies upward forces to the mass of the deck. According to the CALTRANS (CALTRANS, 2013), for ordinary standard bridges, the effect of the vertical load should be considered to estimate the effect of vertical acceleration in regions with site ground acceleration greater than $0.6 \mathrm{~g}$. A uniform vertical force 
equal to 0.25 of the dead load upward and downward should be applied to the deck and a separate analysis conducted to control the capacity of superstructure (CALTRANS, section 2.1.3 and 7.2.2). The influence of the vertical component of earthquake loads on the structural response was studied by Sashi K. Kunnath (Sashi K. Kunnath, May 2008 ). In that research, the current provisions in SDC-2006 for incorporating vertical effects of ground motions were evaluated. The results confirmed that the most vulnerable situation occurs when the predominant period of the vertical motions are close to the vertical period of highway overcrossing. Figure 8-14 shows a schematic deformation of the bridge subjected to the vertical component of seismic forces. This kind of loading was simulated by applying two upward forces at two ends of the girders in the finiteelement model.

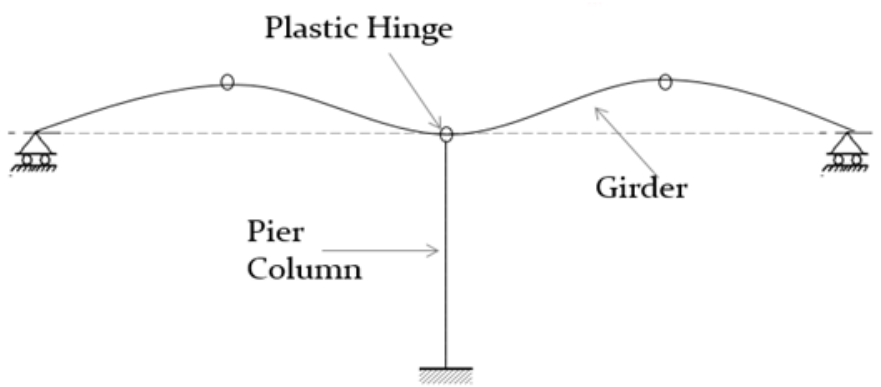

Figure 8-14 Deformation of a two span bridge under the vertical component of the earthquake.

\subsubsection{Global Behavior under Push-Up Forces}

Various models with different details over the pier were analyzed. The observations are discussed in the following sections.

\subsubsection{Effect of Bottom Flange Continuity under Push-Up Forces}

To observe the behavior of the bolted connection under a worst-case scenario, it was assumed that the bottom flanges are not connected to each other and the force was transferred through the lower bolts. Figure 8-15 shows a comparison between the Moment-Drift of two 
different models. In the base model, the bottom flanges were made continuous and in the other, the bottom flanges are not continuous and the lower bolts are the only elements take care of tension forces. According to these results, the bottom flange continuity enhances the flexural strength of the proposed connection significantly.

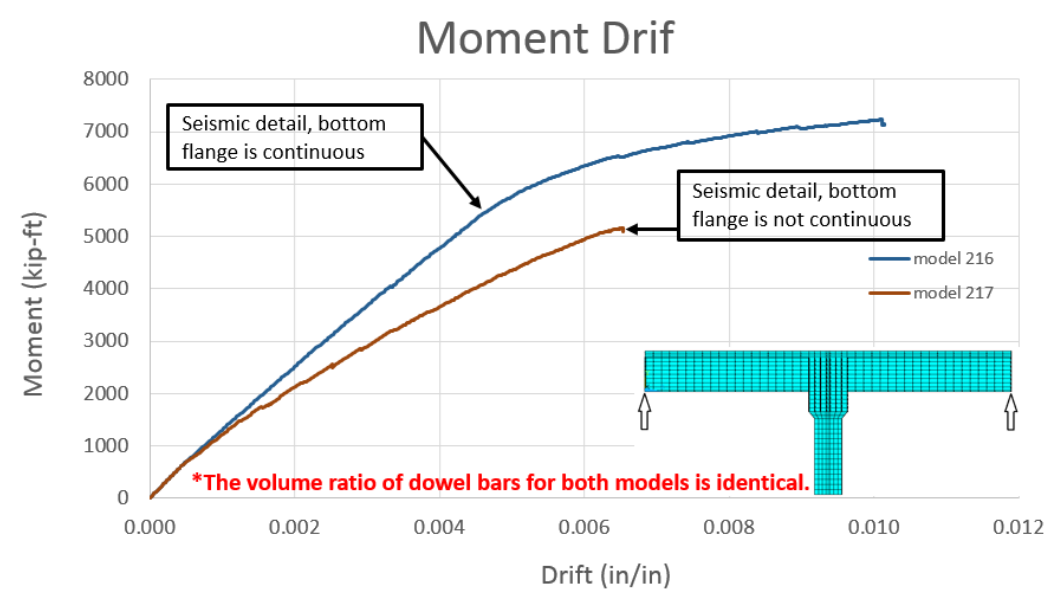

Figure 8-15 Moment-Drift capacity of the brand-new detail for discontinuous and continuous flanges.

\subsubsection{Effect of Bolts under Push-Up Forces}

To begin examining the effect of bolts, two models were considered, in both models the bottom flanges were welded to each other. One model included bolts and the other did not. Figure 8-16 shows the Moment-Drift plot for the connections. As expected, there was little change in behavior due to the presence of the bolts when the flange is continuous.

In the next step, bolt size was considered in the behavior of the system. Finite-element models with varying bolts sizes $\left(0.5,0.75,1.0,2.5\right.$ in^$\left.^{\wedge}\right)$ were analyzed. Figure 8 - 17 shows moment capacity of the connection for continuous and discontinuous bottom flanges with different bolt sizes. It is evident that the size of bolts did not change the moment capacity of the system significantly. 


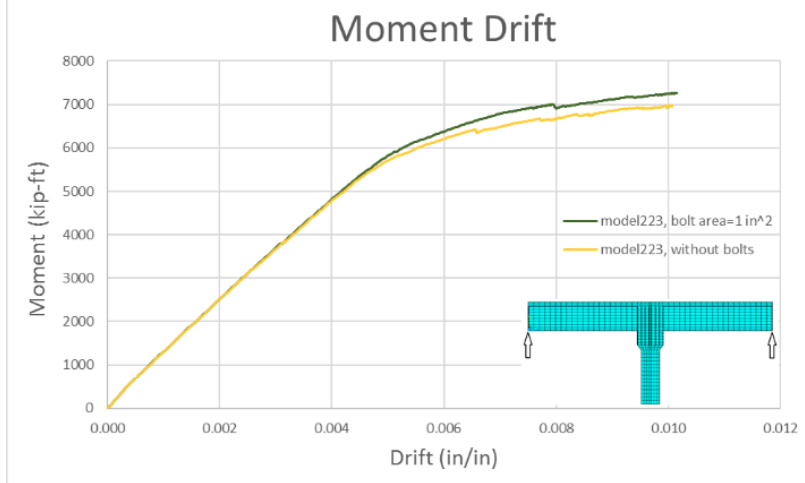

Figure 8-16 Moment-Drift capacity of the brand-new detail for continuous flanges with and without bolts.

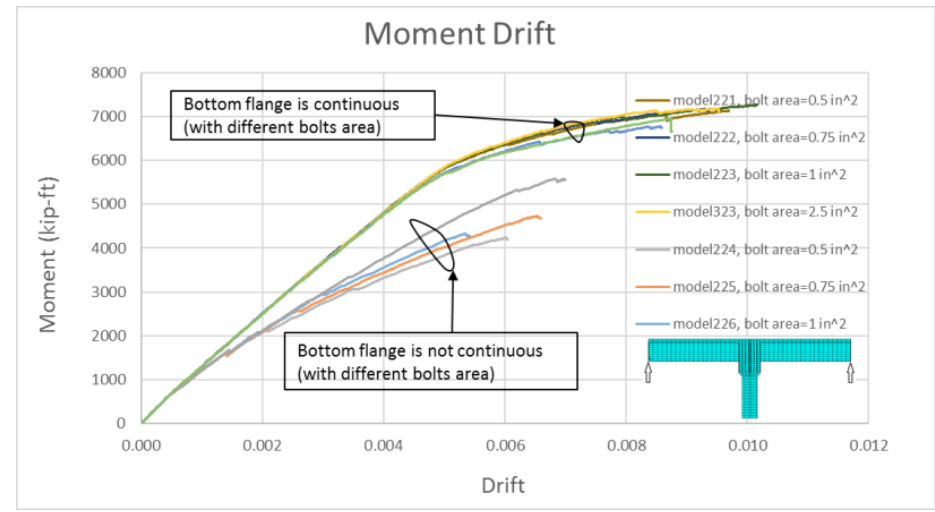

Figure 8-17 Effect of bolt sizes in the capacity of the connection in integral and non-integral bridge model.

Adding bolts to the connection marginally enhanced the capacity of the system subjected to push-up forces. However, with the area of bolts much less than the area of the bottom flange the effect is limited. Additionally, the bolts are close to the neutral axis and therefore not very effective.

\subsubsection{Distribution of Cracks under Push-Up Forces}

When first subjected to push-up forces, cracks initially start to develop in the concrete diaphragm and deck. The reason is that maximum tensile stresses occur at the bottom surface of the deck at the vicinity of the concrete diaphragm. Upon increasing the amount of load, cracks start to develop extending from the centerline of the pier to the middle of the deck. During the last steps of loading, the top layers of the deck, above the concrete diaphragm start to crush. Figure 8-18 illustrates the cracks developed in each step of analysis at the corresponding moment. 


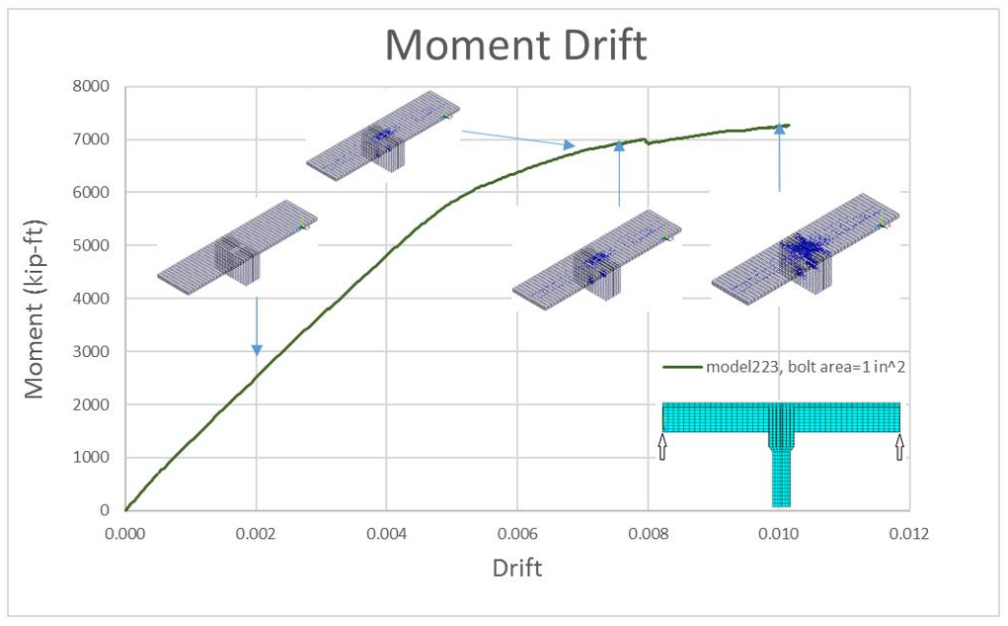

Figure 8-18 Crack pattern under push-up forces.

\subsubsection{Load Resistance Mechanism under Push-Up Forces}

When subjected to push-up forces, the sequence of failure depends on the capacity of the concrete, longitudinal bars in the slab, and top bolts to carry compressive forces and the bottom bolts and bottom flanges to carry tensile forces. The finite-element output indicates that the bottom flange is the most critical element due to push-up loading. The welded bottom flanges are the weak link of the system and nonlinear behavior of the system begins through yielding in the bottom flange. In this stage of analysis (around a drift of 0.0035), concrete in the deck and longitudinal bars in the slab remain in the elastic range, as illustrated in Figure 8-19. After bottom flange yielding, application of additional force caused some cracks in the concrete of the deck. Figure 8-20 demonstrates the distribution of cracks at a drift level of around 0.003 and 0.0035 . Increasing the amount of load resulted in developing additional cracks over the concrete diaphragm and bottom flanges. The last failure mode of the system was the bottom bolts yielding and some concrete crushing in the deck at the centerline of the pier as shown in Figure 8-19. Figure 8-21, Figure 8-22 and Figure 8-23 presents the value of von misses stresses in the bolts and bars. As seen in the figures, once the bottom flange and bottom bolts are in nonlinear range, bars in the deck and top bolts are still in elastic range. Figure 8-24, Figure 8-25 and Figure 8-26 presents the von-Mises 
stresses in connections with different bolt sizes. In all cases, the top bolts remained elastic until the last step of analysis.

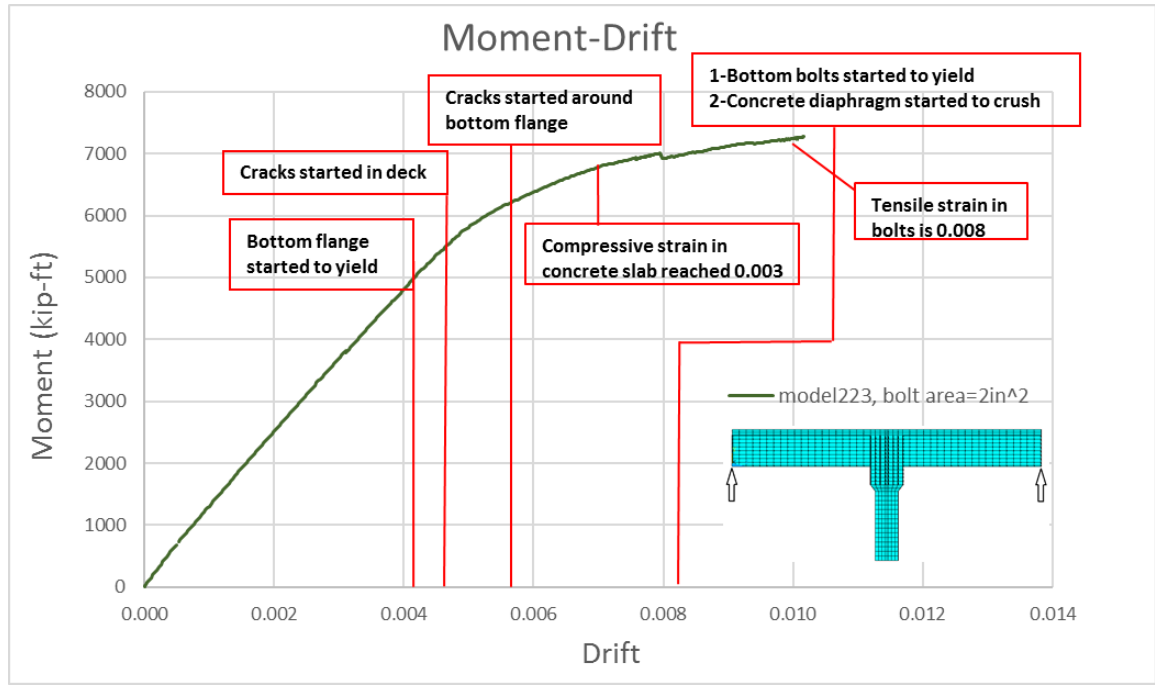

Figure 8-19 Sequence of failure modes under push-up forces.

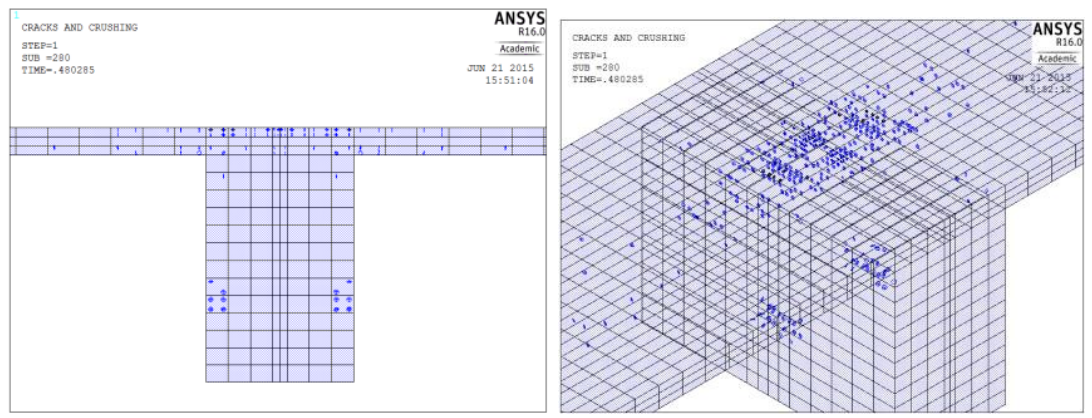

Figure 8-20 Crushes and cracks in concrete under push-up forces at sub step 280 out of 598 (model No. 223).

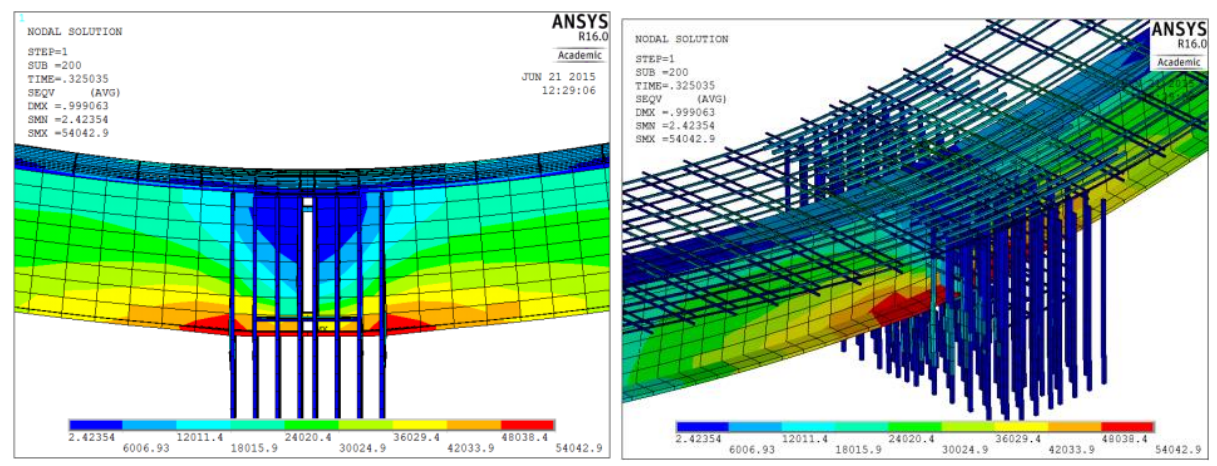

Figure 8-21 von-Mises stress in girders and bars at sub step 200 out of 598 (model No. 223). Bottom bolts start to yield. 

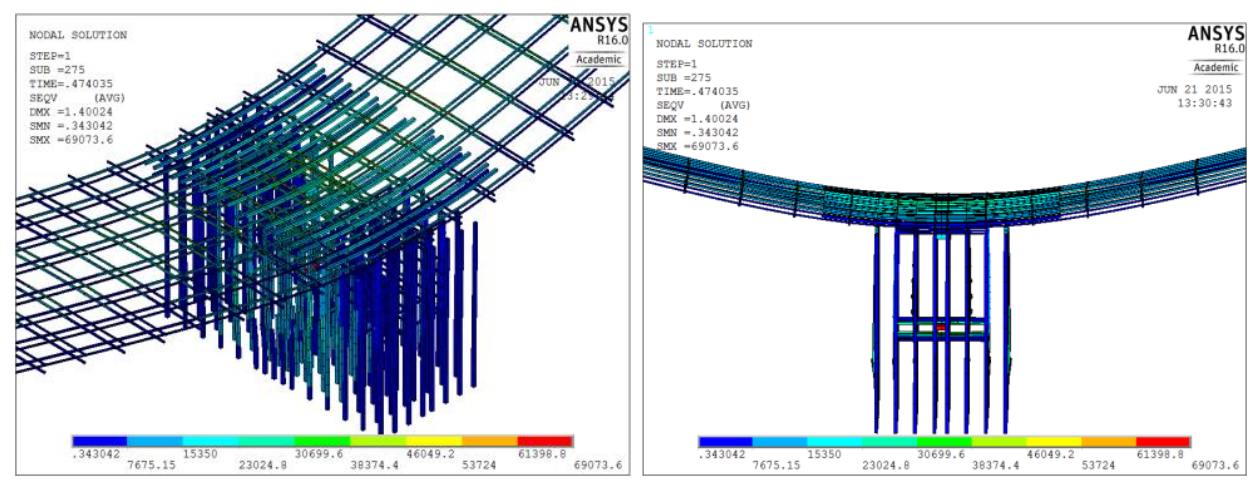

Figure 8-22 von-Mises stress in bars and bolts at sub step 275 out of 598 (model No. 223). Bottom bolts start to yield.

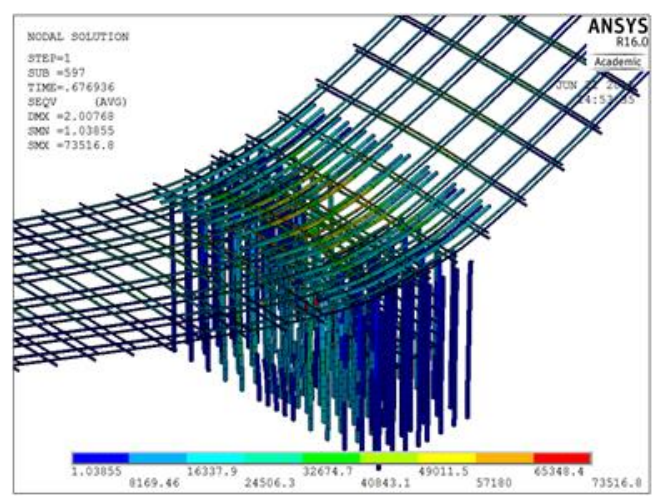

Figure 8-23 von-Mises stress in bars at sub step 597 out of 598 (model No. 223). Top bars remained elastic.

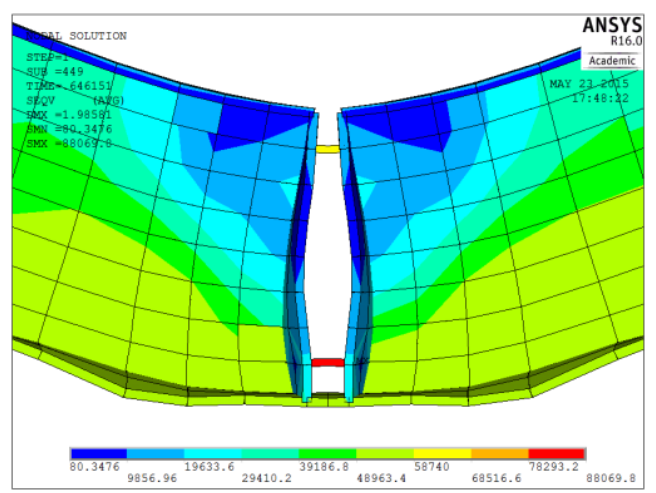

Figure 8-24 von-Mises stress under push-up forces, cross-section area of each bolt=0.5 in^2. 


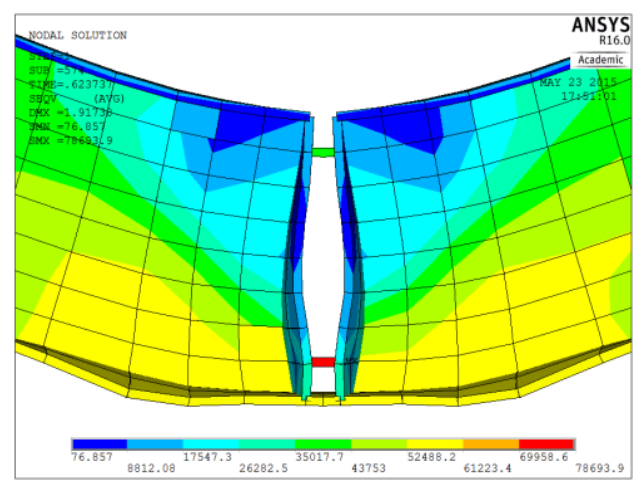

Figure 8-25 von-Mises stress under push-up forces, cross-section area of each bolt=0.75 in^2.

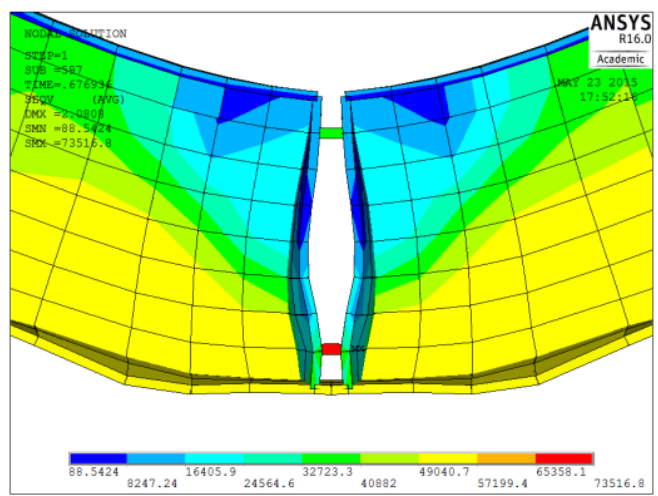

Figure 8-26 von-Mises stress under push-up forces, cross-section area of each bolt=1.0 in^2.

\subsection{Applying Inverse Forces}

The intention of applying inverse loads and axial forces to the end of the girder are to simulate the behavior of the connection due to the longitudinal component of seismic loads. In fact, these two types of loading can produce a backbone curve of cyclic loading (Figure 8-27). The deformation of a three span bridge subject to the longitudinal direction of loading is shown in Figure 8-27. In the new seismic codes, the design philosophy is based upon redundancy, ductility and capacity concepts of structures. In the seismic design of bridge structures, locations of the hinges are preferred to be at the two ends of column, in vicinity of the connection to the cap beam and foundation. Accordingly, modeling the superstructure and substructure with real material properties will result in large deformation and nonlinearity in the column. In this case, studying the load resistance mechanism of the connection is impossible because the superstructure, girders and 
connections stay in elastic range once the column ends experience large deformation and nonlinearity. For this reason, for inverse loading, the stiffness of the column is artificially increased to find the load resistance mechanism of the connection at the ultimate load level (Figure 8-28). The resulting failure mode of the connection and superstructure appears more reasonable than modeling a column with real stiffness and failure of the column will be prevented before failure of the connection.

The next step considered the deformation of the pier in the behavior of the connection. The whole length of the girder (95 feet each span) was modeled and an axial horizontal load applied at one end (Figure 8-29). The following sections detail the results obtained from the modeling.

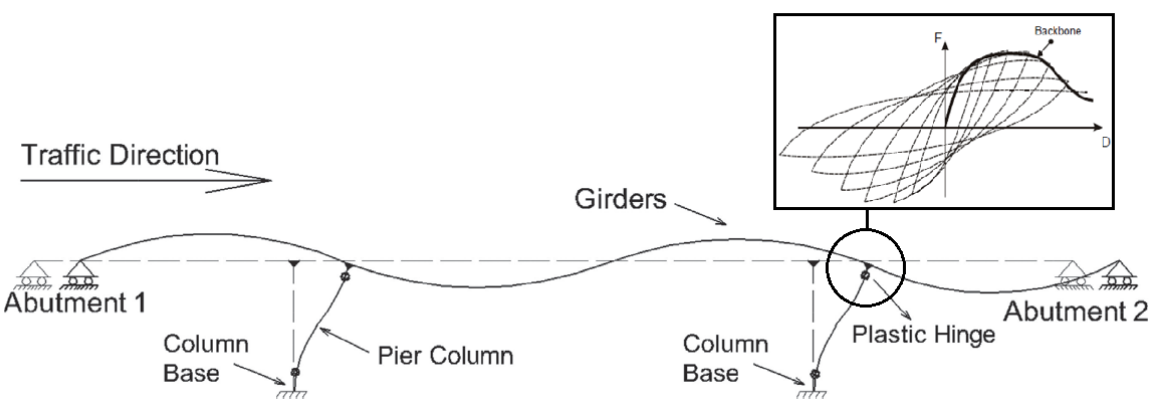

Figure 8-27 Deflected shape of a three-span bridge in the longitudinal (parallel to traffic) direction due to seismic loads.

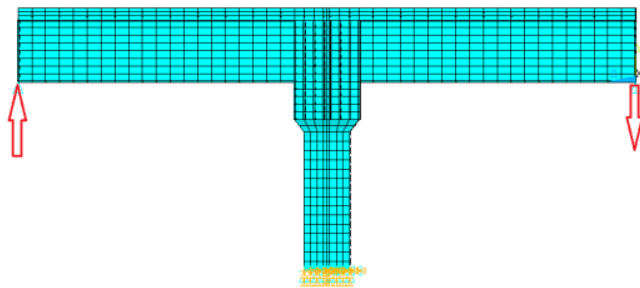

Figure 8-28 Finite-element model and boundary condition for two inverse loads, the stiffness of column increased artificially.

Figure 8-29 Finite-element model and boundary condition for the axial load. 


\subsubsection{Global Behavior of the System under Inverse Forces}

\subsubsection{Effect of Bolts and Stirrups}

In Figure 8-30, the capacity of the bolted connection and conventional SDCL details are shown. To investigate the effects that the bolts and stirrups have on the flexural strength, the area of stirrups, distance between stirrups, area of the bolts was increased (Figure 8-31). The MomentDrift of the system was obtained and compared in Figure 8-32. According to the finite element results, modifying these parameters did not change the capacity or the behavior of the system in The failure mode of the system was limited to cracks around and below of the bottom flange at push-up side as well as cracks and crushing at the push-down side.

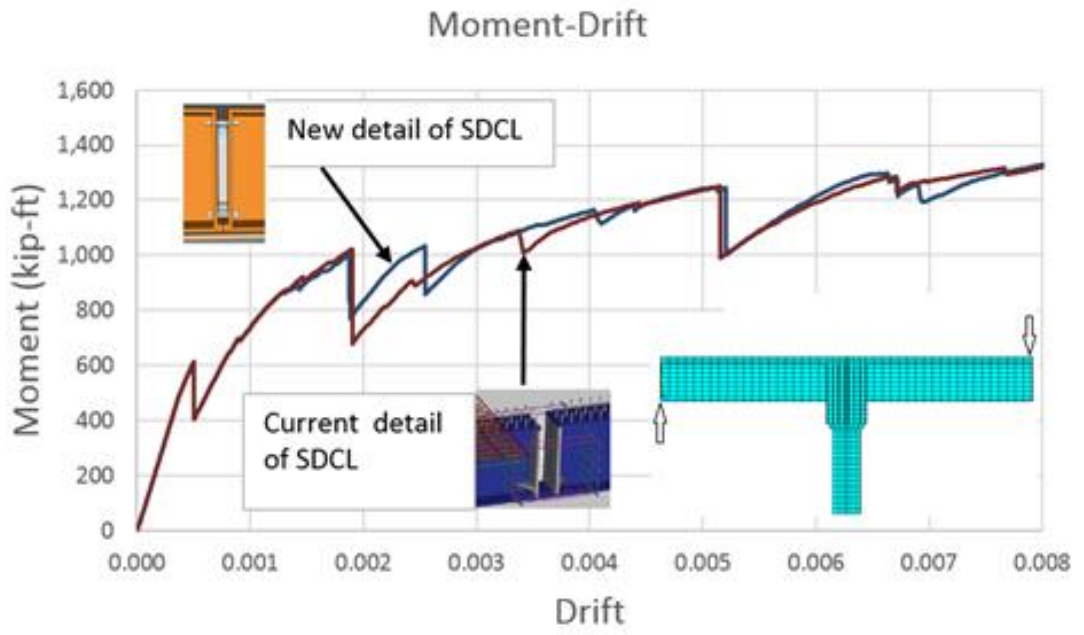

Figure 8-30 Moment-Drift plot under inverse forces for the existing and new SDCL connection before adding dowel bars (stiffness of column increased).

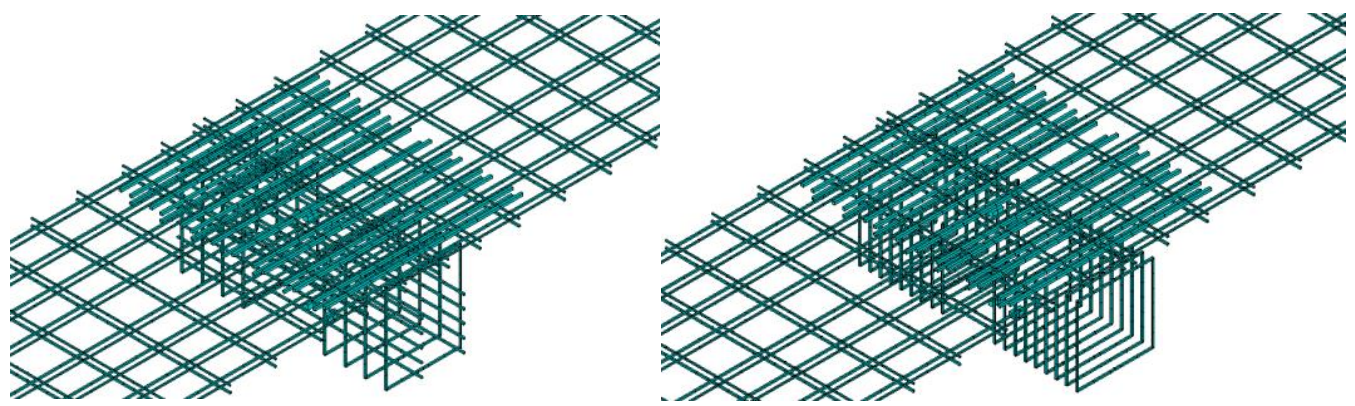

Figure 8-31 Finite-element model before and after increasing the area of stirrups. 


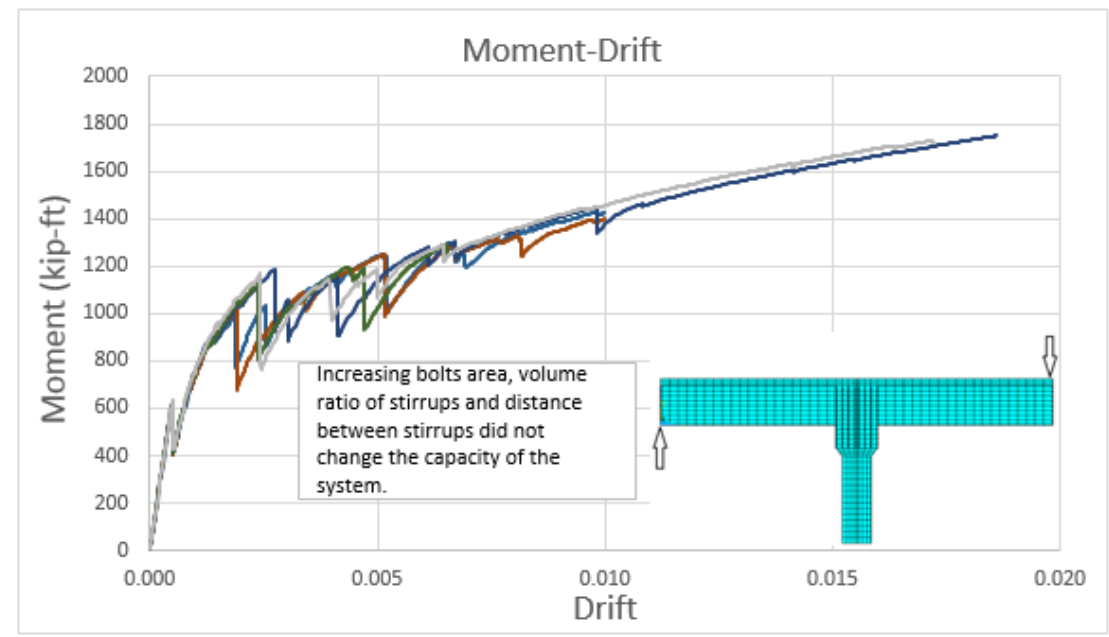

Figure 8-32 Moment-Drift plot under inverse forces for the existing SDCL connection after increasing bolts area and the number of stirrups.

\subsubsection{Effect of Dowel Bars}

Next, dowel bars were added to the bent cap and concrete diaphragm as illustrated in Figure 8-33. These bars made the connection between the bent cap and concrete diaphragms similar to integral bridges. Figure 8-34 shows the effect of dowel bars on the moment capacity of the system. According to this plot, dowel bars have an important role in increasing the moment capacity of the system. In the model, the value of moment capacity increased significantly from around 1500 to 3000 kip-ft. This improvement in the load-carrying capacity of the specimen was due to adding these bars to the interface of bent cap and concrete diaphragm.

Dowel bars enhanced the capacity of the system due to their tension capacity at the pushup side since the tension capacity of the concrete is approximately equal to zero. Results indicate that increasing the volume ratio of the dowel bars can enhance the moment capacity and prevent premature failure of the system.

To find the influence of the dowel bars volume ratio, the analysis was repeated for models with different dowel bar sizes. Figure 8-35 shows the Moment-Drift plots for different dowel bar sizes. In this figure, volume ratio in the legend of the graph presents the projected area of the dowel 
bars to the area of the bent cap. The results, as expected, indicate that increasing the volume ratio of dowel bars (from 0.01 to 0.06 ) increased the moment capacity of the system.

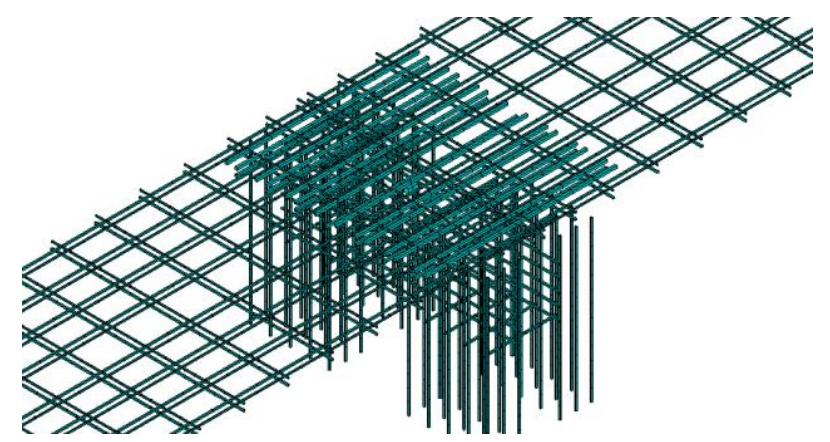

Figure 8-33 Adding dowel bars at the interface of bent cap and concrete diaphragm.

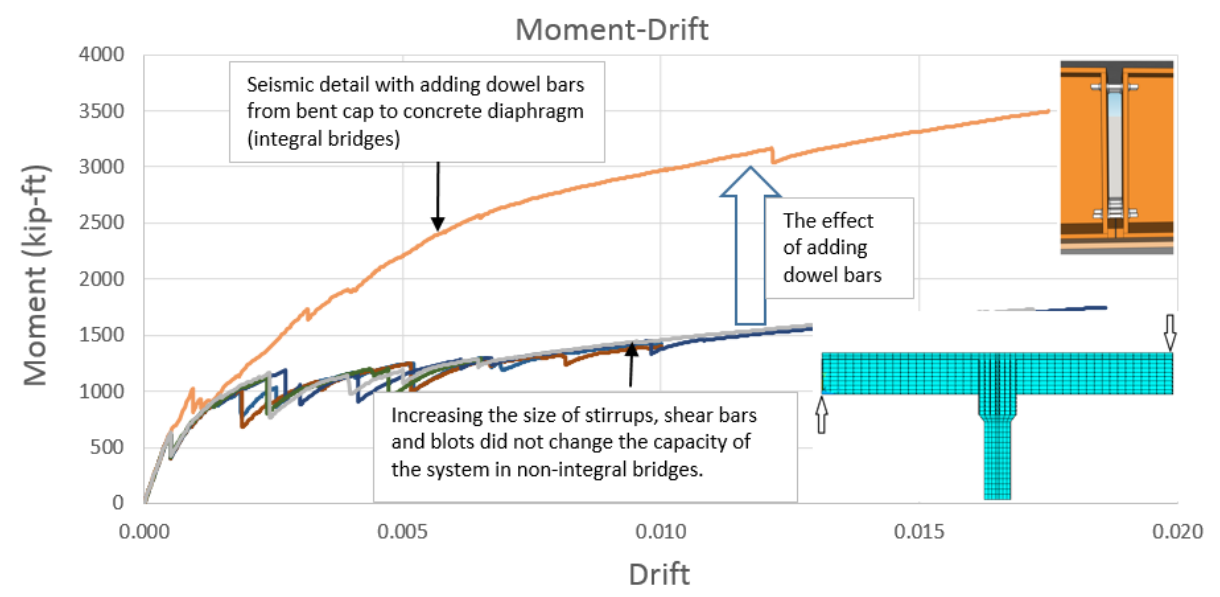

Figure 8-34 Comparison between Moment-Drift before and after adding dowel bars.

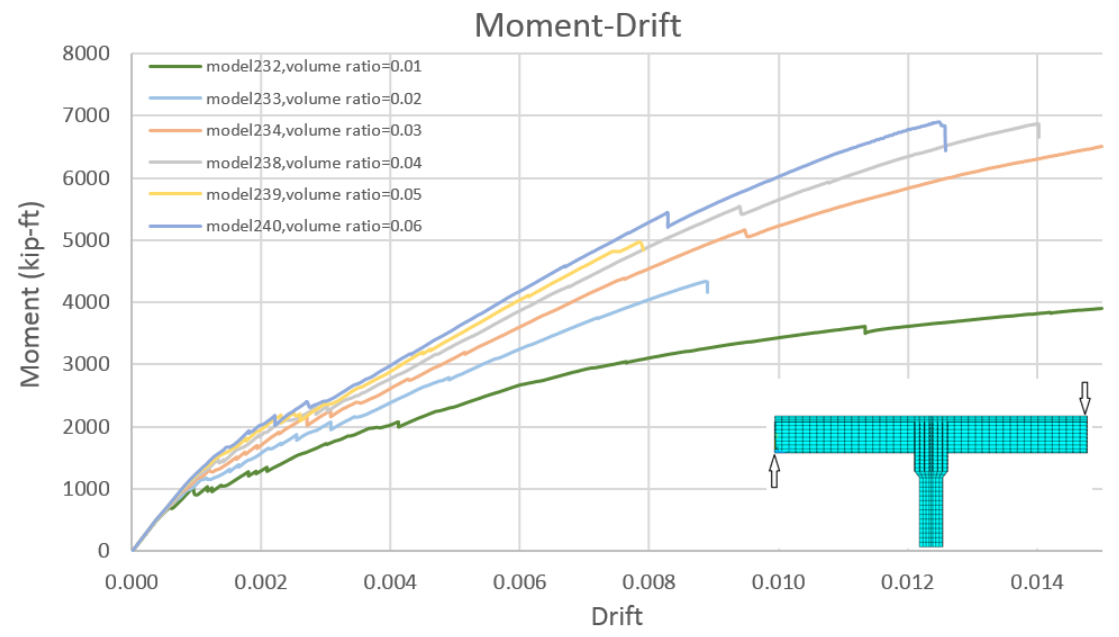

Figure 8-35 Moment-Drift plot for integral bridges with different dowel bars volume ratio. 


\subsubsection{Principal Actions under Inverse Loading}

When downward force at the end of the girder creates tensile stress in the top flange and compressive stress in bottom flange of steel girder, the upward force at the other end of steel girder applies tensile stress in the bottom flange and compressive stresses in top flange. Figure 8-36 shows the principle action between the top and bottom flange of the girders and dowel bars at the interface of the concrete diaphragm and bent cap. In Figure 8-37 and Figure 8-38, the exaggerated deformation of the two finite-element models due to inverse loading and axial loading have been shown. According to these figures, the deformation of the system comes from the flexural behavior of the concrete diaphragm and bent cap.

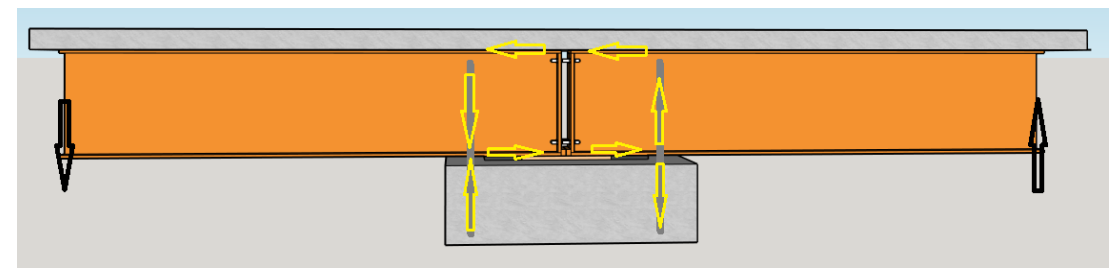

Figure 8-36 Load transfer mechanism under internal forces.

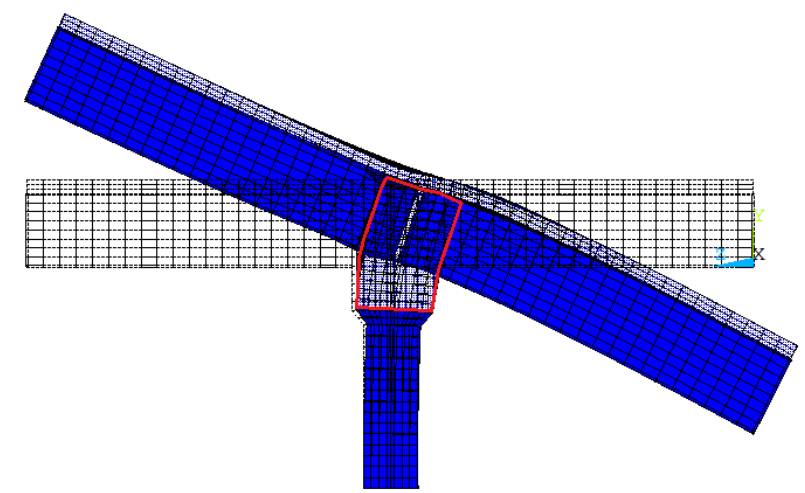

Figure 8-37 Exaggerated deflection of the model under inverse loading.

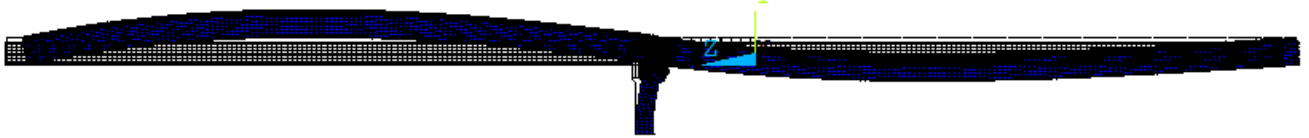

Figure 8-38 Exaggerated deflection of the model under horizontal axial force. 


\subsubsection{Effect of Bottom Flange Continuity under Inverse Forces}

In the previous sections, it was observed the amount of stresses in the continuous bottom flange at pier center line is not significant under inverse loading. Welding the bottom flanges together creates high residual stresses at the weld location inside of the concrete diaphragm. The residual stresses may result in the development of a brittle fracture in the steel girder that can cause significant service level stresses and decrease the service life of the bridge. For theses reason, it was crucial to study the capacity of the system with two different conditions including continuity and non-continuity in the bottom flange. Four different finite-element models were studied to examine the role of bottom flange continuity in the moment capacity of the system when subjected to inverse forces. These configurations, shown in Figure 8-39, are:

-Model 1: Bottom flange is continuous. There is baseplate in the connection.

- Model 2: Bottom flange is not continuous. There is baseplate in the connection.

- Model 3: Bottom flange is continuous. There is no baseplate in the connection.

- Model 4: Bottom flange is not continuous. There is no baseplate in the connection.

Moment-Drift capacity for the different configurations are shown in Figure 8-40. The results indicate that the difference in moment capacity for the different models is insignificant. It was observed that continuity of the bottom flanges is not vital under inverse loading. Figure 8-41 shows the value of von-Mises stresses in the connection. The maximun von-Mises stresses in the connecting plate and baseplate are around $20 \mathrm{ksi}$ and there is no yielding in these parts of the system at the ultimate load level. 

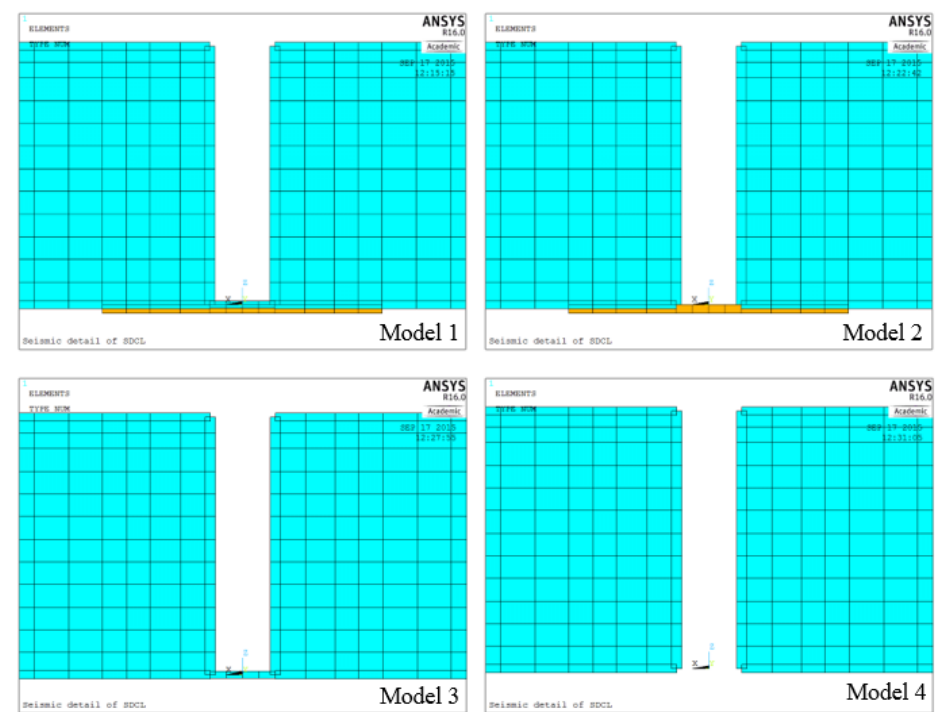

Figure 8-39 Different configurations for connection between bottom flanges and baseplate.

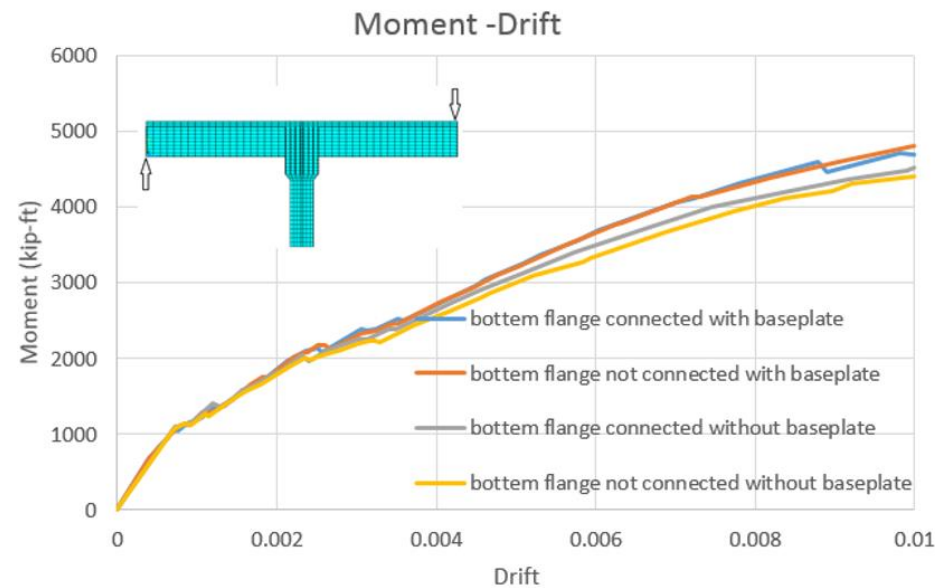

Figure 8-40 Moment-drift curve for the 4 different bottom flange/baseplate configurations. 

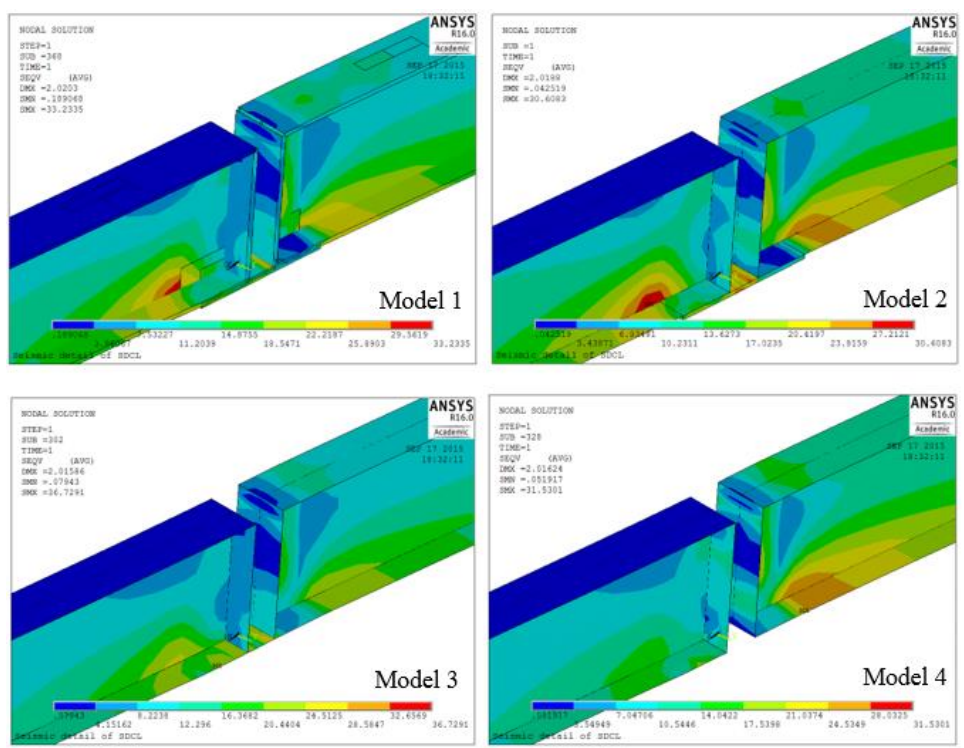

Figure 8-41 von-Mises stresses for different configuration of connection between bottom flanges and baseplate, unit=ksi.

\subsubsection{Distribution of Cracks under Inverse Forces}

For the non-integral bridge model, the joints of the bent cap and concrete diaphragm were merged together in the finite-element model. As long as the tension capacity of the concrete is ignored, merging the common nodes at the interface of the bent cap and concrete diaphragm can simulate the real boundary conditions of a concrete diaphragm that is placed over the bent cap.

Figure 8-42 shows the cracks pattern in the concrete diaphragm and bent cap due to inverse loading at different steps of the analysis. Figure 8-43 shows a plan and section view of the crack pattern for the push-down side of the deck and the interface of the concrete diaphragm and bent cap. In this figure, the crack pattern is not symmetric on the two sides of the pier centerline due to a concentration of nonlinearity in the concrete of slabs, concrete diaphragm and bent cap.

Figure 8-44 illustrates the distribution of cracks in an integral bridge model. As seen in this figure, the concrete cracks of the system started to develop from above the concrete diaphragm and below the bottom flanges. Figure 8-45 shows the cracks and crushing of the concrete with more detail in the left and right sides. Note that in this figure, cracks are labeled first, second, and third 
according to the sequence of occurrence. For example, a crack labeled third represents an integration point with cracks in all three orthogonal directions. In Figure 8-45, the nonlinear behavior of the right and left wing of the model are similar. The main reason is that nonlinearity of the system is concentrated in the dowel bars and the right and left side of the deck are in elastic range.

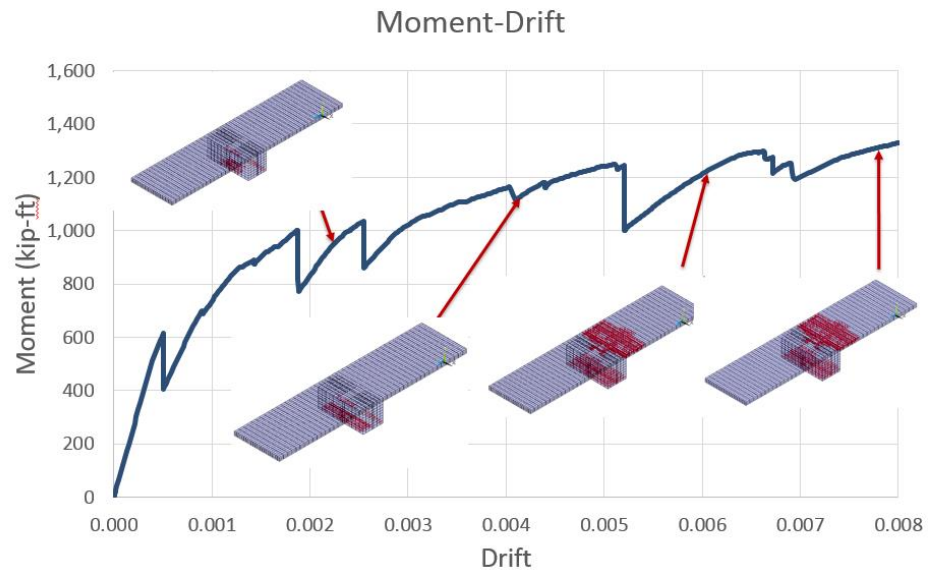

Figure 8-42 Distribution of cracks in the concrete diaphragm and deck under inverse loading in a non-integral bridge.

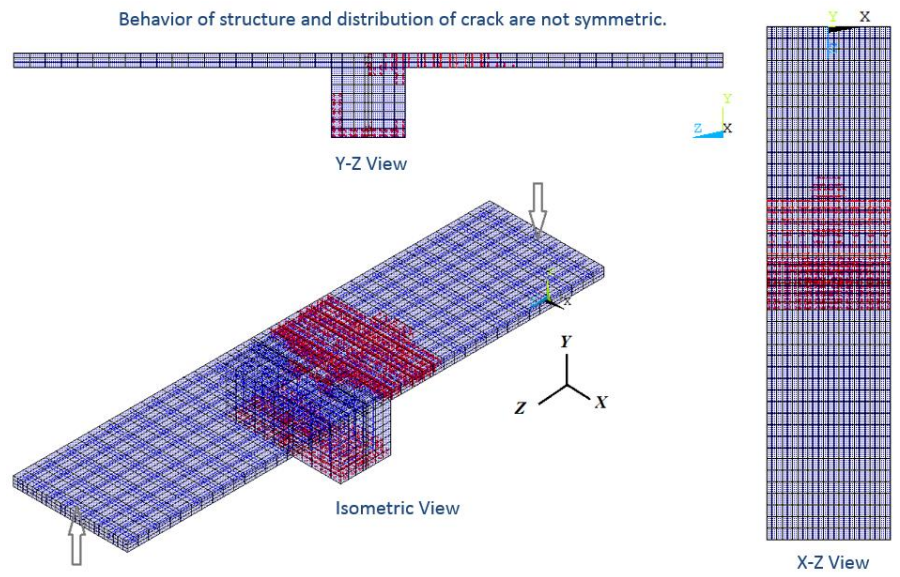

Figure 8-43 Pattern of cracks in the system under inverse loading in non-integral bridge. 


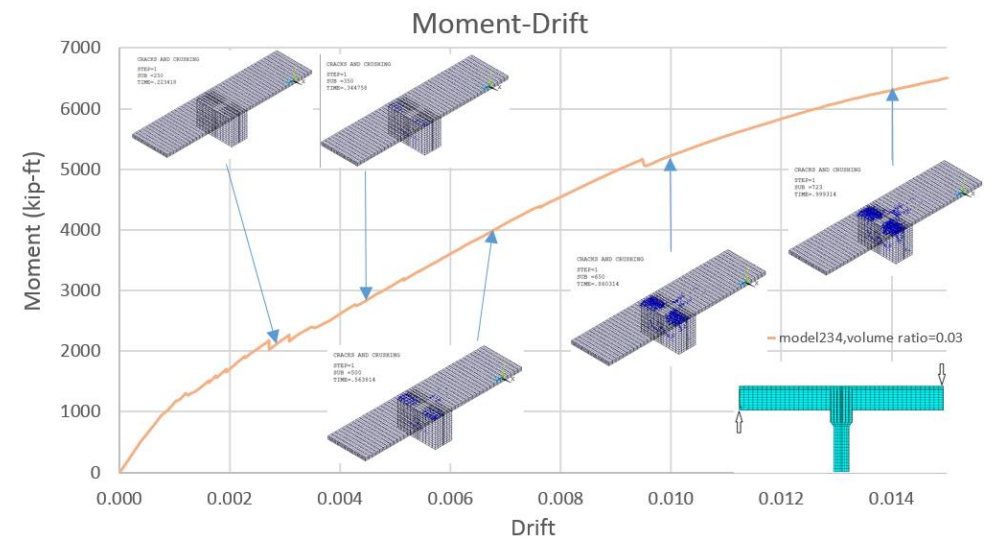

Figure 8-44 Distribution of cracks in concrete diaphragm and deck under inverse loading in integral bridge.

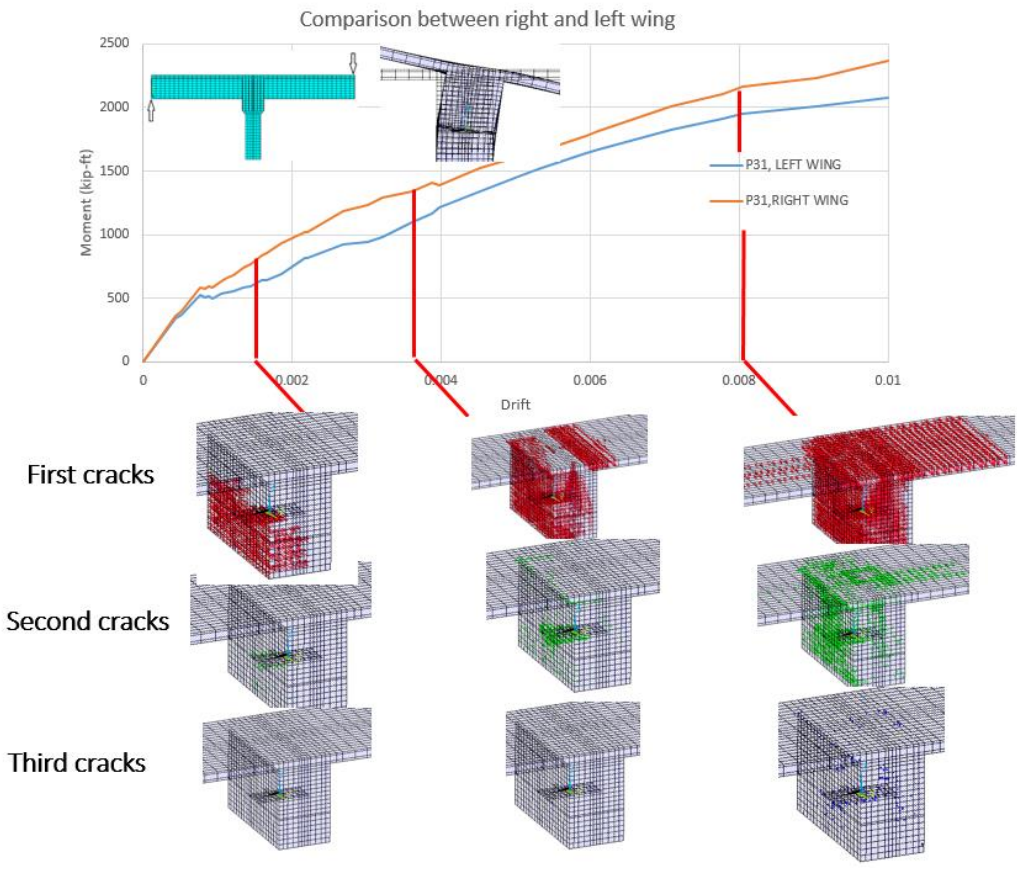

Figure 8-45 Distribution of cracks in the left and right wing of model under inverse loading in integral bridge. 


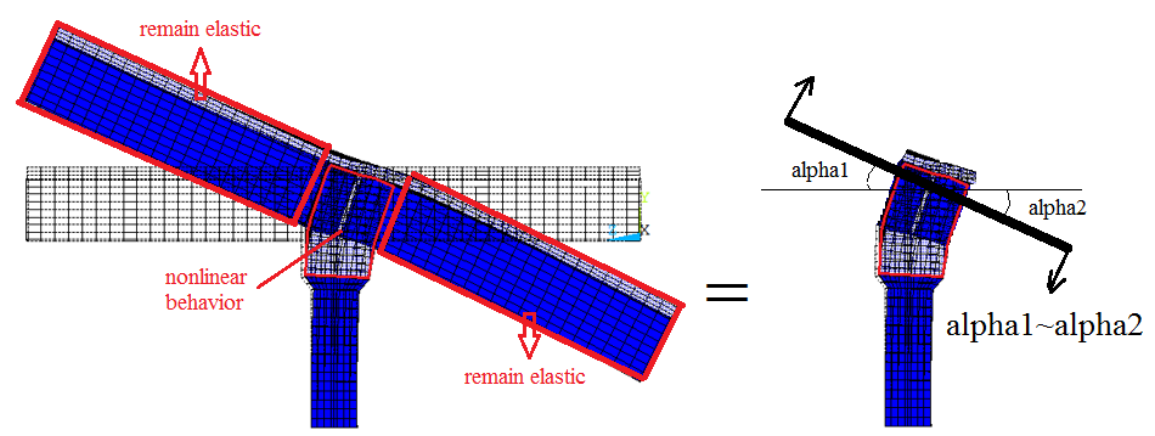

Figure 8-46 Concentration of nonlinearity in the system under inverse loading.

\subsubsection{Load Resistance Mechanism under Inverse Forces}

Results from the finite-element analysis indicate the load resistance mechanism of both models (inverse loading and axial force at one end) is concentrated in the dowel bars between the concrete diaphragm and bent cap. While the push-up side dowel bars and concrete around the bottom flange is under tension, the push-down side dowel bars and concrete around the bottom flange is under compression. As presented in Figure 8-47, at a drift level of 0.0025 and 0.0032 cracks start to develop in the deck and below of the bottom flange, respectively. Figure 8-48 illustrates the initial cracks of the system. These cracks start to happen at the push-up side of the deck at the edge of the diaphragm. In addition, upon increasing the load steps, the concrete below the bottom flange at the push-up side started to crack. Figure 8-49 indicates that at this step of analysis, the von-Mises stresses in the bars and girders remain in elastic range.

The next stage in the failure sequence is yielding of the dowel bars on the tension side. The Moment-Drift plot in Figure 8-47 shows yielding of the dowel bars occurred at a drift of around 0.005. Figure 8-50 and Figure 8-51 show the distribution of von-Mises stresses in bars and locations of cracks in the concrete respectively. After reaching the maximum capacity, some parts of concrete at the interface of the deck and diaphragm and below the bottom flange are crushed. Figure 8-52 shows the locations and signs of crushing in the concrete. The model under axial force indicates similar results to the model subjected to inverse loading. Figure 8-53 presents the moment-axial 
deflection of the system under axial force. In this figure, the amount of moment is equal to the axial force times the half-length of the column (Figure 8-54).

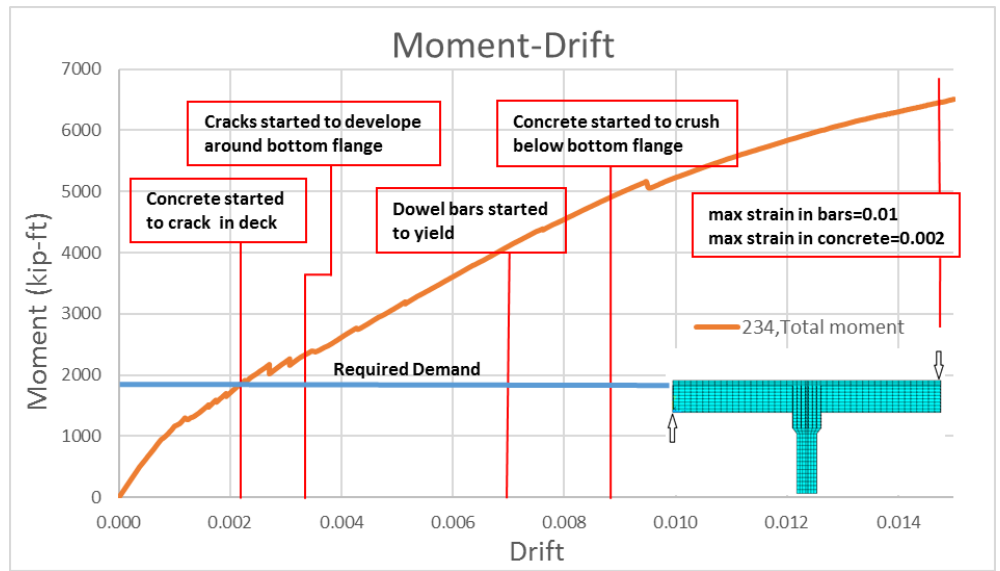

Figure 8-47 Sequence of failure modes under inverse forces.

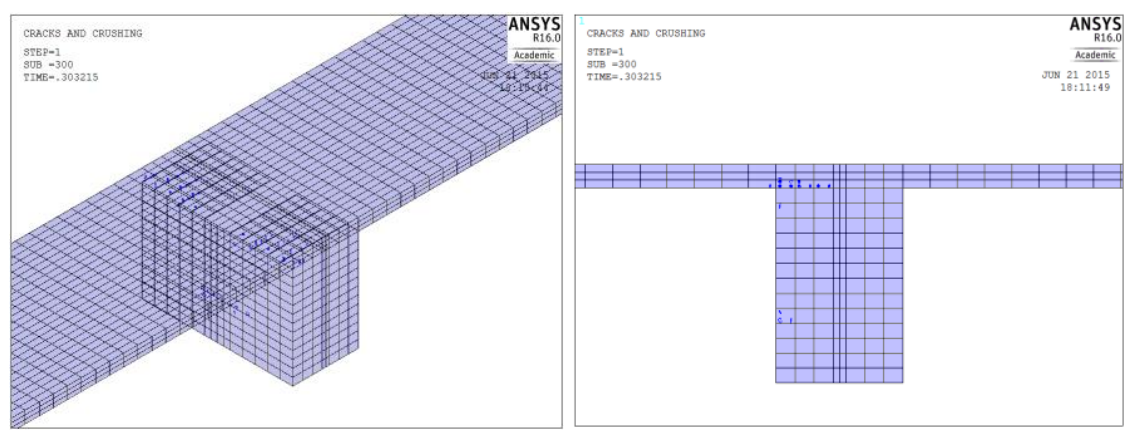

Figure 8-48 Cracks in concrete deck over the concrete diaphragm and below the girder bottom flange (push-up side) at sub step 320 out of 723 (model No. 234).

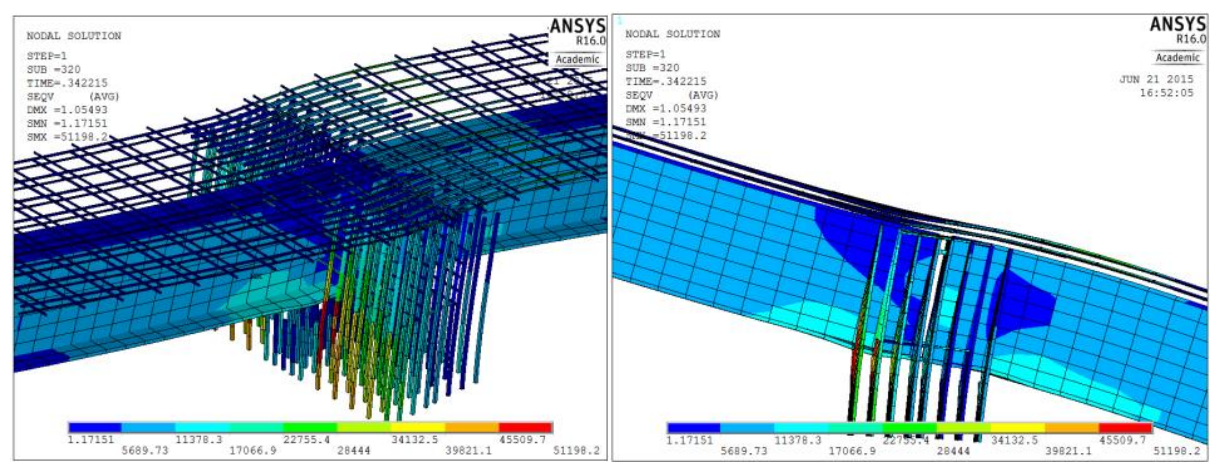

Figure 8-49 von-Mises stress in bars and girders at sub step 320 out of 723 (model No. 234). 


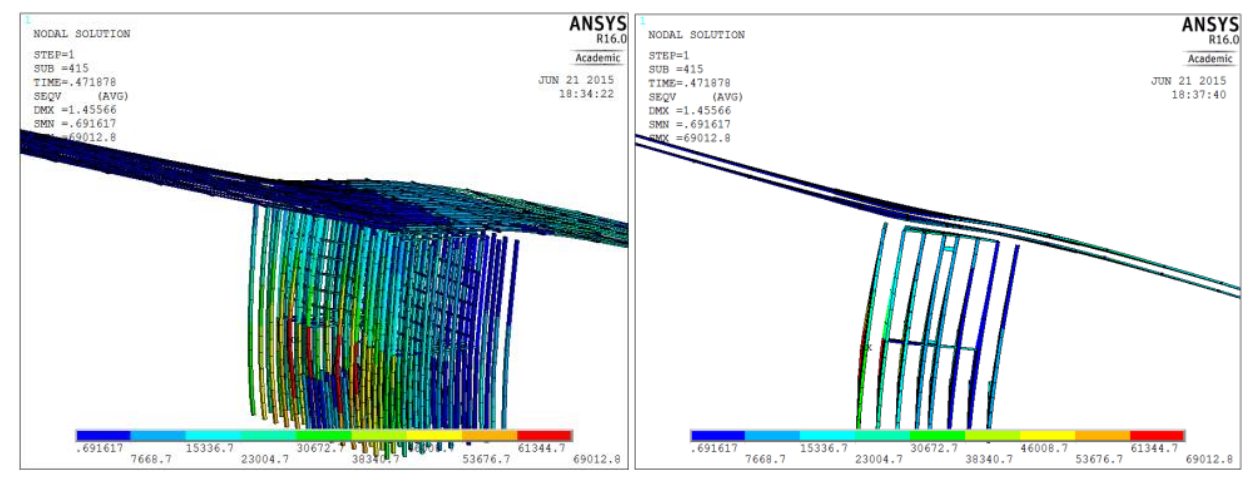

Figure 8-50 von-Mises stress in bars at sub step 415 out of 723 (model No. 234).

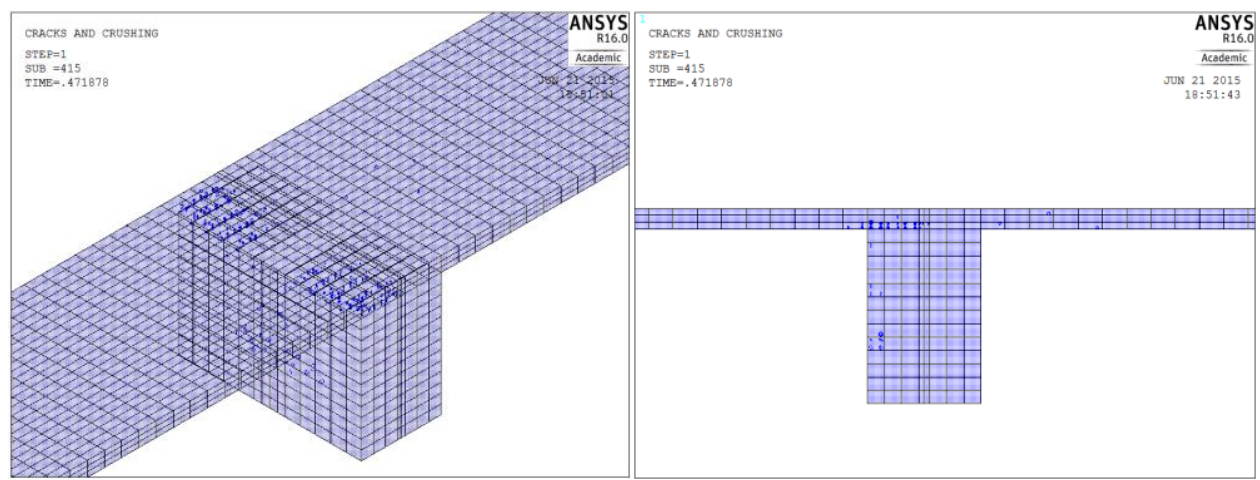

Figure 8-51 Cracks in concrete deck over the concrete diaphragm and below the girder bottom flange (push-up side) at sub step 415 out of 723 (model No. 234).

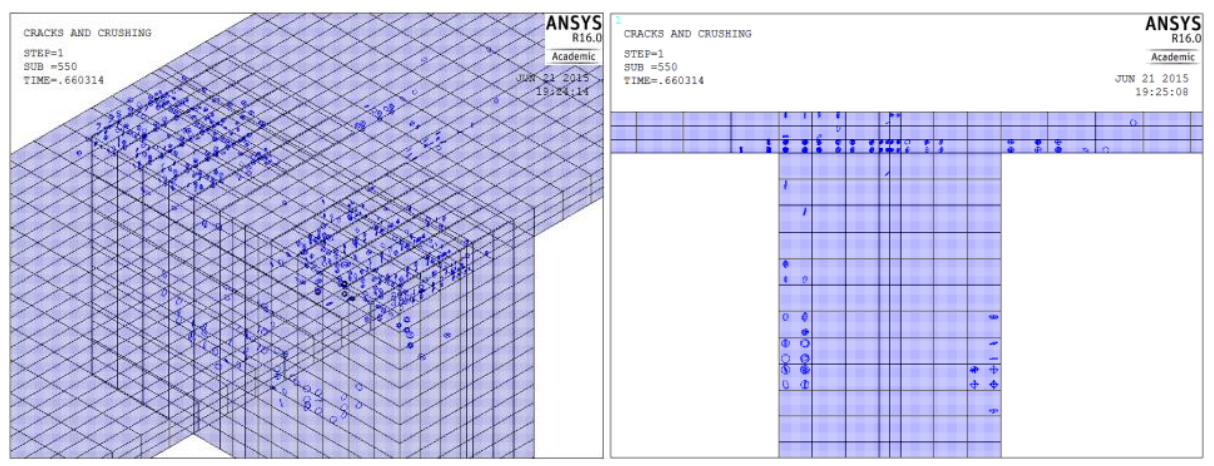

Figure 8-52 Starting of crushing in concrete deck over the concrete diaphragm and below the girder bottom flange (push-up side) at sub step 450 out of 723 (model No. 234). 


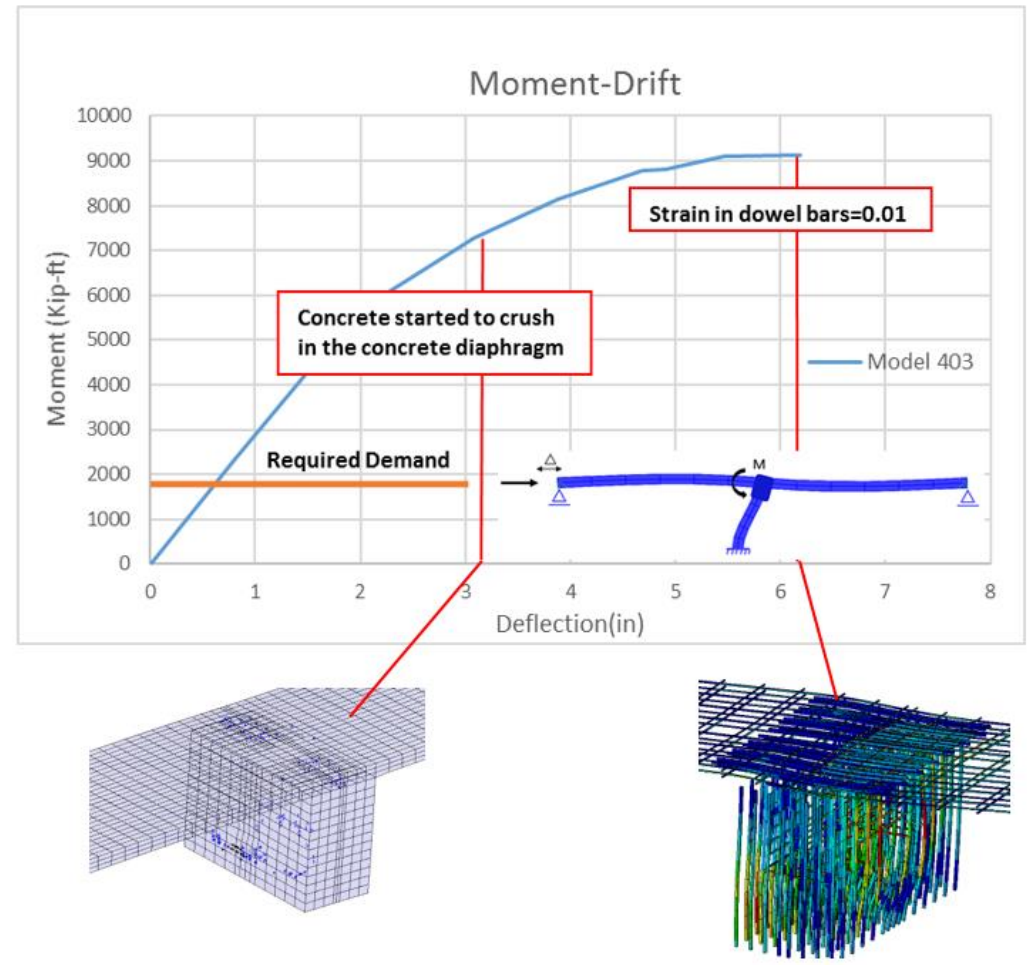

Figure 8-53 Sequence of failure modes under axial forces.

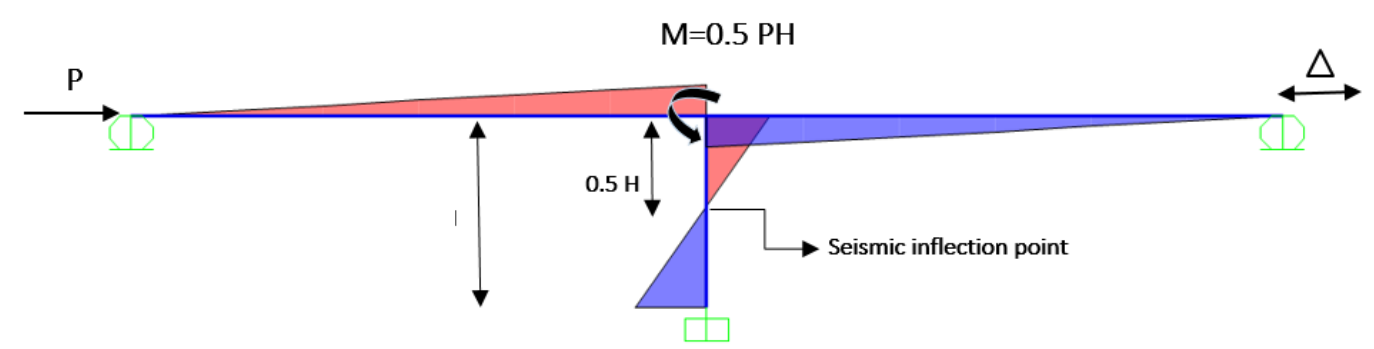

Figure 8-54 Amount of moment at connection of deck and substructure due to axial force.

\subsection{Revised Seismic SDCL Detail}

The preliminary finite element investigation detailed in the previous chapter indicated that bolting the girders together at the top and bottom of the connection does not significantly improve the seismic performance. Specifically, the bolts were not effective under inverse loading, which is a simulation of seismic loads in longitudinal direction of earthquake ground motion. Therefore, it was determined that a revised connection detail be considered. 


\subsubsection{Configuration of the Revised Seismic Detail}

Two variations were considered as demonstrated in Figure 8-55. In both details, shear studs and horizontal reinforcement bars were added near the bottom flange. In the first detail, shear studs and reinforcement bars were added above the bottom flange. In the next detail, shear studs and reinforcement bars were added below the bottom flange, which places the reinforcement further from the deck thereby increasing the moment are. To ease of construction, the detail with reinforcement above the bottom flange was selected for further investigation. A 3D schematic view of this detail presented in Figure 8-56. Finite element analyses were conducted to investigate the detail, the results of which are presented in the following sections.
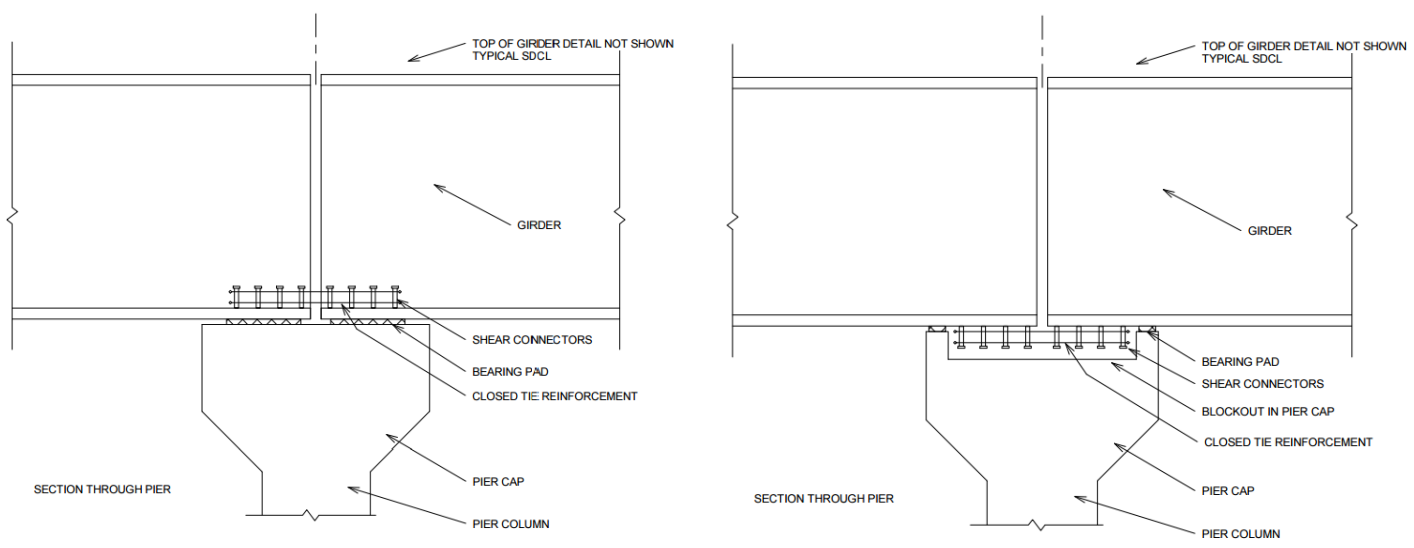

Figure 8-55 Two alternative connections for revised detail. 

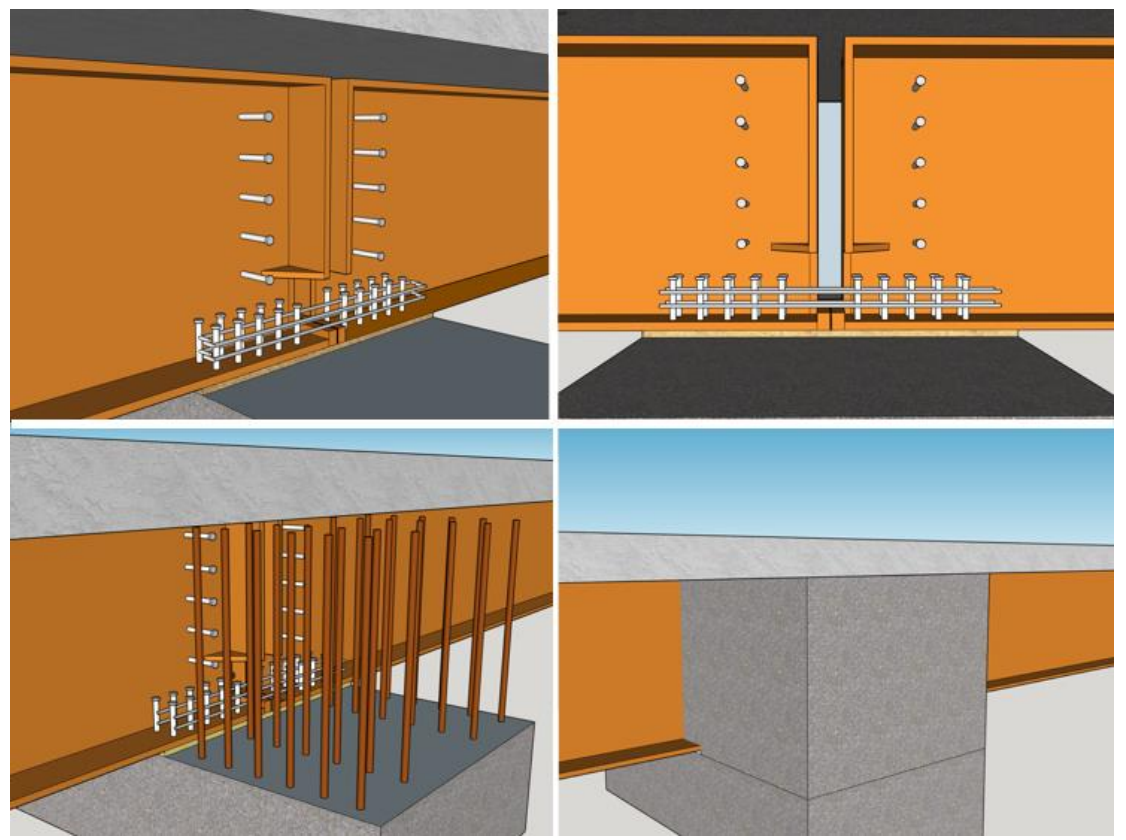

Figure 8-56 Revised seismic detail of SDCL bridge connection over the pier.

\subsubsection{Flange continuity comparisons}

The first step in evaluating the connection was to perform a comparative study and see how the detail behaved relative to various idealized conditions. To evaluate the performance of the revised detail, four different finite element models were considered. These are listed in Table 8-1 and shown in Figure 8-57.

Table 8-1Bottom flange/tie bars configurations.

\begin{tabular}{|c|c|c|}
\hline Case No. & Bottom flange connected? & Tie bars added to the detail? \\
\hline ModelP49 & Yes & Yes \\
\hline ModelP50 & No & Yes \\
\hline ModelP51 & Yes & No \\
\hline ModelP52 & No & No \\
\hline
\end{tabular}

The contribution of the bottom flange and horizontal bars were found under different load conditions. The area of the horizontal tie bars was assumed to be equal to the area of the bottom flange. Accordingly, a comparison between the flexural strength of ModelP50 and ModelP51 would be reasonable.. 


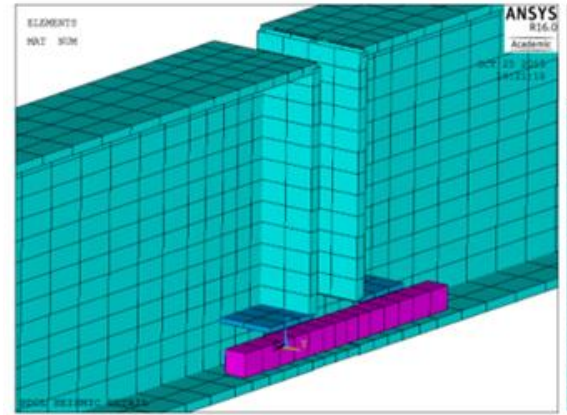

bottom flange connected+tie bars (modelP49)

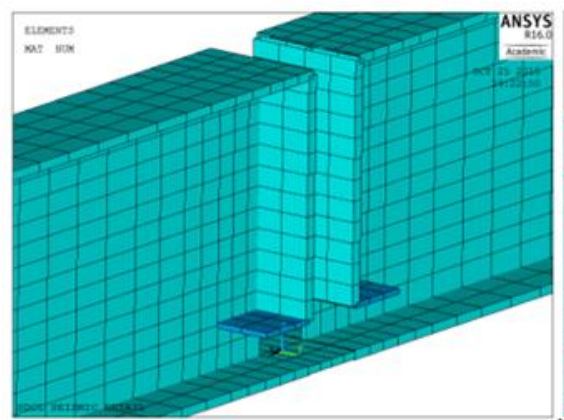

bottom flange connected +no tie bars (modelP51)

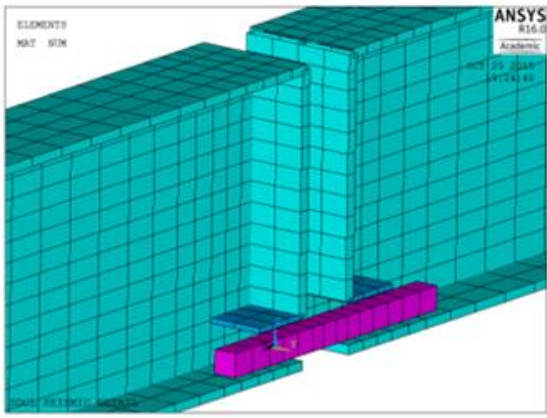

bottom flange not connected+tie bars (modelP50)

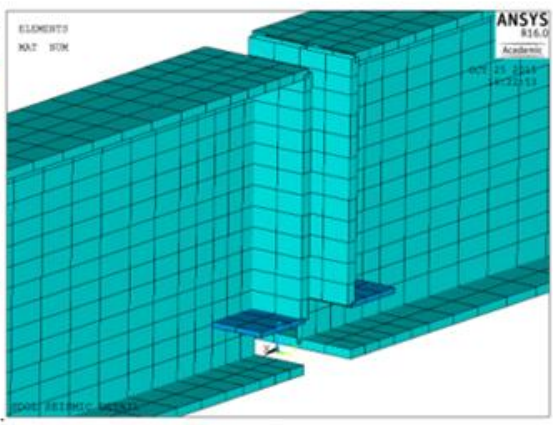

bottom flange not connected+no tie bars (modelP52)

Figure 8-57 Different finite element models to check the performance of revised detail.

\subsubsection{Evaluation of Revised Detail Under Different Load Conditions}

Finite element analyses were conducted for the different models due to push-up, pushdown and inverse loading to study the performance of each model. The conclusions obtained from each load case scenario are summarized below.

\section{Inverse loading:}

1- Continuity of the bottom flange did not change the ultimate moment capacity of the system significantly. Connecting the bottom flanges together increased the capacity slightly (see Figure $8-58)$.

2- Adding horizontal reinforcement bars did not change the capacity of the system. The role of these bars in the moment capacity is insignificant under this loading (see Figure 8-58) 
3- Results indicate that adding bolts, horizontal bars or continuity of the bottom flange are not able to enhance the capacity of the system under inverse loading.

4- Outcomes from both the previous (bolted) and revised seismic details, indicate that the dowel bars are the critical component of the system under inverse loading (see Figure 8-59)

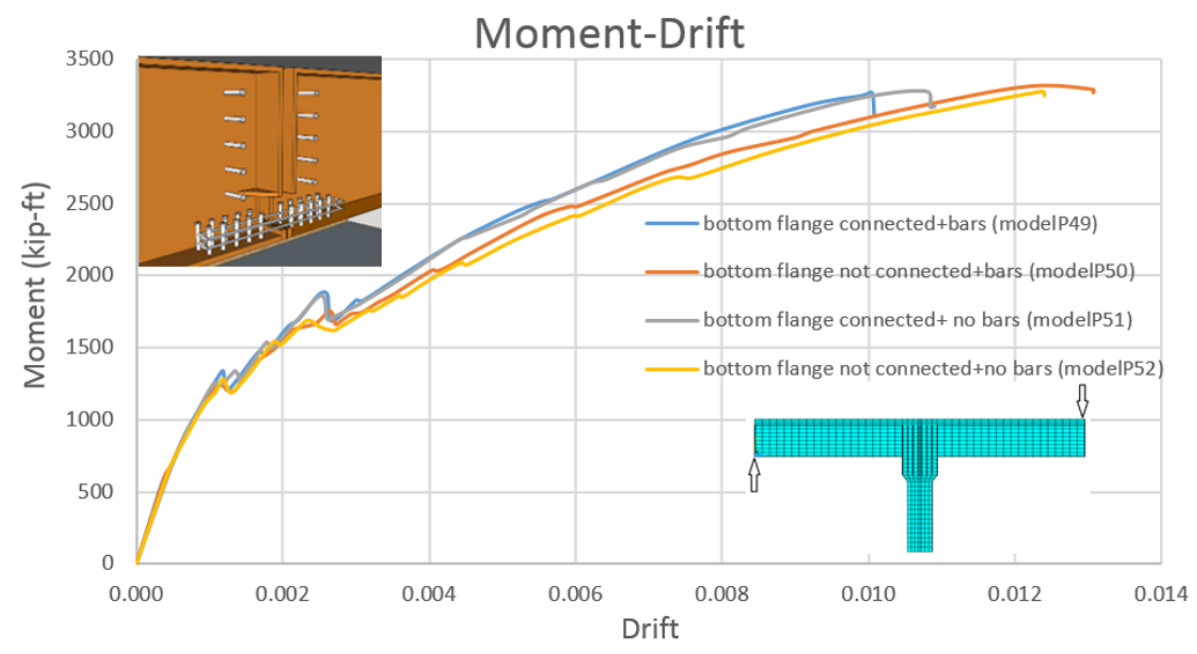

Figure 8-58 Moment-Drift plot of revised seismic detail under inverse loading. 


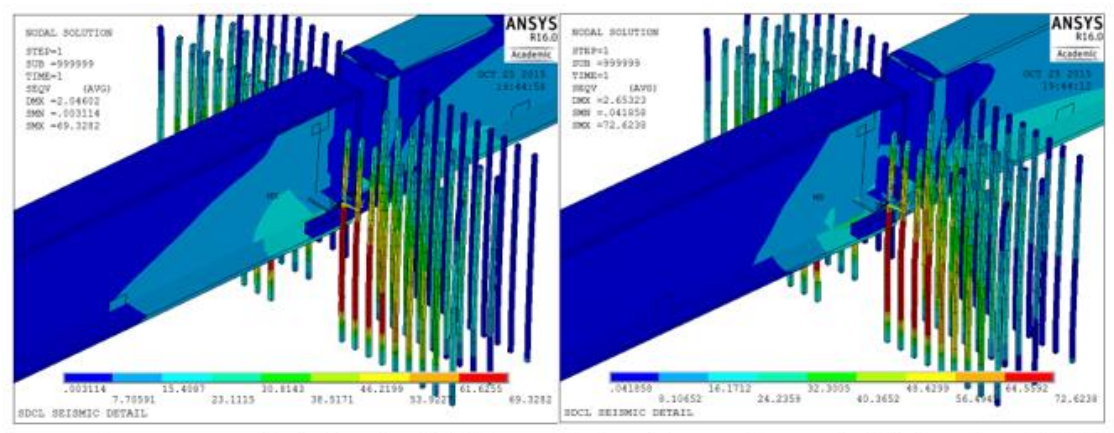

bottom flange connected +tie bars (modelP49)

bottom flange not connected +tie bars (modelP50)

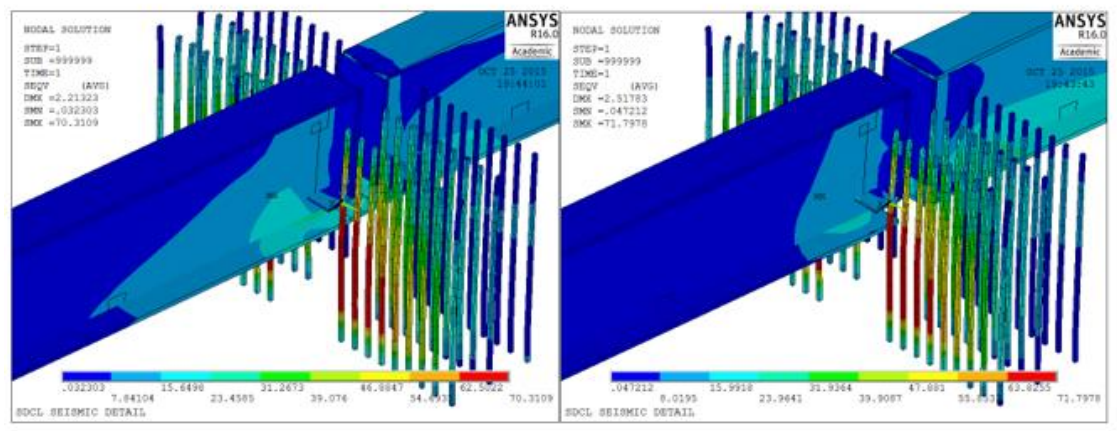

bottom flange connected + no tie bars (modelP51) bottom flange not connected + no tie bars (modelP52)

Figure 8-59 von-Mises stresses for different finite element models under inverse loading.

\section{Push-down loading:}

1-Continuity of the bottom flange increased the ductility and capacity of the system while the role of the horizontal reinforcing bars is insignificant. This conclusion is similar to that obtained in the preliminary (bolted) detail (see Figure 8-60).

2-When the bottom flange is not continuous, horizontal reinforcement bars increased the capacity of the system in a small amount (see Figure 8-60).

3-Reinforcement in the slab and tie bars (when the bottom flange is not continuous) above the bottom flange are the most critical elements of the system under push-down forces (see Figure $8-61)$. 


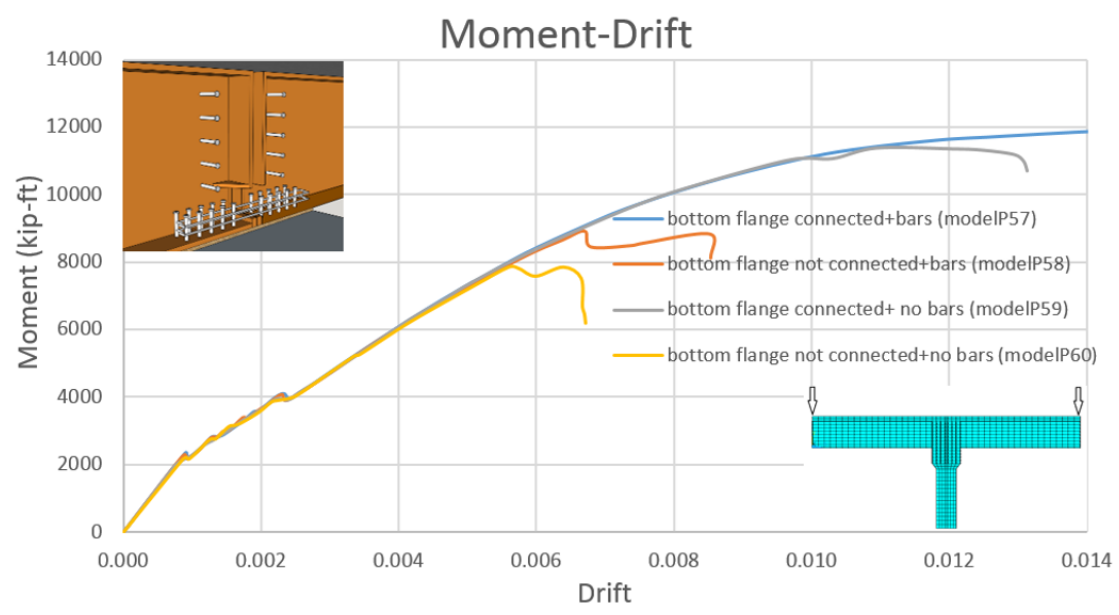

Figure 8-60 Moment-Drift plot of revised seismic detail under push-down forces.

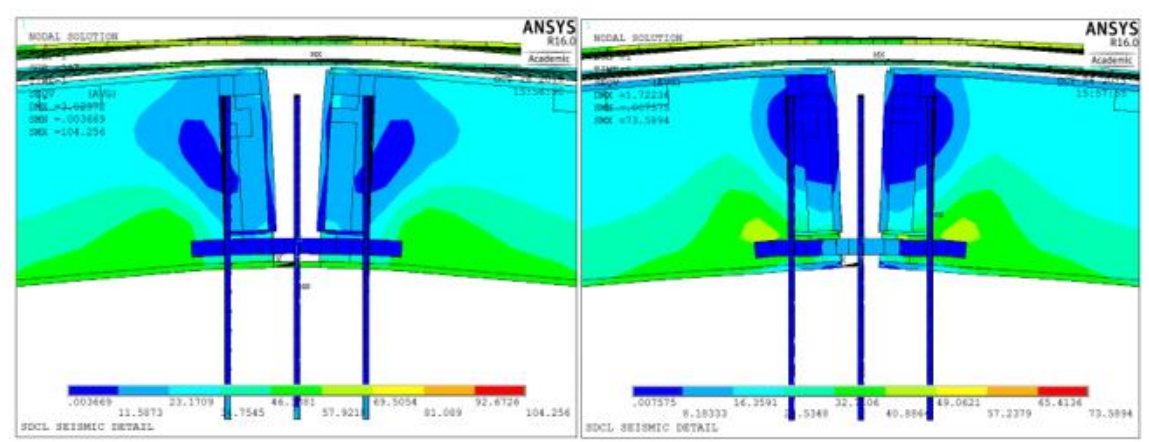

bottom flange connected +tie bars (modelP49) bottom flange not connected+tie bars (modelP50)

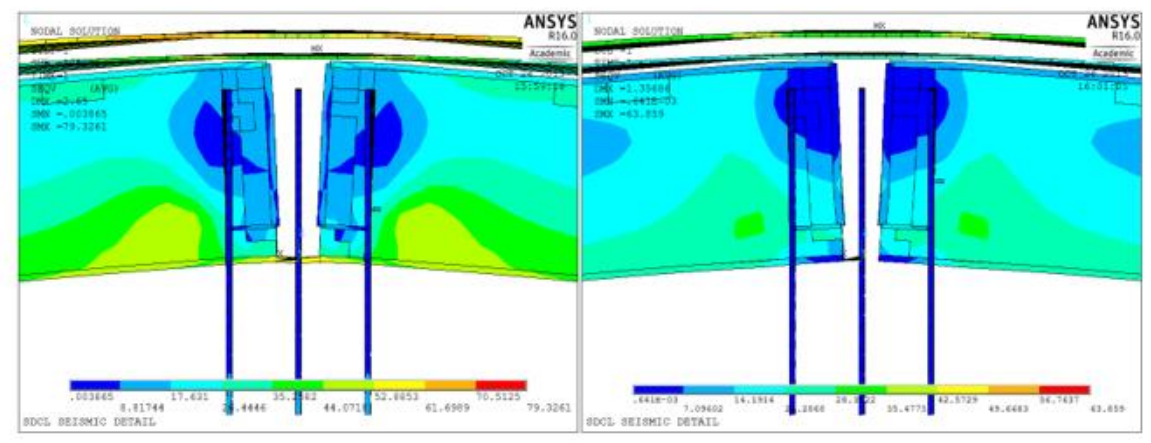

bottom flange connected+no tie bars (modelP51) bottom flange not connected+no tie bars (modelP52)

Figure 8-61 von-Mises stresses for different finite element models under push-down forces.

\section{Push-up loading:}

1-Continuity of the bottom flange increased the moment capacity of the system significantly (see

Figure 8-62). 
2-Adding horizontal bars enhanced the capacity of the system about $10 \%$ when the bottom flange was continuous and more than 50\% when the bottom flange was not continuous (see Figure 8-62).

3-Bottom flange and dowel bars near the bottom flange are the critical elements of the system under push up loading (see Figure 8-63)

4-Theoretically, if the area of the two horizontal bars were the same as the area of the bottom flange, the ultimate capacity of the "bottom flange not connected + bars (modelP54)" and "bottom flange connected + no bars (modelP55)" would be close. However, the result indicates there is a considerable difference between the resulting ultimate moment in these two cases. (see Figure $8-62)$.

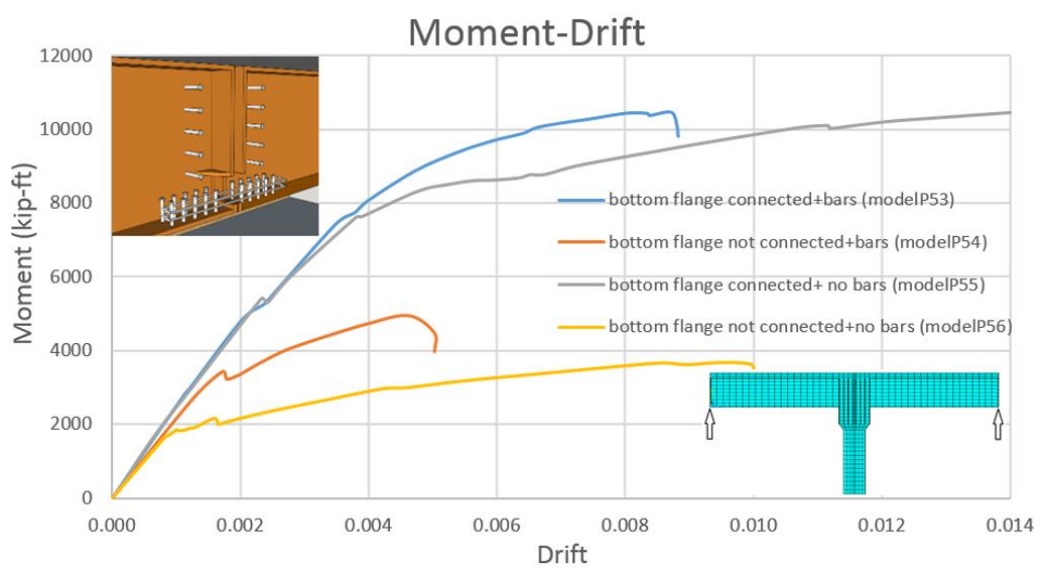

Figure 8-62 Moment-Drift plot of revised seismic detail under push-up forces. 


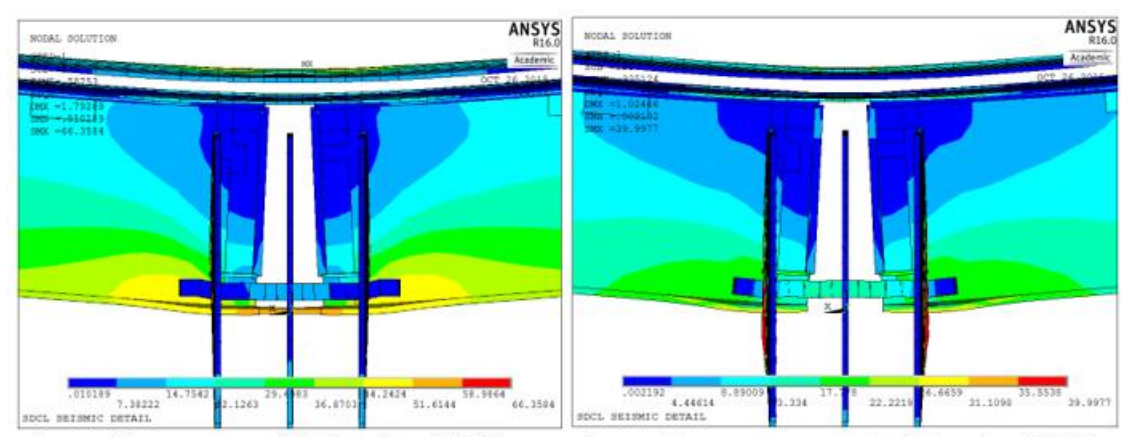

bottom flange connected +tie bars (modelP49)

bottom flange not connected +tie bars (modelP50)

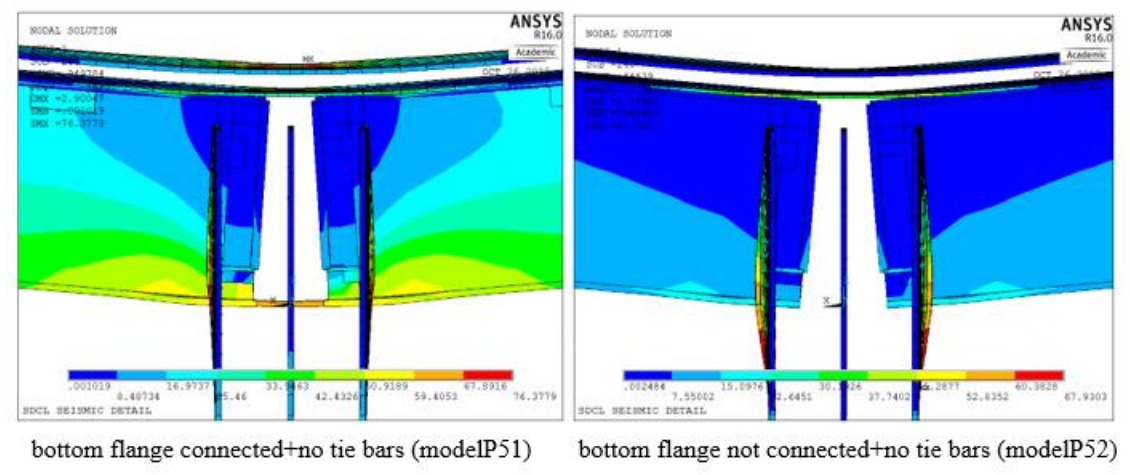

Figure 8-63 von-Mises stresses for different finite element models under push-up forces.

\subsubsection{The Rate of Stress Increase In Different Elements}

Results indicate the majority of internal force is carried by the dowel bars that connect the bent cap to the concrete diaphragm. The amount of force in the concrete and tie bars is less than that in the dowel bars. To find the rate of stress increase in different elements, the value of stress versus drift of the system is plotted in Figure 8-64. This plot shows the rate of stress increase in the dowel bars, tie bars and concrete below the steel girder. 


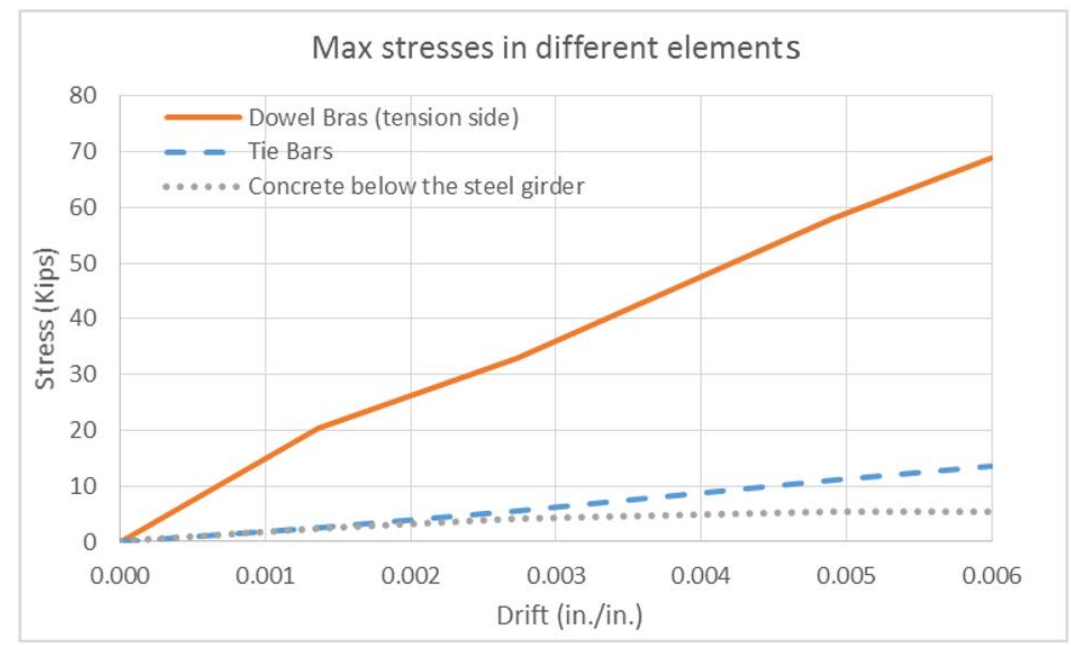

Figure 8-64 Value of maximum stress in different elements.

\subsubsection{Monolithic Versus Cold Joint Assumption In The Moment Capacity}

There are two ways to connect the bent cap into the concrete diaphragm. Up to this point in the research, it was assumed that the connection between the bent cap and concrete diaphragm was rigid. In other words, from the construction point of view, the bent cap and concrete diaphragm are monolithic. To achieve this behavior, the nodes at the interface of the bent cap and concrete diaphragm were merged together in the finite element model. However, the cap beam is precast and the concrete of the diaphragm will be cast after placing the girders over the bent cap. Therefore, assuming a cold joint exists between the bent cap and concrete diaphragm would be an acceptable and conservative assumption. Effectively, the cold joint between the bent cap and concrete diaphragm results in neglecting the tension capacity of the concrete. In the finite element model, the nodes are coincident, but not joined at the interface of the cap beam and concrete diaphragm.

The optimal method of modeling the interface would be introducing contact elements with zero tension capacity between the two bodies. However, preliminary efforts indicated that the model with the contact interface was computationally expensive and time consuming so the approach was not pursued further. 
The results shown in Figure 8-65 indicates that in the cold joint model, the dowel bars on the compression side and tension side are the only elements carrying the forces. Consequently, the compression capacity of concrete at the push-down side was neglected.

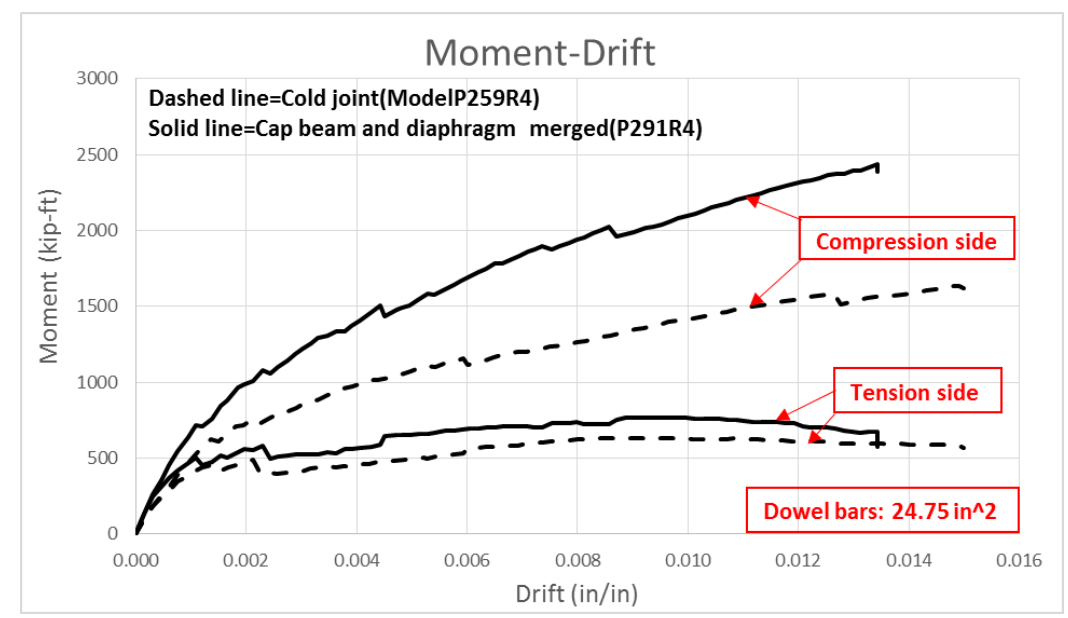

Figure 8-65 Difference between models with merged joint and separated joint at the interface of bent cap and concrete diaphragm.

\subsubsection{Effect Of Dowel Bars Location}

Results indicated the dowel bars near the flange contribute a majority of the tension and compression forces. Therefore, additional dowel bars were added along the sides of girders. The ultimate moment capacities shown in Figure 8-66 indicate the additional volume of steel does not significantly enhance the performance of the system. The explanation is that the added dowel bars are near to the centerline of the pier (neutral axis of the up-down for couple), thus they are not as effective as dowel bars near the two faces of the diaphragm. 


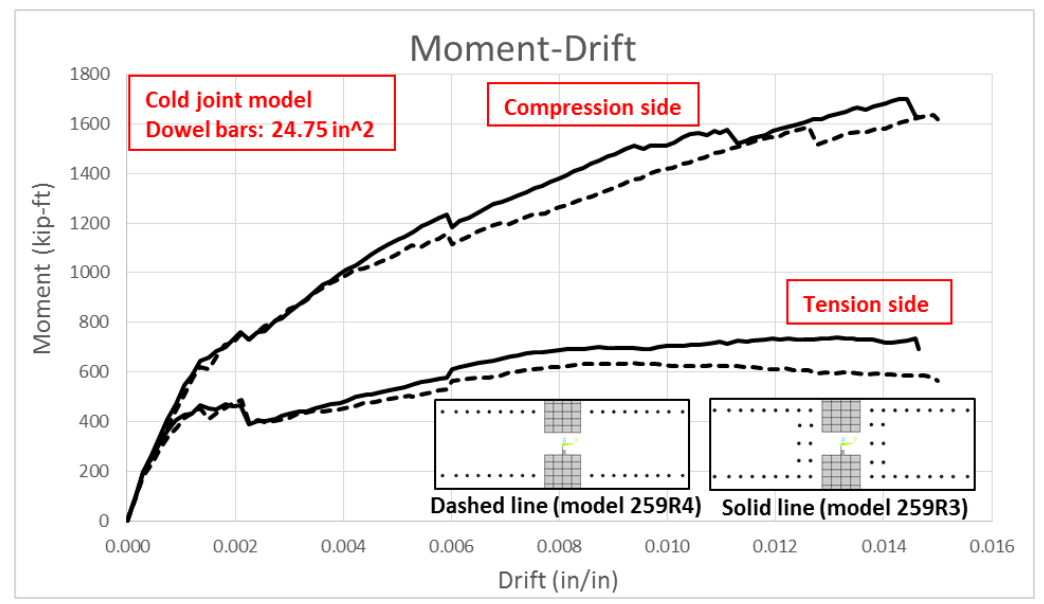

Figure 8-66 Moment capacity of the system with two different layouts for dowel bars.

\subsection{Evaluating Local Behavior of Resisting Elements}

To develop a design formula, the local behavior and distribution of strain and stress in the resisting elements should be studied in addition to the global behavior of the system. Based on the reported results, tie bars and dowel bars are the most critical elements of the system for the pushup and inverse loading respectively. Therefore, in this section, the local stresses and strains of these elements at the ultimate load level and yielding will be investigated. Figure 8-67 presents the strain distribution once the first dowel bars have yielded and again at the ultimate load level. Both plots indicate that the strains on the push-up side are much greater than the strains on the compressive side. On the tensile side, the concrete cracked yet on the compressive side, the concrete helps the dowel bars to take the compressive stresses. Furthermore, the plots show that at the ultimate load level, the maximum strain is much greater than the yielding strain of the reinforcing bars. The strain distribution is also observed to be similar to an exponential distribution along the bent cap rebar.

The strain distribution in the tie bars is shown in Figure 8-68. Plots at both the first yielding and at the ultimate load level imply the tie bars remain elastic, even until the last step of analysis. The strain in the longitudinal bars in the concrete slab and tie bars also remain in the elastic range until the last step of the analysis. The stresses in the tie and dowel bars are shown in Figure 8-71. 
Strain in the slab reinforcement is shown in Figure 8-69. Note that the strain distribution is not symmetric with respect to the pier centerline. The reason is the behavior of the system is not symmetric and cracking is concentrated on the push down side. The stress pattern below the bottom flange of push down girder is shown in Figure 8-70. The value of stress below the bottom flange center is maximum and immediately after moving two side of the bottom flange, it decreased. The amount of stress in the tie and dowel bars is shown in Figure 8-71.
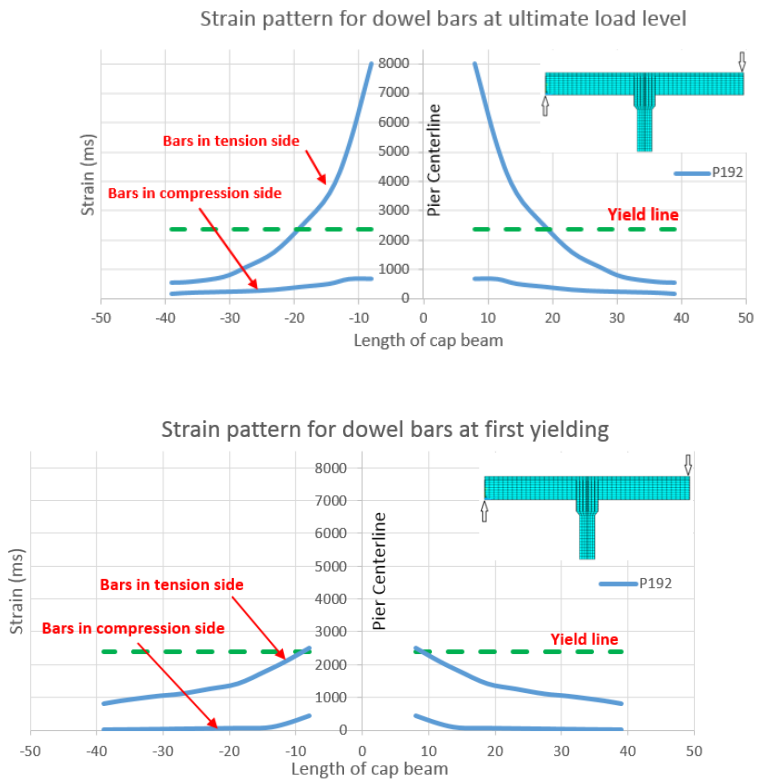

Figure 8-67 Strain patterns in the dowel bars.
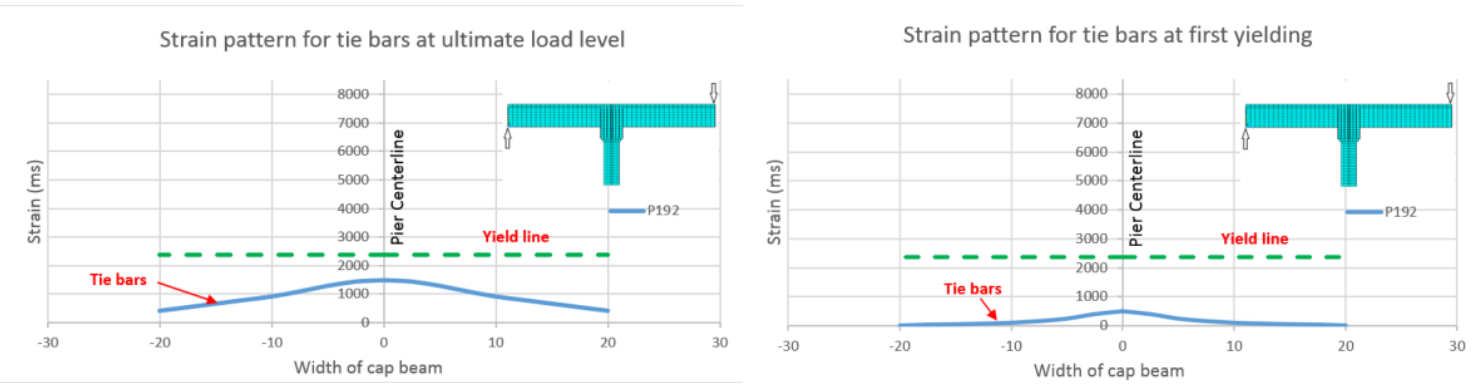

Figure 8-68 Strain patterns in the tie bars. 

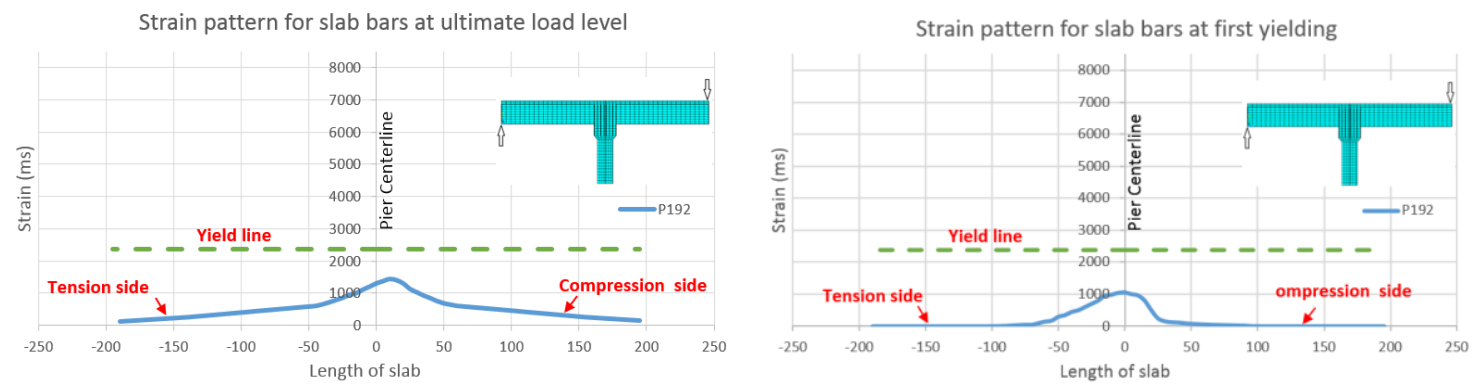

Figure 8-69 Strain patterns in the longitudinal bars in the slab.
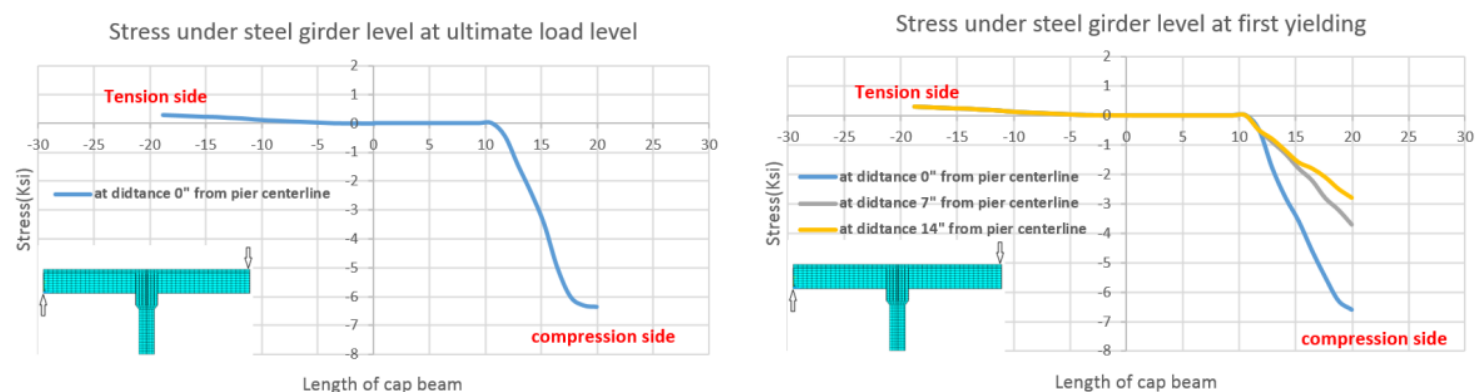

Figure 8-70 Stress patterns in the concrete below the bottom flange.
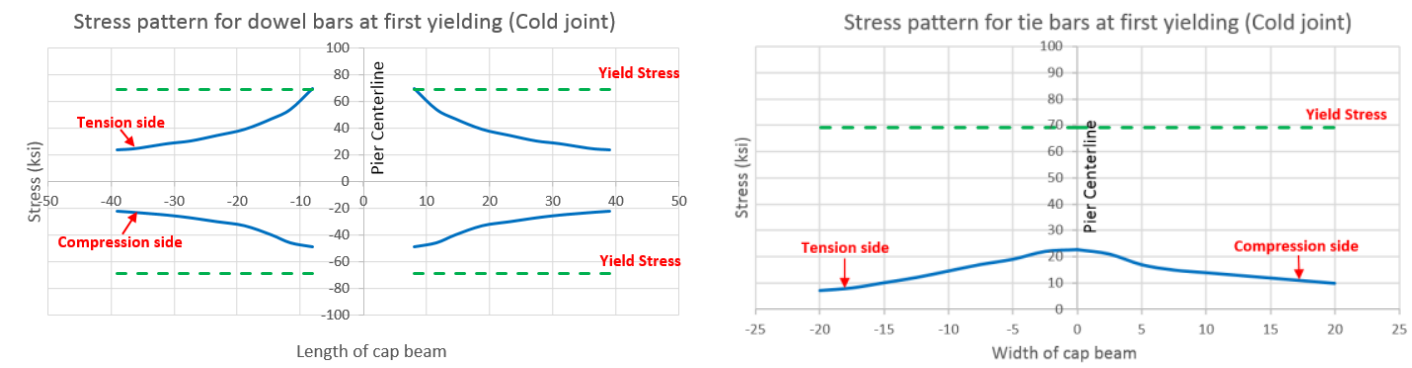

Figure 8-71 Stress patterns in the dowel bars (left) and tie bars (right). 


\section{PARAMETRIC FINITE ELEMENT ANALYSIS}

\subsection{Introduction}

The roles of different elements in the proposed detail were evaluated in Chapter 8. In this chapter, the results of a parametric finite element analysis are presented. The study was conducted to investigate how the area of steel in various elements affects the ultimate moment capacity of the system.

\subsection{Parametric Finite Element Models}

A fully parameterized finite element model was developed using ANSYS APDL. Parametric models have several advantages to Graphical User Interface (GUI). In the parametric models, the user does not need to start over when changing geometric variables such as span length, cap beam width, or size of steel girder. An important result of is avoiding accidental mistakes that can occur when using a graphical interface for construct each model.

\subsection{Selecting the Parameter Matrix}

The study was conducted to evaluate the behavior of the connection with varying amounts of reinforcement. Three different amounts of steel for the tie bars and dowel bars were selected as shown in Table 9-1. The area of dowel bars reported in the figure is the total area of steel at each face of the diaphragm and the area of tie bars reported is the total area of tie bars at the bottom flange. 
Table 9-1 Parametric Finite Element Models (FEM)

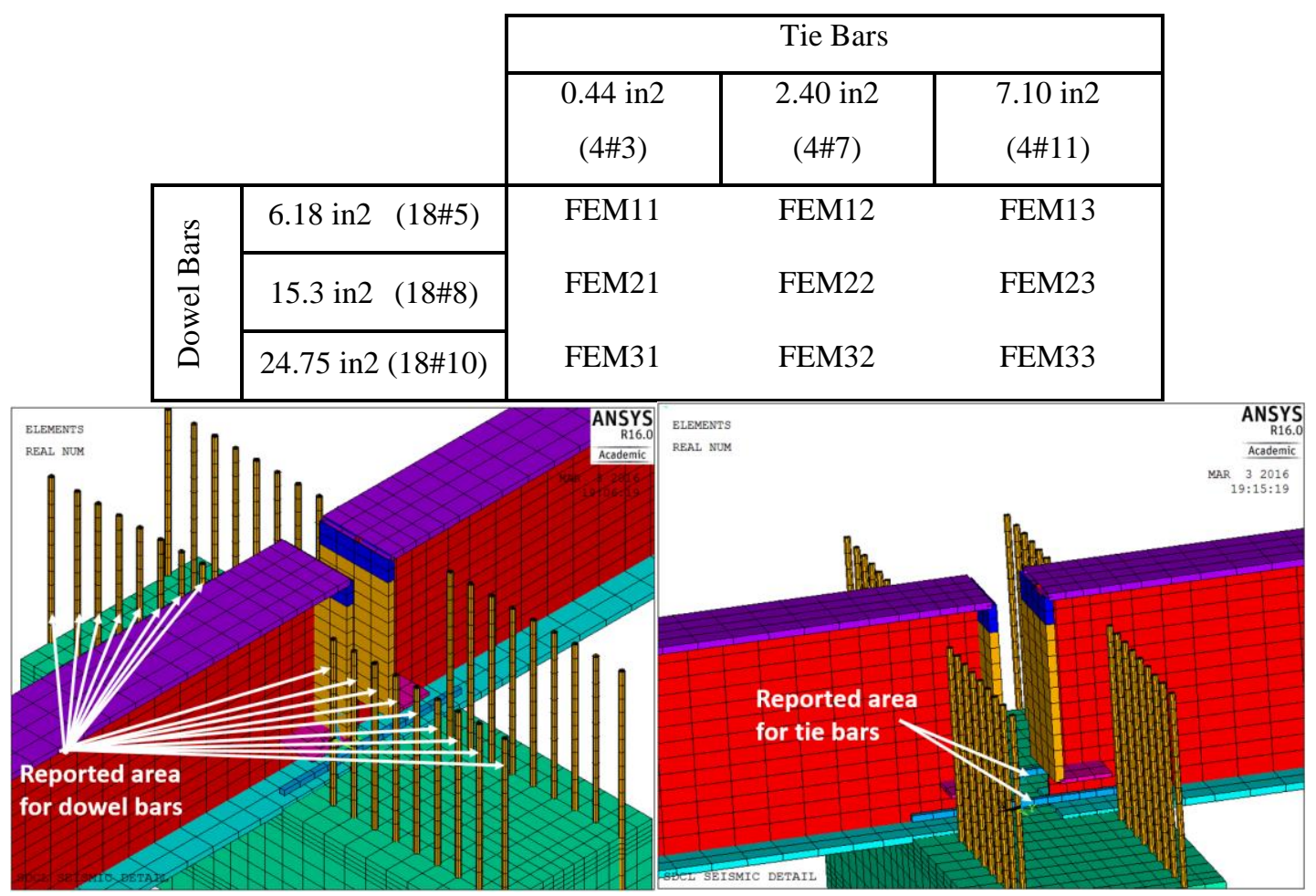

Figure 9-1 Reported dowel bars and tie bars.

\subsection{Parametric Model under Push Up Loading}

Figure 9-2 shows the role of dowel bars and tie bars when the connection is loaded by push up forces only. The results indicate that changing the amount of steel in the tie bars has a large effect on the moment capacity while varying the area of the dowels did not affect the strength. Of course if the dowel area were reduced to zero the only resistance to global uplift would be the selfweight of the system. 


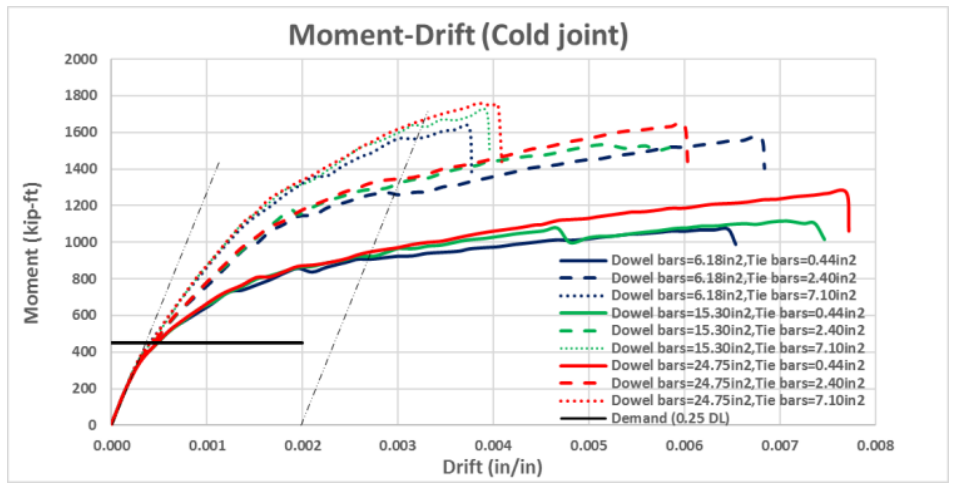

Figure 9-2 Effect of dowel bars and tie bars in the moment capacity under push-up loading.

Preliminary results indicated the demand under vertical ground acceleration (25\% weight of superstructure upward) is much less than the capacity of the system under push up forces.

It is desirable to quantify the capacity of the system in order to compare the results under various scenarios and look for trends. The ultimate capacity was taken to be the value when the load deflection curve reached a $0.2 \%$ offset of the initial stiffness. Graphically, the value of moment when the individual curves crosses a line parallel with the initial stiffness and offset $0.2 \%$. This capacity value is used in subsequent discussions. Figure 9-3 and Figure 9-4, plot the observed moment versus the areas of dowel and tie bar steel. The results indicate that increasing the area of dowel steel by a factor of approximately 4 only increases the capacity of the system by $5 \%$ to $15 \%$. Consider the case of minimal dowels ( $\left.6.18 \mathrm{in}^{\wedge} 2\right)$ and minimal of tie bars $\left(0.44 \mathrm{in}^{\wedge} 2\right)$, which results in an observed capacity of $1096 \mathrm{k}-\mathrm{ft}$. Increasing the dowels to $24.75 \mathrm{in}^{\wedge} 2$ resulted in a capacity of $1,270 \mathrm{k}-\mathrm{ft}$. However, a tie bar area of only $2.4 \mathrm{in}^{\wedge} 2$ was required to achieve a capacity of $1,500 \mathrm{k}-$ $\mathrm{ft}$.

Figure 9-5 shows the values of the von-Misses stresses in the dowel bars and tie bars compared with the values in the steel girders, slab bars and hooks. 


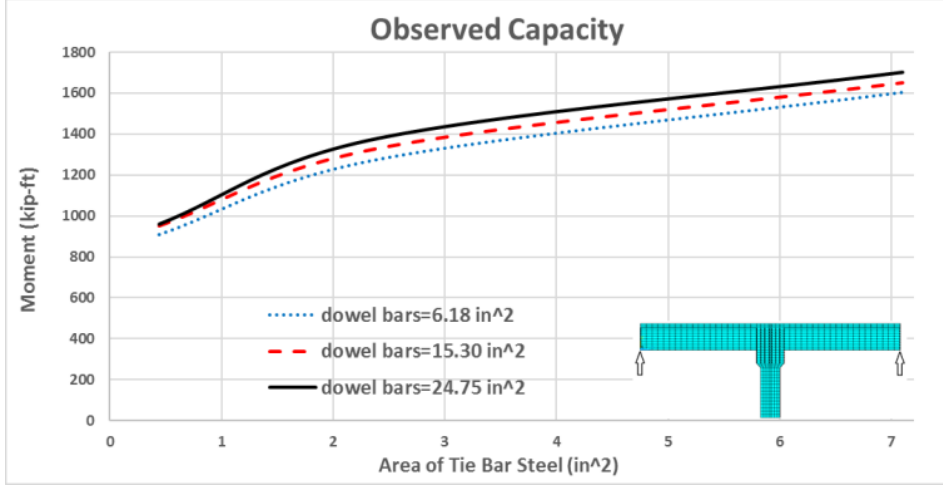

Figure 9-3 Observed capacity at $0.2 \%$ drift offset according to area of tie bar steel under push-up forces.

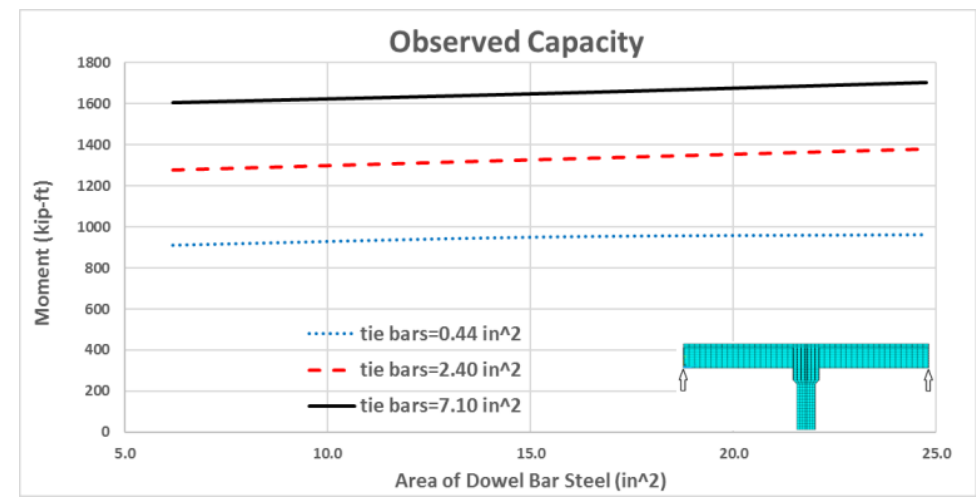

Figure 9-4 Observed capacity at $0.2 \%$ drift offset according to area of dowel bar steel under push-up forces.

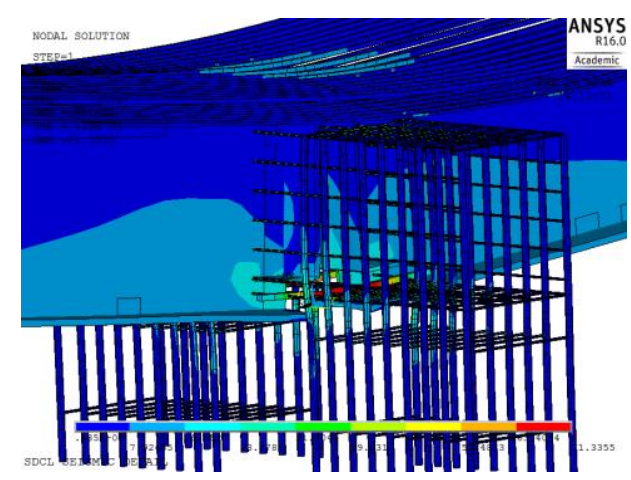

Figure 9-5 von-Mises stresses in dowel bars and tie bars under push-up forces (dowel bars $=24.75$ in 2 , tie bars $=2.4$ in2).

\subsection{Parametric Model under Reverse Loading}

The second series of analyses was conducted on the revised detail to evaluate the performance of the system under the inverse loading pattern. Figure 9-6 and Figure 9-7 present the Moment-Drift of the system for varying amounts of steel in the dowel bars and tie bars in tension 
side and compression side separately. The value of moment in compression side and tension side is equal to the value of push down and push up force times the length of the steel girder respectively. The total moment is equal to moment in compression side plus moment in tension side. Figure 9-7 shows that the tie bars have no effect on the capacity. This observation was also made for the preliminary bolted detail wherein the bolts at the top and bottom of the connection had no effect on the response of the system.

Figure 9-8 and Figure 9-9 demonstrate the ultimate moment capacity of the system according to different dowel bars and tie bars area. In addition, plots in Figure 9-8 shows there is a linear relation between the area of dowel bar and moment capacity of the system.

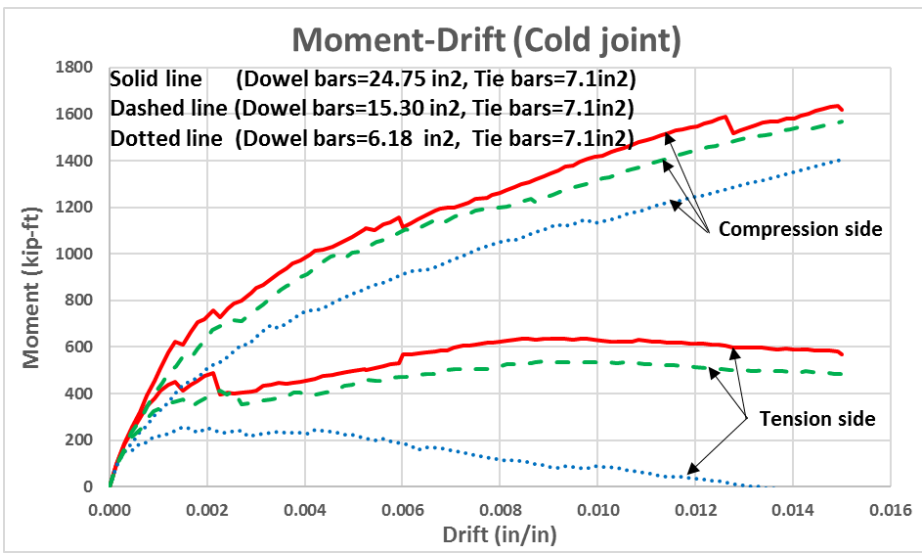

Figure 9-6 Effect of dowel bars in the moment capacity under inverse loading (Cold joint).

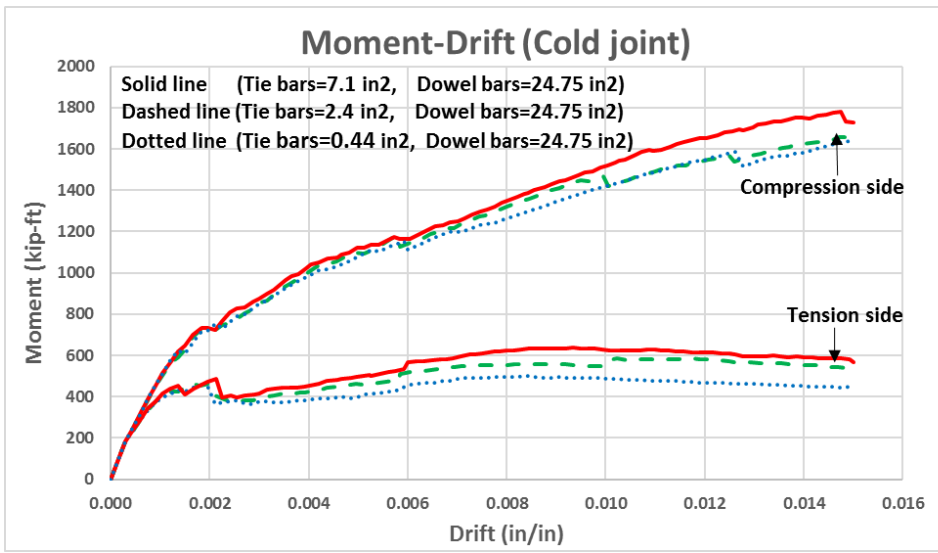

Figure 9-7 Effect of tie bars in the moment capacity under inverse loading. 


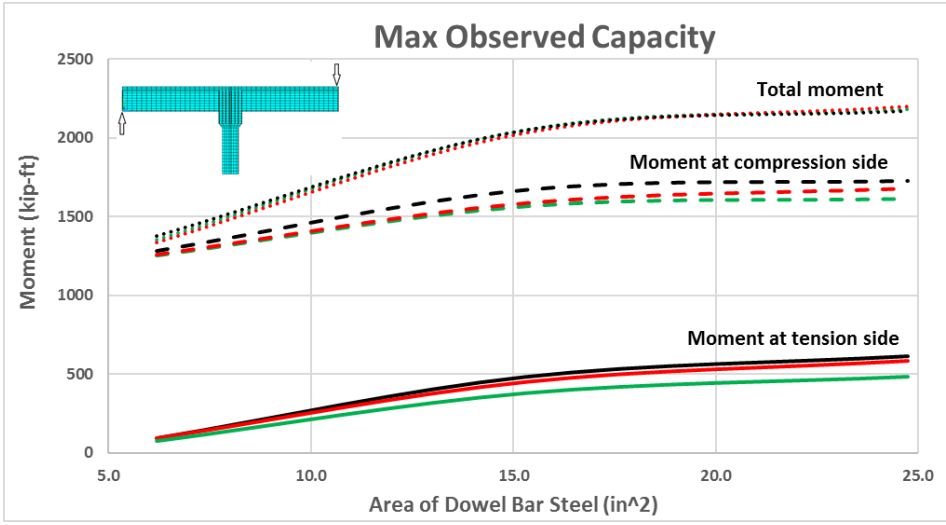

Figure 9-8 Maximum observed capacity according to area of dowel bar steel under inverse forces.

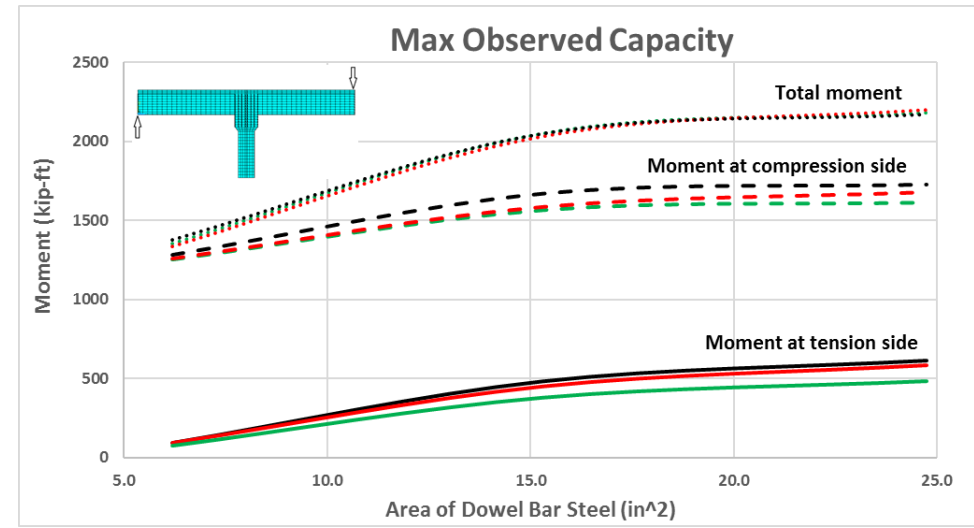

Figure 9-9 Maximum observed capacity according to area of tie bar steel under inverse forces.

The difference between horizontal movements of the two bottom flanges into the concrete diaphragm was measured in the model under inverse loading. Figure 9-10 shows the moment in the compression side and tension side of the pier centerline versus the difference in movement between the two bottom flanges. The results indicate very little movement occurs. 


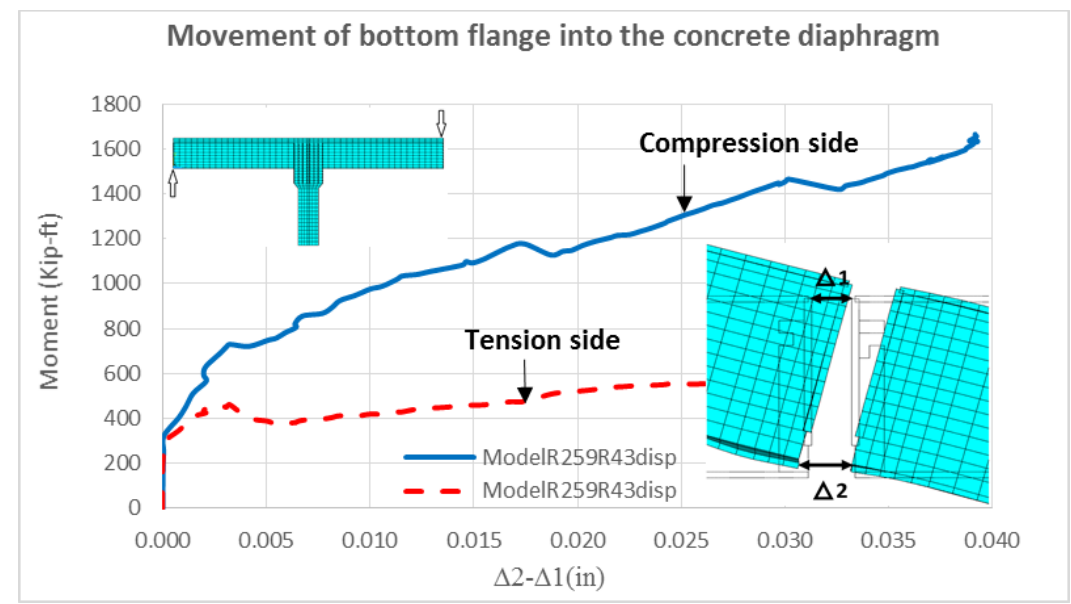

Figure 9-10 Movement of bottom flange into concrete diaphragm.

\subsubsection{Stress Distribution in Dowel Bars}

Understanding the stress distribution in the dowel bars is an important step towards developing a design formula for the detail. Figure 9-11 presents the value of axial stresses in the dowel bars versus location for each of the different levels of steel considered. The plot shows that when a small amount of steel was used then all of the bars across the full width. However, when a large amount of steel is present, only the bars nearest the girder yield. This phenomenon is further discussed in Chapter 10.

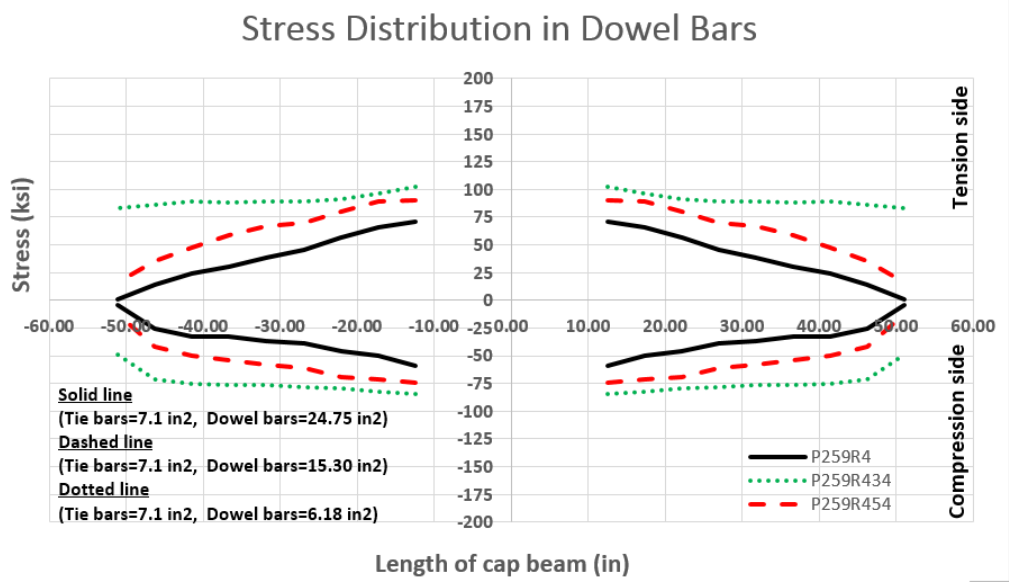

Figure 9-11 stress distribution in dowel bars along the cap beam. 


\subsubsection{Effect of Diaphragm Face Reinforcement}

Face reinforcement, which are perpendicular to the web, run through holes in the beam web. Up to this point, the area of each face bar was to be $0.13 \mathrm{in}^{2}$ in all models. To evaluate their role in the behavior of the connection, the area of face reinforcement was increased by a factor of five. Figure 9-12 shows the resulting von-Mises stresses in the reinforcement bars before and after the increase while Figure 9-13 shows the capacity. Increasing the steel volume of the face bars by $400 \%$ only increased the capacity of the system by $7 \%$; which indicates the role of the face reinforcement is not significant with regards to the global capacity of the system.

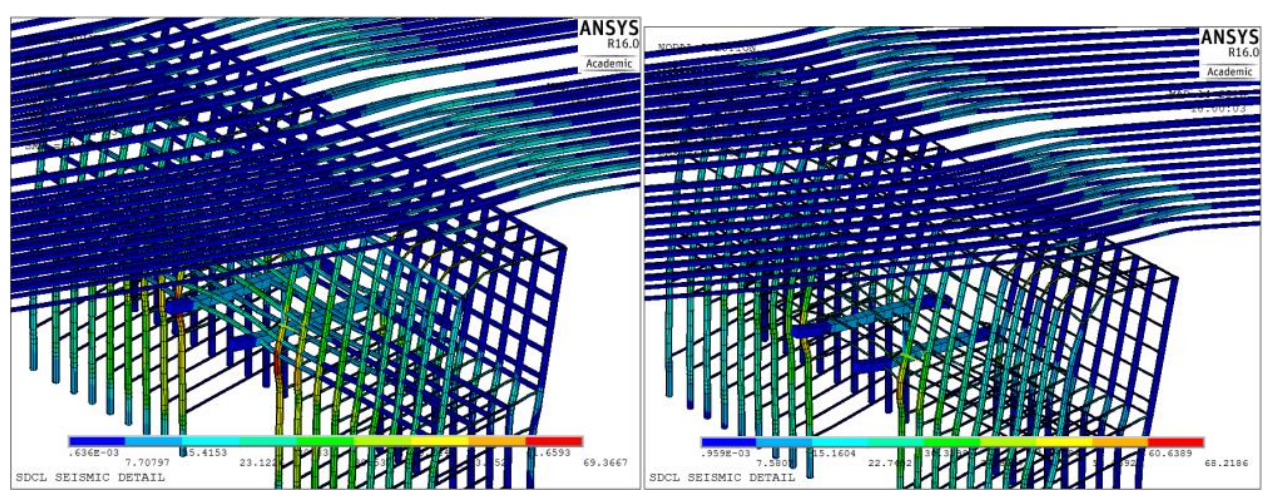

Figure 9-12 von-Mises stresses in two different models, left: $15.7 \mathrm{in}^{2}$, right: $2.8 \mathrm{in}^{2}$.

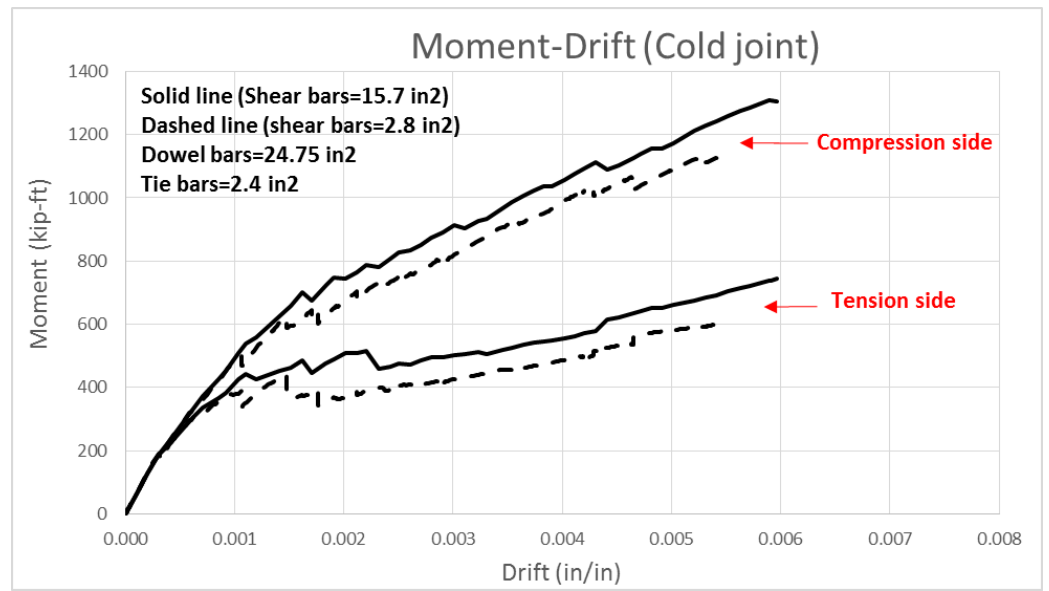

Figure 9-13 Moment capacity of the system with two different amounts of shear bar steel. 


\subsection{Moment-Drift of Monolithic System}

Figure 9-14 shows the Moment-Drift relationship when the nodes of the bent cap and concrete diaphragm are merged together. The behavior of the system is similar to the monotonic system. The results of this section, as well as results from the cold joint model in Section 9.5, indicate that increasing the amount of dowel bar steel area increases the ultimate moment capacity.

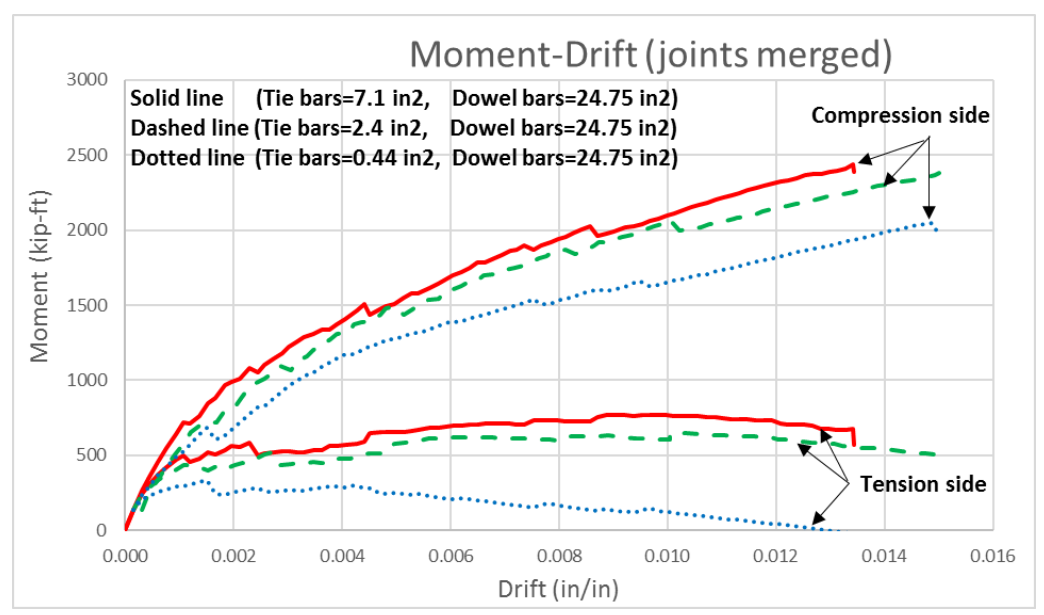

Figure 9-14 Effect of dowel bars in the Monolithic model under inverse loading. 


\section{RECOMMENDED SEISMIC DESIGN PROVISIONS}

\subsection{Introduction}

According to the results from the previous chapters, the load resistance mechanisms of the connection subjected to the push-up, push-down and inverse loading were found for the pier centerline section at the ultimate load level. This chapter will present the development of a design formula based on the outcomes from previous chapters. The design provisions that were developed for the connection are very similar to the current design methodology that is used for designing reinforced concrete beams.

\subsection{Design Formula under Different Load Condition}

The following section consider each of the loading patterns considered in the study.

\subsubsection{Connection under Push-Down Forces}

Comprehensive experimental and numerical investigations were conducted to study the force transfer mechanism for the detail with a steel block at the end of the bottom flange under push down forces (Farimani M. M., 2006). The recommended design formula provides good agreement with the experimental results. This design approach can be used for the proposed seismic detail as well for the case of as gravity loads, which result in under push down forces. When the connection is subjected to push down forces, the dowel bars do not affect the behavior of the system and the tie bars over the bottom flange help the connection at the compression side. Therefore, the recommended design formula for the non-seismic detail would be slightly conservative. 


\subsubsection{Connection under Push-Up Forces}

In the chapter 9, the nonlinear behavior of the system was investigated and the load resistance mechanism was found under push up forces. According to the results, the sequence of failure modes included yielding in the bottom flange (when the bottom is continuous), cracks in the concrete diaphragm, and crushing of the concrete slab over the pier centerline. Based on the results from section 9.4 and Figure 9-2, the capacity of the system increases as the area of tie bar steel is increased. According to CALTRANS, in order to consider the demand of the superstructure due to vertical acceleration of earthquake loads, a uniform vertical force equal to $25 \%$ of the dead load should be applied as illustrated in Figure 10-1.
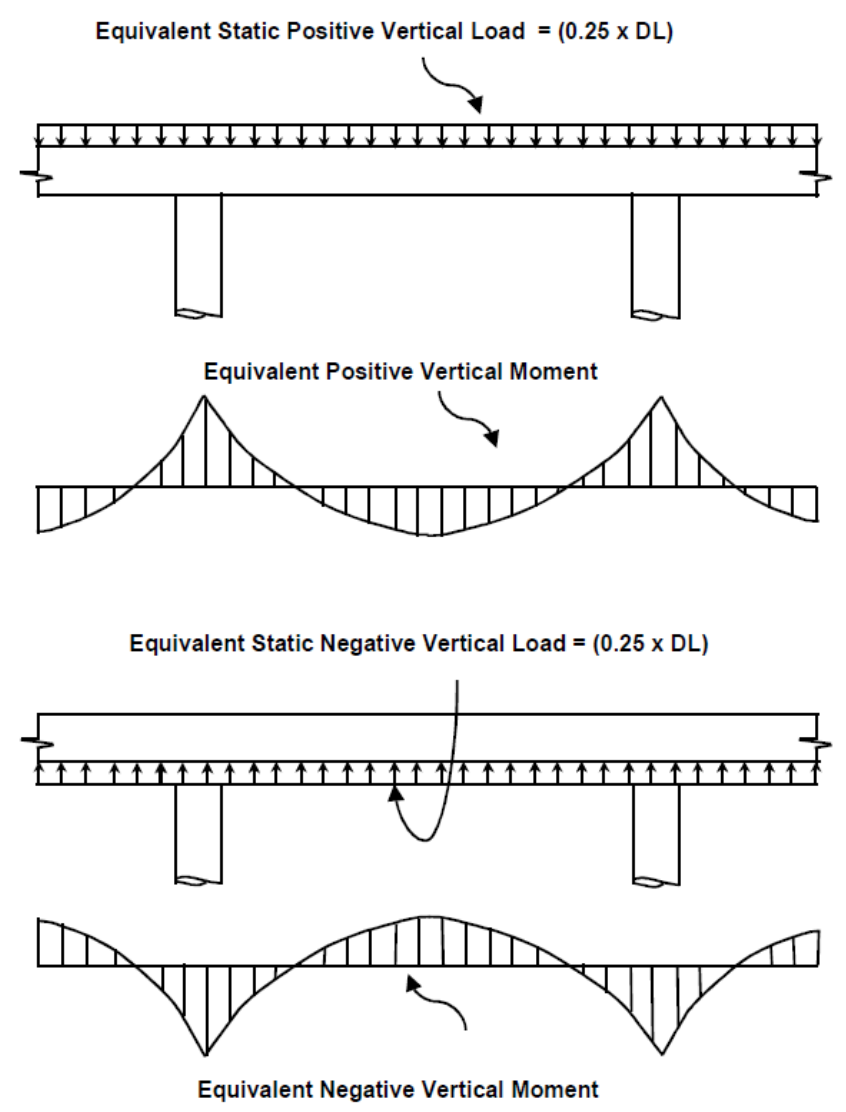

Figure 10-1 Equivalent static vertical loads and moments (CALTRANS, 2013). 


\subsubsection{Calculating the Demand for the Prototype Bridge under Push-Up Forces}

In this section, the demand of the prototype bridge was calculated based on the CALTRANS specification. The Military Road geometry, which the finite element models are based on, was selected for a demonstration to find the value of the moment over the middle support for an interior girder (Lampe N. J., December, 2001). The properties of the bridge are:

- span length $=95^{\prime}$

- W40 x 215 I-section girders

- number of girders $=4$

- girder spacing = 8' 4"

- slab depth $=7.5^{\prime \prime}$

The value of dead load over the deck is equal to:

Deck: $\left(8^{\prime \prime} / 12\right) *\left(8.3333^{\prime}\right) *(0.15 \mathrm{k} / \mathrm{ft} 3)=0.833 \mathrm{k} / \mathrm{ft}$

Steel: $0.235 \mathrm{k} / \mathrm{ft}$

Note: To be conservative, it was assumed the steel girder and deck were not precast and the construction method is not accelerated (ABC). This makes the amount of moment from the girder and precast slab self-weight over the middle support zero. Therefore, the weight of the steel girder and deck come into account for calculating the dead load, DL.

DC2: Long-Term Composite Dead Load

Assume the weight per unit length of the barrier is $536 \mathrm{lb} / \mathrm{ft}$, and all girders carry the load equally.

$\mathrm{DC} 2=(0.536 * 2) / 4=0.268 \mathrm{k} / \mathrm{ft}$ 
DW: Future Wearing Surface Load

Assume equal distribution among all girders.

$\mathrm{DW}=(0.025 * 30) / 4=0.188 \mathrm{k} / \mathrm{ft}$

Total dead load: $0.833+0.235+0.268+0.188=1.5 \mathrm{k} / \mathrm{ft}$ (for one girder)

In this section, the demand of the system was only calculated for 0.25DL upward force because the performance of the detail already was controlled for gravity loads which is more than 0.25DL downward force (Nick Lampe, 2014). Figure 10-2 shows the value of the load that was applied to one girder upward $(0.25 * 1.5=0.375 \mathrm{k} / \mathrm{ft})$ and the corresponding moment along the girder. The value of moment at the middle support, based on a static analysis, is equal to $450 \mathrm{kip}-\mathrm{ft}$.

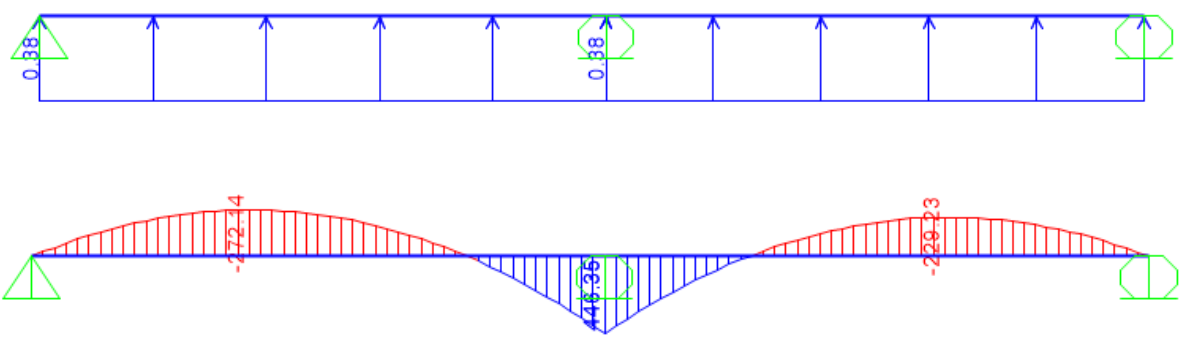

Figure 10-2 The value of load and moment under 0.25DL in one girder.

\subsubsection{Comparison between Demand and Capacity under Push-Up Forces}

Figure 10-3 shows the capacity of the system for different amounts of steel in the dowel bars and tie bars when the system was subjected to push down forces. The horizontal line represents the demand of the system, based on the earlier calculations, for the prototype bridge. A comparison between the demand and capacity indicates that at the demand level, the behavior of the system is in the linear range. Although this is not a general conclusion for SDCL bridges, according to the SDCL construction sequence, this is a conservative outcome for the selected prototype bridge when the real dead load is less than the assumed one. In such cases, like casting the deck onto the girders 
(Figure 10-4), the final load and moment over the pier could be less than half of the considered load in this section once moment corresponding to the girder and slab is zero over the middle support.

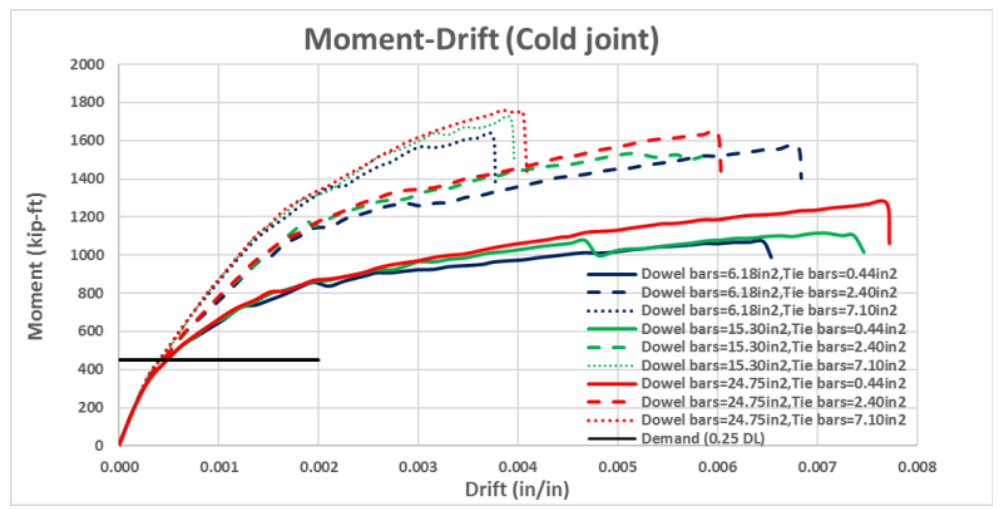

Figure 10-3 Comparison between demand and capacity for different models (steel varies for the tie bars and dowel bars).

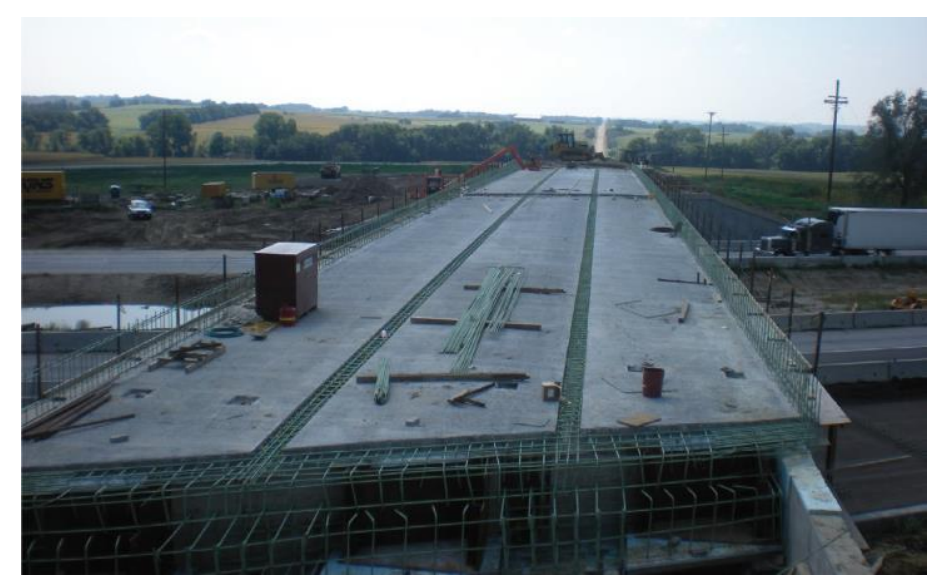

Figure 10-4 Completing the placement of the pre-topped units for the bridge over I- 80 at 262nd Street in Nebraska (AZIZINAMINI, 2014).

\subsubsection{Connection under Inverse Loading}

According to finite-element results, dowel bars are the most critical elements in the proposed connection subjected to the longitudinal component of earthquake loads. Figure 10-5 shows the deflection of the system under inverse loading. The results strongly imply the failure mode of the system is comparable with the flexural failure of a doubly reinforced beam. This is the 
cause of dowel bars yielding at the ultimate load level while there is no non-linearity in the other parts of the connection such as the girders, connecting plate, bolts or tie bars.

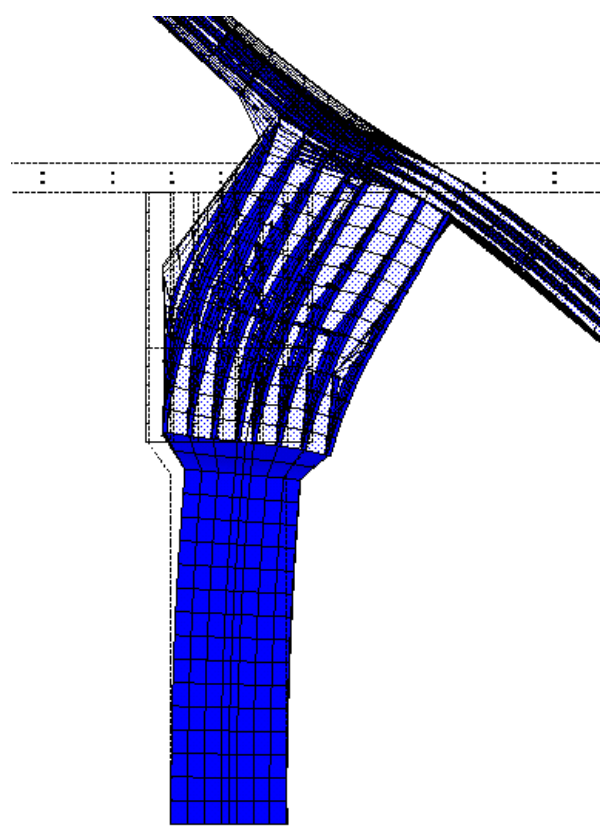

Figure 10-5 Exaggerate deformation of the bent cap and concrete diaphragm.

\subsubsection{Comparison between Moment-Curvature and Finite Element Analysis}

Early finite element analysis indicates flexural behavior is governed at the interface of the bent cap and concrete diaphragm. To investigate this assumption, the moment capacity curve, which was obtained from Moment-Curvature analysis, was considered in this section. Accordingly, a Moment-Curvature analysis was conducted in addition to the finite-element analysis. In one set of models, only the effect of dowel bars examined and in the other set, the effect of the concrete came into account as well. The difference between two methods comes from the distribution of stresses in each scenario. Figure 10-6 and Figure 10-7 illustrate the location of applied force and resulting stress distribution at the interface of the bent cap and concrete diaphragm.

In the finite-element analysis, the compressive stress in the concrete comes from the contact area between the bottom flange and bent cap, which is maximum below the bottom flange 
and minimum at the end edge of the bent cap. In the Moment-Curvature analysis, the moment comes from a uniform distribution of forces along the length of the bent cap. Figure 10-8 shows Moment-Curvature curves and Figure 10-9 and Figure 10-10 repeated here again for comparison.

The simulation observations imply there is good agreement between the complex nonlinear finite-element analysis and the simple Moment-Curvature analysis in the model which all dowel bars yielded.

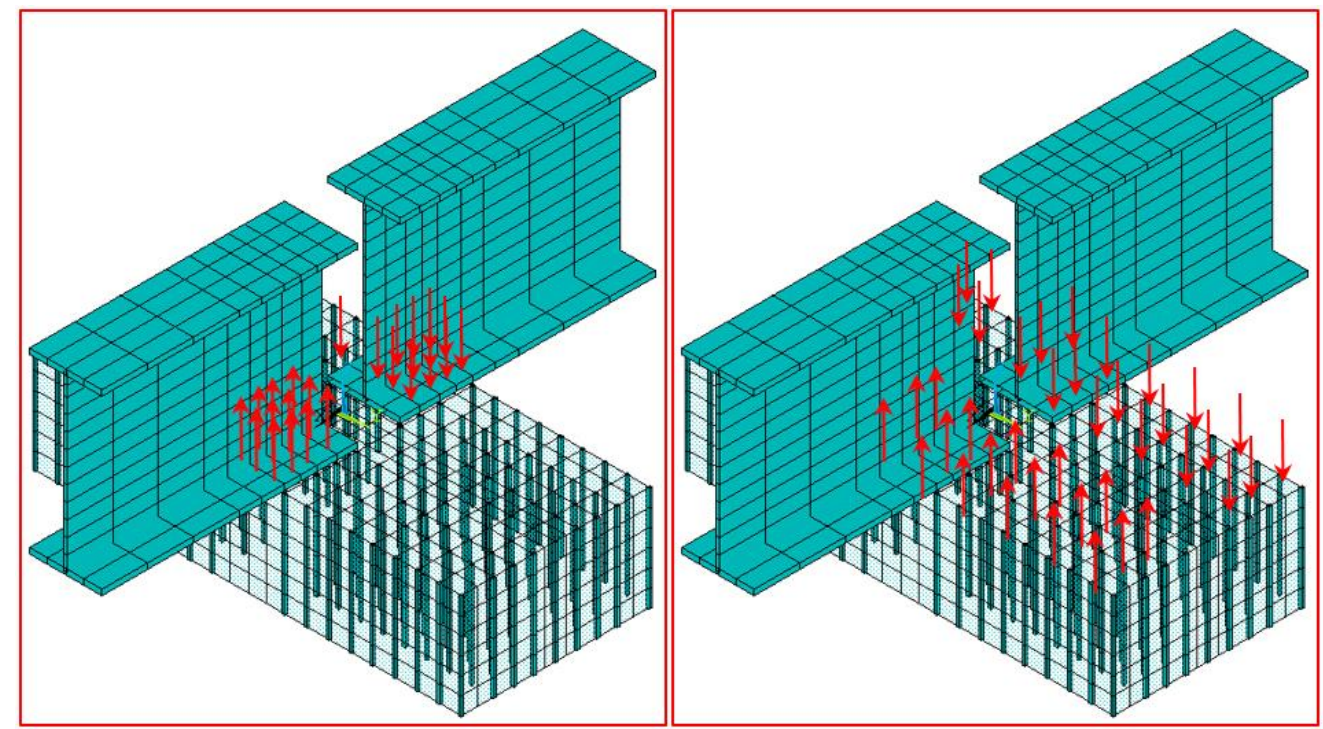

Figure 10-6 The location of applied forces in the finite-element analysis (left) and in Moment-Curvature analysis (right).
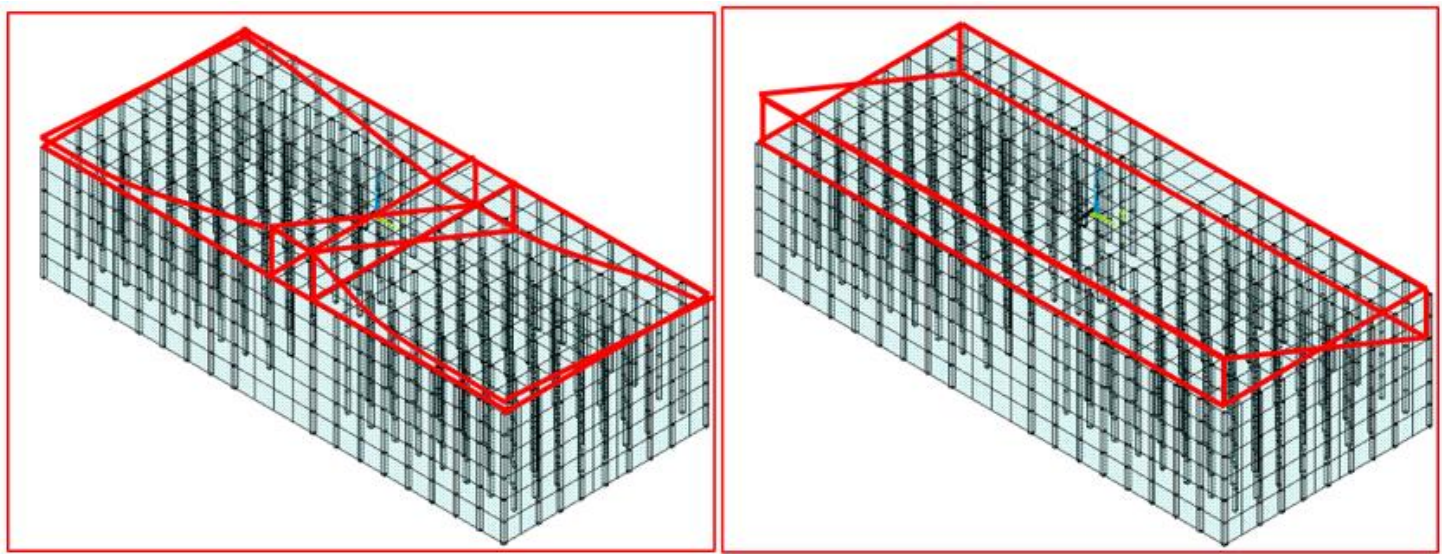

Figure 10-7 The approximate distribution of stresses in finite-element model (left) and in Moment-Curvature analysis (right) when materials are in the elastic range. 


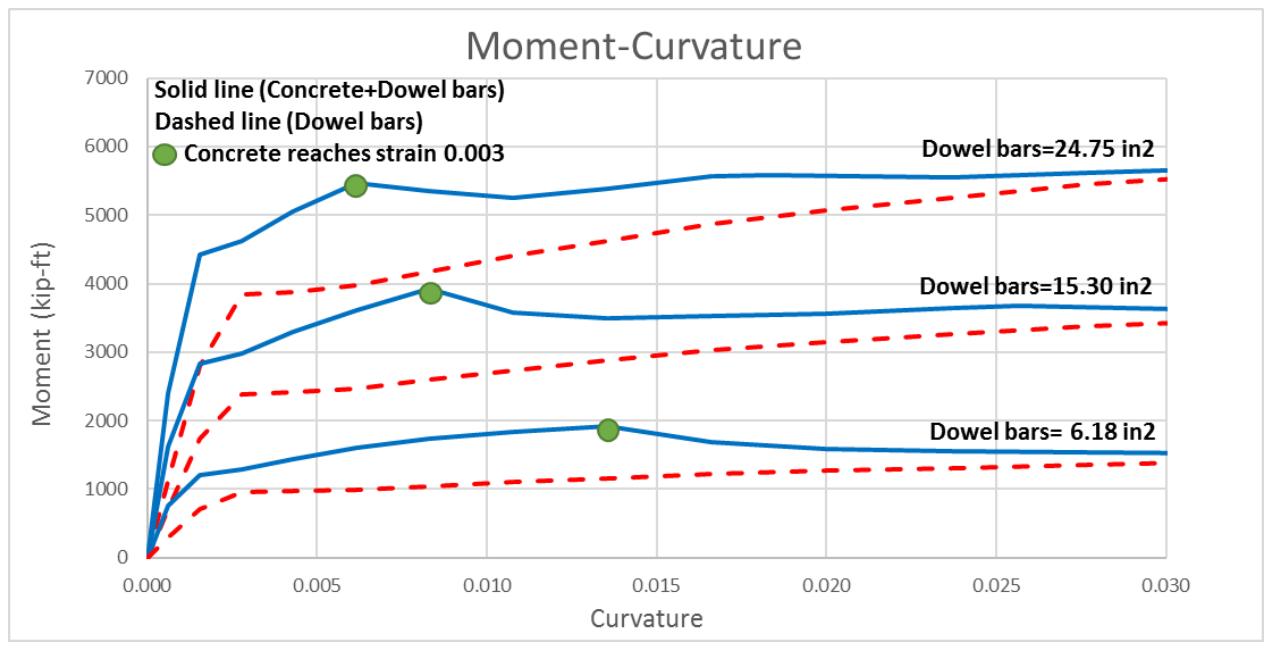

Figure 10-8 Ultimate moment capacity of the system based on Moment-Curvature analysis.

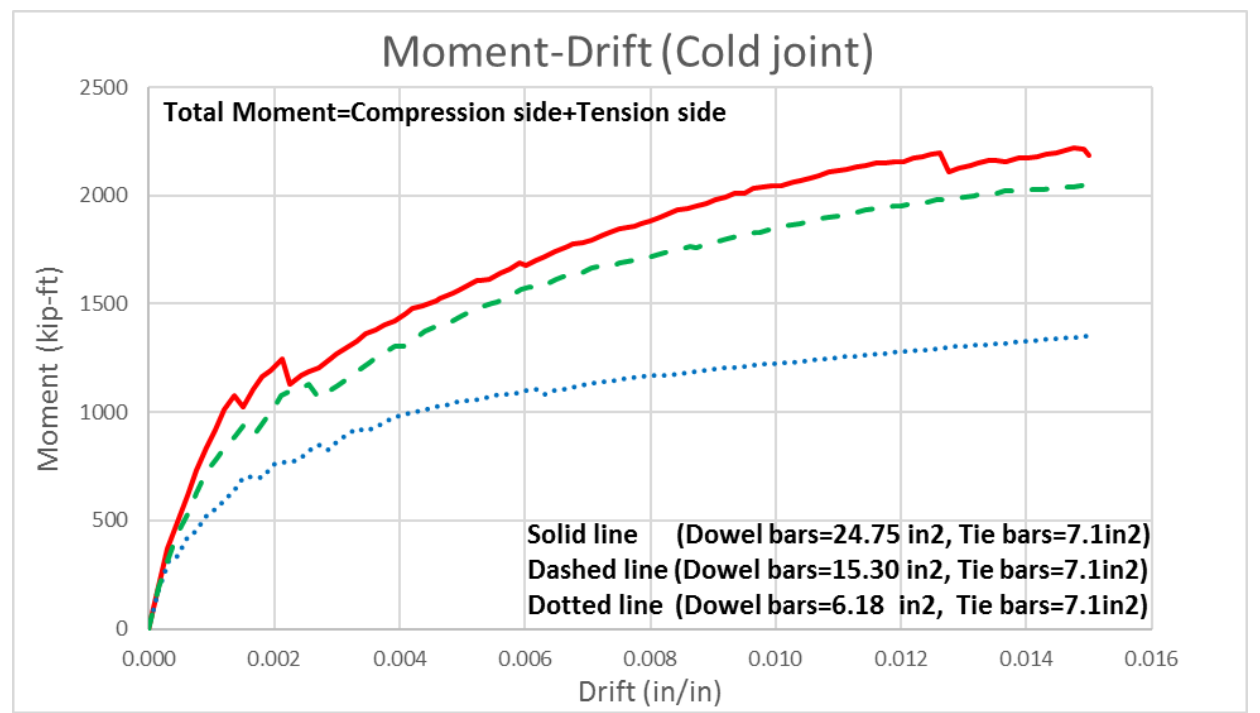

Figure 10-9 Ultimate moment capacity of the system based on finite element analysis in cold joint model. 


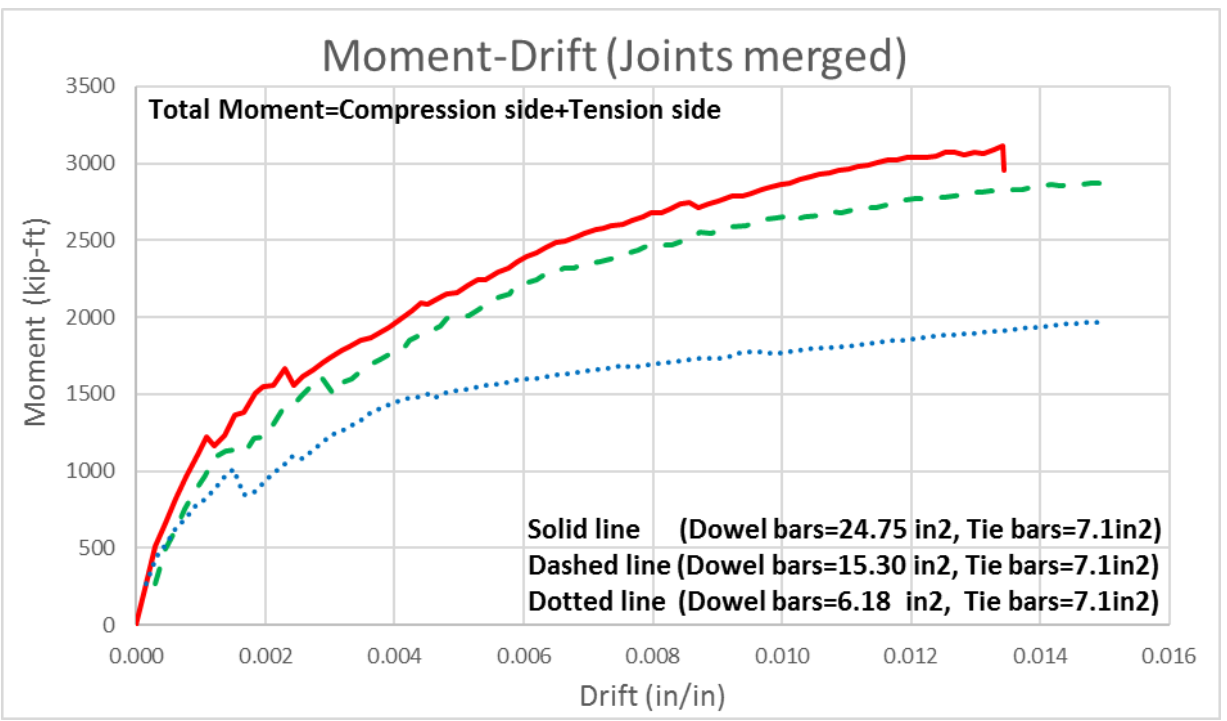

Figure 10-10 Ultimate moment capacity of the system based on finite element analysis in monolithic model.

\subsubsection{Strain-Stress Distribution in Finite Element Model}

Figure 10-11 illustrates the stress distribution in the interface of the bent cap and concrete

diaphragm. According to this plot, the amount of compression stress below the bottom flange is at its maximum and the value reduces exponentially as the distance from the steel girder increases. Furthermore, this plot shows a small percentage of the total area of concrete can withstand compressive stresses under inverse loading. 
Stress distribution at the interface of cap beam and concrete diaphragm

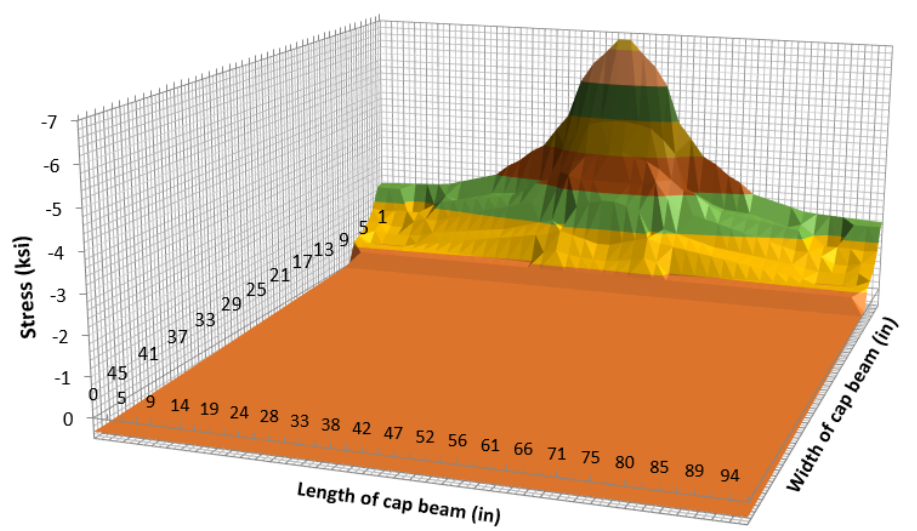

Figure 10-11 Stress distribution at the interface of bent cap and concrete diaphragm.

\subsection{Design Assumption}

Based on the results from the previous chapters, the following assumptions were made for developing the design formula under inverse loading.

-The strain distribution in the concrete is assumed linear at the interface of bent cap and concrete diaphragm (Figure 10-12 and Figure 10-13).

-The tensile strength of concrete was ignored (Figure 10-14).

-Tension stiffness of the concrete was ignored after cracking has occurred.

-A uniform stress distribution was assumed in the compression zone of the concrete. Thus, an equivalent concrete block was used for equilibrium equations (Figure 10-14).

-The maximum width of the equivalent compressive block was limited to the width of bottom flange sitting over the bent cap. 
-All the dowel bars in the effective width of the bent cap are considered for calculating the capacity of the section. Strain hardening of the bars was ignored in the calculation of the capacity of the section.

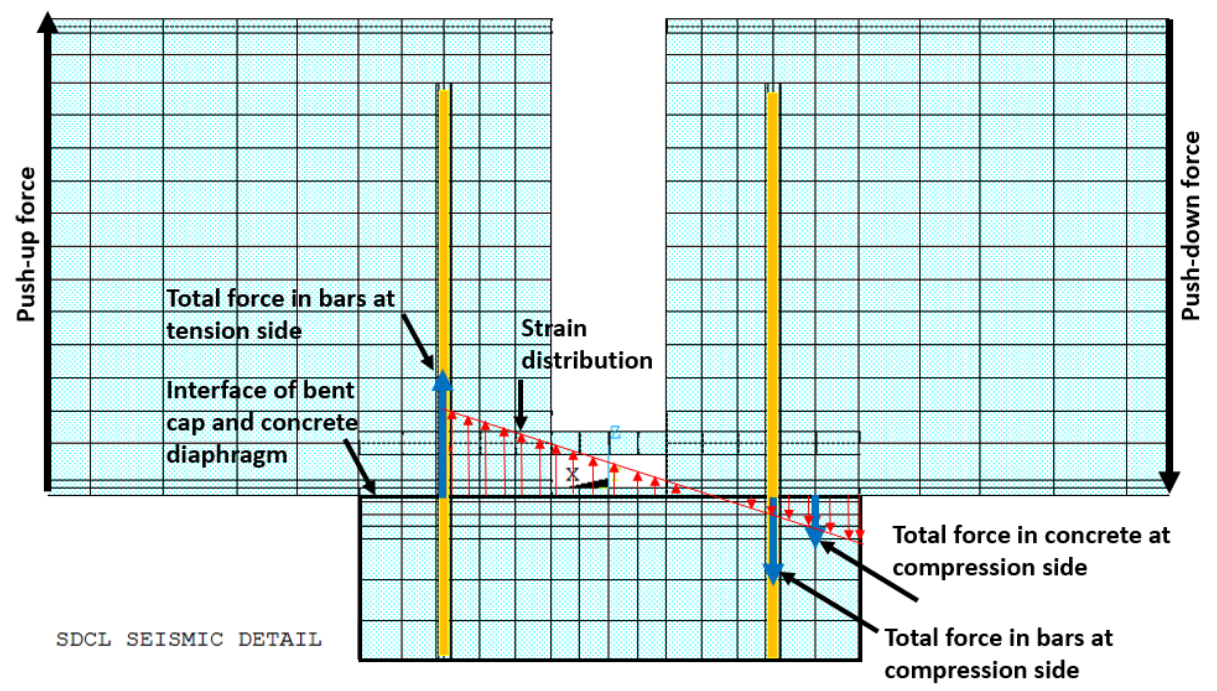

Figure 10-12 Bent cap and dowel bars under inverse loading.

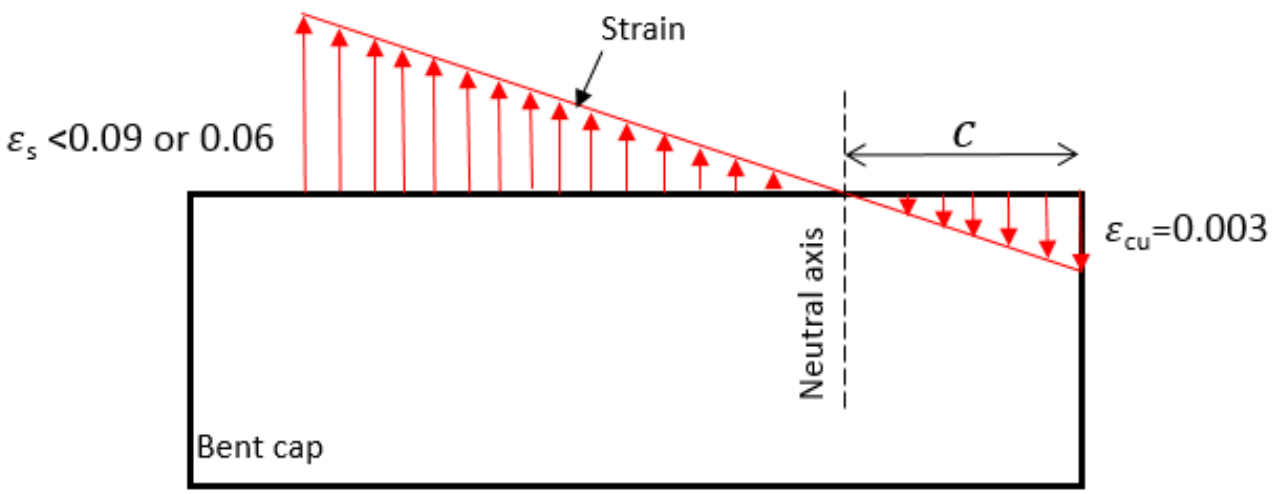

Figure 10-13 Strain diagrams at the interface of bent cap and concrete diaphragm. 


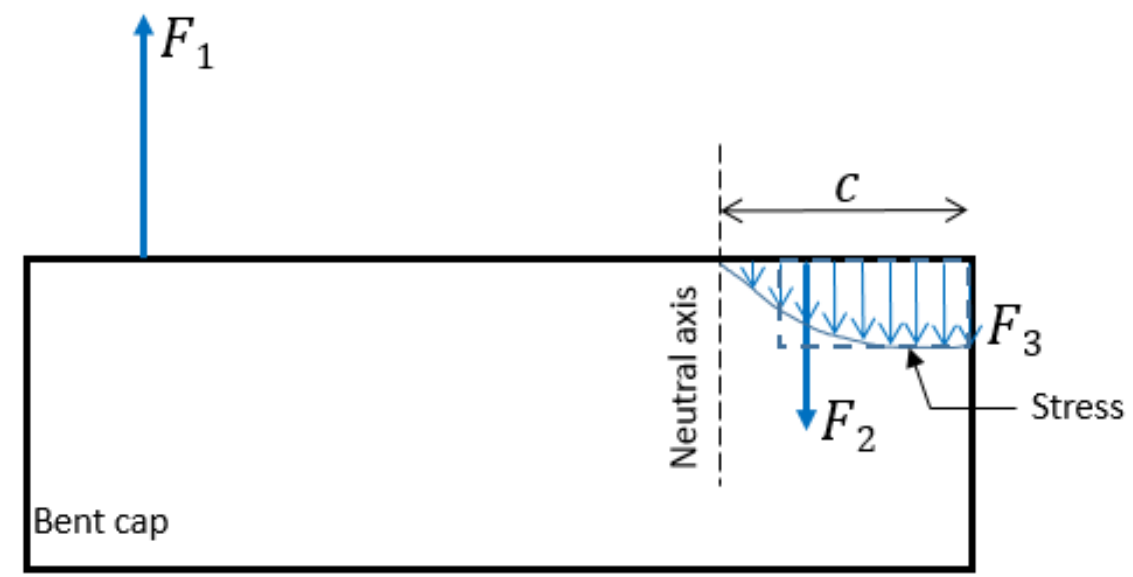

Figure 10-14 Stress and force diagrams at the interface of bent cap and concrete diaphragm.

\subsubsection{Using Winkler Foundation Method to Find Forces in Dowel Bars}

Up to this point, the finite element results indicate the distribution of stresses in the dowel bars are not uniform along the bent cap. As expected, the dowel bars that are closer to the steel girder carry more forces than the dowel bars further away. To calculate the ultimate moment capacity, the value of forces in the dowel bars and concrete diaphragm should be computed and obtained from finite element analysis results. Consider a beam that is supported with several springs as shown in Figure 10-15. In this model, the beam and springs represent the concrete diaphragm and dowel bars respectively (see Figure 10-16). It was assumed that the beam alone can carry the shear deformations. To calculate the value of deformation in this beam (strain in dowel bars in the finite element model) the Winkler foundation method was used. The governing differential equation for this beam is:

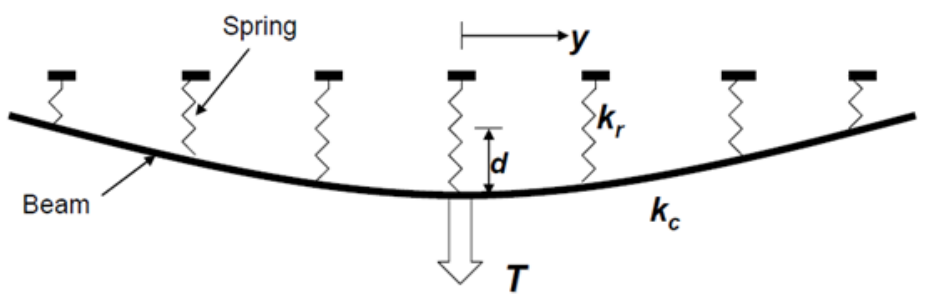

Figure 10-15 Beam-spring model for a slice of the concrete diaphragm and the dowel bars. 


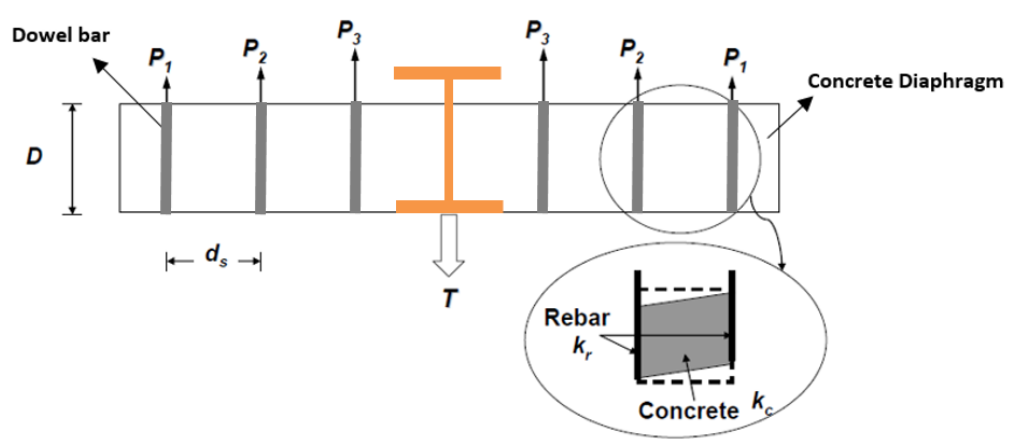

Figure 10-16 A strip of the concrete diaphragm with the dowel bars and the applied force.

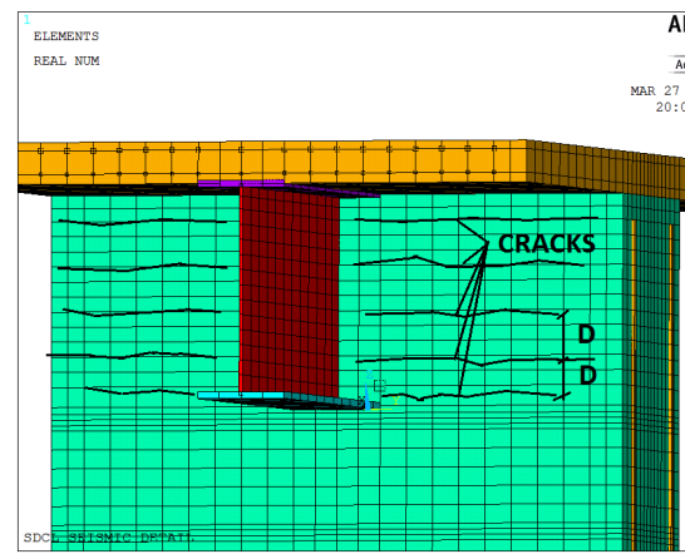

Figure 10-17 Side view of concrete diaphragm and parallel cracks

$$
\begin{aligned}
& \frac{\mathrm{d} \delta}{\mathrm{d} y}=\frac{k V}{G_{C} A_{C}} \\
& G_{c}=\frac{E_{c}}{2(1+v)} \\
& A_{c}=t_{s} \Delta \\
& \Delta=\frac{0.4 b_{s} t_{s}}{n}
\end{aligned}
$$$$
\text { Equation 10-3 }
$$

$\delta=$ deflection along y direction

$k=$ shear stress factor (about 1.5 for rectangular sections) 
$t_{s}=$ assumed thickness for concrete diaphragm

$b_{s}=$ width of the concrete diaphragm

$G_{C}=$ shear modulus of concrete for the closed cracks as 0.4 of the elastic state

$\Delta=$ crack spacing based on Figure 10-17 (Nawy, 2003)

$v=$ Poisson's ratio $(0.2)$

The value of shear force in any section of the beam in Figure 10-15 based on force equilibrium in vertical direction is:

$$
\begin{aligned}
& V=\frac{T}{2}-\int_{O}^{y} k_{r} \delta \mathrm{d} y \\
& k_{r}=\frac{E_{s} A_{s}}{b_{s} \Delta}
\end{aligned}
$$

Equation 10-6

$\mathrm{T}=$ applied force at one end of the girder (in the finite element model) or value of the shear force in the deck at the face of the bent cap and concrete diaphragm which applies axial stress in the dowel bars

$\mathrm{V}=$ shear force along $\mathrm{y}$ direction

$k_{r}=$ stiffness of dowel bar along the concrete diaphragm

Es $=$ tangent modulus of the slab reinforcements. It assumed that tangent modulus is about $5 \%$ of the elastic modulus, Es $=0.05(29000)=14500 \mathrm{ksi}($ Farimani M. M., 2006)

$\mathrm{A}_{\mathrm{s}}=$ total area of dowel bars 


$$
\frac{\mathrm{d} \delta}{\mathrm{d} y}=\frac{1.5}{0.4 G_{C} A_{C}}\left(\frac{T}{2}-\int_{O}^{y} k_{r} \delta \mathrm{d} y\right)
$$

Equation 10-7

Taking derivation of the above equation with respect to y results in:

$$
\frac{\mathrm{d}^{2} \delta}{\mathrm{d}^{2} \mathrm{y}}-\frac{1.5 \mathrm{k}_{\mathrm{r}}}{0.4 \mathrm{G}_{\mathrm{C}} \mathrm{A}_{\mathrm{C}}} \delta=0
$$

Equation 10-8

This is an ordinary differential equation and the general solution is:

$$
\lambda=\sqrt{\frac{1.5 k_{r}}{0.4 G_{c} A_{c}}}
$$

Equation 10-9

Using boundary condition to solve this differential equation results in:

$\delta=0$ for $\mathrm{y} \rightarrow \infty$

$\mathrm{V}=0$ for $\mathrm{y}=\frac{\mathrm{b}_{\mathrm{s}}}{2}$

By applying these two boundary conditions to the differential equation, the deflection of the beam can be calculated according the below formula:

$$
\delta=\frac{T \lambda}{2 k_{r}\left(1-e^{\frac{-\lambda b_{s}}{2}}\right)} e^{-\lambda y}
$$

If the assumed value of strain is uniform along the height of the concrete diaphragm, the amount of strain can be computed as: 


$$
\begin{aligned}
& \varepsilon=\frac{\delta}{L}=\frac{T \lambda}{2 L k_{r}\left(1-e^{\frac{-\lambda b_{s}}{2}}\right)} e^{-\lambda y} \\
& =\varepsilon_{S} e^{-\lambda y}
\end{aligned}
$$

$\varepsilon=$ strain in each spring (in each dowel bar) as a function of $\mathrm{y}$

$L=$ height of concrete diaphragm

\subsubsection{Numerical Example of Strain Distribution}

The value of strain with an exponential distribution along the bent cap can be derived using Equation 10-11. In the linear region of strain stress curve of steel, the stress follows the strain. Beyond yielding, the stress is assumed uniform. The material and geometry of the parametric models were selected to derive the strain distribution along the beam cap length. Based on Equation 10-11, the strain distribution for models with dowel bar areas equal to $24.75,15.3$ and $6.18 \mathrm{in}^{2}$ are presented here. In Figure 10-18, the origin of the y coordinate is shifted half of the flange to the right and left of centerline for clarity.

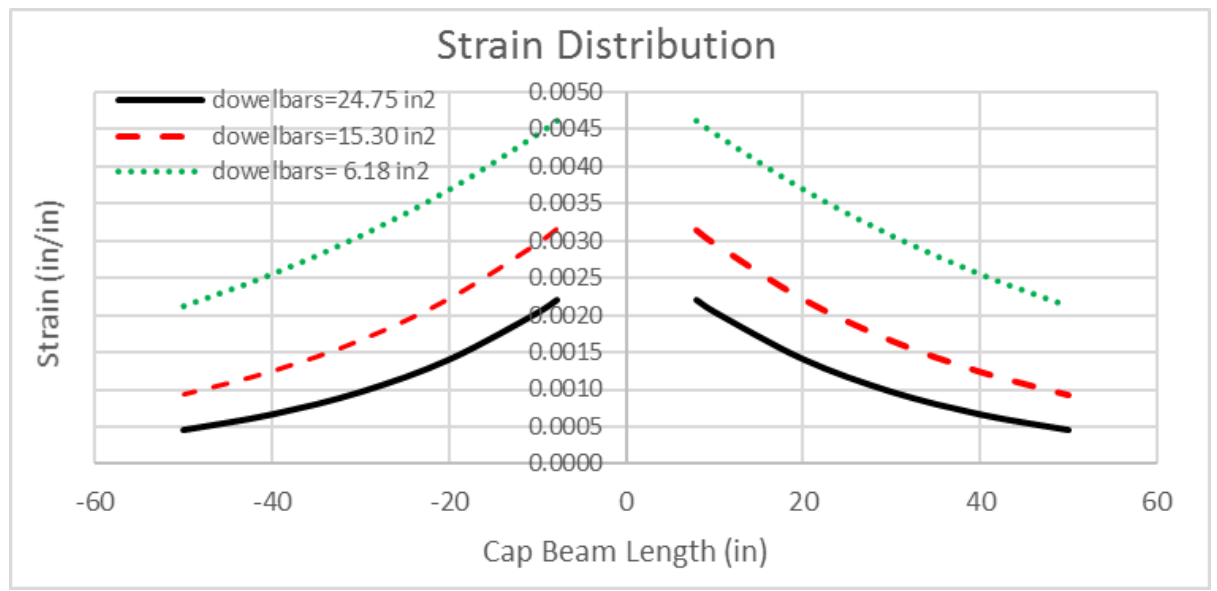

Figure 10-18 Value of strain in dowel bars across the length of cap beam. 


\subsubsection{Dowel Bars Strength}

It was assumed that part of the dowel bars at the interface of bent cap and concrete diaphragm might yield. The region within which the bars yield is denoted by $b_{\text {eff, }}$ see Figure 10-19. Dowel bars outside of $b_{\text {eff }}$ behave elastically and the stress strain relationship follows the linear part of the stress strain curve. Therefore, for design purposes, a uniform strain and stress distribution is assumed below the width of bottom flange. According to the Winkler foundation method described earlier, and the strain distribution plotted in Figure 10-19, the total force in dowel bars at the interface of the bent cap and concrete diaphragm could be computed as:

$$
F_{s}=E_{s} \varepsilon_{s} A_{s} \frac{b_{f}}{b_{s}}+2 \int_{0}^{\left(\frac{b_{s}-b_{f}}{2}\right)} E_{s} \varepsilon_{s} e^{-\lambda y} \frac{A_{s}}{b_{s}} d_{y}
$$

Where:

$$
\begin{aligned}
& F_{s}=\rho b_{f}+2 \frac{\rho}{\lambda}\left[1-e^{\frac{-\lambda\left(b_{s}-b_{f}\right)}{2}}\right] \\
& \rho=\frac{E_{S} \varepsilon_{s} A_{s}}{b_{s}}
\end{aligned}
$$

$E_{S}=$ dowel bar elasticity modulus

$$
b_{e}=\frac{-2}{\lambda} \ln \frac{\varepsilon_{y}}{\varepsilon_{s}}+b_{f}
$$

$\varepsilon_{y}=$ yield strain of the dowel bars 
$F_{s}=\frac{b_{e}}{b_{s}} A_{s} F_{y r}+\frac{2 E_{s} \varepsilon_{s} A_{s} e^{\frac{\lambda b_{f}}{2}}}{\lambda b_{s}}\left(e^{\frac{-\lambda b_{e}}{2}}-e^{\frac{-\lambda b_{s}}{2}}\right)$

Equation 10-16

Where:

$F_{y r}=$ average of yield and ultimate strength of the slab bar

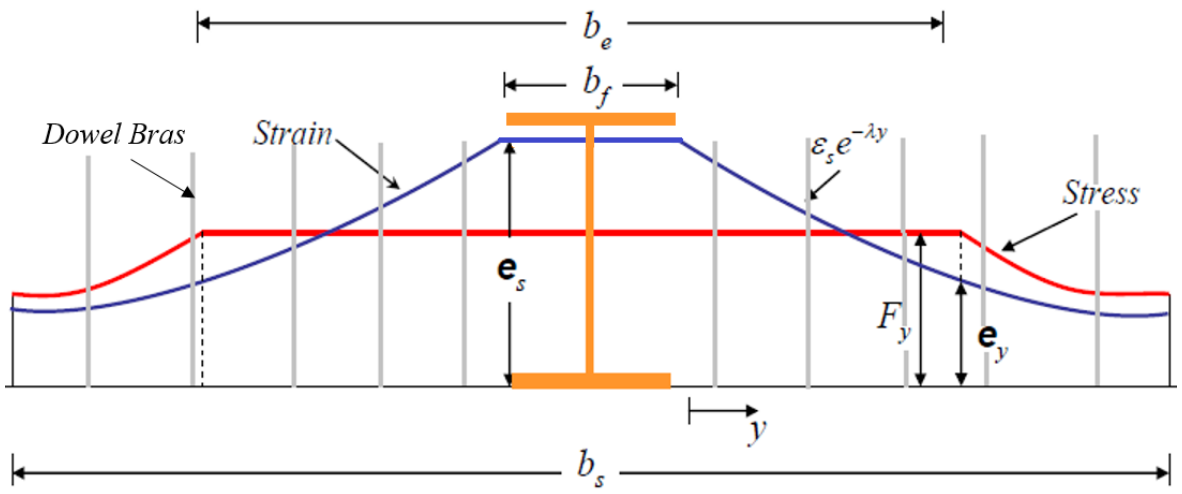

Figure 10-19 Distribution of stress and strain across the length of bent cap.

\subsubsection{Developing Simple Formula to Calculate Moment Capacity}

The design provision of this section is concentrated on the design of the dowel bars, but it is strongly suggested that adequate shear reinforcement (bars perpendicular to the web) be provided for confining the concrete. Tests of doubly reinforced beams have shown that even after crushing of concrete in the compression zone, the beam will not collapse if longitudinal reinforcement (here referred as dowel bars) are enclosed by stirrups (here referred as shear bars perpendicular to the web). Once the concrete in the compression zone reaches its crushing strain, if the reinforcement confined by closed stirrups, then the reinforcement will not buckle and the beam can carry additional loads. In sections with compression and tension steel to display ductile behavior, both the compression and tension steel should yield simultaneously. In this case, the resistance moment of the section consists of resistance of compression concrete and balancing tensile reinforcement plus the balancing amount of additional tensile reinforcement. In the following formulation, the 
amount of concrete that was replaced by the dowel bars was ignored. In this section, step-by-step calculation of the ultimate moment capacity of the system is explained.

1- Approximately calculate the amount of steel for dowel bars $A_{s}=\frac{M_{u}}{0.75 f_{y} d}$

2- Compute crack spacing $\Delta=\frac{0.4 b_{s} t_{s}}{n}$

3- Compute stiffness of dowel bar along the concrete diaphragm $k_{r}=\frac{E_{S} A_{s}}{b_{s} \Delta}$

4- Compute concrete beam section area between dowel bars $A_{c}=t_{s} \Delta$

5- Compute parameter $\lambda=\sqrt{\frac{1.5 k_{r}}{0.4 G_{c} A_{c}}}$

6- Compute the strain distribution in dowel bars along the cap beam $\frac{\delta}{L}=$ $\frac{T \lambda}{2 L k_{r}\left(1-e^{\frac{-\lambda b_{S}}{2}}\right)} e^{-\lambda y}=\varepsilon_{S} e^{-\lambda y}$

7- Compute density of reinforcement along the cap beam $\rho=\frac{E_{s} \varepsilon_{s} A_{s}}{b_{s}}$

8- Compute the effective width of cap beam over which the dowel bars yielded $b_{e}=\frac{-2}{\lambda} \ln \frac{\varepsilon_{y}}{\varepsilon_{s}}+b_{f}$

9-If $b_{e}>b_{s}$ then be=bs If $b_{e}<b_{s}$ go step 10

10- Compute total force in dowel bars on the tensile side

$$
F_{S}=\frac{b_{e}}{b_{s}} A_{s} F_{y r}+\frac{2 E_{s} \varepsilon_{s} A_{s} e^{\frac{\lambda b_{f}}{2}}}{\lambda b_{s}}\left(e^{\frac{-\lambda b_{e}}{2}}-e^{\frac{-\lambda b_{s}}{2}}\right)
$$


11- Assume the distance of the neutral axis from the extreme compression fiber in concrete is equal to $\mathrm{c}$, assume the value of steel strain in tension side equal to $\varepsilon_{s}$ from Step 6, and assume the amount of concrete below the bottom flange in compression side equal to 0.003. Compute the strain in dowel bars in compression side $\varepsilon_{s}^{\prime}=\left(\frac{c-d^{\prime}}{c}\right) \varepsilon_{c u}$

12- Compute the compressive force in concrete below the bottom flange (the capacity of compressive force out of the below of bottom flange was ignored) $F_{c}=0.85 f_{c}^{\prime} b \beta_{1} c$

13- Compute total force in the dowel bars on compressive side $F_{S}^{\prime}=\frac{\varepsilon_{s}}{\varepsilon_{s}^{\prime}} F_{S}$

14- Control section equilibrium. If $F_{S}=F_{S}^{\prime}+F_{c}$, go to Step 17, otherwise change the assumed value of $\mathrm{c}$ in Step 11

15- Compute moment strength $M_{n}=C_{c}\left(d-\frac{a}{2}\right)+C_{s}\left(d-d^{\prime}\right)$

\subsubsection{Example of Calculating the Ultimate Moment Capacity}

The derived equations were used for the models with dowel bars area $=24.75 \mathrm{in}^{2}$ to find the ultimate moment capacity in the connection detail. The results are compared to the finite element analysis in the next step.

$t s=$ considered thickness of concrete diaphragm $=5$ in

$b s=$ width of the concrete diaphragm $=93$ in

$\mathrm{T}=977$ kips

$L=$ height of concrete diaphragm $=37.7$ in 
$\mathrm{A}_{\mathrm{s}}=$ total area of dowel bars $=24.75 \mathrm{in}^{2}$

$\Delta=\frac{0.4 b_{s} t_{s}}{n}=\frac{0.4 * 93 * 5}{18}=10.33 \mathrm{in}$

To calculate $\mathrm{k}_{\mathrm{r}}$ it was assumed that tangent modulus is about five percent of the elastic modulus, $\mathrm{E}_{\mathrm{s}}$ $=0.05(29000)=14500 \mathrm{ksi}($ Farimani M. J., 2014)

$$
\begin{aligned}
& k_{r}=\frac{E_{s} A_{s}}{b_{s} \Delta}=\frac{1450 * 24.75}{93 * 10.33}=37.34 \mathrm{in} \\
& G_{c}=\frac{E_{c}}{2(1+v)}=\frac{4800}{2(1+0.2)}=2000 \frac{\mathrm{kip}}{\mathrm{in}^{2}}
\end{aligned}
$$

$A_{c}=t_{s} \Delta=5 * 10.33=51.66 \mathrm{in}^{2}$

$$
\begin{aligned}
& \lambda=\sqrt{\frac{1.5 k_{r}}{0.4 G_{C} A_{c}}}=\sqrt{\frac{1.5 * 37.34}{0.4 * 2000 * 51.66}}=0.036 \\
& \varepsilon=\frac{\delta}{L}=\frac{T \lambda}{2 L k_{r}\left(1-e^{\frac{-\lambda b_{S}}{2}}\right)} e^{-\lambda y}=\varepsilon_{s} e^{-\lambda y}=\frac{977 * 0.036}{2 * 37.7 * 37.34\left(1-e^{\left.\frac{-0.036 * 93}{2}\right)}\right.} e^{-0.036(y=7.9)}=0.00294 * \\
& e^{-0.036(y=7.9)}=0.0022 \\
& \rho=\frac{E_{S} \varepsilon_{S} A_{s}}{b_{s}}=\frac{29000 * 0.00294 * 24.75}{93}=22.69 \\
& b_{e}=\frac{-2}{\lambda} \ln \frac{\varepsilon_{y}}{\varepsilon_{s}}+b_{f}=\frac{-2}{0.036} \ln \frac{0.002}{0.00294}+15.8=36.7 \mathrm{in}
\end{aligned}
$$




$$
\begin{aligned}
F_{S}=\frac{b_{e}}{b_{s}} A_{s} F_{y r}+ & \frac{2 E_{s} \varepsilon_{s} A_{s} e^{\frac{\lambda b_{f}}{2}}}{\lambda b_{s}}\left(e^{\frac{-\lambda b_{e}}{2}}-e^{\frac{-\lambda b_{s}}{2}}\right) \\
& =\frac{36.7}{93} * 24.75 * 88 \\
& +\frac{2 * 1450 * 0.00294 * 24.75 * e^{\frac{0.036 * 15.8}{2}}}{0.036 * 93}\left(e^{\frac{-0.036 * 36.7}{2}}-e^{\frac{-0.036 * 93}{2}}\right) \\
& =859+82.4 *(0.33)=886.2 \frac{\mathrm{kip}}{\mathrm{in}^{2}}
\end{aligned}
$$

\subsubsection{Comparing Finite Element Results with Developed Formula}

The numerical values from the developed formula, including effective length and ultimate moment capacity and finite element analysis, are listed in Table 10-1. Figure 10-20 shows a

\begin{tabular}{|c|c|c|c|c|c|c|c|c|c|c|c|c|}
\hline \begin{tabular}{|c|}
$\mathrm{V}$ \\
(kips)
\end{tabular} & \begin{tabular}{|c|} 
Dowel bar \\
(in2)
\end{tabular} & be $(F)$ & be(D) & be(D)/be(F) & $M(F)$ & $M(D)$ simplified & $\mathrm{M}(\mathrm{D})$ exact & $\begin{array}{c}\mathrm{M}(\mathrm{D}) \text { exact,con } \\
\text { crete }\end{array}$ & C & $\begin{array}{c}M(D) \text { simplified } \\
/ M(F)\end{array}$ & $\begin{array}{c}M(D) \text { exact/ } \\
M(F)\end{array}$ & \begin{tabular}{|c|}
$\mathrm{M}(\mathrm{D})$ exact,co \\
ncrete $/ \mathrm{M}(\mathrm{F})$
\end{tabular} \\
\hline 977 & 24.75 & 30 & 37 & 1.23 & 2200 & 2519 & 1980 & 2627 & 10.50 & 1.15 & 0.90 & 1.19 \\
\hline 933 & 15.3 & 50 & 62 & 1.24 & 2100 & 2380 & 2069 & 2497 & 11.00 & 1.13 & 0.99 & 1.19 \\
\hline 622 & 6.18 & 93 & 93 & 1.00 & 1400 & 1224 & 1224 & 1365 & 7.50 & 0.87 & 0.87 & 0.98 \\
\hline
\end{tabular}
comparison between the finite element analysis and developed formula. The results indicate there is good agreement between the three methods for computing the moment strength.

Table 10-1 Results of finite element analysis and developed formula.

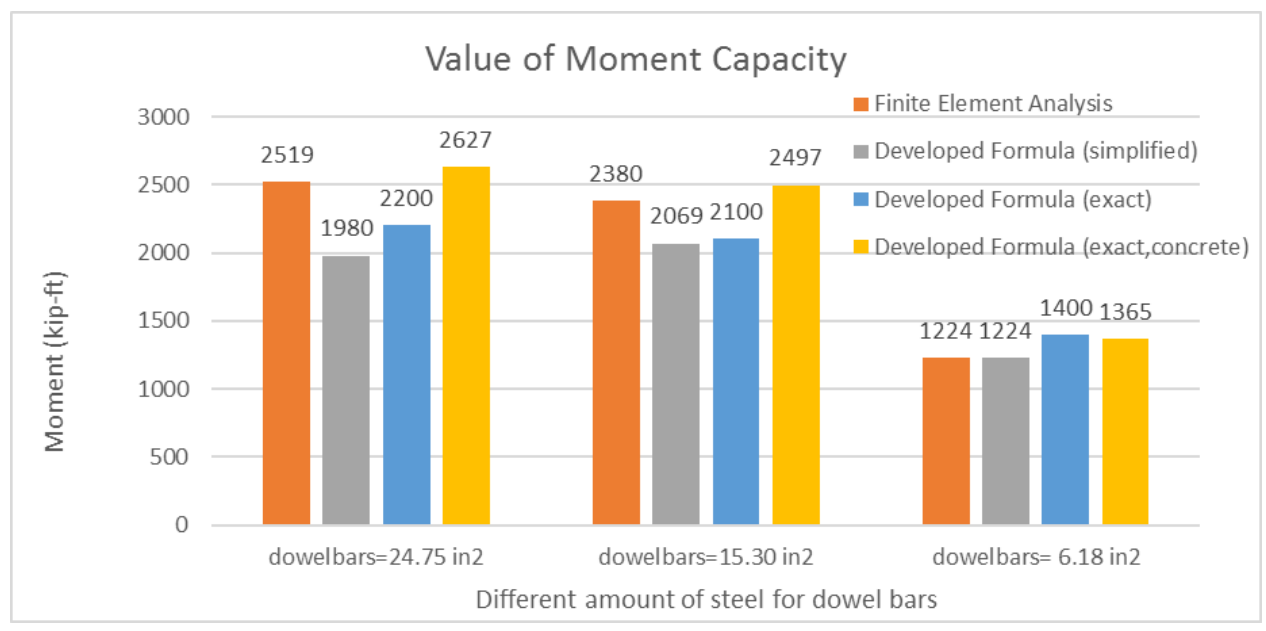

Figure 10-20 Bar chart comparison between finite element results and developed formula. 


\section{PHASE II, EXPERIMENTAL TEST SPECIMEN AND TEST SETUP}

Phase I of this research concentrated on developing suitable details mainly through numerical analysis and provided a comprehensive numerical study for the design of SDCL detail in steel bridges. In Phase II of this research project, an experimental test will be conducted as a proof of concept test and evaluate the validity of the design recommendations. In the phase III of this project, a scale model bridge containing the SDCL detail will be subjected to a shake table test at the University of Nevada-Reno.

The following section reviews previous test configurations used by other researcher for the purpose of seismic assessment of integral steel bridges. Finally, the component test will be described and details of the one-third scale specimen will be presented.

\subsection{A Review of Previous Test Setup for Integral Bridges}

In this chapter, the construction process and test setup for the component test of Phase II is discussed. The intent of the component test is to load the connection between the deck and substructure in order to study the nonlinear behavior of the system and understand the load resistance mechanism.

\subsubsection{Testing Method at UCSD}

The following test setup was part of experimental testing conducted at the University of California in San Diego (UCSD) by Jill Patty, Frieder Seible and Chia-Ming Uang, to characterize the response of a bridge design detail in an integral bridge with steel superstructure and concrete substructure (Jill Patty, 2001). The main goal of this research was controlling the detail connection inside of the bent cap to be capacity protected and remain essentially elastic during the force transfer. 
When an integral bridge is subjected to earthquake loads in the longitudinal direction, the deformed shape of the column is one of double curvature with the inflection point at the middle of column length. The deflection and moment distribution along the girder and column is similar to that shown in Figure 11-1. The value of moment at the mid-height of the column is equal to 0.0 and the value of moment in the deck (at the inflection point under gravity loads) is equal to $0.3 \mathrm{M}$ (M=maximum moment in column) as illustrated in Figure 11-2.

The moment at the inflection point of the girder under gravity loads is simulated by applying two horizontal forces at a distance $\mathrm{h}$ above the girder of the inverted specimen (Figure 11-3). Different components of the test specimen are shown in Figure 11-4. The specimen scale in this research was $40 \%$. The specimen constructed was in an inverted orientation. The length of the girders in the specimen was taken equal to the distance from the column to the dead load inflection point. The support at the two ends of specimen were constructed as rollers. More information about this research is mentioned in section 1.3.2.

Advantages of this setup are:

-It is supported at the superstructure dead load inflection point (0.2 span length) rather than the seismic inflection point (0.5 span length).

-Just one actuator is required for applying seismic forces located at the mid-height of the column.

-Constructing half of the column height reduces the vertical dimension of the test setup.

A disadvantage of this load setup is the generation of artificial stresses in the deck due to applying the equivalent dead force at the end of column. 


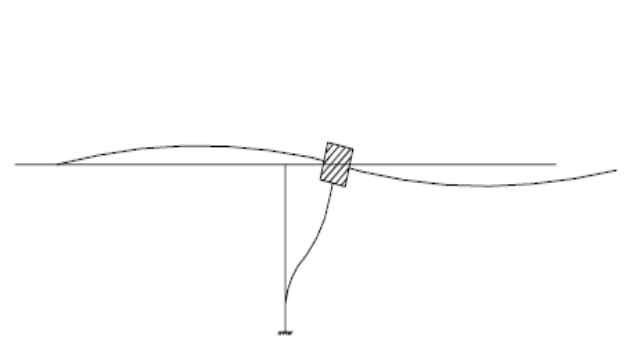

a) Deflected Shape

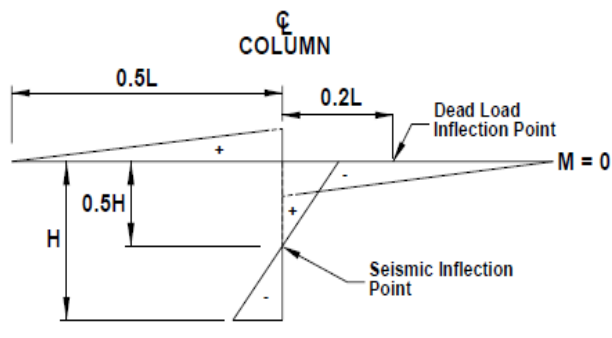

b) Moment

Figure 11-1 Deflected shape and column moment diagram under longitudinal component of earthquake.

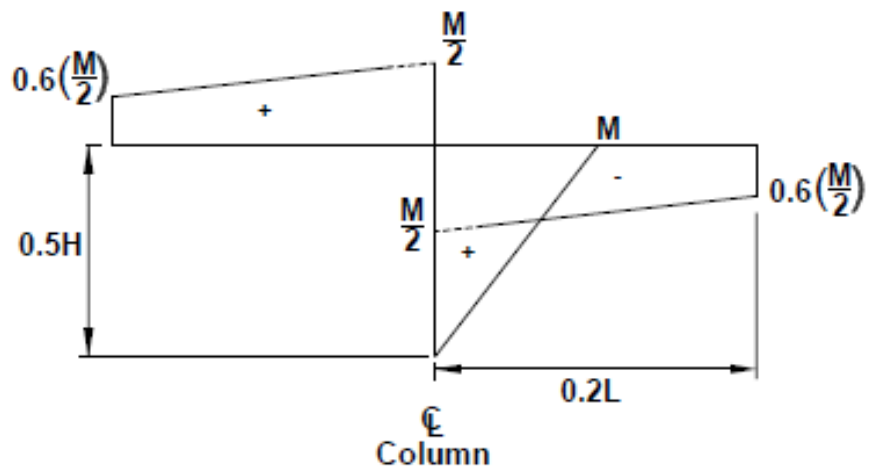

Figure 11-2 Amount of moment at boundary condition of specimen.

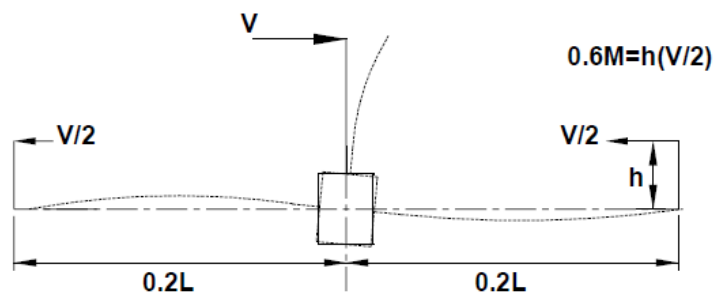

a) Deflected Shape

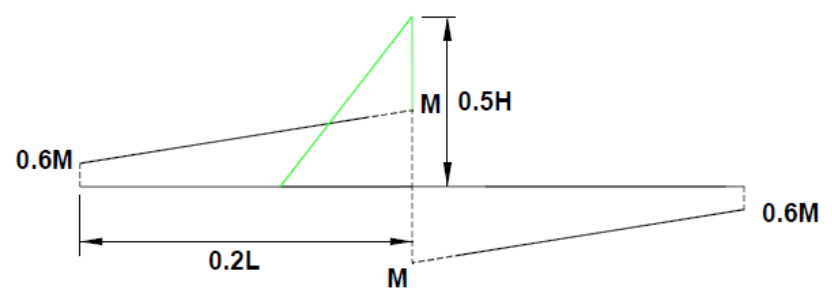

\section{b) Moment}

Figure 11-3 Location and amount of forces in specimen model. 

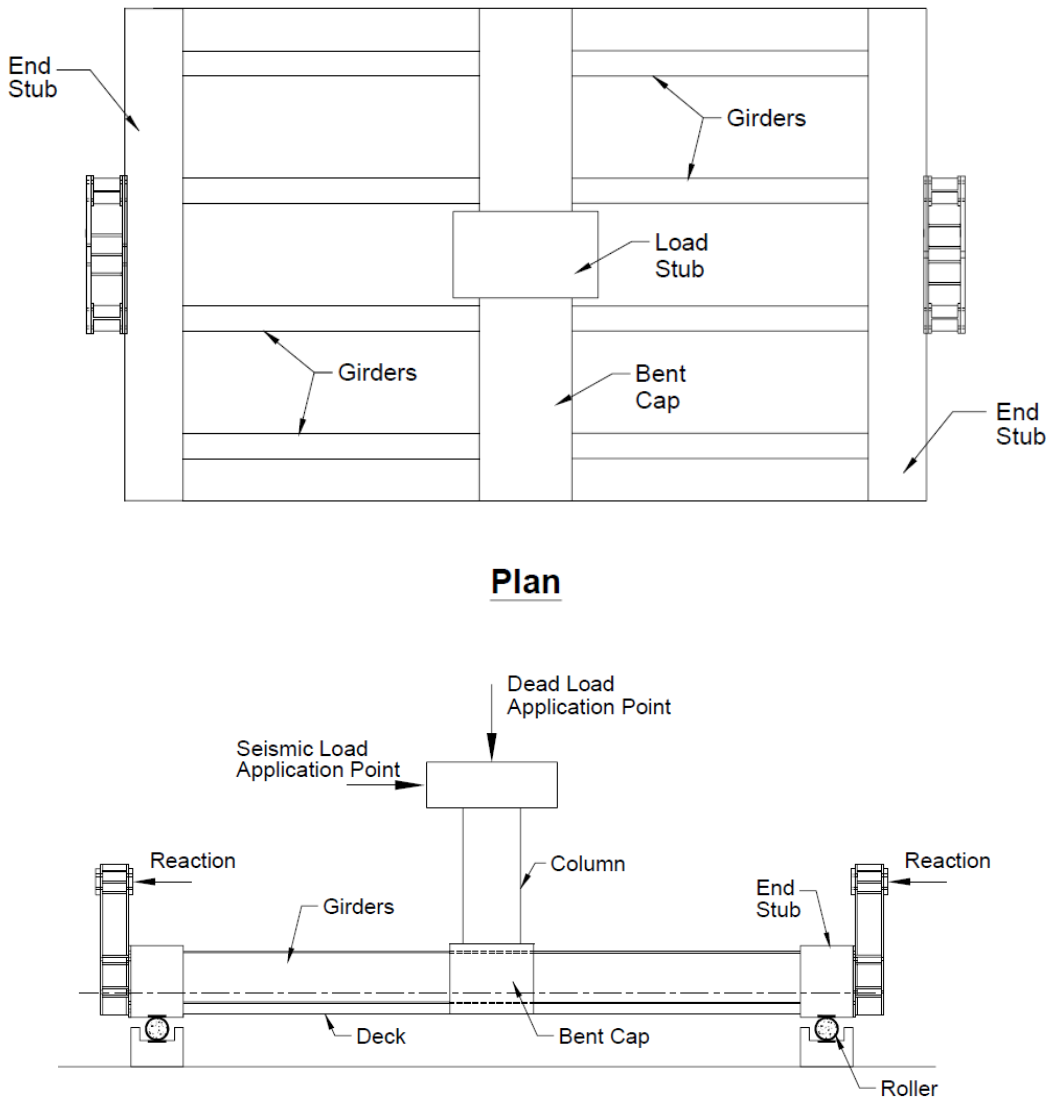

Elevation

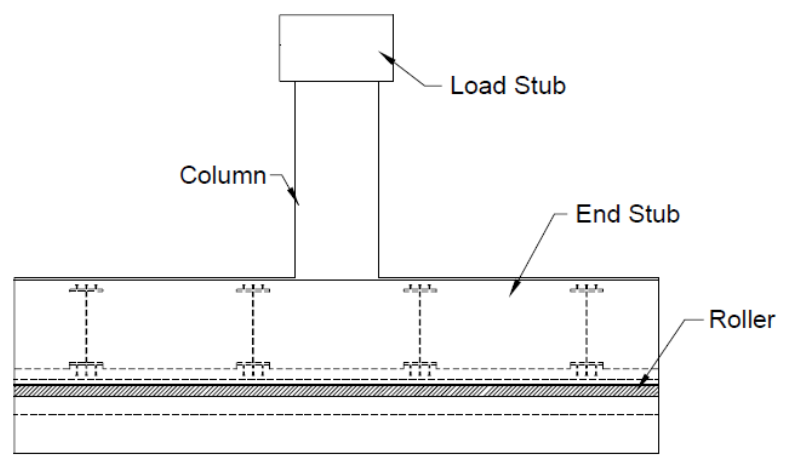

\section{End View}

Figure 11-4 Different component of test specimen.

\subsubsection{Testing Method at Iowa State University}

A continuous two span bridge was evaluated in NCHRP report 527 to check the integral connection between steel girder, steel box beam and reinforced concrete column by Sri Sritharan, 
justin R. Vander Werff, Robert E. Abendroth, Juli Redmond, Lowell F. Greimann (NCHRP, 2004). More information about this research is mentioned in 1.3.2. The geometry of the prototype bridge is shown in Figure 11-5. The specimen scale factor was one-third and was constructed and tested at the Iowa State University Structures Laboratory. The test specimen was very similar to the UCSD test specimen and was constructed in a similar inverted position with roller supports at end of girders. The portion of structure selected for construction and testing is shown inside the dashed lines in Figure 11-6 and Figure 11-7. The loading process was to first apply the axial load at the end of the column and then subject it to cyclic loading.

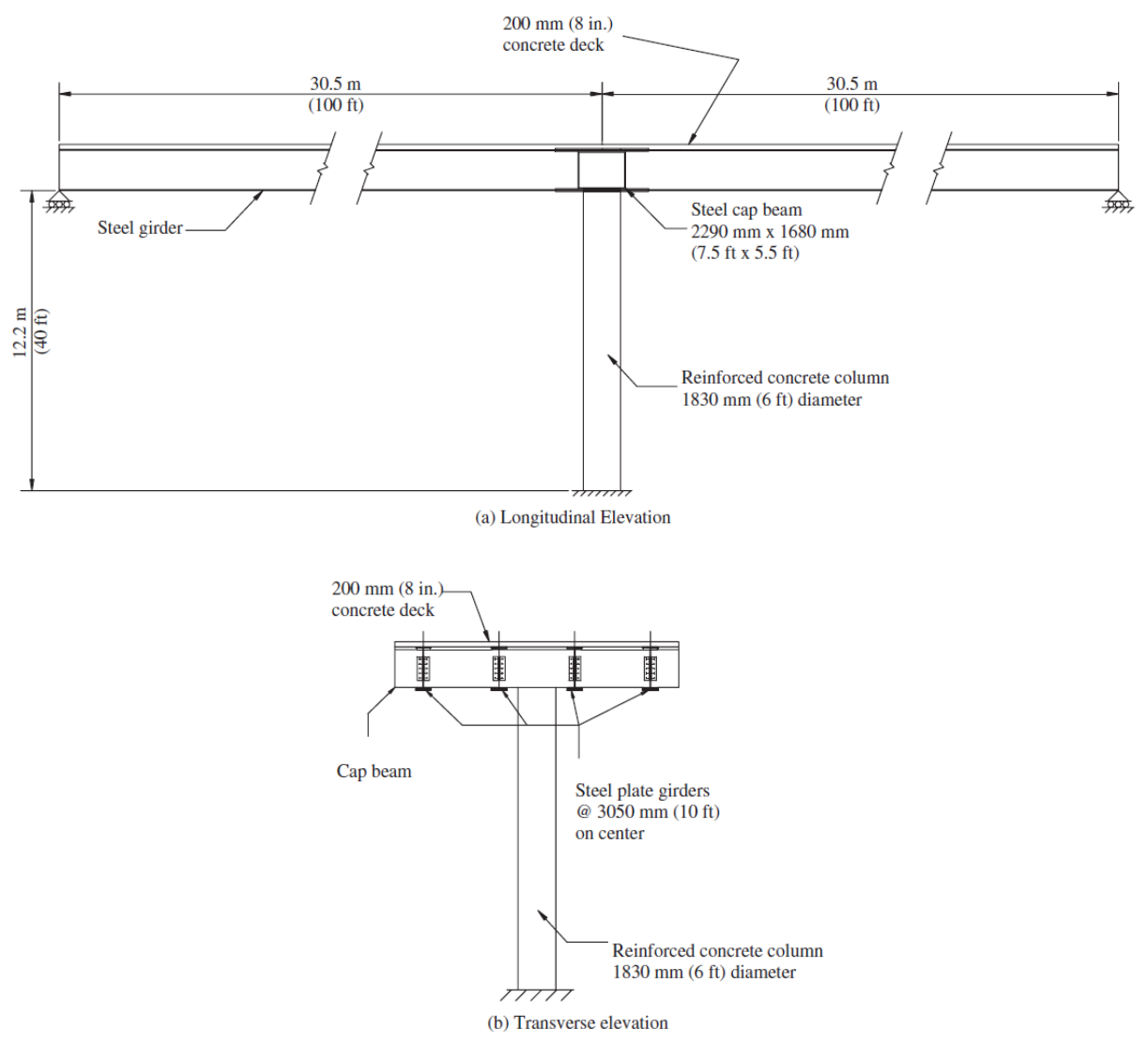

Figure 11-5 Geometry and dimensions of prototype bridge. 


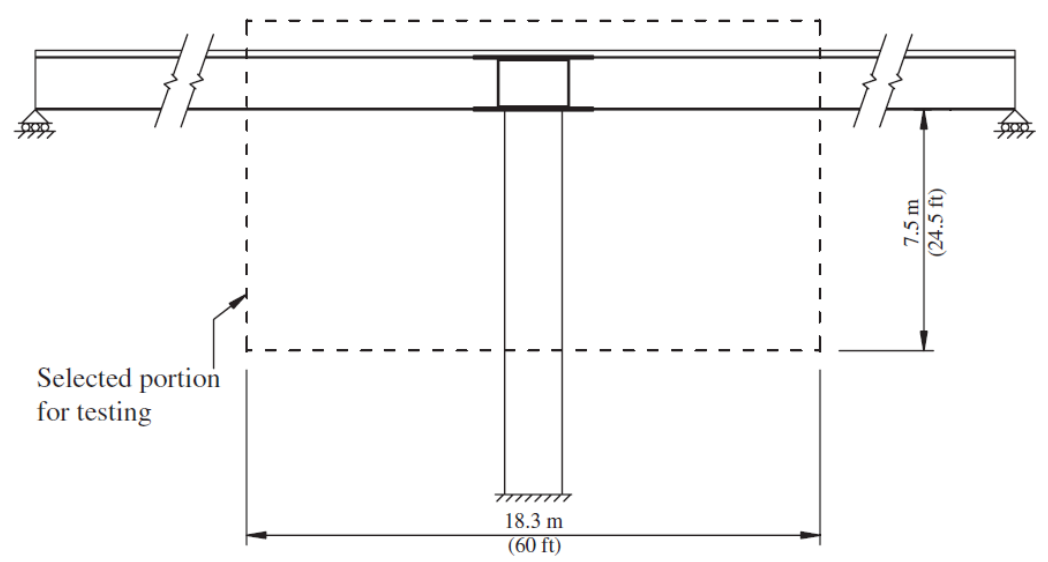

Figure 11-6 Selected portion for construction and testing.

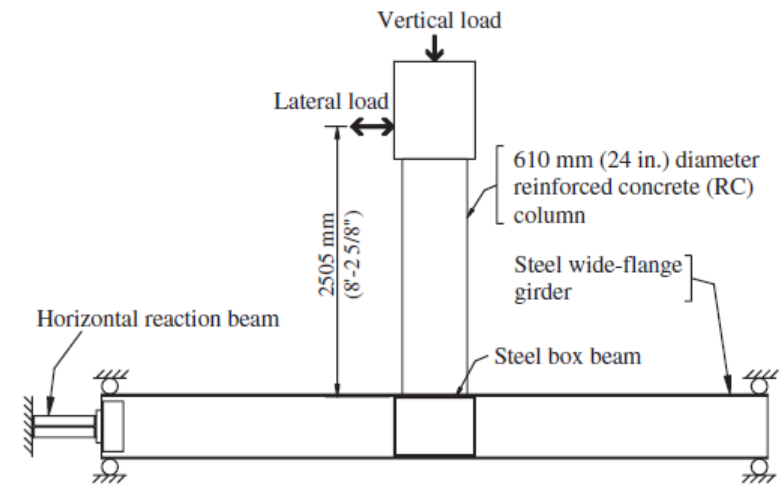

(a) Elevation

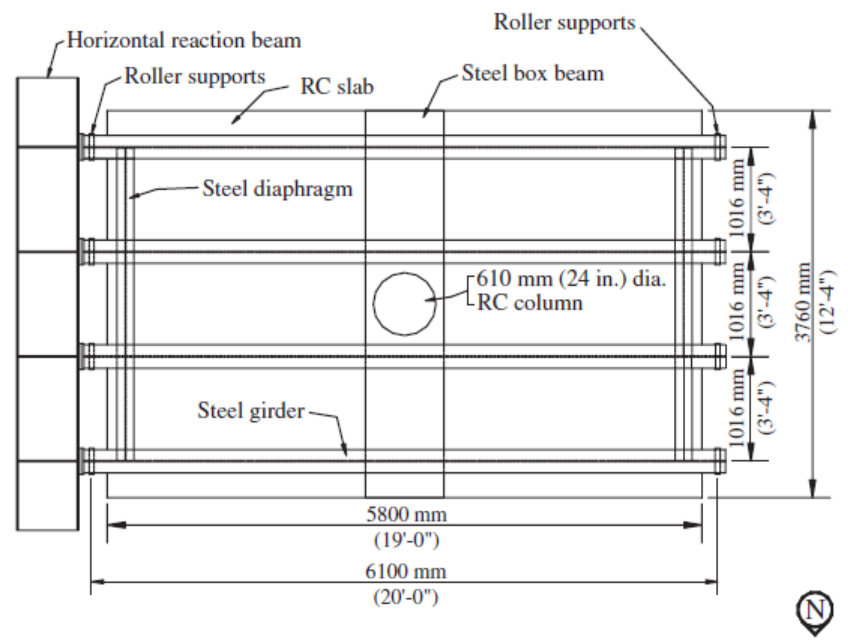

(b) Plan view

Figure 11-7 Different components of test specimen. 


\subsubsection{Testing Method at Iowa State University}

To study the seismic performance of an I-girder to inverted-tee bent cap connection, a four span prototype bridge was developed by Sri Sritharan, Ron Bromenschenkel, Justin Vander Werff and Robert Peggar (Sri Sritharan, 2014). In Figure 11-8, the selected bridge and modeled region are shown. A 50\% scaled model of the center portion of the prototype bridge was constructed for the experimental test. To investigate the seismic behavior of the connection, the specimen was subjected to cyclic loading. Figure 11-9 illustrates schematic configuration of the system test.

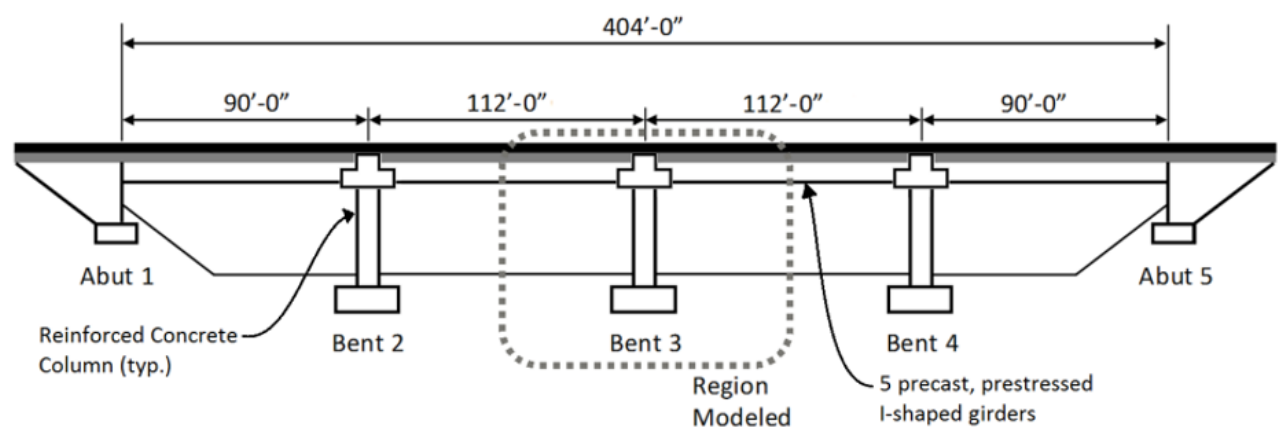

Figure 11-8 Prototype bridge for testing the connection between I-girder and inverted cap beam.

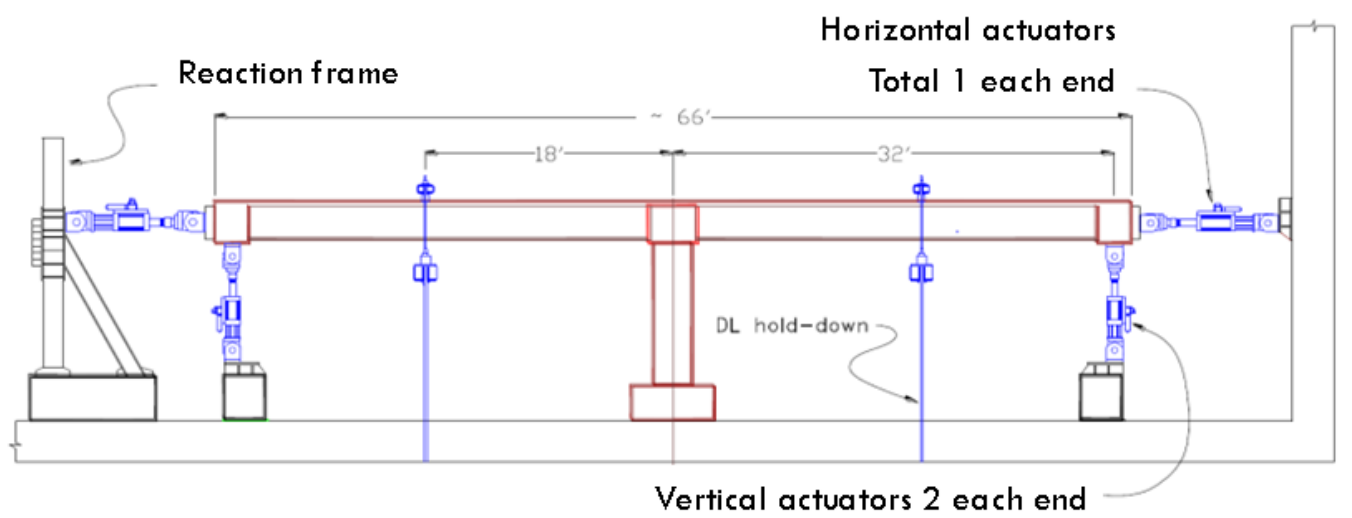

Figure 11-9 Test component.

After completion the cyclic test, a component test was designed and constructed to control the moment and shear behavior of the connection, with the intent of placing a larger moment demand on the connection. A looped unstressed strand connection (LUSC), a girder to cap 
connection alternative was selected for the component test. The details of this connection are shown in Figure 11-10. Figure 11-11 shows a schematic view of test setup.

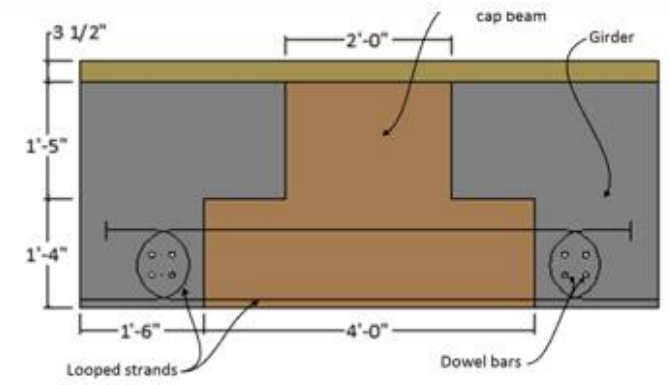

(a) Cross-section through girder-to-cap connection region

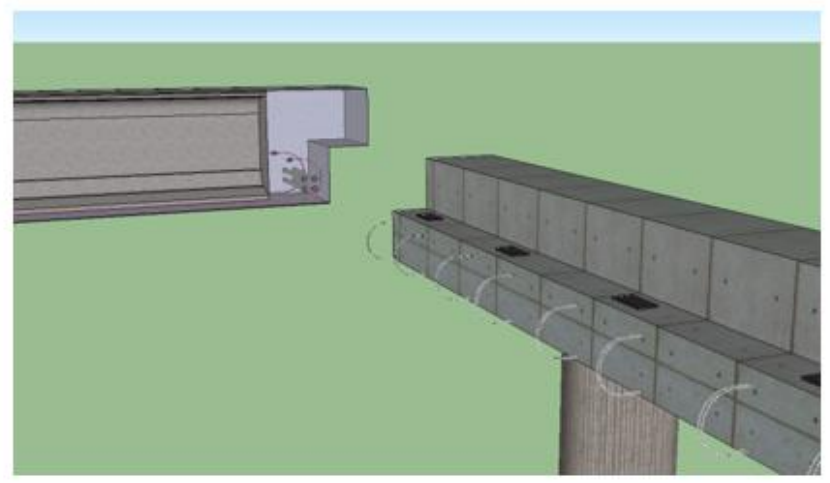

(b) Cutaway view of girder loops and dowel pipes

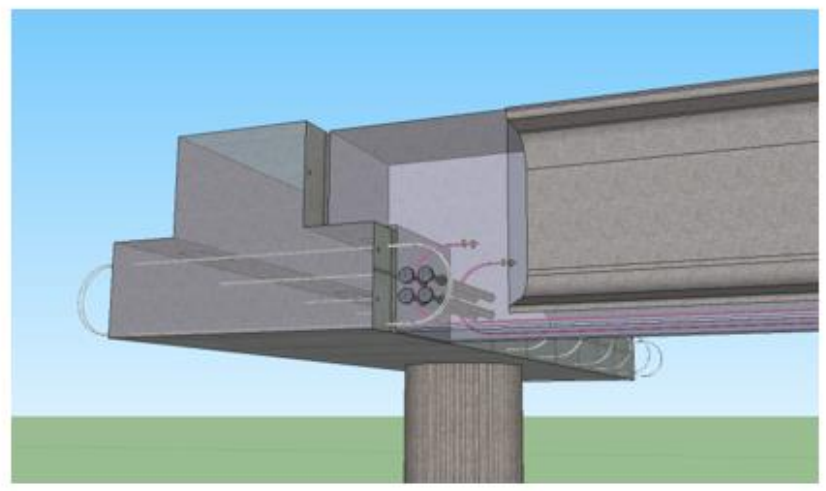

(c) Cutaway view of assembly before diaphragm concrete placement

Figure 11-10 Details of looped unstressed strand connection and load transfer mechanism. 


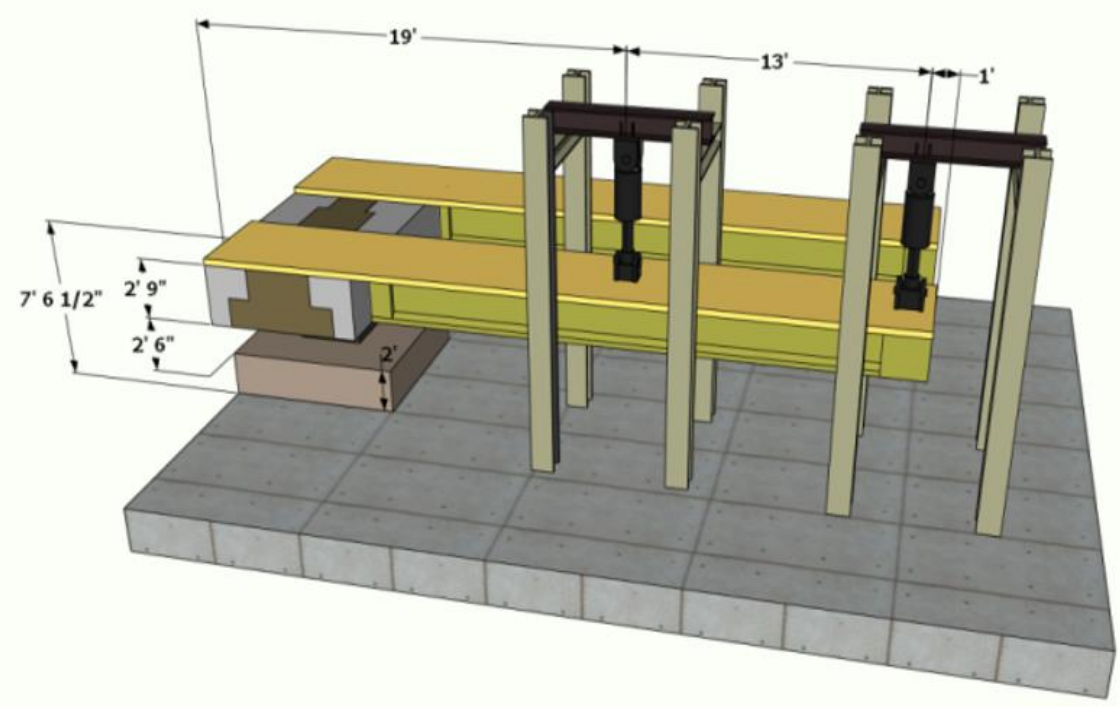

Figure 11-11 Connection test configuration.

\subsection{Selected System for the Phase II Component Test}

After investigating different test setups for the component test to simulate seismic loads, a test setup similar to the one introduced in 11.1.1 was selected for the test specimen. Based on the documents provided by the University of Nevada - Reno, a bridge with two spans, each span equal to 100 feet, was considered for a prototype. The substructure of this bridge is made up of two columns with four steel girders supporting the deck. The columns are connected monolithically to the bent cap. The design strategy for the component test is similar to a bridge with a ductile substructure and an essentially elastic superstructure. Accordingly, the plastic hinges should form at end of the columns. Due to the symmetrical behavior of the bridge, it was decided only one column with two girders need be constructed and tested. A schematic view of the component test shown in Figure 11-12. 

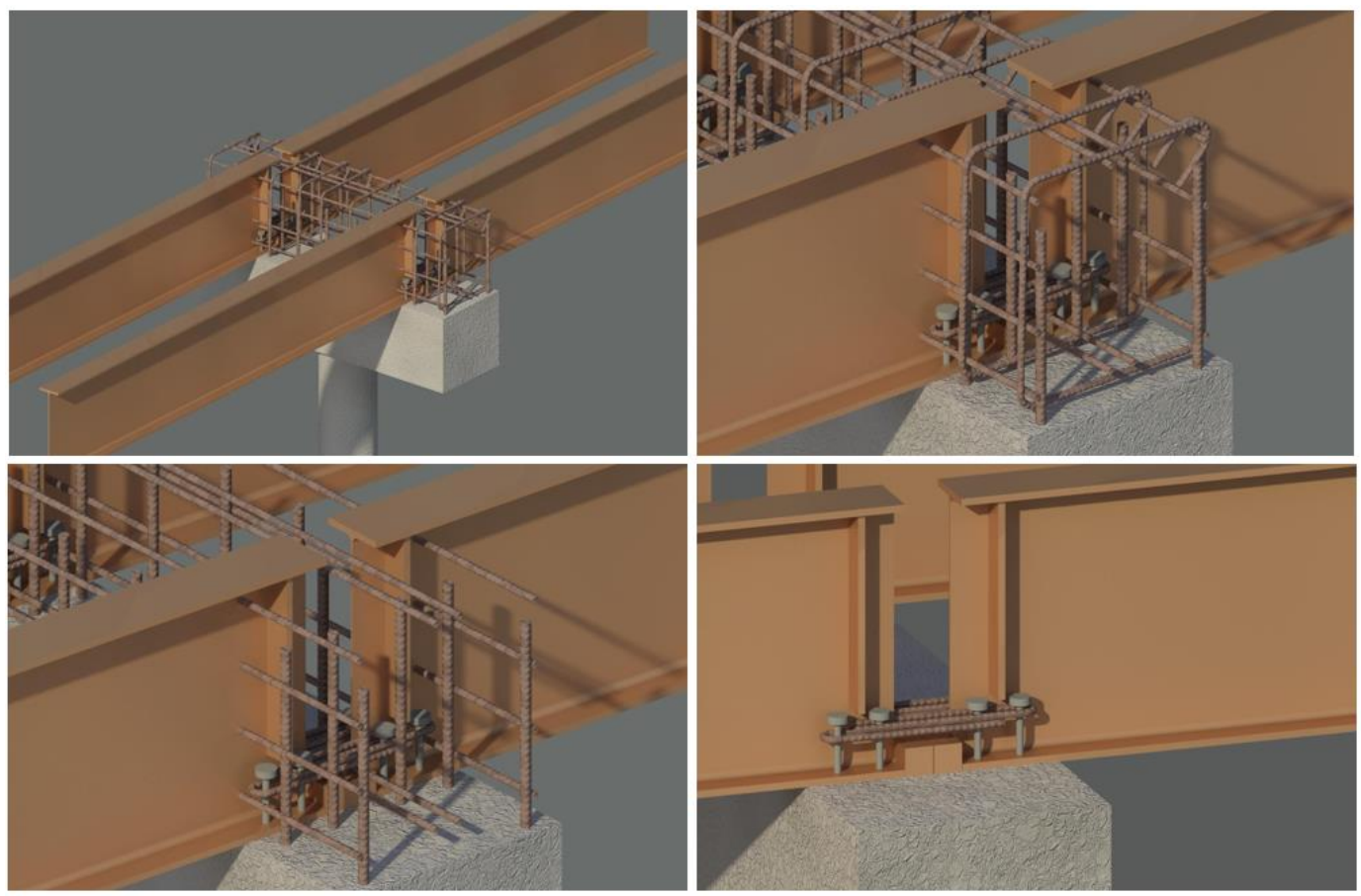

Figure 11-12 Component test including one column with two girders.

\subsubsection{Column Property of Component Test}

The column for the component test was designed by the UNR research team. Based on information provided by UNR, the prototype bridge is a two-span steel I-girder bridge. The substructure uses 48 in diameter concrete columns that are reinforced with 32-\#11 vertical bars and a \#7 hoop every 4 in. A one-third scale specimen of this bridge is going to be constructed in the FIU structures lab. The scaled specimen consists of a 16 in diameter concrete column that is reinforced with 12-\#5 vertical bars and a \#3 hoop every $2.5 \mathrm{in}$. The compressive strength of the concrete is assumed 5000 psi with grade 60 reinforcement (Figure 11-13). The stress-strain curve of the core concrete is considered to behave according to the confined Mander model as shown in Figure 11-14. The geometry and reinforcement of the column is shown in Figure 11-15. 

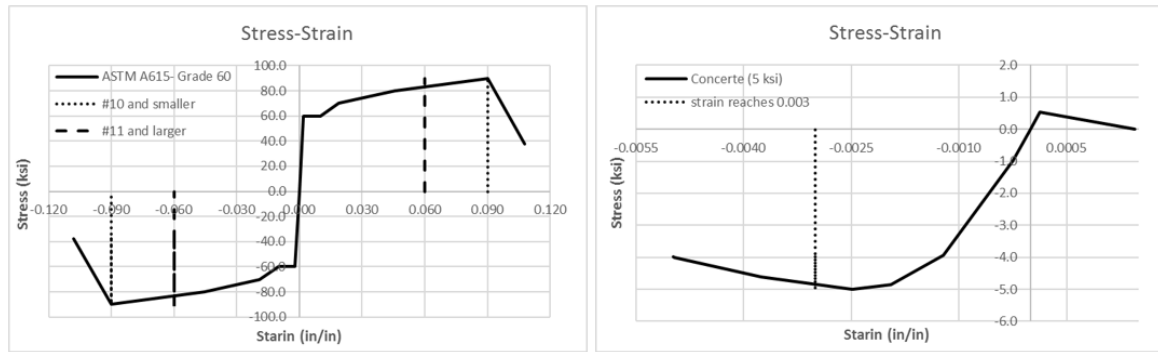

Figure 11-13 Material property for steel (left) and concrete (right).
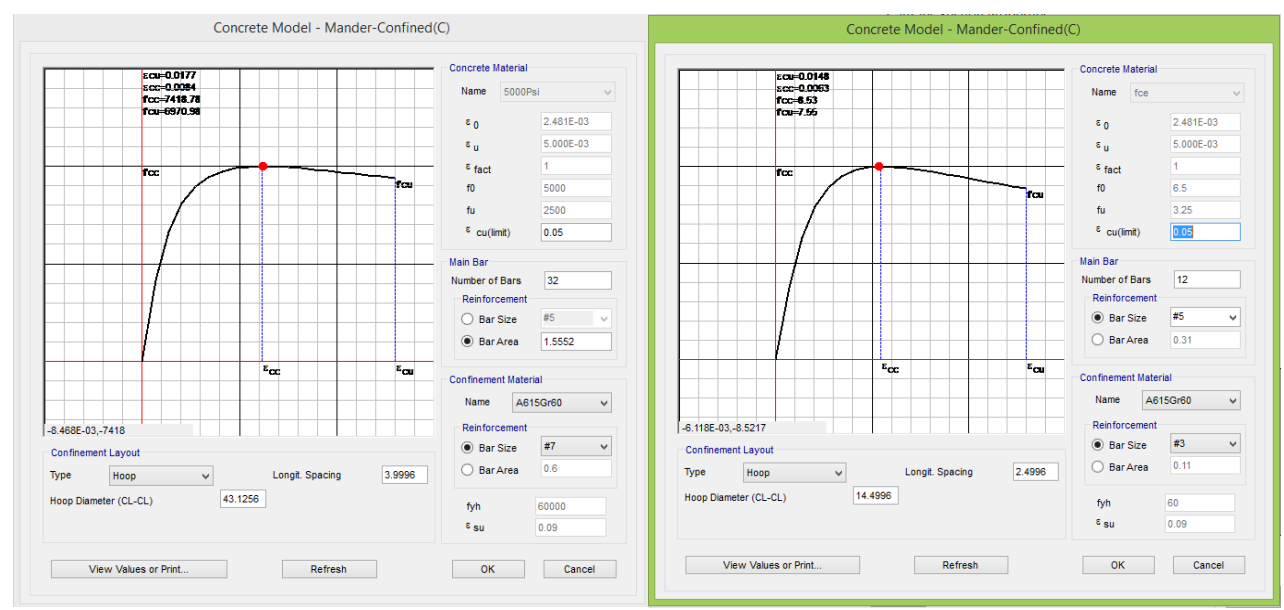

Figure 11-14 Mander-Confined model right, left (full-scale ), right (one-third scale).

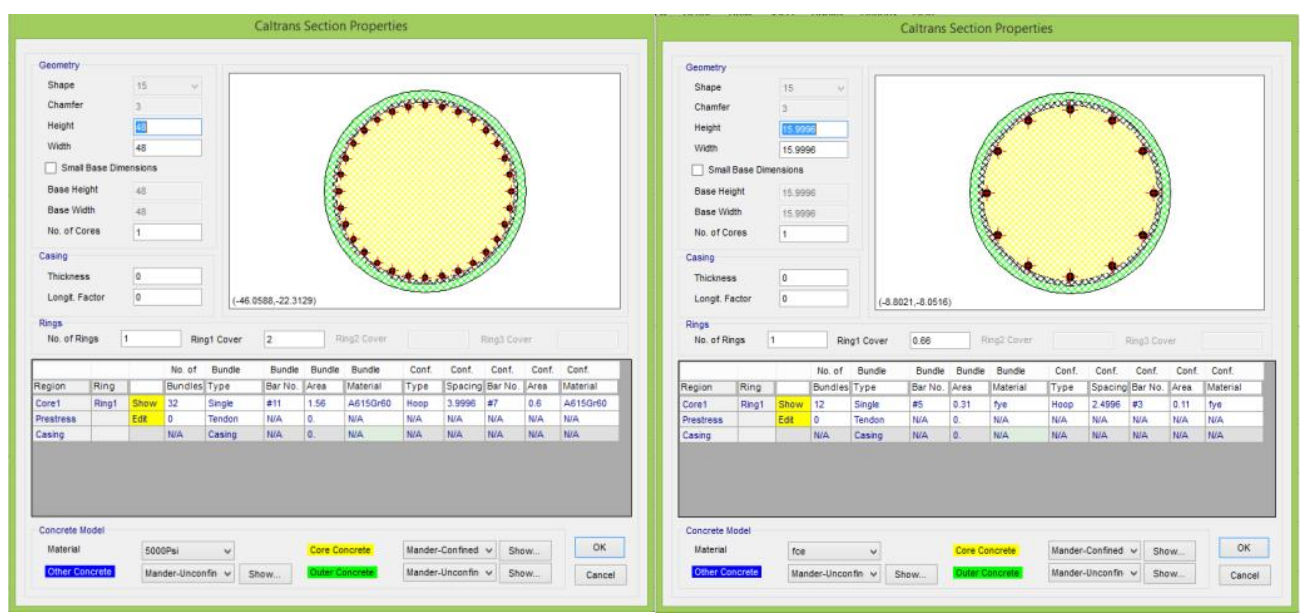

Figure 11-15 Column property definition- left (full-scale), right (one-third scale). 


\subsubsection{Calculating the steel reinforcement in the cap beam}

moment resisting connection between the super structure and column shall be designed to transfer forces when the column reaches its over strength moment capacity including the effects of over strength shear (CALTRANS, 2013).

\section{Joint Proportioning}

All superstructure/column moment resisting joints shall be proportioned such that the principal stresses shall satisfy the Equations below.

Principal compression: $\mathrm{p}_{\mathrm{c}} \leq 0.25 \mathrm{f}_{\mathrm{c}}^{\prime}(\mathrm{psi})=0.25 * 5000=1250 \mathrm{psi}$

Principal tension: $\mathrm{p}_{\mathrm{t}} \leq 12 \sqrt{\mathrm{f}_{\mathrm{c}}^{\prime}}(\mathrm{psi})=12 \sqrt{5000}=848 \mathrm{psi}$

\section{Minimum Bent Cap Width}

The minimum bent cap shall be calculated according to Figure 11-16. This width is required for adequate joint shear transfer. A larger cap width is required to develop the compression strut outside the joint for columns with large diameter.

$\mathrm{B}_{\text {cap }}=\mathrm{D}_{\mathrm{c}}+2(\mathrm{ft})=16+2 * 12 / 3=24$ in

$B_{\text {eff }}=B_{\text {cap }}+(12 t)=24+12 * 3=60$ in

$t=$ Thickness of the top or bottom slab 


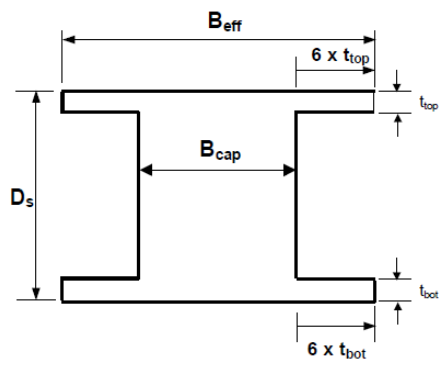

Figure 11-16 Effective Bent Cap Width

\section{T Joint Shear Reinforcement}

\section{A) Vertical Stirrups:}

$\mathrm{A}_{\text {st }}=$ Area $(12 \# 5)=12 * 0.31=3.72$

$\mathrm{A}_{\mathrm{s}}^{\mathrm{jv}}=0.2 \mathrm{~A}_{\mathrm{st}}=0.2(3.72)=0.744$

Ast $=$ Total area of column longitudinal reinforcement anchored in the joint $\left(\mathrm{in}^{2}\right)$

Within a distance $\mathrm{D}_{\mathrm{c}}$, extending from either side of the column centerline, vertical stirrups or ties shall be placed transversely. $A_{j v s}$ (the vertical stirrup area) is required on each side of the column or pier wall (Figure 11-17). 


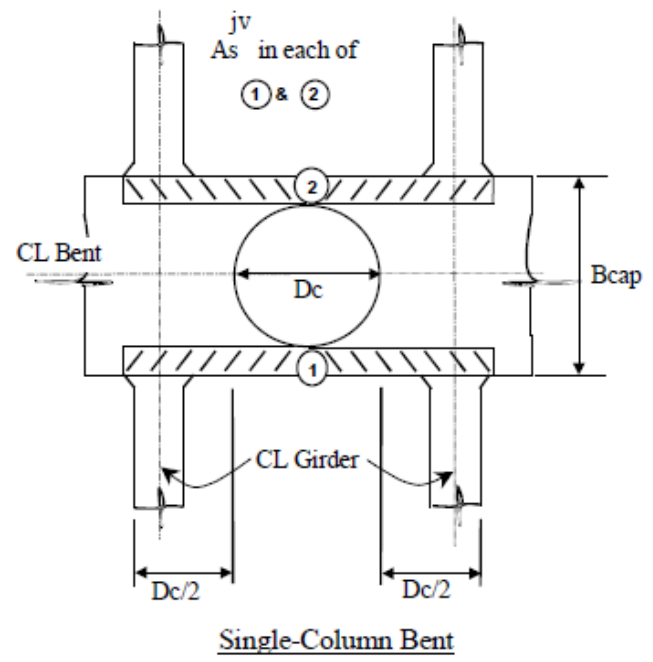

Figure 11-17 Location of Vertical Joint Reinforcement (Plan View of Bridge)

\section{B) Horizontal Stirrups:}

Horizontal stirrups or ties shall be placed transversely around the vertical stirrups or ties in two or more intermediate layers spaced vertically at less than 18 inches (in $1 / 3$ scale 6 in). This horizontal reinforcement shall be placed within a distance $\mathrm{D}_{\mathrm{c}}$ either side of the column centerline (Figure 11-18).

$A_{s}^{\mathrm{jh}}=0.1 \mathrm{~A}_{\mathrm{st}}=.1(3.72)=0.372$

\section{C) Horizontal Side Reinforcement:}

The total longitudinal side face reinforcement in the bent cap shall be more than the greater of the areas based on equation below. These reinforcements shall be placed near the side faces of the bent cap within a distance less than 12 inches (in 1/3 scale 4in), see Figure 11-18. Any side reinforcement placed to meet other requirements shall be count to meet the requirement in this section.

$\mathrm{A}_{\mathrm{S}}^{\mathrm{sf}}=\max \left(0.1 \mathrm{~A}_{\text {cap }}^{\mathrm{top}}, 0.1 \mathrm{~A}_{\text {cap }}^{\mathrm{bot}}\right)=0.1(6 \# 4+4 \# 4)=0.1(10 * 0.2)=0.2$ 
$\mathrm{A}_{\text {cap }}=$ Area of bent cap top or bottom flexural steel (in $\left.{ }^{2}\right)$

\section{D) Transverse Reinforcement}

The transverse reinforcement in the joint region shall include hoops with a minimum reinforcement ratio based on equation below. The column confinement reinforcement extended into the bent cap may be used to meet this requirement (\#3 @ 2.5 in was used in the column)

$\rho_{\mathrm{s}}=0.4 \frac{\mathrm{A}_{\mathrm{st}}}{\mathrm{l}_{\mathrm{ac}}^{2}}=0.4 *(3.72) /(27 * 27)=0.002$

$\rho_{\text {provided }}=\frac{4 \mathrm{~A}_{\mathrm{b}}}{\mathrm{D}^{\prime} S}=\frac{4 * 0.11}{14.5 * 5}=0.006(\# 3 @ 5$ in $)$ for inside of diaphragm

$l_{\mathrm{ac}}=$ Minimum length of column longitudinal reinforcement extension into the bent cap

Main column reinforcements shall be extended to the top concrete diaphragm reinforcement.

Table 11-1 shows a summary of calculated reinforcement.

\section{E) Main Column Reinforcement}

The main column reinforcement shall extend into the cap beam and concrete diaphragm as deep as possible to fully develop the compression strut mechanism in the joint. 


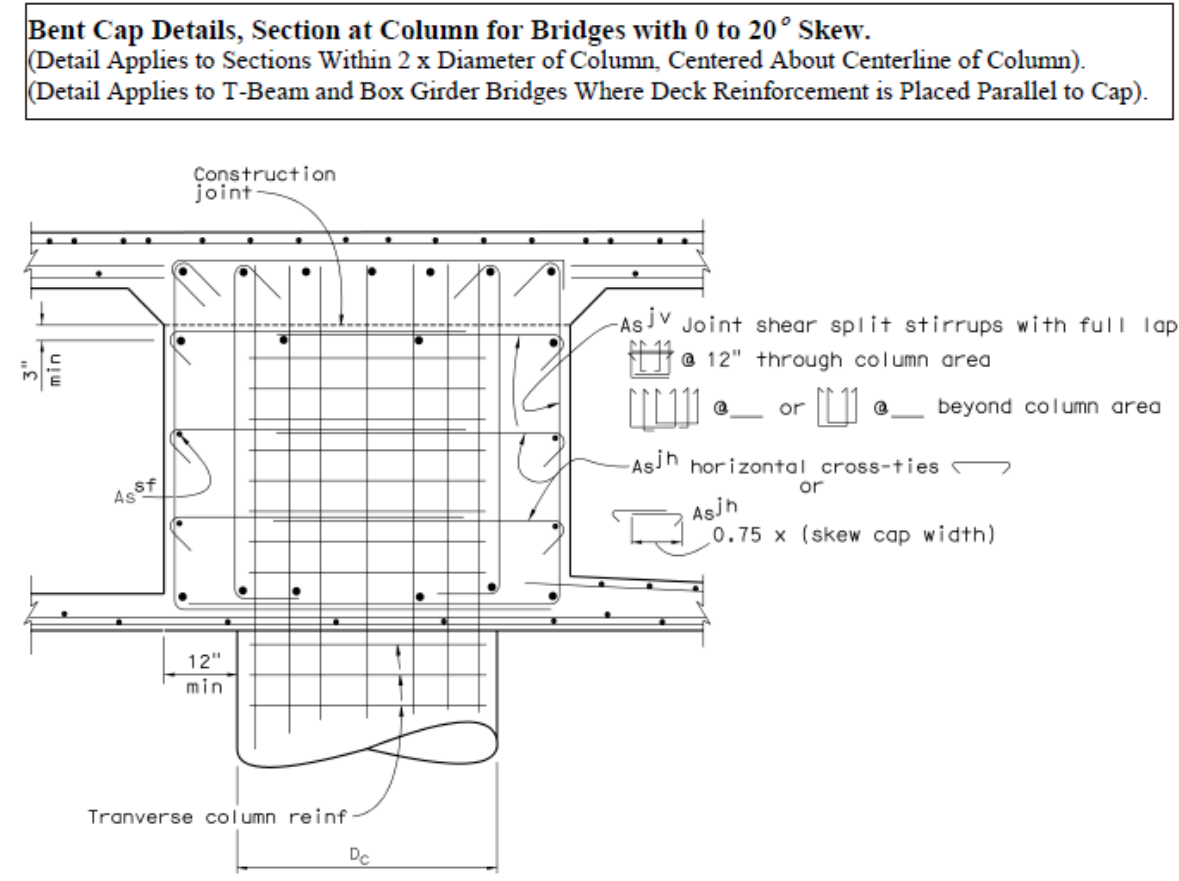

Figure 11-18 Joint Shear Reinforcement Detail

Table 11-1 Summary of results.

\begin{tabular}{|c|c|c|c|}
\hline Parameter & Required & Provided & Description \\
\hline$A_{s t}$ & 3.72 & 3.72 & $12 \# 5$ \\
\hline$A_{s}^{j v}$ & 0.744 & 0.88 & 8 leg \#3 each side of the concrete diaphragm \\
\hline$A_{s}^{j h}$ & 0.37 & 1.76 & 4 horizontal legs \#3, 4 set (Max dist. bars $<6)$ \\
\hline$A_{s}^{s f}$ & 0.2 & 1.1 & $5 \# 3$ bars each side (Max dist. bars $<4)$ \\
\hline$\rho_{s}$ & 0.002 & 0.006 & $\# 3 @ 5$ \\
\hline
\end{tabular}

\subsubsection{Column and Bent Cap Flexural Capacity}

The moment capacity of the column and cap beam in the transverse direction (here cap beam refers to the concrete beam that contains the bent cap and concrete diaphragm) was calculated by a Moment-Curvature analysis. Section Designer, inside of SAP2000, was used for this purpose and calculated $\mathrm{I}_{\text {cracked }}$ for the column (SAP2000). The finite element software ANSYS was used to compute the moment capacity of the system in the longitudinal direction (traffic direction). Notice that for the moment curvature analysis in the transverse direction, the section is not symmetric. Therefore, the analysis was conducted for both negative and positive moments and the minimum was considered for comparison with the column capacity. 
According to CALTRANS, the bent cap should be designed as a capacity protected member and remain essentially elastic for the flexural forces up to the point that the column reaches its over strength moment capacity. The capacity design approach guarantees the superstructure and the bent cap have enough demand strength to carry the transferred forces from the column at the ultimate load level. The expected nominal moment capacity $\mathrm{Mne}_{\mathrm{ne}}$ of the capacity protected members may be computed using M- $\phi$ analysis. The expected nominal moment capacity should be based on expected material properties and equal to the moment when the concrete strain reaches 0.003 or the steel strain reaches $\varepsilon_{s u}^{R}$. The reduced ultimate tensile strain $\left(\varepsilon_{s u}^{R}\right)$ is equal to 0.09 for \#10 bars and smaller, and is equal to 0.06 for \#11 and larger. The following figures show the moment capacity of the column and bent cap (longitudinal and transverse direction) for the full-scale and one-third scale model. For the bent cap in the longitudinal direction, the moment capacity of only one girder was obtained from the finite element model, so two times this capacity was compared with moment capacity of the column.

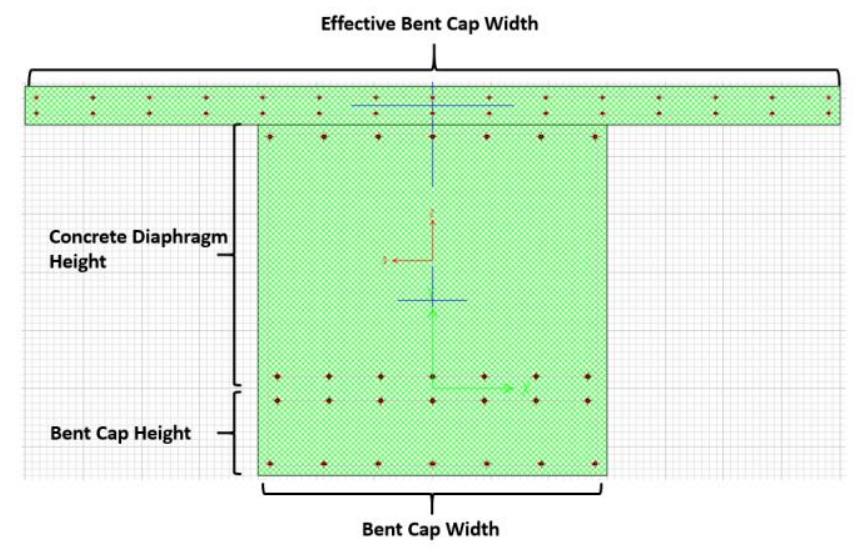

Figure 11-19 Bent cap geometry. 

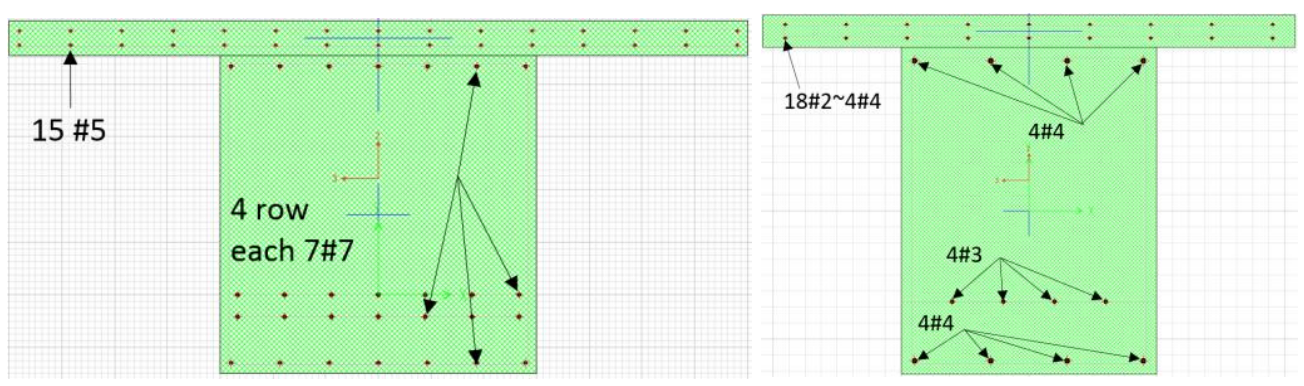

Figure 11-20Concrete diaphragm and bent cap reinforcements (left: full-scale model, right: onethird scale model)

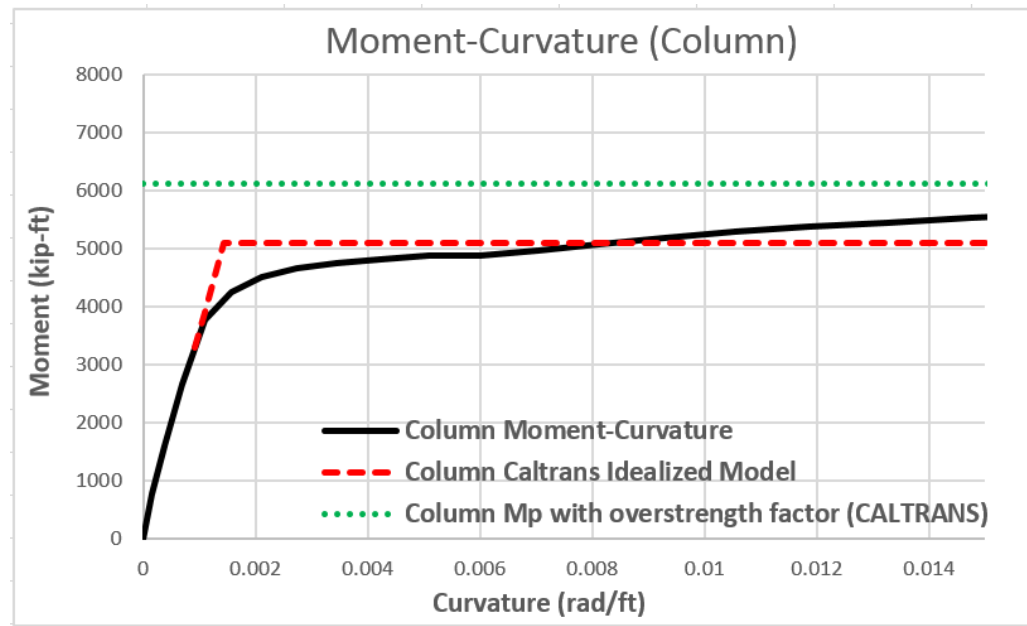

Figure 11-21 Column Moment-Curvature for the full-scale model.

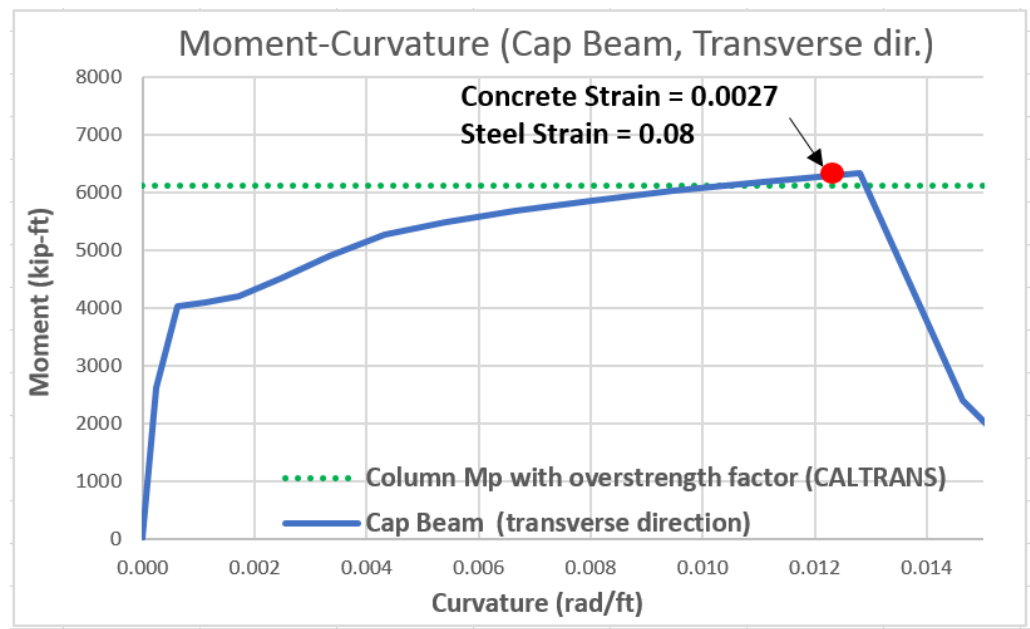

Figure 11-22 Cap beam Moment-Curvature in transverse direction for the full-scale model. 


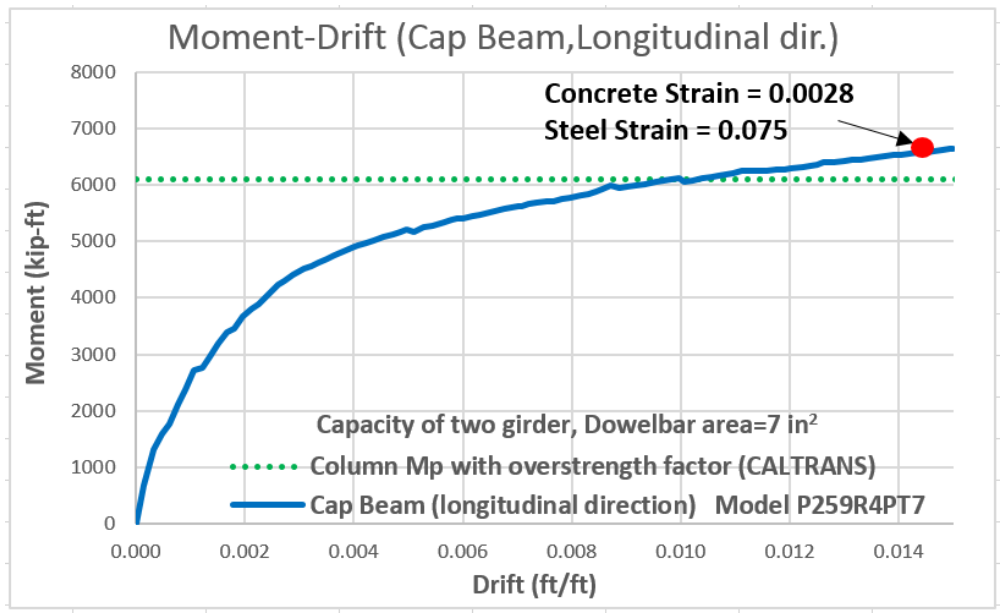

Figure 11-23 Cap beam Moment-Drift in longitudinal direction for the full-scale model.

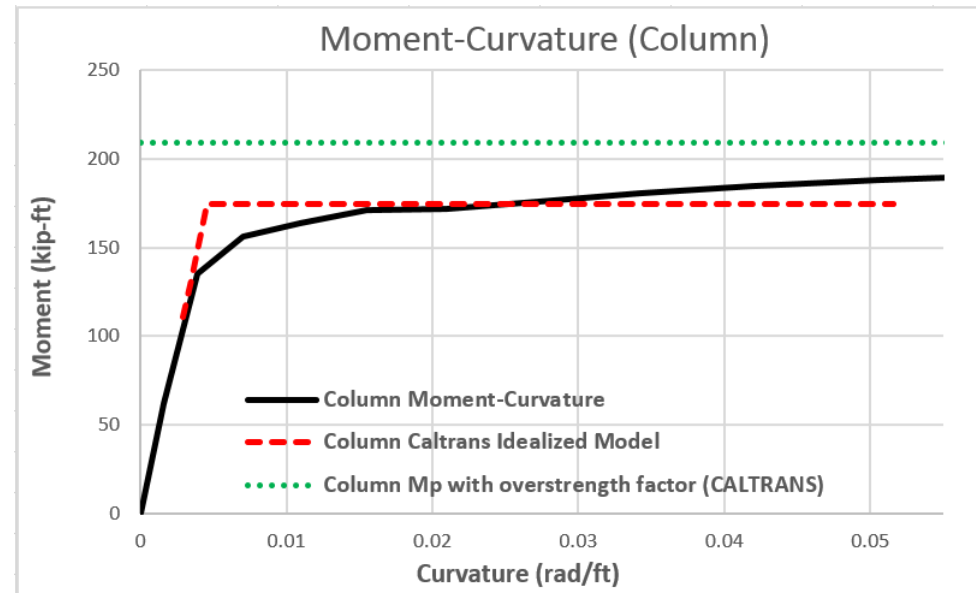

Figure 11-24 Column Moment-Curvature for the one-third scale model. 


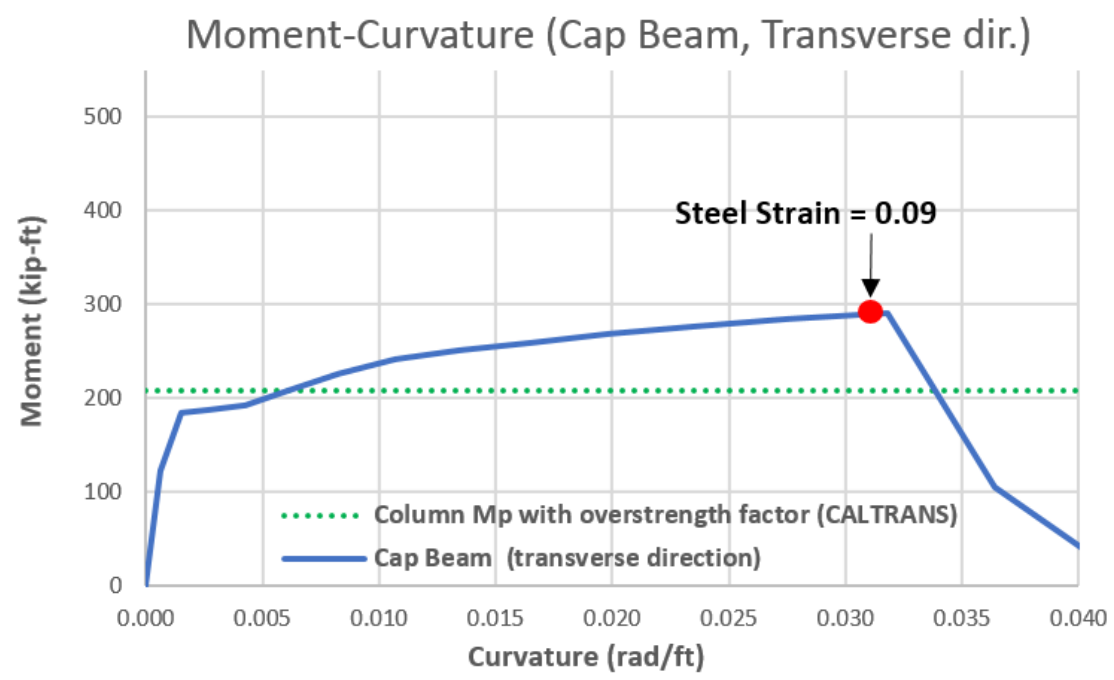

Figure 11-25 Cap beam Moment-Curvature in transverse direction for the one-third scale model.

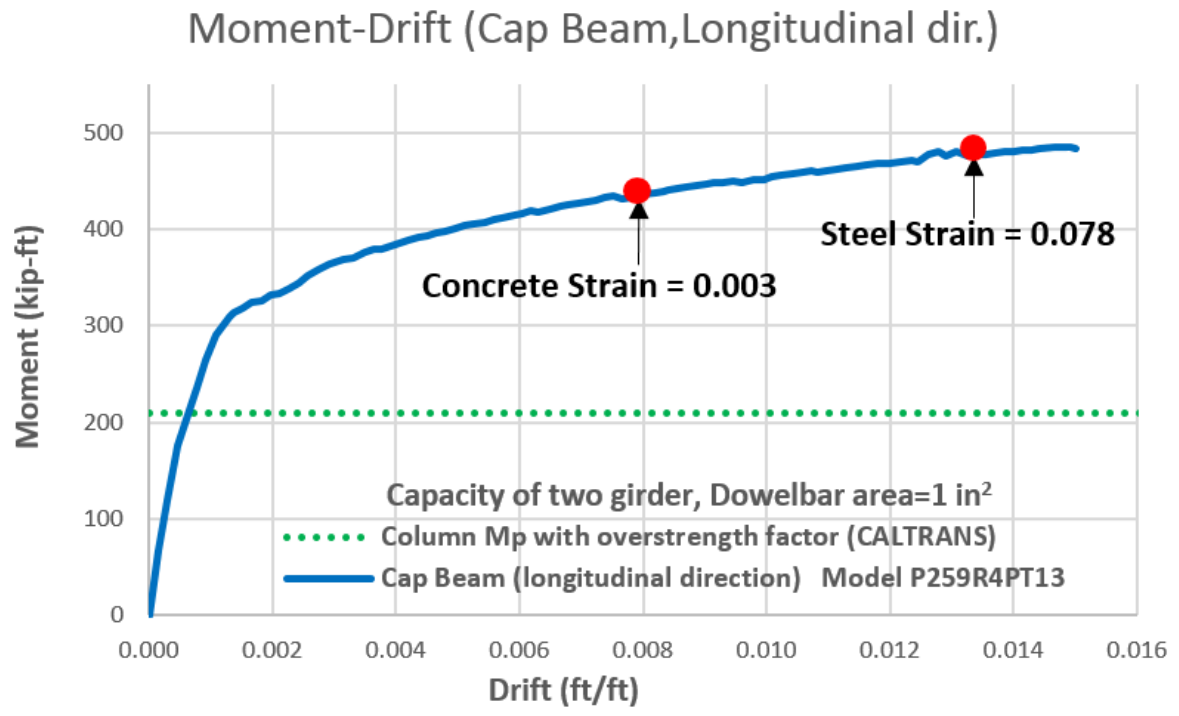

Figure 11-26 Cap beam Moment-Drift in longitudinal direction for one-third scale model.

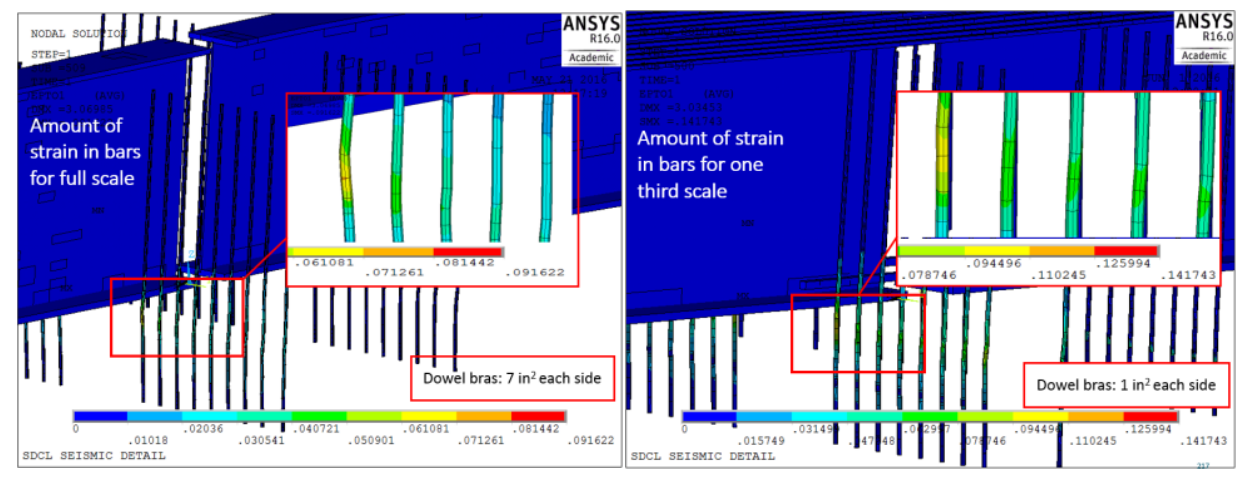

Figure 11-27 Amount of strain in dowel bars in full-scale model (left) and one-third scale model (right). 


\subsubsection{Maximum Possible Displacement of Test Specimen}

In this section, the maximum demand displacement of the one-third scale specimen is calculated according to CALTRANS specifications. It was assumed the bridge is integral and there is the possibility of two hinges forming; one at each end of the column.
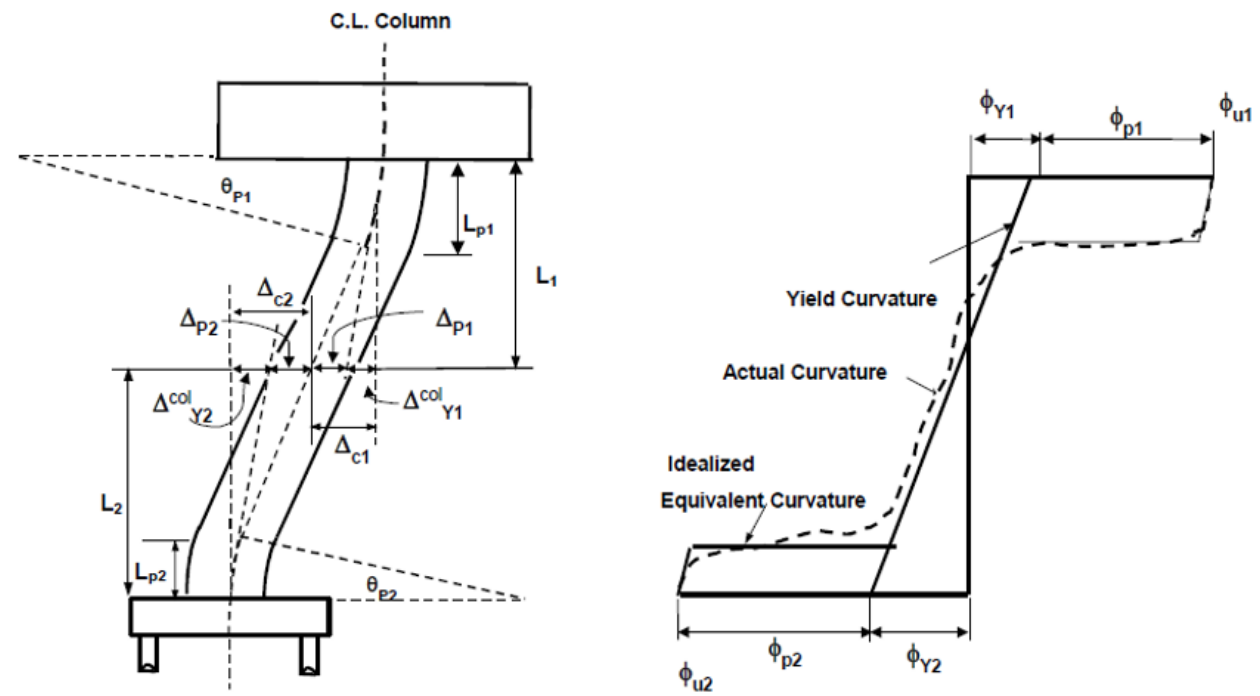

Figure 11-28 Column deformation and curvature along the column length.

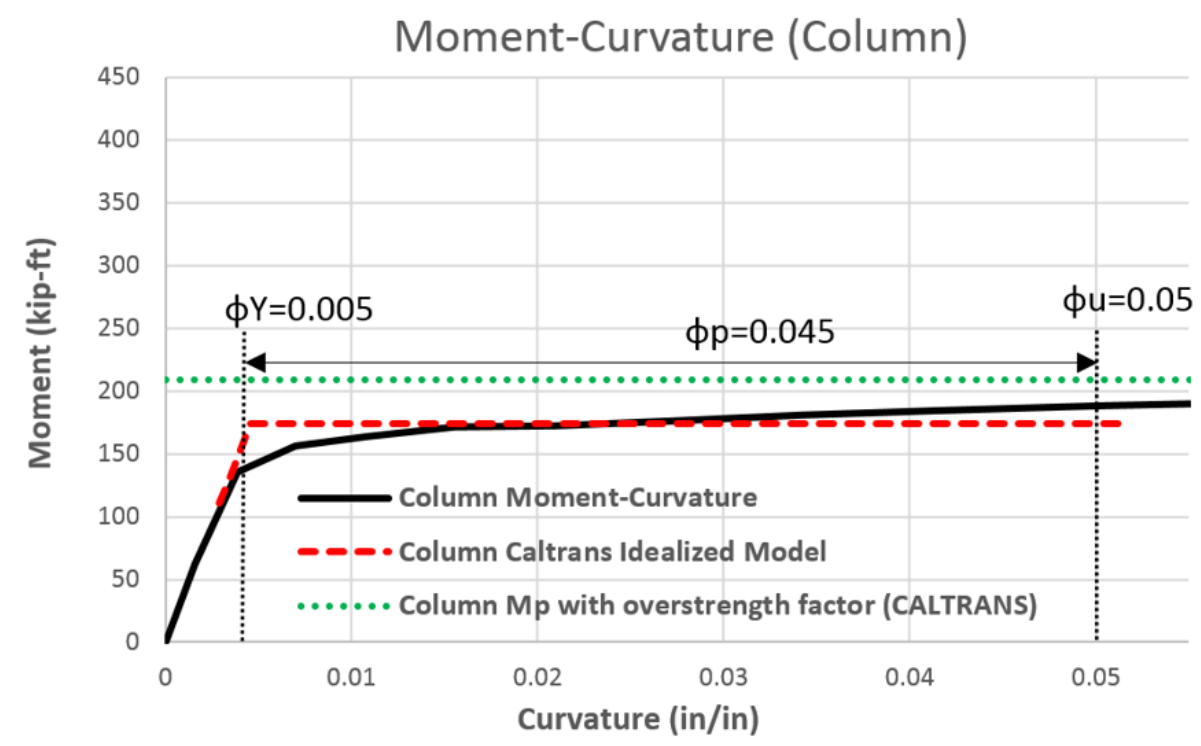

Figure 11-29 Yield, plastic and ultimate curvature.

$L=$ Distance from the point of maximum moment to the point of contra-flexure (in) 
$L P=$ Equivalent analytical plastic hinge length (in)

$\Delta_{p}=$ Idealized plastic displacement capacity due to rotation of the plastic hinge (in)

$\Delta_{Y}{ }^{c o l}=$ The idealized yield displacement of the column at the formation of the plastic hinge (in)

$\varphi_{Y}=$ Idealized yield curvature defined by an elastic-perfectly-plastic representation of the cross section's $M$ - $\varphi$ curve (rad/in)

$\varphi_{p}=$ Idealized plastic curvature capacity (assumed constant over $\left.L_{p}\right)(\mathrm{rad} / \mathrm{in})$

$\varphi_{u}=$ Curvature capacity at the Failure Limit State, defined as the concrete strain reaching $\varepsilon_{c u}$ or the longitudinal reinforcing steel reaching the reduced ultimate strain $\varepsilon_{s u R}(\mathrm{rad} / \mathrm{in})$

$\theta_{p}=$ Plastic rotation capacity (radian)

$L_{p}=0.08 L+0.15 f_{y e} d_{b l} \geq 0.3 f_{y e} d_{b l}$

$L_{p}=0.08 * 5.4 * 12+0.15 * 68 * 0.625 \geq 0.3 * 68 * 0.625$

$L_{p}=11.55 \geq 12.75 \rightarrow L_{p}=12.75$ in

$\theta_{p 1}=L_{p 1} \emptyset_{p 1}=12.75 * \frac{0.045}{12}=0.047$

$\Delta_{Y 1}^{c o l}=\frac{L_{1}^{2}}{3} \emptyset_{Y 1}=\frac{(5.4 * 12)^{2}}{3} * 0.005 / 12=0.59 \mathrm{in}$

$\Delta_{p 1}=\theta_{p 1}\left(L_{1}-\frac{L_{p 1}}{2}\right)=0.047 *\left(5.4 * 12-\frac{12.75}{2}\right)=2.75 \mathrm{in}$

$\Delta_{c 1}=\Delta_{Y 1}^{c o l}+\Delta_{p 1}=0.59+2.75=3.34 i n$

And the force which should be applied to the end of the column = over strength moment capacity/high of the column= $210 \mathrm{kip}-\mathrm{ft} / 5.4 \mathrm{ft} \sim 40 \mathrm{kip}$ (look at Figure 11-30) 


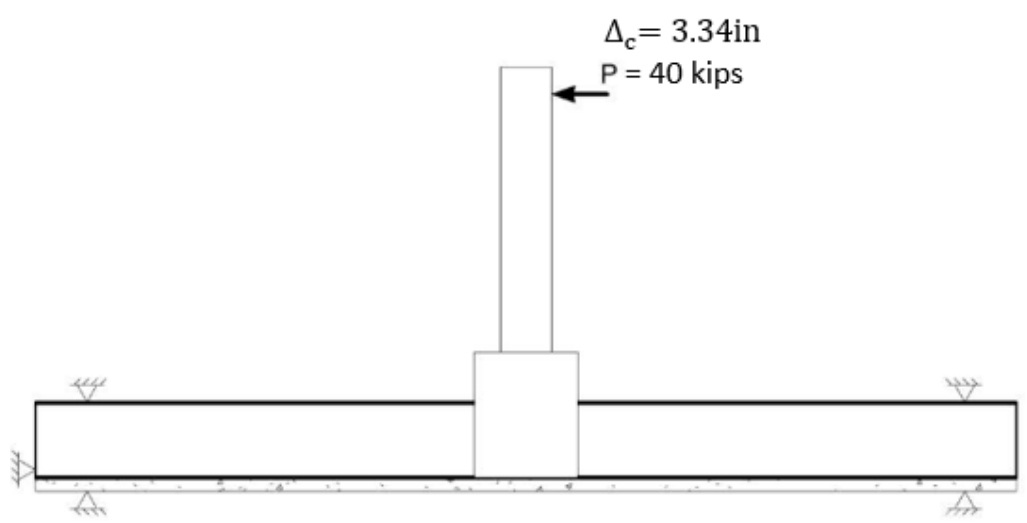

Figure 11-30 The value of force and displacement at the end of the column. 


\section{CONCLUSIONS AND RECOMMENDATIONS}

\subsection{Summary}

The main objectives of this research study were to provide an in-depth understanding of the behavior of SDCL connection subjected to seismic loading and to develop design provisions that can be used in design offices. The SDCL concept for seismic areas needs a suitable connection between the steel girder and pier. It should be noted that no previous research studies dealing with the seismic performance of SDCL bridges.

In this research, the structural behavior and force resistance mechanism of the proposed seismic detail was investigated through analytical study. The detail considered consisted of an integral type pier connection. The proposed connection was evaluated under push-up, push-down, inverse and axial loadings to find the sequence of failure modes. These loading modes were found to be representative of the loading modes imposed by seismic excitation. This summary and conclusion provides highlights of the results obtained in the research. Complete discussions of each of the following sections can be found in the appropriate chapters.

\subsection{Integral and Non-Integral Bridge Systems}

The type of connection between bent and superstructure has an important role in the seismic response of the bridge, as does the connection between abutment and superstructure. In non-integral bridges, the girders are allowed some to rotate with respect to the pier or abutment. In an integral system, the connection provides some degree of rigidity. Therefore, moment transfers from the superstructure to substructure during dynamic excitation. The behavior of the bent frame (including bent cap and bent columns) and location of hinges in the columns depend on the connectivity of the bent frame to the superstructure and relative stiffness in each direction of the 
bridge. Integral bridges engage larger portions of the pier column to participate in energy dissipation in the longitudinal direction. This is because integral systems bend in double curvature and have two plastic hinges versus single curvature and one plastic hinge for non-integral systems. The results of our inquiry of DOTs in seismic areas indicate that Alaska and Washington State prefer non-integral connection between super and sub structure due to the simplified details and reduced time for construction. In the state of California, most bridges are monolithic concrete multicell box superstructures.

In summary, advantages of integral over non-integral bridge systems include past performance, increased clearance below the structure, enhanced seismic performance and reduced maintenance. Disadvantages of integral systems are the difficulty during construction, congestion of reinforcement at the column to the pier cap joint and need for the shoring system.

\subsection{Demand Side of the SDCL Bridges}

Nonlinear time history analysis indicated that for integral bridges, the majority portion of the moment at the connection of bent cap and column is due to the longitudinal component of the earthquake while the effect of the vertical and transverse component was negligible. In addition, nonlinear time history analysis demonstrated that there is a high probability that bottom flange sustains some tension force under seismic events.

The entire bridge response depends on the Earthquake Resisting System (ERS) under seismic load. In this research plastic hinges were assumed to form at the top and bottom of the column. Considering the distribution of moment along the deck length for an integral SDCL bridge system and finding the maximum demand value at the pier centerline provides the magnitude of forces for which the super structure should be designed. According to CALTRANS, the superstructure is a capacity protected member and not part of energy dissipation system. Therefore, 
the superstructure and SDCL detail should be designed to remain essentially elastic during seismic excitation when the column reaches its over strength moment capacity. Once the demand of the system has been determined (Phase I of the research) based on the over strength moment capacity of the column it can be compared with the capacities of the superstructure and SDCL connection detail (Phase II of the research).

\subsection{Capacity of the SDCL Bridges}

To ensure the performance of the bridge is satisfactory, the capacity of the superstructure and connecting elements must be determined to verify they satisfy the requirements of capacity protected elements under the various components of seismic loading.

\subsubsection{Load Resistance Mechanism of the Connection}

To study the load resistance mechanism, a detailed three-dimensional nonlinear finite element analysis was carried out on the SDCL connection. Conducting a detailed time-history nonlinear finite element analysis under multiple ground motion accelerations is too expensive and time-consuming. To develop a complete methodology and associated tools that can be used to evaluate the performance and sequence of failure modes of SDCL bridges under seismic loads, the proposed connection was subjected to three distinct loading types representative of the loading imposed by general seismic accelerations. These are referred to as push-up, push-down, and inverse loading. The finite element models were able to capture the global behaviors, the load resistance mechanism, and the maximum load-carrying capacity. A comparison between the finite element model and previously conducted experimental testing of the SDCL connection under push-down forces verified the accuracy of the modeling techniques that was then employed to study the behavior of the system under other load case scenarios. 
The analyses were carried out on two different potential connection details. In the investigation of the preliminary detail consisting of bolts connecting the adjacent girders, dowel bars connecting the pile cap and diaphragm were found to fail predominantly due to tensile stress. After revising the connection detail and replacing the bolted detail with headed studs and tie bars, several finite element analyses were performed to investigate the role of each component.

When the model was subjected to push-up forces and the bottom flange was not continuous, the tie bars were the controlling element and increasing the amount of tie reinforcement increased the ultimate moment capacity. To model the longitudinal effect of earthquake loads, the model subjected to inverse forces as well as axial forces at one end. In this scenario, the dowel bars are the critical elements of the system.

All the results from both the preliminary and revised seismic detail, demonstrated that continuity of the bottom flange, whether using bolts (preliminary detail), or tie bars over the bottom flange (in revised detail), did not affect the moment capacity of the system under the component of seismic loading in the direction of traffic. The only element that affected the moment capacity was

the dowel bars. Note that these dowel bars correspond to the vertical stirrups $\left(A_{s}^{j v}\right)$ referred to in CALTRANS Specification Section 7.4.4.3. These are recommended on each side of the concrete diaphragm in the direction of traffic. Increasing the volume ratio of dowel bars increases the moment capacity of the system.

\subsubsection{The Sequence of Failures in the SDCL Connection}

A number of nonlinear finite element models were analyzed in order to isolate the various modes of failure under different types of loading and identify the load resistance mechanisms.

When the bridge is subjected to gravity loads, dowel bars and closed stirrups have no effect on the moment capacity of the system. Stresses in the dowel bars and closed stirrups remained in 
elastic range even after the system reaches its maximum capacity. Finite element analysis indicates the sequence of failures under push-down forces includes (1-cracks in the deck, 2-yielding of top bars in the deck, 3-yielding of top bolts in the case of the preliminary detail and 4-yielding of the bottom flange).

When the finite element model was loaded with concentrated push up forces at each end of the deck, the continuity of bottom flange and tie bars played a major role in to resisting the applied loads. When the bottom flange was considered fully continuous, the capacity obtained was found to be much higher than the with the discontinuous bottom flange. For the case when the bottom flange was not continuous, failure predominantly occurred in the tie bars. The vertical dowel bars were effective but not as much as the tie bars. Due to push-up forces, the sequence of failures was (1-yielding of the bottom flange in the case which the bottom flange was continuous or yielding in tie bars in the revised seismic detail, 2-cracks in the deck, 3-cracks in the vicinity of bottom flange, 4-crushing in the deck). No yielding was observed in the dowel bars and closed stirrups at the time of failure.

Under reversal type loading, the preliminary and revised versions of the seismic detail showed similar behaviors such that both models experienced similar forces and the applied load was mainly resisted by the dowel bars. For comparison, the performance of the system in the case of continuous bottom flange was studied. The objective of this analysis was to observe the behavior of a model with connected bottom flange under inverse loading. The observations agreed with the conclusions of the bolted detail and connection with tie bars and the flexural moment capacity did not change significantly. Steel girders, reinforcement bars in the slab deck, top and bottom bolts in the preliminary detail, and tie bars in the final detail, and continuity of the bottom flange did not affect the moment capacity of the system as much as the vertical bars (dowels) that connected bent cap and concrete diaphragm to each other. When the model was subjected to reversal concentrated 
loads at each end of the deck, the sequence of failures included (1-cracks in the deck, 2-cracks in the vicinity of the bottom flange at the push-up side, 3-dowel bars yielding, 4-crushing below the bottom flange at push-down side and above the top of the bottom flange at the vicinity of the face of concrete diaphragm at the push-up side).

\subsubsection{Parametric Finite Element Analysis}

A summary of the results from a parametric study on the finite element models is discussed in this section. Preliminary analyses performed on the proposed detail indicated that the two most influential parameters are the amount of horizontal tie steel at the bottom flange, and the amount of the dowel bars between the pier cap and diaphragm. The suggested methodology was using a matrix with different values for tie bars and dowel bars. For instance, once the value of steel for tie bars was constant the value of steel for dowel bars changed. For each combination, the moment capacity and failure modes were investigated. There are several notable observations that can be made about the results of the parametric analysis when the connection is subjected to push-up and inverse forces.

\section{Under push-up loading:}

- Comparing the ultimate moment resistance with different amounts of steel in the dowel bars and tie bars indicates the amount of moment increased by using more steel in the tie bars while the amount dowel bars does not the capacity of the system significantly.

- The connection detail has some resistance to upward force even with a small amount of tie bars.

- The value of the upward resistance is not heavily influenced by the amount of steel in the dowel bars. 
- The presence of the tie steel increases the capacity of the system, and finally, the inclusion of tie steel is a more efficient means of increasing the capacity versus increasing the dowel steel.

\section{Under reverse loading:}

- The parametric analysis indicates that increasing the size of the dowel bars enhances the flexural strength of the connection.

- There are several evidences indicating that the role of dowel bars is more significant in the nonlinear range of the connection detail.

- The stress distribution in dowel bars shows those located nearest the steel girders are more effective once into the nonlinear range.

- The nonlinearity of dowel bars depends on the amount of steel used in the connection. In cases with large amounts of steel (dowel bars), only the dowel bars next to the steel girder yielded.

- When a small amount of steel was used, yielding occurred across the full width of the specimen.

- In some models, additional rows of bars were placed near the steel girder but this configuration did not increase the capacity, which indicates the distance of the bars from the natural axis is an important factor. This result corresponded to CALTRANS specification for the single column bent.

\subsubsection{Developed Formula to Design Seismic Detail of SDCL}

Finite element analysis outcomes from previous chapters were considered as the main method to develop a simple design formula that is suitable for use in design offices. The details of the considered approach are provided in Chapter 10 of this research. The finite element observations in Chapter 8 indicated mainly there is a flexural behavior between the bent cap and 
concrete diaphragm while the major nonlinearity of the system is due to the nonlinear behavior of the dowel bars. Comparison of the Moment-Curvature analysis and the resultant capacity from finite element analysis of the connection between the bent cap and the concrete diaphragm is similar in cases for which all of the dowel bars yielded. In these cases, use of Moment-Curvature analysis may be a good alternative to deriving the ultimate moment capacity and computing the required volume ratio of dowel bars at the interface of bent cap and concrete diaphragm. For cases where not all of the dowel bars yield, the Winkler foundation method was used to develop a design formula for the SDCL detail connection under seismic loads. The developed formula was compared against the different finite element models and in general, the developed formula was in good agreement with the finite element analysis. The percentage differences between FEM analysis results and the developed formula in terms of maximum moment capacity obtained was $10 \%$ on average.

\subsection{Further Research}

Discussions in Chapter 11 identify the remaining tasks that are required to completely develop the comprehensive methodology that allows DOTs to assess the seismic performance of SDCL bridges and determine whether these bridges are a suitable option in seismic areas. These remaining tasks and the approaches to complete these tasks will be proposed for future research.

In Phase I of this research, the load resistance mechanism was identified and the seismic behavior of the SDCL detail evaluated. Phase II of this project is an ongoing project and currently the component specimen design and test setup are under consideration. The test specimen is going to be constructed and tested in the structures lab of Florida International University. A cyclic loading will be applied to the specimen to investigate the possible damages and load resistance mechanism. These results will be compared with the analysis results. In the next step, as phase III, a complete bridge with all the components will be constructed in the structures lab at the University of Nevada-Reno. The connection between steel girders will be an SDCL connection and the 
behavior of the bridge will be subjected to a shake table test to study the real performance of the connection due to earthquake excitation. These remaining works are left to be completed under future research. 


\section{REFERENCES}

(n.d.). Retrieved from Pacific Earthquake Engineering Research Center (PEER): http://peer.berkeley.edu/

AARON YAKEL, A. A. (2014). Field Application Case Studies and Long-Term Monitoring of Bridges Utilizing the Simple for Dead - Continuous for Live Bridge System. Engineering Journal, 155-175.

AASHTO. (2012). LRFD Bridge Design Specifications. Washington, DC.: American Association of State Highway and Transportation Officials.

Ady Aviram, K. R. (2008). Guidelines for Nonlinear Analysis of Bridge Structures in California. PACIFIC EARTHQUAKE ENGINEERING RESEARCH CENTER.

ANSYS. (2014). Release 16. Canonsburg, PA: ANSYS INC.

Astaneh-Asl, A. B. (1994). Seismic Performance of Steel Bridges During the 1994 Northridge Earthquake. Department of Civil and Environmental Engineering, University of California, Berkeley, CA.

Azizinamini, A. (2014, Second Quarter). Simple for Dead Load-Continuous for Live Load Steel Bridge Systems. AISC, Engineering Journal.

AZIZINAMINI, A. (2014). Simple for Dead Load-Continuous for Live Load Steel Bridge Systems. Engineering Journal, 51, 59-81.

BEINING, A. R. (2014, second Quarter). Continuous for Live Load Steel Girder Construction in the Northern Panhandle of West Virginia. Engineering Journal, 51.

Bozorgzadeh, A. M. (2006). Capacity Evaluation of Exterior Sacrificial Shear Keys of Bridge Abutments. Journal of Bridge Engineering.

(September 2015). Bridge Seismic Design. CSiBridge.

CALTRANS. (2013). CALTRANS SEISMIC DESIGN CRITERIA. CALIFORNIA: CALTRANS.

Farimani, M. J. (2014, Second Quarter). Numerical Analysis and Design Provision Development for the Simple for Dead Load-Continuous for Live Load Steel Bridge System. AISC, Engineering Journal.

Farimani, M. M. (2006). RESISTANCE MECHANISM OF SIMPLE-MADE-CONTINUOUS CONNECTIONS IN STEEL GIRDER BRIDGES. Lincoln, Nebraska. 
Javidi, S. (2009). Resistance Mechanism of Simple-Made-Continuous Connections in Skew and Non-Skew Steel Girder Bridges Using Conventional and Accelerated Types of Construction, Ph.D. dissertation. Lincoln, NE: University of Nebraska-Lincoln.

Javidi, S. Y. (2014, Third Quarter). Experimental Investigation, Application and Monitoring of a Simple for Dead Load-Continuous for Live Load Connection for Accelerated Modular Steel Bridge Construction. AISC, Engineering Journal.

Jill Patty, F. S.-M. (2001). Seismic Response of Integral Bridge Connections. Caltrans.

Kowalski, D. (2007). Development and Evaluation of Design Equations for the Simple-MadeContinuous Steel Bridge System, M.S. Thesis. Lincoln, NE: University of NebraskaLincoln.

Lampe, N. J. (December, 2001). STEEL GIRDER BRIDGES ENHANCING THE ECONOMY. Lincoln, Nebraska.

Lampe, N. M. (2014, Second Quarter). Development and Experimental Testing of Connections for the Simple for Dead Load-Continuous for Live Load Steel Bridge System. AISC, Engineering Journal.

M. Lee Marsh, I. G. (October 2014). LRFD Seismic Analysis and Design of Bridges Reference Manual. U.S. Department of Transportation, National Highway Institute, U.S. Department of Transportation. Washington, D.C.: Federal Highway Administration.

M. Lee Marsh, S. J. (2013). Performance-Based Seismic Bridge Design. WASHINGTON, D.C.: NCHRP SYNTHESIS 440.

Mackie, K. S. (2006). Seismic Vulnerability of Typical Multi-Span California Highway Bridges. Proceedings of the Fifth National Seismic Conference on Bridges and Highways. San Francisco.

Maroney, B. a. (1994). Seismic design and retrofitting of reinforced concrete bridges. Proceedings of 2nd International Workshop, Earthquake Commission of New Zealand. Queenstown.

Mossahebi, N. (2004). New Steel Bridge System: Simple for Dead Load, Continuous for Live Loads, M.S. Thesis. Lincoln, NE: University of Nebraska-Lincoln.

National Bridge Inventory (NBI). (2015). Retrieved from Federal Highway Administration : https://www.fhwa.dot.gov/bridge/nbi.cfm

Nawy, E. (2003). Prestressed Concrete, a Fundamental Approach (Fourth Edition ed.). NJ: Prentice.

NCHRP. (2004). Integral Steel Box-Beam Pier Caps. transportation research board. 
Nick Lampe, N. M. (2014). Development and Experimental Testing of connections for the simple for dead load- continuous for live load steel bridge system. Engineering Journal, 51, No. 2.

Otte, M. (2006). Field monitoring of steel bridges-simple for dead, continuous for live, M.S. Thesis. Lincoln, NE: University of Nebraska-Lincoln.

PEER Ground Motion Database. (n.d.). Retrieved from PACIFIC EARTHQUAKE ENGINEERING RESEARCH CENTER: http://peer.berkeley.edu/products/strong_ground_motion_db.html

R. Snyder, J. V. (SEPTEMBER 2011). Seismic Performance of an I-Girder to Inverted-T Bent Cap Connection. IOWA STATE UNIVERSITY.

Reginald DesRoches, E. C. (2004). Seismic Response of Multiple Span Steel Bridges in Central and Southeastern United States. I: As Built. JOURNAL OF BRIDGE ENGINEERING.

Roy A. Imbsen, I. C. (May 2007). AASHTO guide specifications for LRFD seismic. AASHTO publications.

SAP2000. (n.d.). integrated finite element analysis and desing of structures. Version 18.0.1. Berkeley, CA, USA: omputers and Structures INC. Retrieved from https://www.csiamerica.com/

Sashi K. Kunnath, N. A. (May 2008 ). DEVELOPMENT OF GUIDELINES FOR INCORPORATION OF VERTICAL GROUND MOTION EFFECTS IN SEISMIC DESIGN OF HIGHWAY BRIDGES . Sacramento CA 95814: California Department of Transportation.

Sri Sritharan, J. V. (2014). Seismic Performance of Precast Girder-to-Cap Beam Connections Designed for $\mathrm{ABC}$.

(n.d.). Structure Maintenance And Investigations. Caltrans.

Taghinezhad, R. (2011). Seismic design and rehabilitation of structures based on performance level with SAP2000 and ETABS pushover analysis. Tehran: university book publisher.

Zhang, J. a. (2002). Kinematic response functions and dynamic stiffnesses of soil-structure interaction. Earthquake Engineering \& Structural Dynamic. 


\section{APPENDICES}

\section{A) Nonlinear Time History Analysis Results}

In this appendix some outputs of nonlinear time history analysis of prototype bridge in Chapter 4.9 demonstrated.

\section{A-1) Hinge Locations and Deformation of Bridge}

The hinge property which assigned at two ends of the columns calculated with the respect of P-M interaction curve based on the CALTRANS. The acceptance criteria that labeled as IO, LS and CP stand for Immediate Occupancy, Life Safety, and Collapse Prevention respectively. The force deformation curve and acceptance criteria of hinges presented below. The following pictures present the deformation of the bridge under different ground motions. The acceptance criteria for hinges shown with a colored spot at two ends of the columns at the last step of analysis before the collapse.

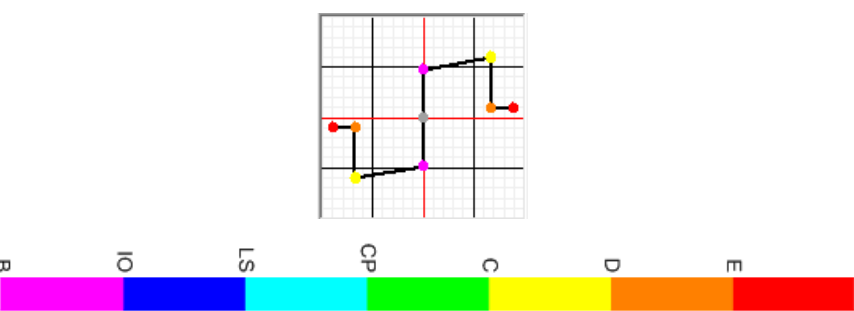

Figure A-1 Force deformation behavior and acceptance criteria for hinges.

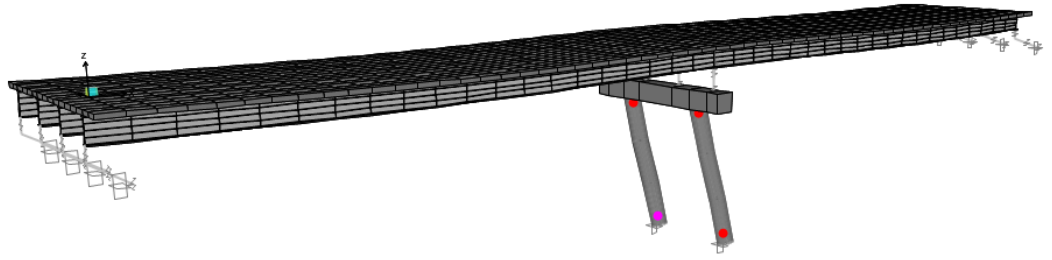

Figure A-2 Bridge deformation and hinge acceptance criteria under Darfield ground motion (Model No. 17). 


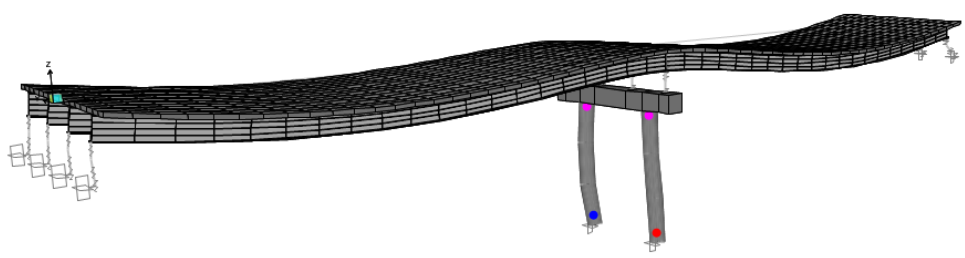

Figure A-3 Bridge deformation and hinge acceptance criteria under Duzce ground motion (Model No. 17).

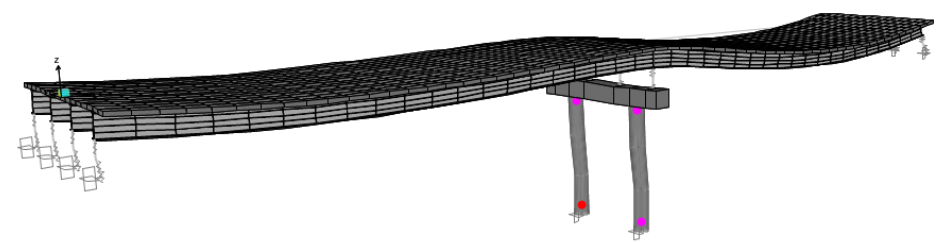

Figure A-4 Bridge deformation and hinge acceptance criteria under Irpinia ground motion (Model No. 17).

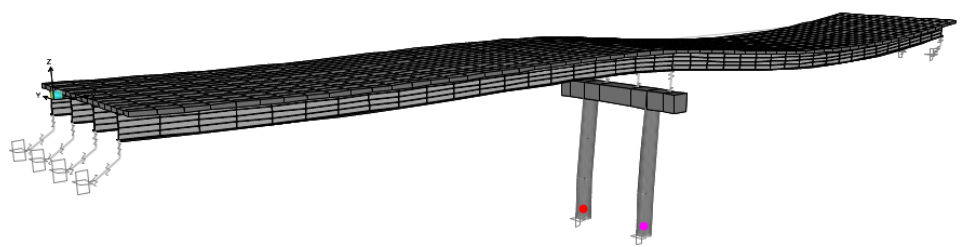

Figure A-5 Bridge deformation and hinge acceptance criteria under Loma ground motion (Model No. 17).

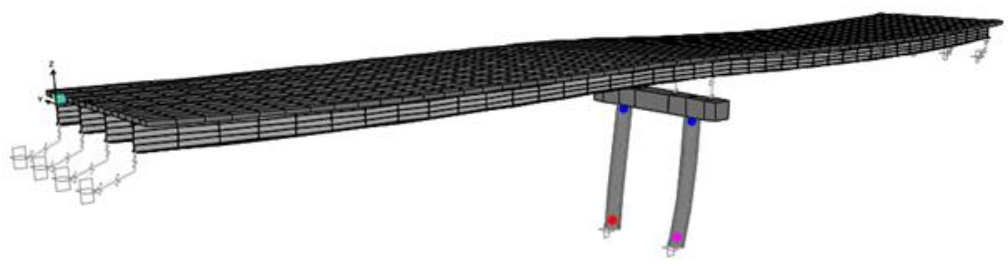

Figure A-6 Bridge deformation and hinge acceptance criteria under Manjil ground motion (Model No. 17).

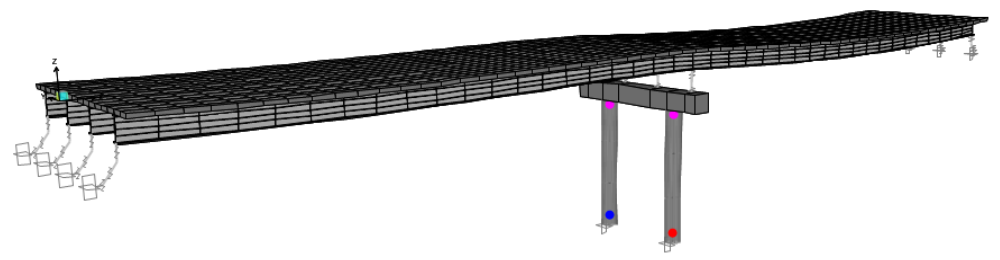

Figure A-7 Bridge deformation and hinge acceptance criteria under Northridge ground motion (Model No. 17).

\section{A-2) Moment Distribution Along the Deck}


The figures below show an envelope and a mean of linear add of moments due to earthquake loads for the entire bridge section respectively. The moment diagram shows the value of moment for the entire bridge section (including 4 girders). The moment diagram units is Kip,ft.

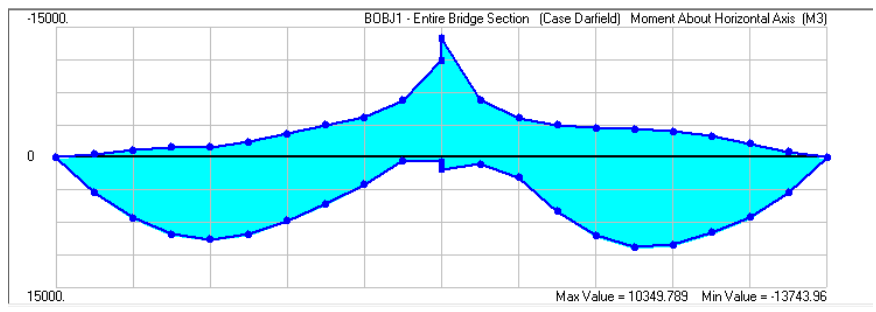

Figure A-8 Moment plot under Darfield ground motion, (Model No. 17).

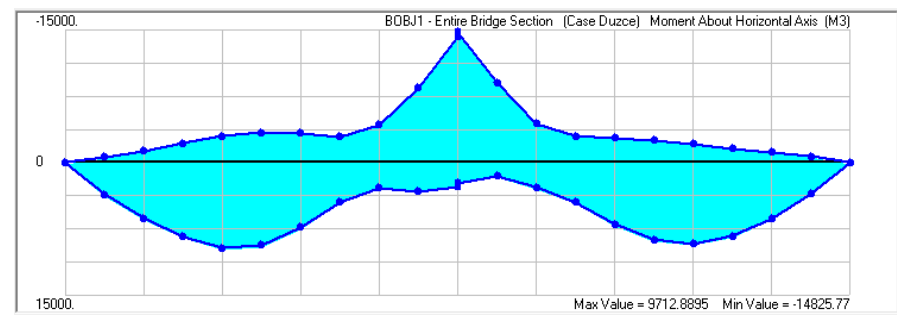

Figure A-9 Moment plot under Duzce ground motion, (Model No. 17).

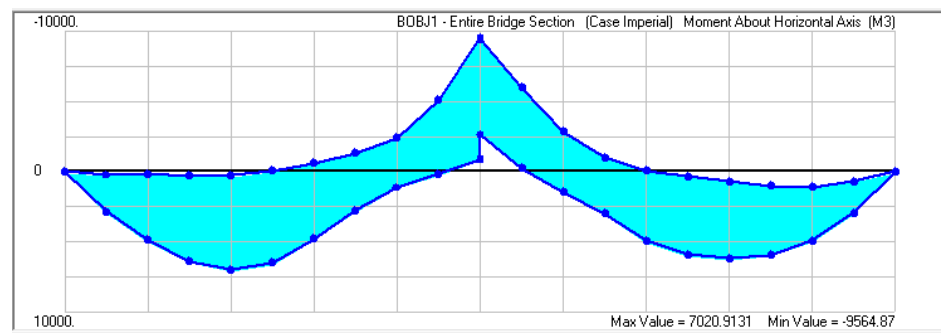

Figure A-10 Moment plot under Imperial ground motion, (Model No. 17).

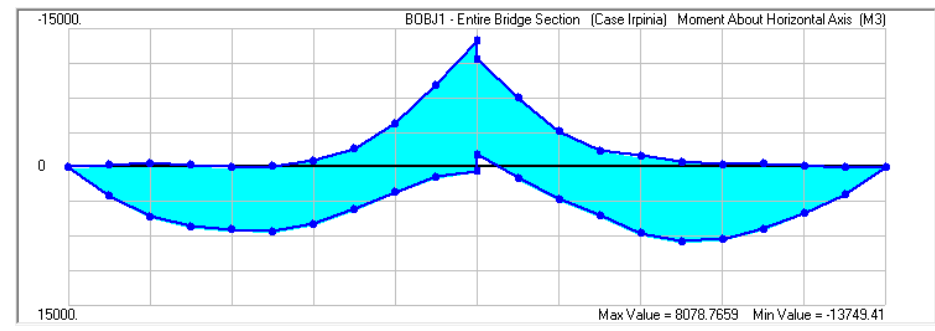

Figure A-11 Moment plot under Irpinia ground motion, (Model No. 17). 


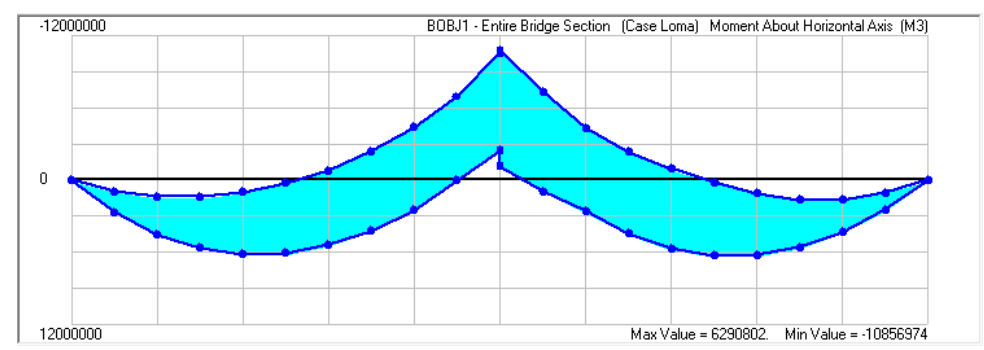

Figure A-12 Moment plot under Loma ground motion, (Model No. 17).

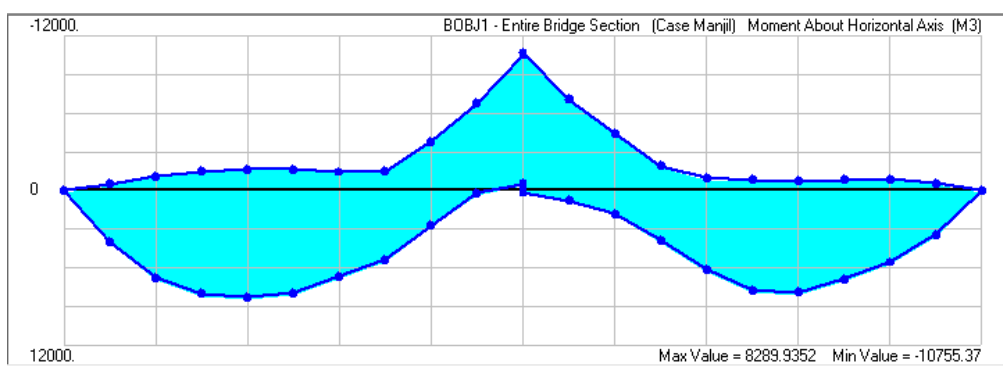

Figure A-13 Moment plot under Manjil ground motion, (Model No. 17).

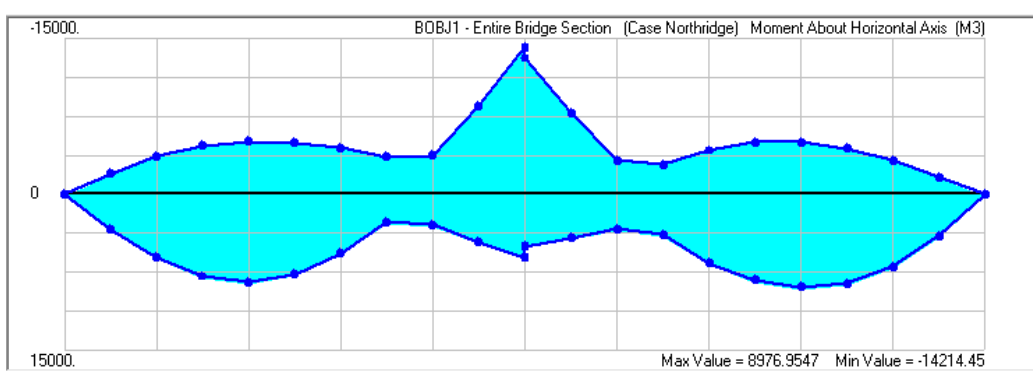

Figure A-14 Moment plot under Northridge ground motion, (Model No. 17).

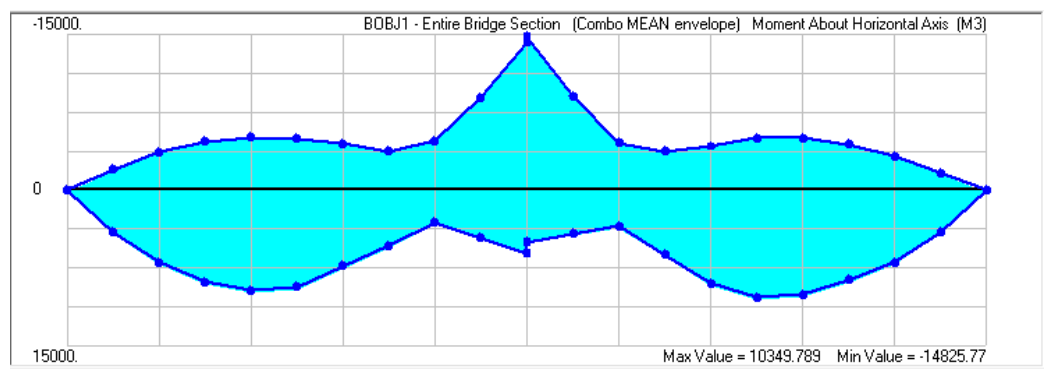

Figure A-15 Envelope of moment plots for all selected ground motions, (Model No. 17). 


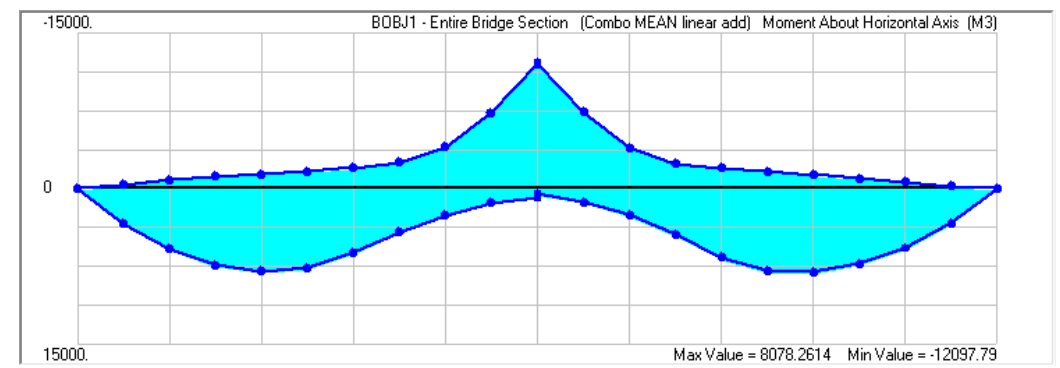

Figure A-16 Mean of moment plots for all selected ground motions, (Model No. 17).

Results indicate in some earthquake ground motions, the bottom flange is subjected to tension forces. Up to now, moment plots derived from a nonlinear time history analysis while all three components of earthquake applied to the structure simultaneously. Therefore, to understand the portion of each component, the analysis was repeated for all three components of Duzce and Darfied separately. Figures below show a plot of moment distribution in the entire bridge deck due to the longitudinal, transverse and vertical component of Duzce and Darfield earthquake ground motions. The moment diagram shows the value of moment for the entire bridge section (including 4 girders). The moment diagram units is Kip,ft.

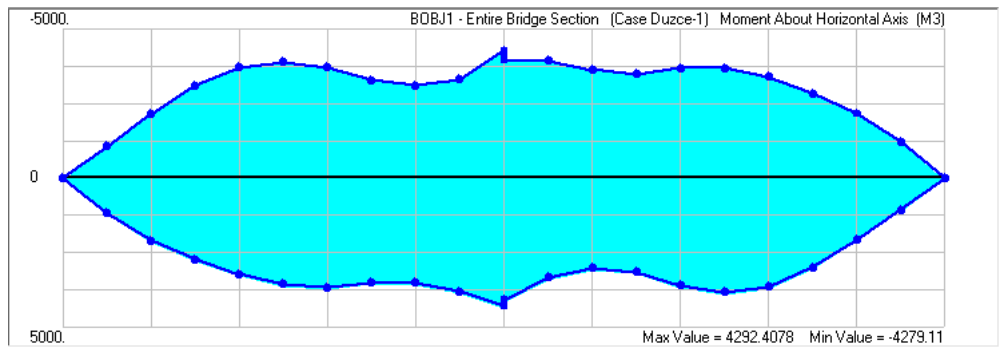

Figure A-17 Moment plot under longitudinal component of Duzce ground motion without considering the effect of gravity loads, (Model No. 18).

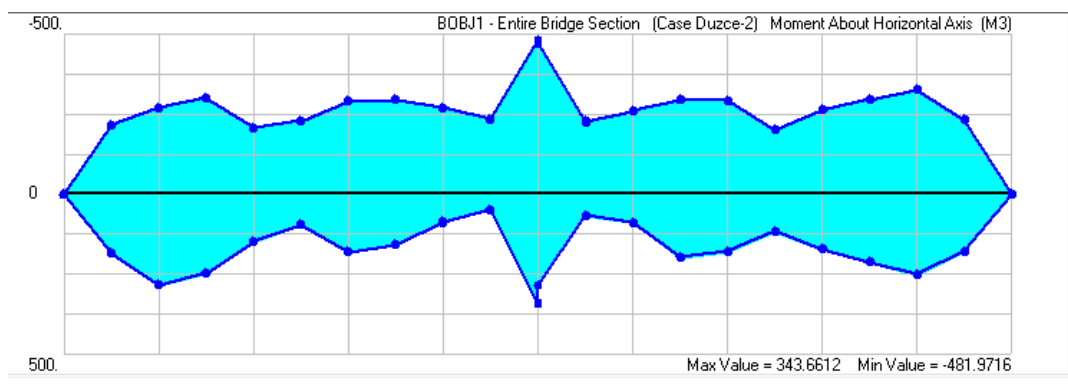

Figure A-18 Moment plot under transverse component of Duzce ground motion without considering the effect of gravity loads, (Model No. 18). 


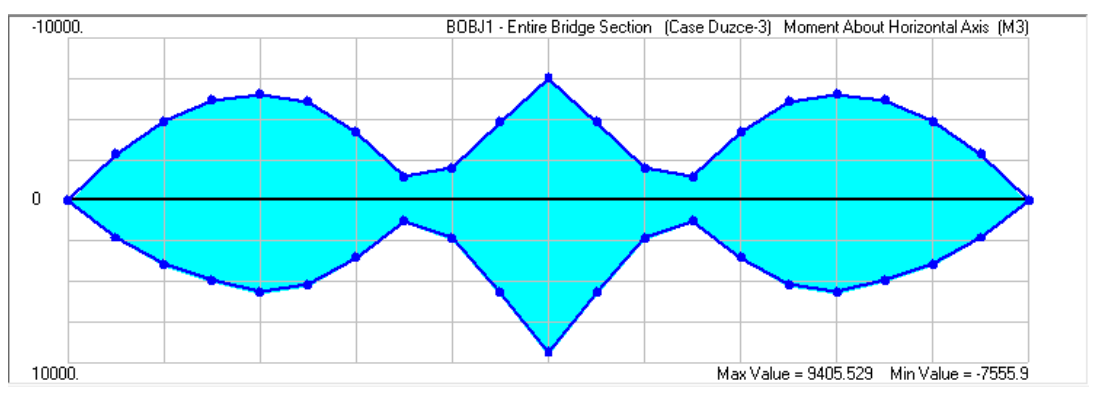

Figure A-19 Moment plot under vertical component of Duzce ground motion without considering the effect of gravity loads, (Model No. 18).

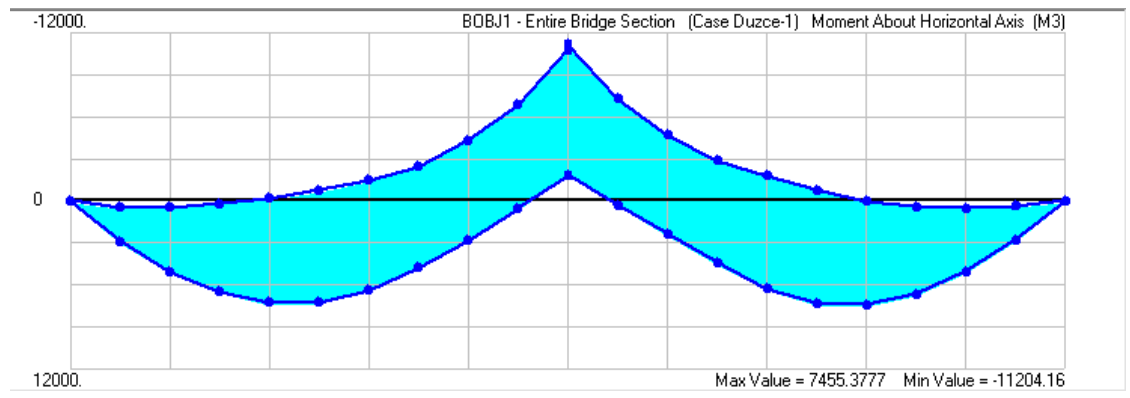

Figure A-20 Moment plot under longitudinal component of Duzce ground motion without considering the effect of gravity loads, (Model No. 22).

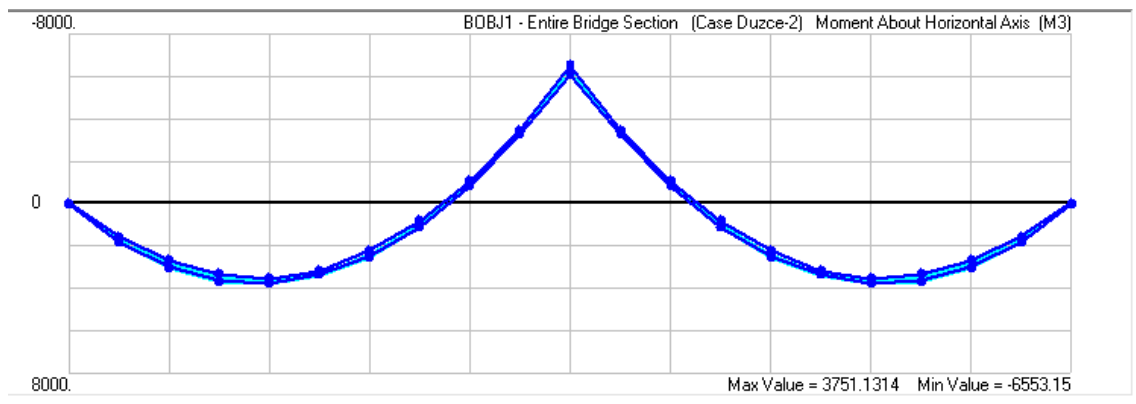

Figure A-21 Moment plot under transverse component of Duzce ground motion with considering the effect of gravity loads, (Model No. 22).

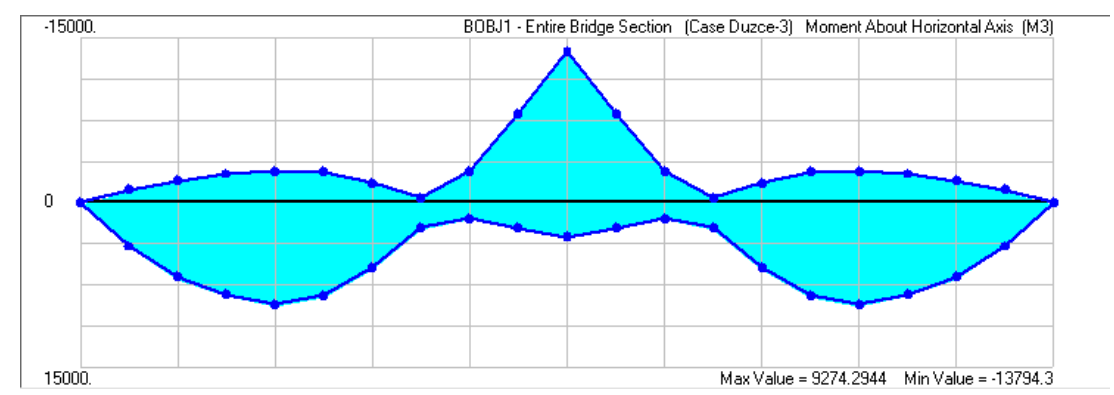

Figure A-22 Moment plot under vertical component of Duzce ground motion with considering the effect of gravity loads, (Model No. 22). 


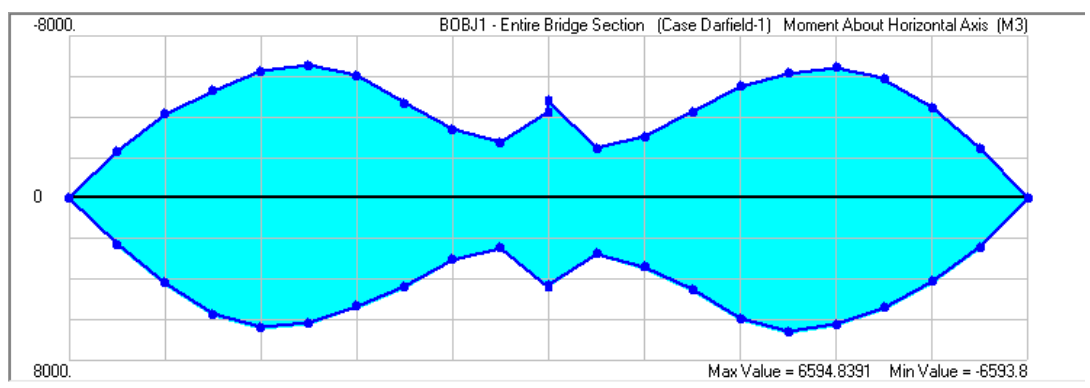

Figure A-23 Moment plot under longitudinal component of Darfield ground motion without considering the effect of gravity loads, (Model No. 19).

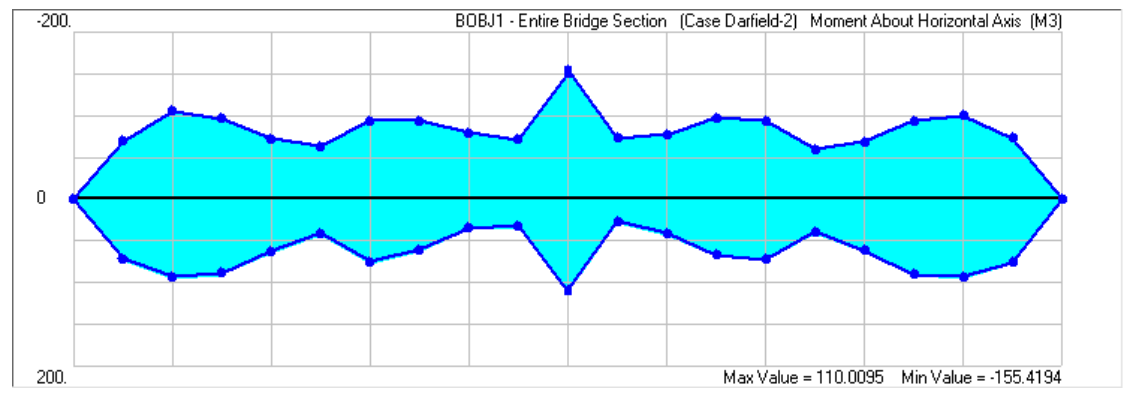

Figure A-24 Moment plot under transverse component of Darfield ground motion without considering the effect of gravity loads, (Model No. 19).

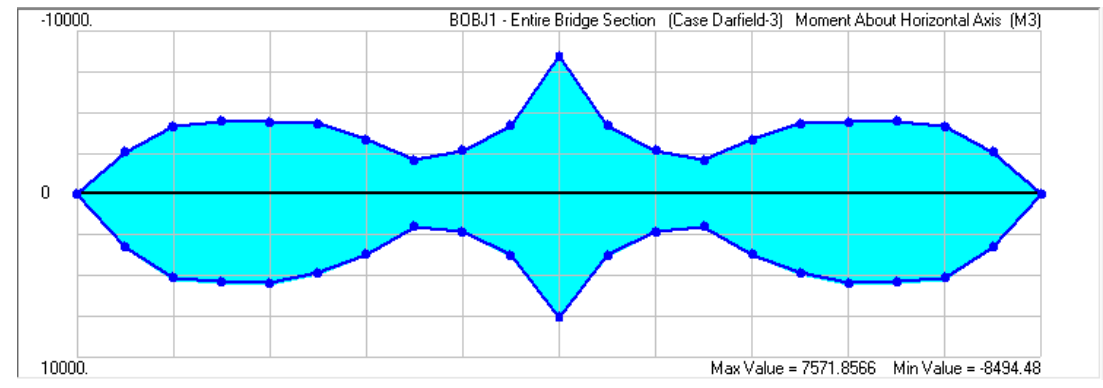

Figure A-25 Moment plot under vertical component of Darfield ground motion without considering the effect of gravity loads, (Model No. 19).

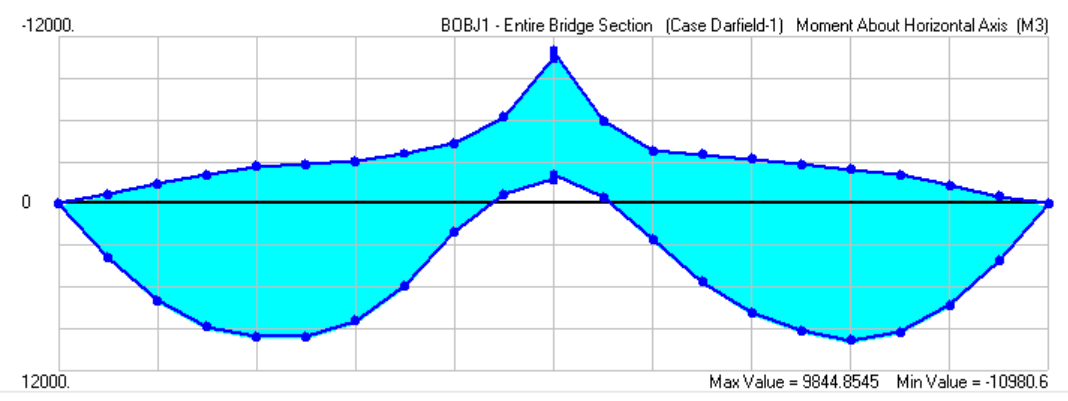

Figure A-26 Moment plot under longitudinal component of Darfield ground motion with considering the effect of gravity loads, (Model No. 27). 


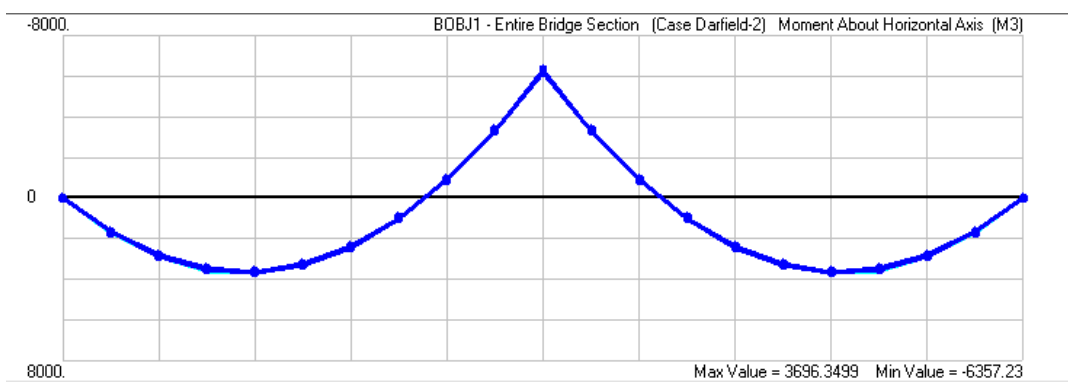

Figure A-27 Moment plot under transverse component of Darfield ground motion with considering the effect of gravity loads, (Model No. 27).

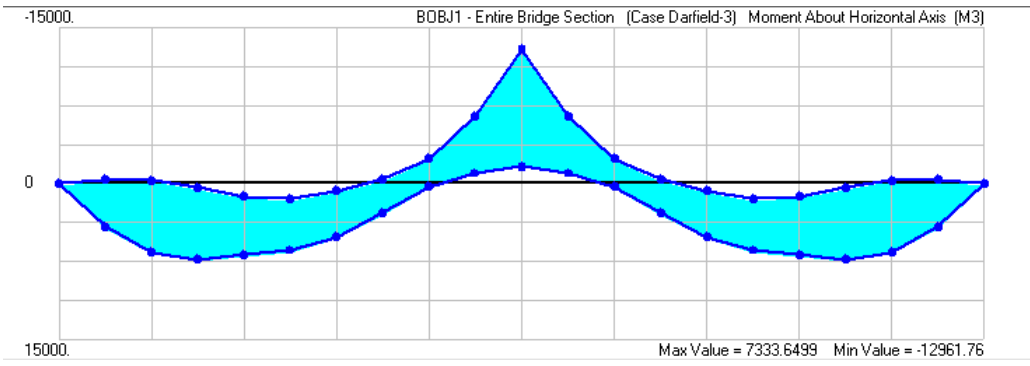

Figure A-28 Moment plot under vertical component of Darfield ground motion with considering the effect of gravity loads, (Model No. 27).

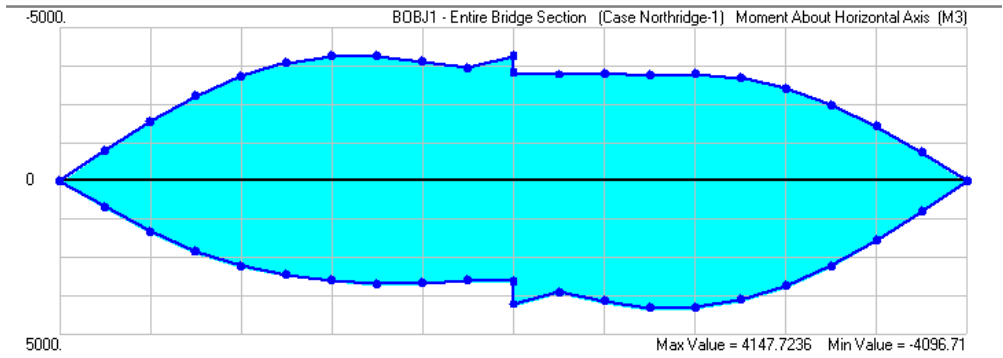

Figure A-29 Moment plot under longitudinal component of Northridge ground motion without considering the effect of gravity loads, (Model No. 25).

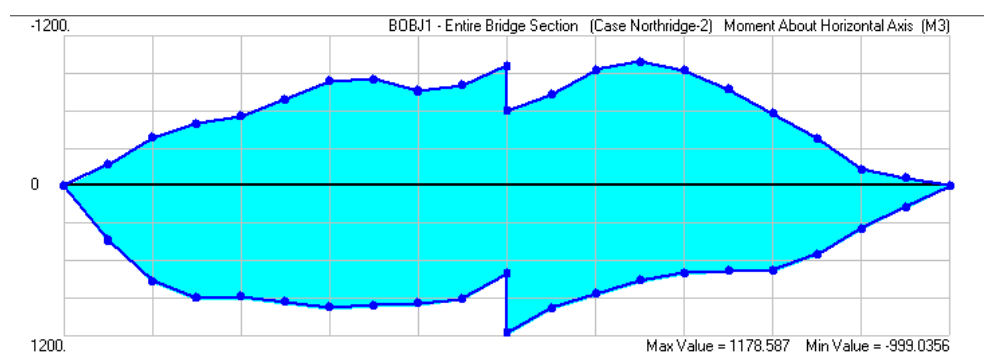

Figure A-30 Moment plot under transverse component of Northridge ground motion without considering the effect of gravity loads, (Model No. 25). 


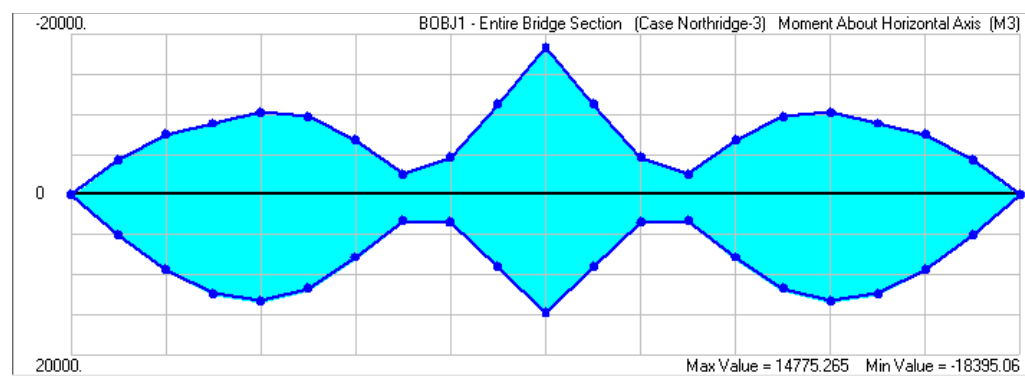

Figure A-31 Moment plot under vertical component of Northridge ground motion without considering the effect of gravity loads, (Model No. 25).

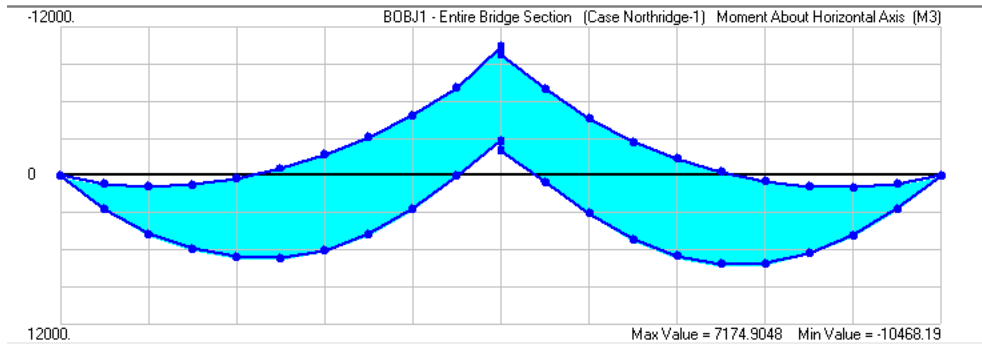

Figure A-32 Moment plot under longitudinal component of Northridge ground motion with considering the effect of gravity loads, (Model No. 20).

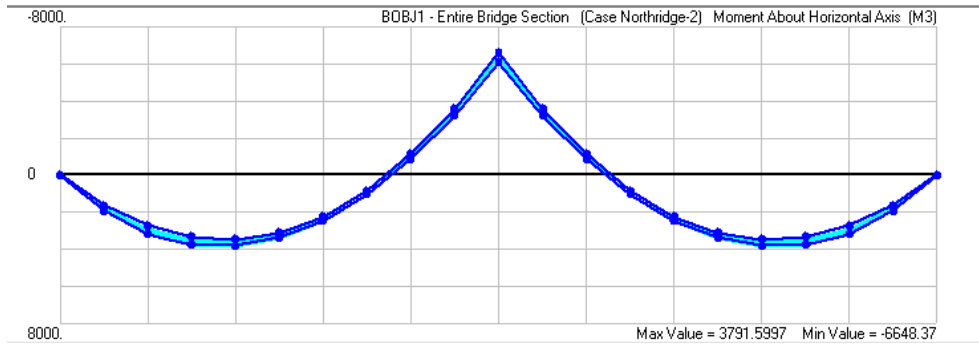

Figure A-33 Moment plot under transverse component of Northridge ground motion with considering the effect of gravity loads, (Model No. 20).

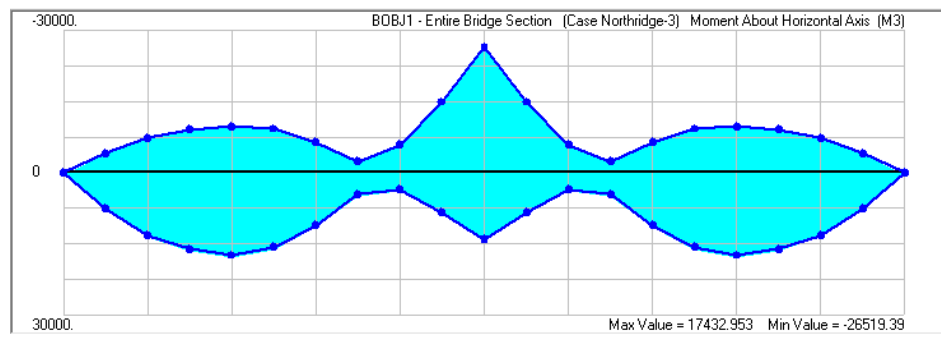

Figure A-34 Moment plot under vertical component of Northridge ground motion with considering the effect of gravity loads, (Model No. 20).

\section{B) Component Test Drawing Details}


The following pictures shows the geometry, dimensions and amount of steel in different component of the one-third scale test specimen.

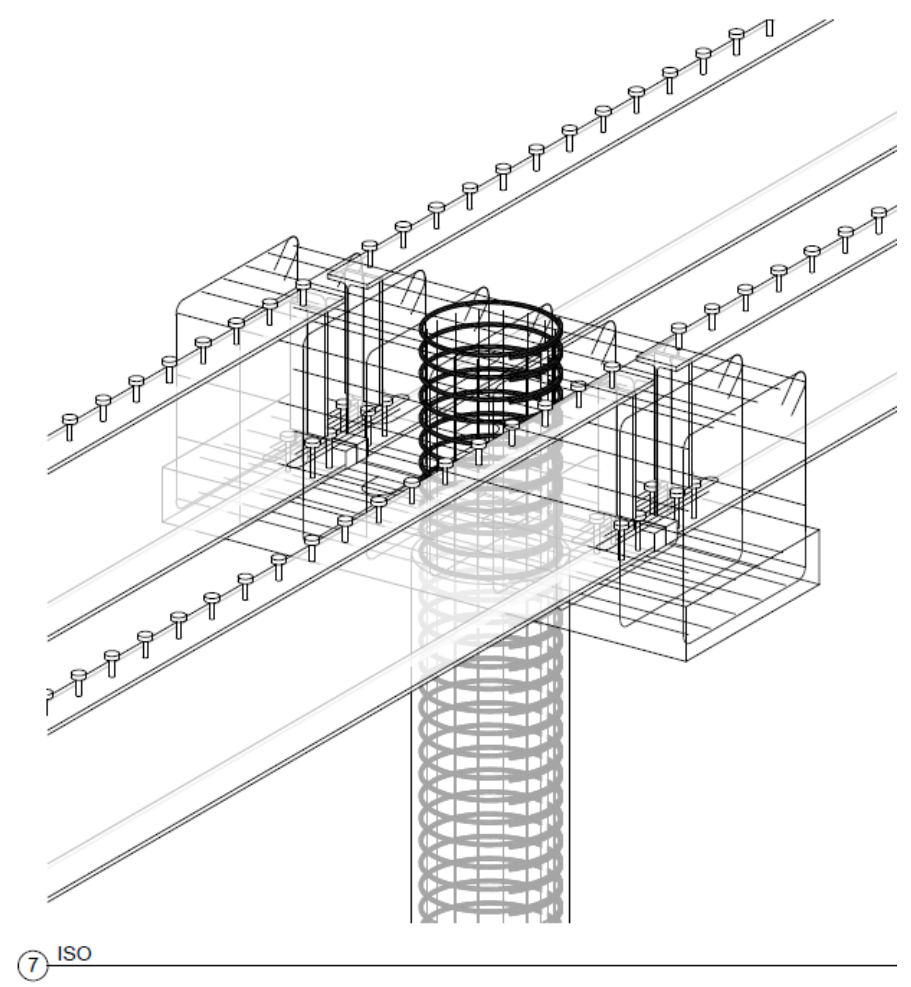

Figure B-35 Overall view of experimental test specimen. 


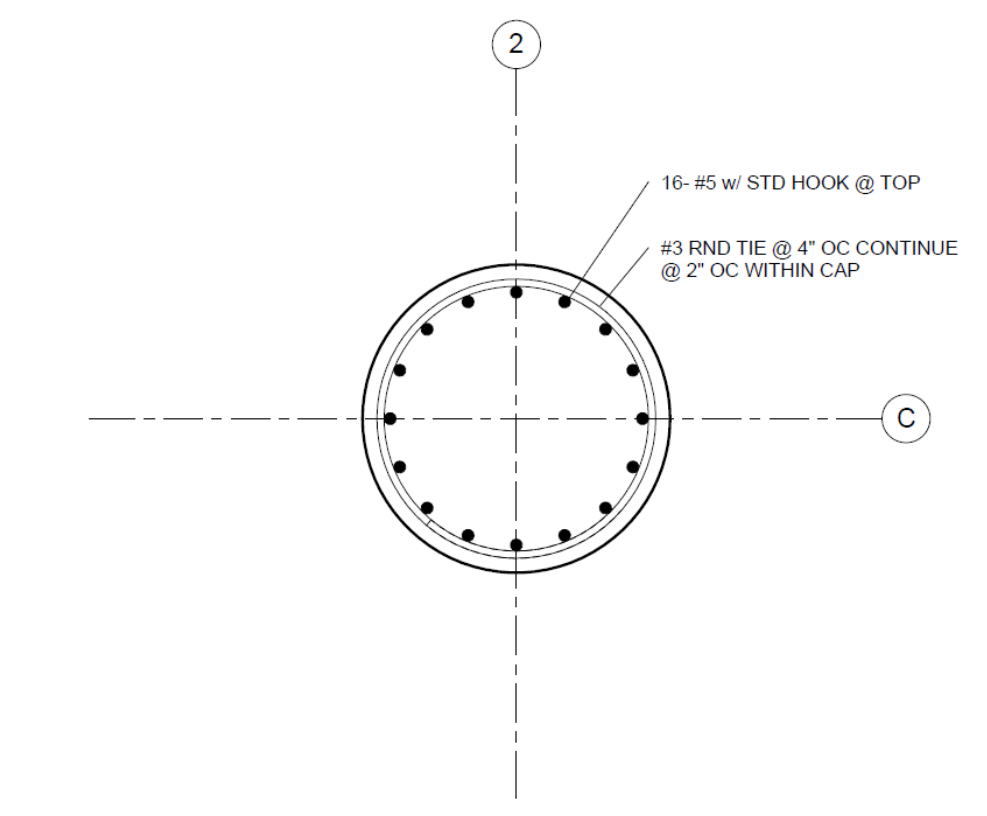

(8) $\frac{\text { COLUMN SECTION }}{11 / 2^{\prime \prime}=1^{1}-0^{\prime \prime}}$

Figure B-36 Column bar sizes and dimensions.

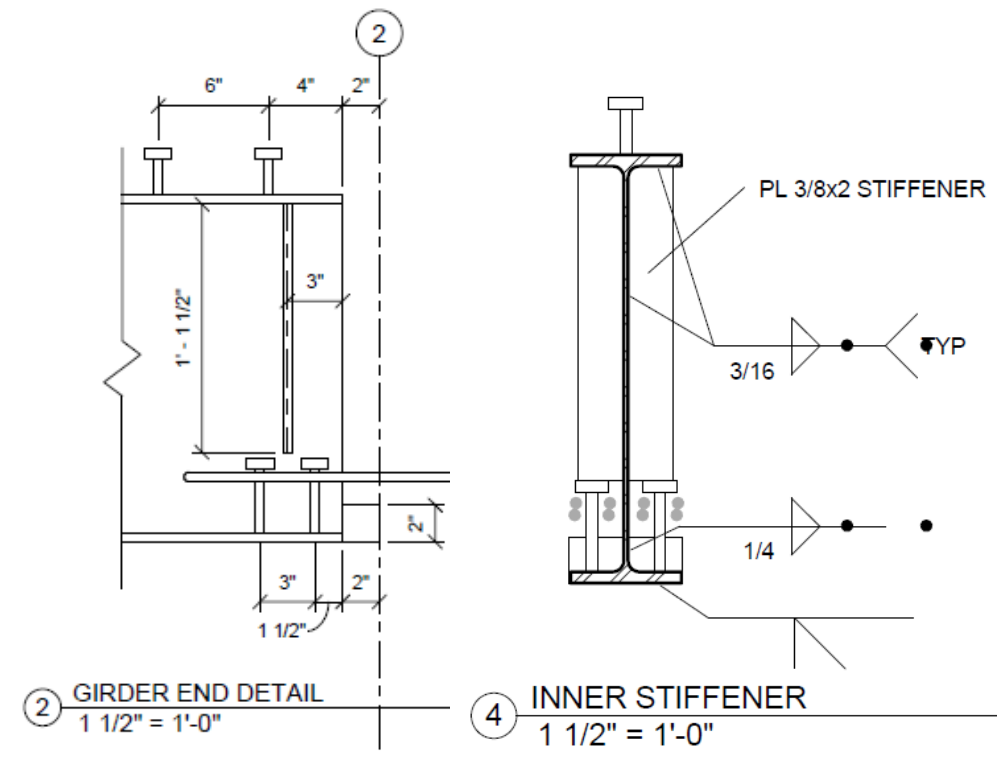

Figure B-37 Connection detail. 


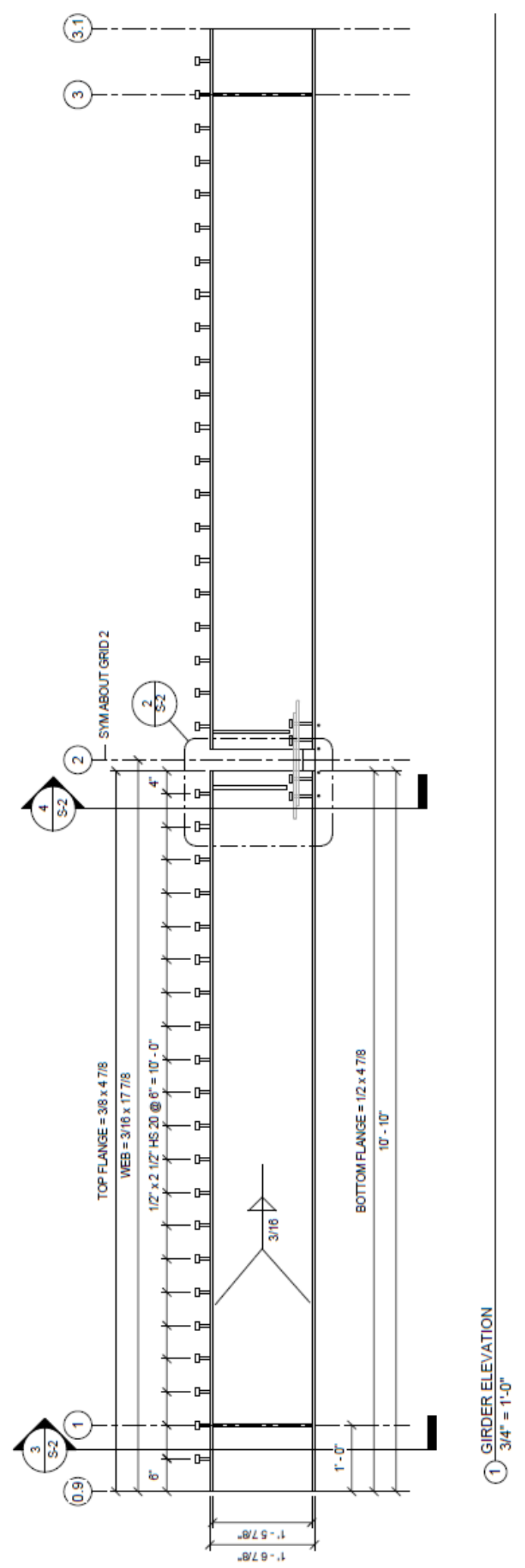

Figure B-38 Steel girder details 


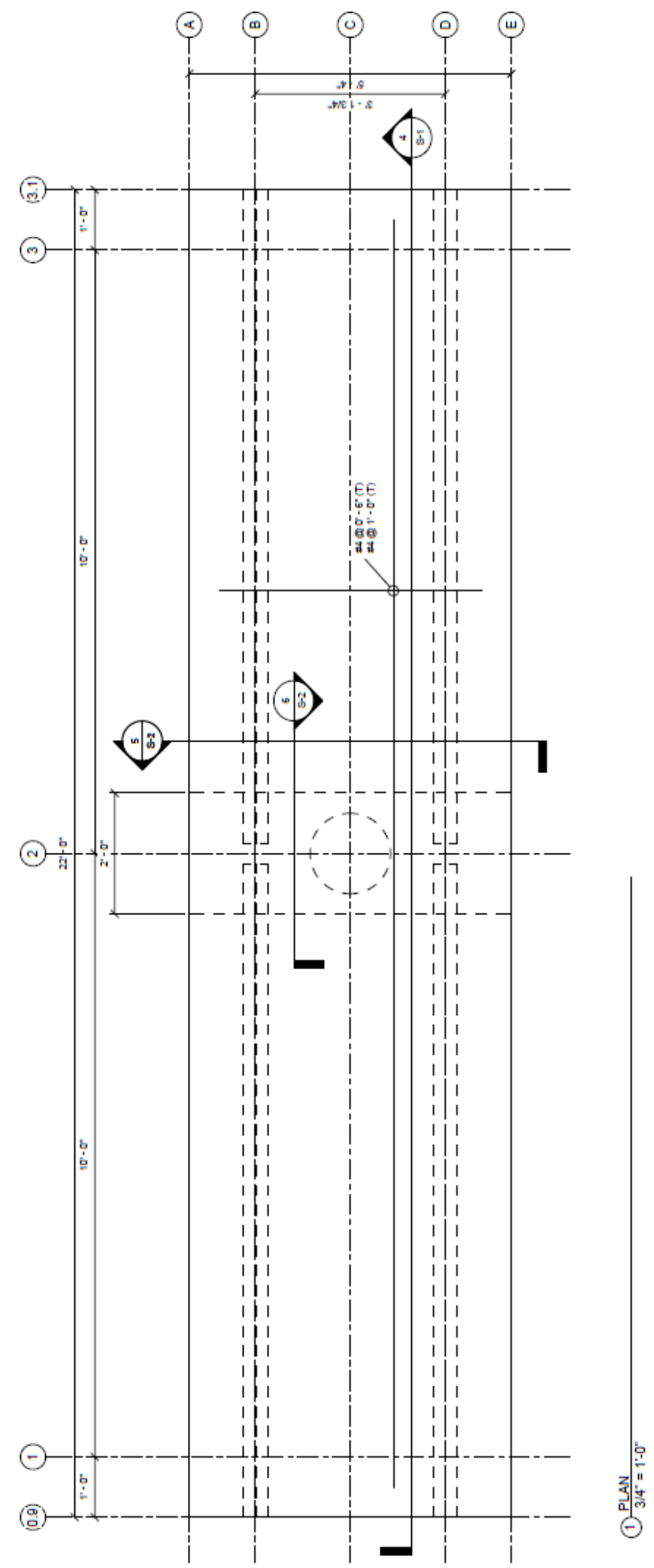

Figure B-39 Plan of deck. 


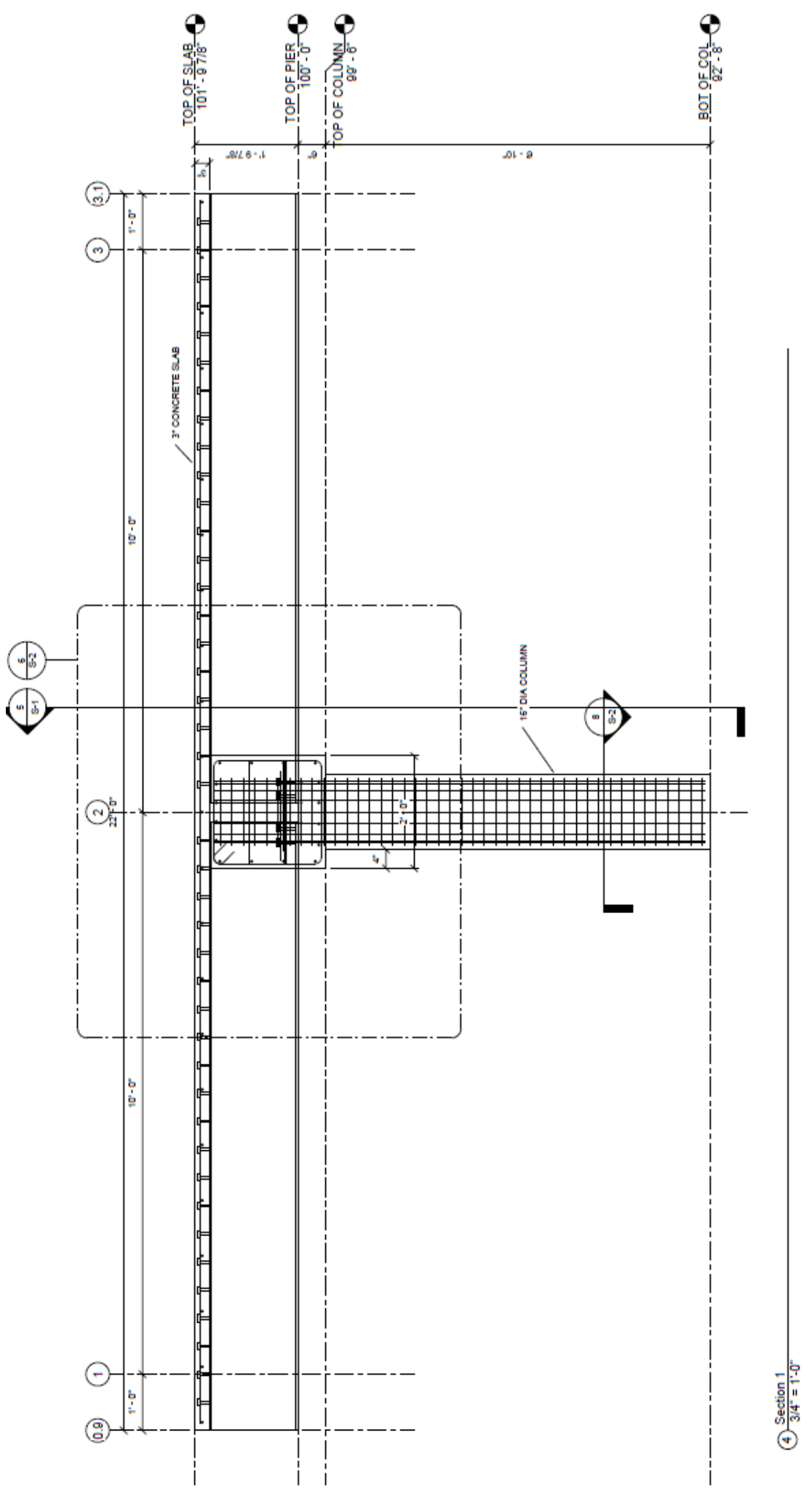

Figure B-40 Elevation of specimen in longitudinal direction. 


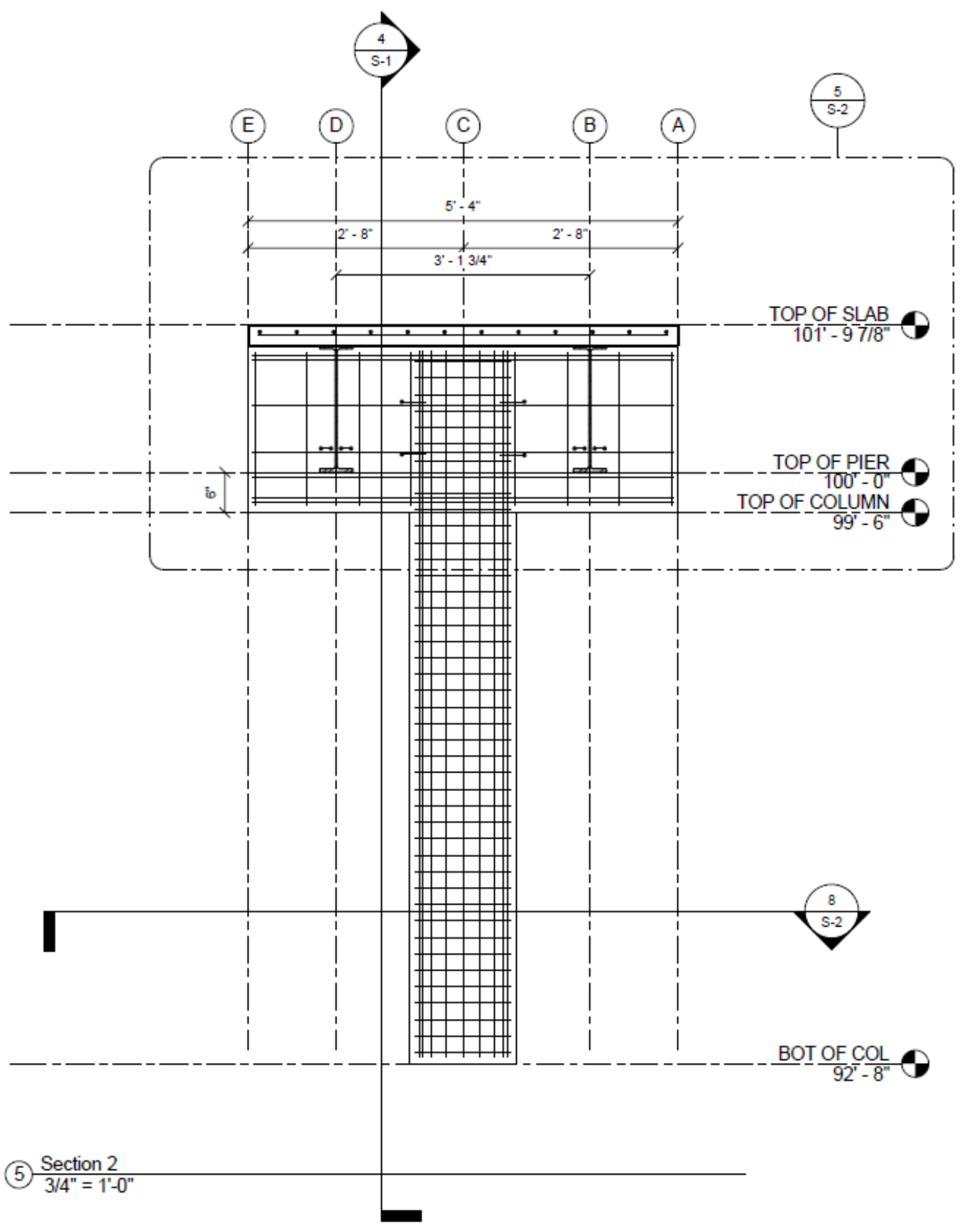

Figure B-41 Elevation of specimen in transverse direction. 


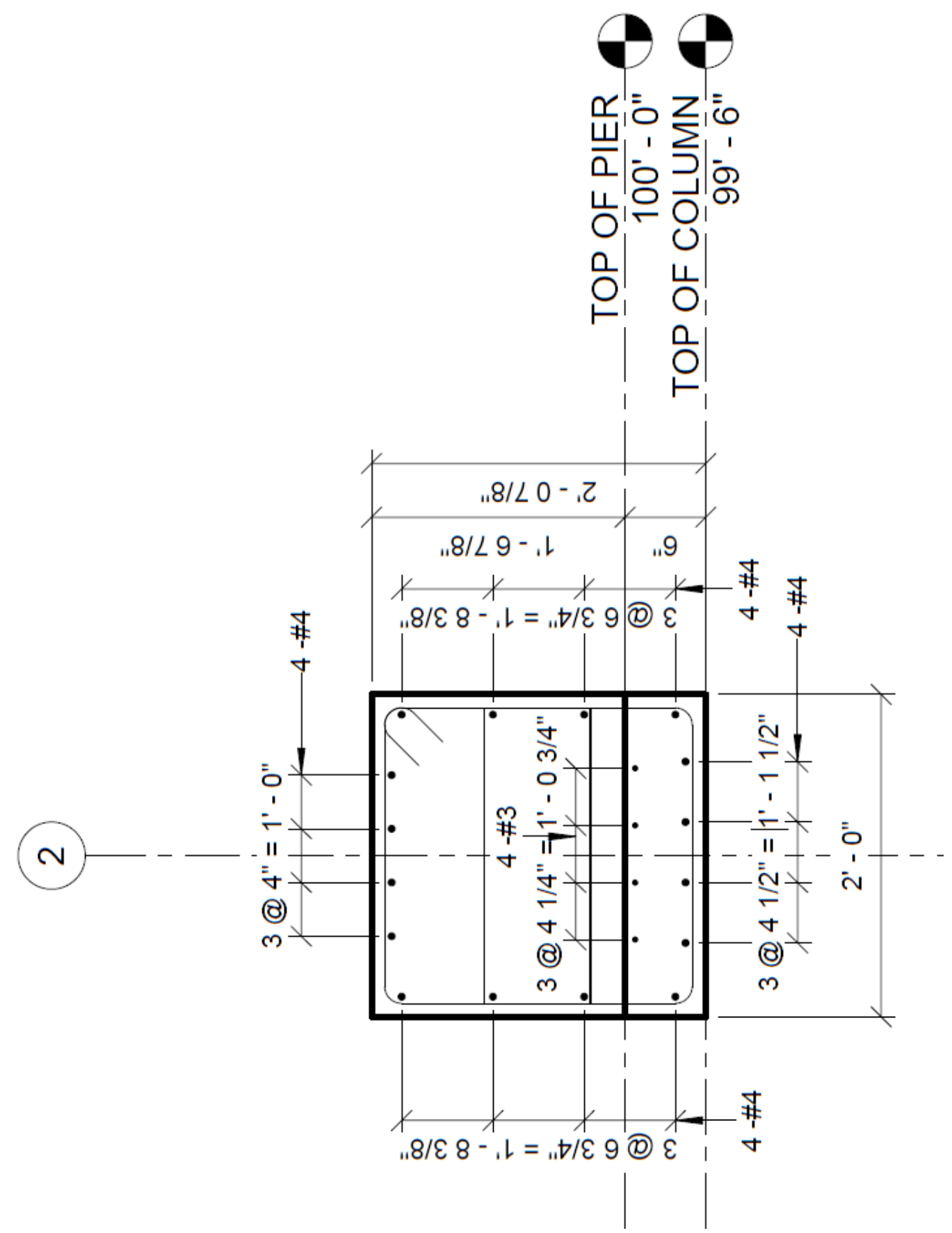

Figure B-42 Cap bean reinforcement bar size and dimension. 


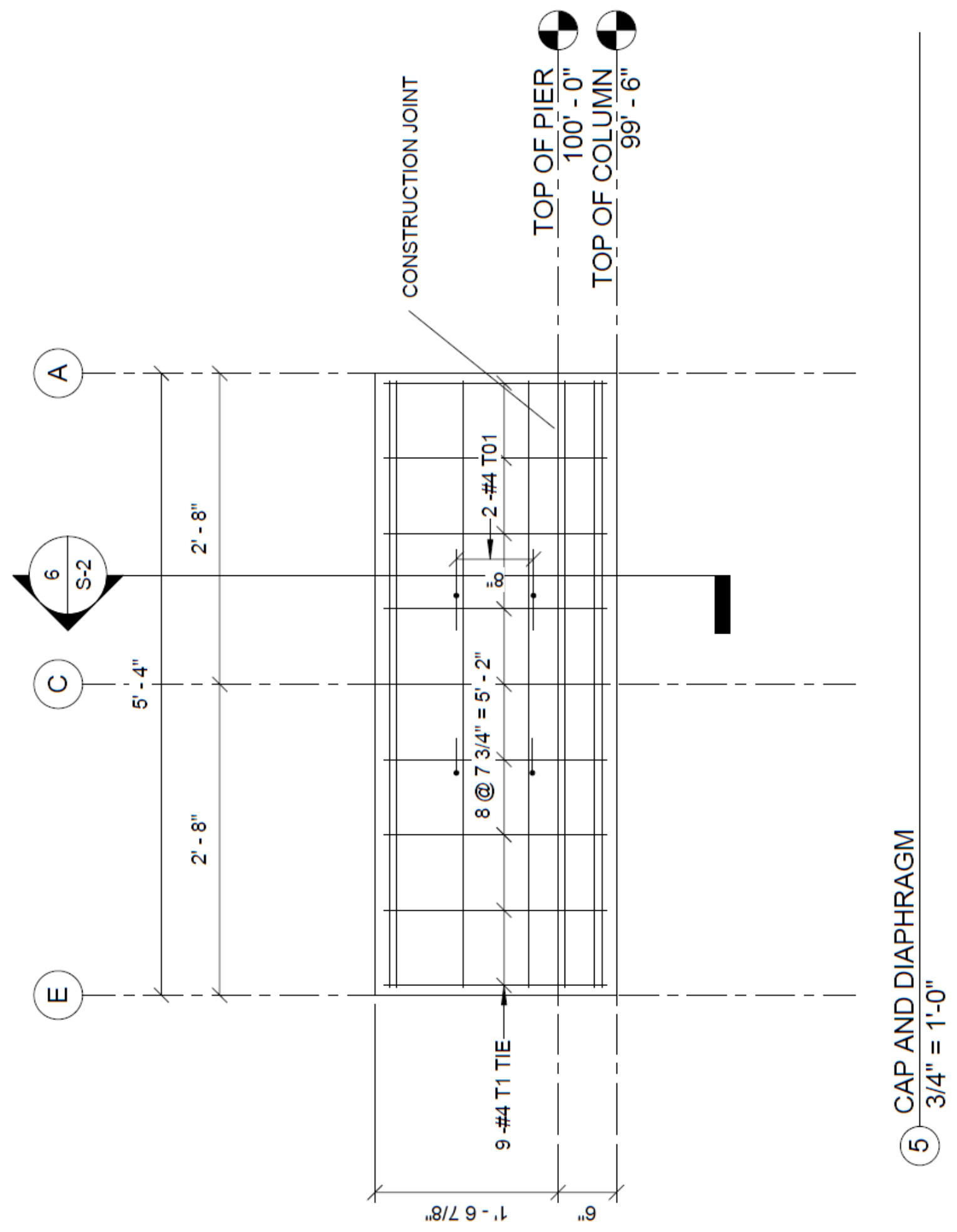

Figure B-43 Cap beam bar sizes. 
VITA

\section{RAMIN TAGHINEZHADBILONDY}

1996-2001

2001-2004

2011-2013

2013-2016
B.Sc. Civil Engineering

Ferdowsi University of Mashhad

Mashhad, Iran

M.Sc. Structural Engineering

Urmia University

Urmia, Iran

Ph.D. Construction/Structural Engineering

University of Nebraska-Lincoln

Omaha, Nebraska (transferred to FIU)

Ph.D. Structural Engineering

Florida International University

Miami, Florida

\section{PUBLICATIONS AND PRESENTATIONS}

Taghinezhad, Ramin, Seismic Design and Rehabilitation of Structures Based on Performance Levels with SAP2000 and ETABS Pushover Analysis, 2016, Nashre Ketabe Daneshgahi, http://www.ketabedaneshgahi.com/, Tehran, 4th Edition

In this book defining plastic hinges, nonlinear static analysis parameters, calculating target displacement in push over curve and performance levels based on ASCE 41 were explained. This book is an introduction to code specifications, the research background of each specification and corresponding command in SAP2000 and ETABS. This book includes several comprehensive step by step examples and program results were controlled by hand calculation in each section. (republished 3 times, each time 2000 copy, 388 pages)

Mohammadi, A., Gull, J. H., Taghinezhad, R., Azizinamini, A. (2014). Assessment and Evaluation of Timber Piles Used in Nebraska for Retrofit and Rating. Nebraska Department of Roads, 2014. Web. 11 Aug. 2014.

Gull, J. H., Mohammadi, A., Taghinezhad, R., \& Azizinamini, A. (2015). Experimental Evaluation of Repair Options for Timber Piles. Transportation Research Record: Journal of the Transportation Research Board, (2481), 124-131.

Mohammadi, A., Taghinezhad, R., Garber, D., \& Azizinamini, A. (2015). A Review of three Ongoing Researches in ABC-UTC Center at Florida International University. In UTC Conference for the Southeastern Region. Birmingham, Alabama, March 26-27, 2015.

Acoustic Emission Monitoring During the Deconstruction of a Post-Tensioned Segmental Bridge: Case Study, Ramin Taghinezhad, Jawad H. Gull, Huy Pham, Larry D. Olson, Atorod Azizinamini, TRB (Transportation Research Board), 2016 
Experimental Investigation of Redundancy of Twin Steel Box-Girder Bridges Under Concentrated Load, Huy Pham, Ramin Taghinezhad, Atorod Azizinamini, TRB (Transportation Research Board), 2016

Flexible Pile Head in Jointless Bridges: Design Provisions for $2 \mathrm{H}-\mathrm{Piles}$ in Cohesive Soils, American Society of Civil Engineers (ASCE), Journal of Bridge Engineering, Atorod Azizinamini, Aaron Yakel, Ardalan Sherafati, Ramin Taghinezhad, October 1, 2015

Extending Application of SDCL Steel Bridge System to ABC Application in Seismic Regions, National accelerated bridge construction conference, Ramin Taghinezhad, Reza Farimani, Atorod Azizinamini, Miami FL, December 4, 2015 